\title{
Spleen as a site for hematopoiesis
}

\author{
Hong Kiat (Don) Lim
}

April 2017

A thesis submitted for the degree of Doctor of Philosophy

of The Australian National University

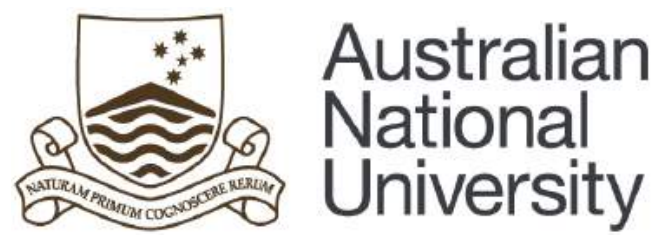

Immunology and Stem Cell Laboratory

Research School of Biology

The Australian National University

(C) Copyright by Hong Kiat (Don) Lim 2017

All Rights Reserved 
STATEMENT

Except where otherwise indicated, this thesis is entirely my own work.

Signature

Hong Kiat (Don) Lim

Supervisor

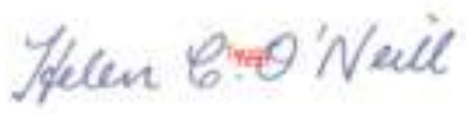

Signature

Professor Helen O’Neill 


\section{ACKNOWLEDGMENTS}

I would like to express my utmost gratitude to my supervisor, Prof. Helen O'Neill and my advisors, Prof. David Tscharke and Dr. Jonathan Tan, who supported me through excellent supervision, expertise, patience and encouragement during my $\mathrm{PhD}$ program. Also, I would like to thank Dr. Aude Fahrer for the laboratory space and advice. I gratefully acknowledge the award of an Australian National University PhD scholarship.

In my day-to-day work, I was blessed to have a group of friendly and helpful O'Neill lab mates, past and present, Pravin, Ying Ying, Vinson, Jing and Sawang. I am grateful for all their help and support. They made my $\mathrm{PhD}$ journey a fun and memorable one; those barbecues and weekly badminton sessions are certainly unforgettable.

I would also like to thank the BSB team of Farid, Ushi and Graham for their technical and administrative support. Also, I cannot forget Harpreet, Cathy and Mick from the JCSMR, Imaging and Cytometry Facility for their assistance in immunofluorescence microscopy, cell sorting and flow cytometry, and also Milburn and Cameron from the JCSMR ACRF Biomolecular Resource Facility for their help with sequencing and analysis.

The friends and colleagues I have in RSB have been amazing, particularly Thilaga, Ryan, Jacinta, Lauren, Sabrina, Sophie, Jason, Meenu, Melanie and Erin. They made my day-to-day work experience an interesting and enjoyable one.

I also owe a great deal of gratitude to my good friends Edna, Angeline, Shu Xuan, Andreas, Christopher, Pheng Hui, Daniel S., Daniel M., Robert, Corey, Nhat, Julie, Nu, Zakkiyyah, Suriani, Gabriel, Kim Heng, Debra and Wilson for always being there for me through thick and thin.

Last but not least, a big thank you goes to my Mum for her unconditional love and support. I thank her for being such an amazing pal in my life who never fails to bring comfort to me in times of difficulty. Also, to my aunt, uncles and cousins; this thesis would not be possible without their love, support and patience.

This acknowledgment would not be complete without thanking my teachers and lecturers in school, in particular Ms Susan Lim, Mrs Lee S.C., Ms Irene Ng, Dr. Koh 
T.Y. and Dr. Sara Zaman and anyone who has helped me one way or another to make this thesis possible. 


\section{ABSTRACT}

Hematopoiesis occurs throughout the lifespan of an organism and involves the formation of blood cells from hematopoietic stem cell (HSC) which are self-renewing multipotent progenitors. The hematopoietic niche environment comprises nonhematopoietic cells, extracellular matrix components and soluble regulatory factors which contribute to the quiescence, dormancy, self-renewal and differentiation of HSC. While multiple HSC niches have been described in bone marrow, as endosteal, vascular and perivascular, niches which support hematopoiesis in other sites like spleen remain to be elucidated. Previous studies in this lab have described unique splenic stroma cell lines 5G3 and 3B5 which can support hematopoiesis and reflect HSC niches. In addition, previously obtained transcriptome data has shown that 5G3 and 3B5 stroma express many genes in parallel with perivascular cells described in bone marrow. This information forms the basis of the current study.

In this thesis, both 5G3 and 3B5 stroma have been shown to share a mesenchymal lineage origin with perivascular cells in bone marrow, including mesenchymal stem cells and C-XC motif ligand 12 (CXCL12)-abundant reticular cells. 5G3 and 3B5 express many cell surface markers in common with these cells including CD105, CD29, VCAM1, Sca-1, CD51, CD140a and Thy1.2. In addition, the concept of niches for hematopoiesis in spleen has been advanced. Splenic stromal cells with the phenotype of Sca- $1^{+}$gp $38^{+}$Thy $1.2^{+} \mathrm{CD} 29^{+} \mathrm{CD} 51^{+}$were found to be important for in vitro hematopoiesis. Their phenotype reflects cells of mesenchymal lineage, consistent with our primary hypothesis that HSC niches involve at least perivascular reticular cells resembling the stromal line models of 5G3 and 3B5. Stromal cells expressing gp38 or Thy1.2 appear to be associated with some HSC in spleen identified through section staining, although this is restricted to neonatal spleen in the case of gp $38^{+}$stromal cells. Restricted hematopoiesis giving rise to L-DC and myeloid cells was replicated in vivo following grafting of splenic stromal cell lines including 5G3 and 3B5 under the kidney capsule. While L-DC production was clearly shown to occur within 3B5 grafts, 5G3 was difficult to engraft and then formed niches which appeared to support hematopoietic cells with a transformed phenotype. Specific signaling pathway inhibitors added into in vitro stromal co-cultures involving lineage-depleted bone marrow over $5 \mathrm{G} 3$ stroma, was also used to identify the important role of SCF but not CXCL12 in supporting in vitro hematopoiesis. In similar experiments, the DAPT inhibitor of Notch signalling was used 
to identify a role for Notch signalling in the development of L-DC from MPP added into co-cultures over $5 \mathrm{G} 3$ stroma in vitro.

This study has improved our current understanding of HSC niches in spleen and identified some of the molecular regulators of hematopoiesis. Information obtained in this thesis verifies the existence of HSC niches in spleen and will be important for development therapies involving spleen as an extramedullary niche for hematopoiesis. The amplification of existing splenic niches or the ability to generate ectopic niches could be used to support enhancement of hematopoietic output, in immunocompromised patients or following HSC transplantation. 


\section{TABLE OF CONTENTS}

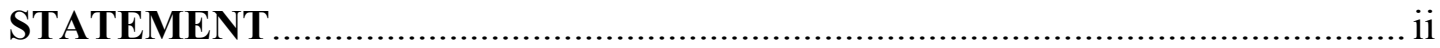

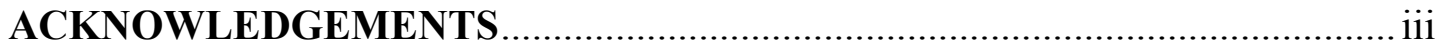

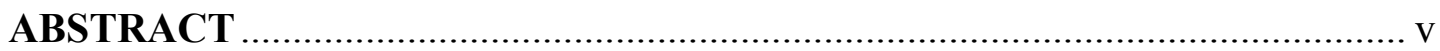

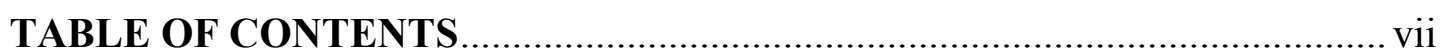

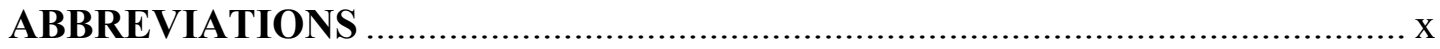

\section{CHAPTER ONE: INTRODUCTION}

1.1 Introduction 1

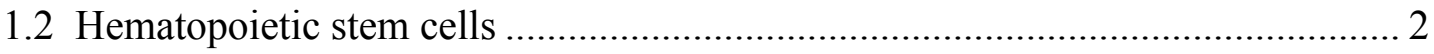

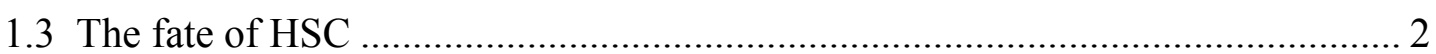

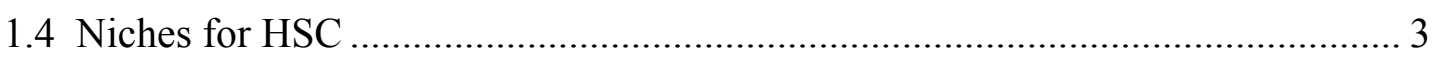

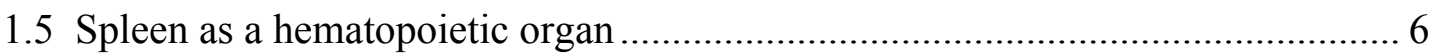

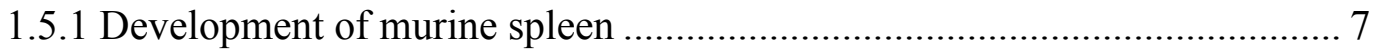

1.5.2 The red pulp regulates erythrocyte turnover ............................................ 8

1.5.3 The white pulp facilitates $\mathrm{T}$ and $\mathrm{B}$ lymphoid responses ............................ 9

1.5.4 Multiple subsets of DC exist in spleen.................................................. 9

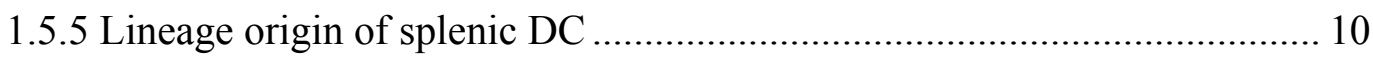

1.6 Extramedullary hematopoiesis in spleen.................................................... 11

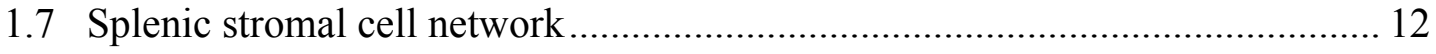

1.8 Evidence that splenic stroma supports hematopoiesis ................................. 13

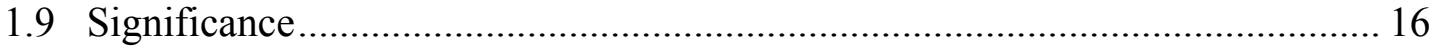

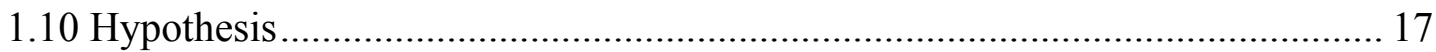

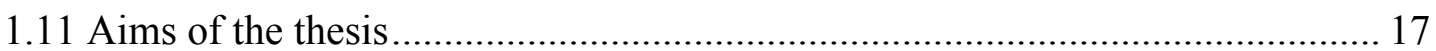

\section{CHAPTER TWO: MATERIALS AND METHODS}

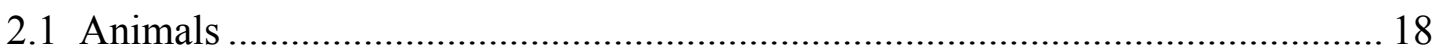

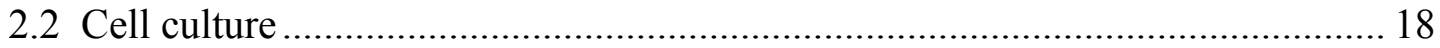

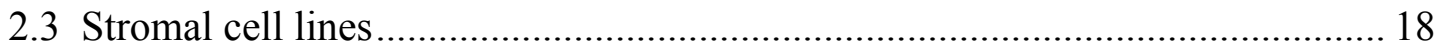

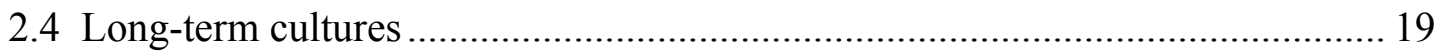

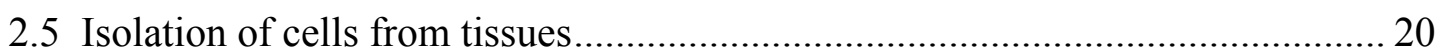

2.6 Lineage depletion of bone marrow ................................................................ 20

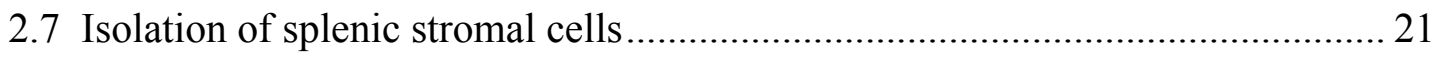

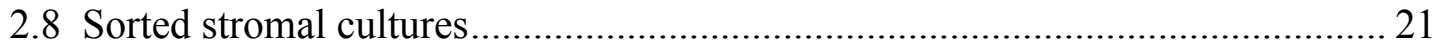




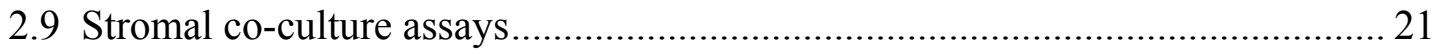

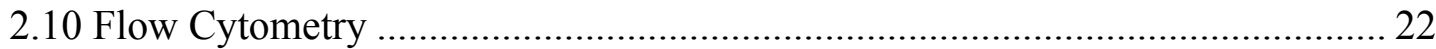

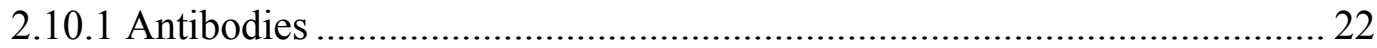

2.10.2 Antibody staining of cells ..................................................................... 22

2.10.3 Flow cytometric analysis of cell surface marker expression ................... 23

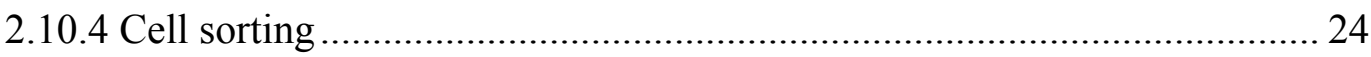

2.10.5 Detection of apoptotic and necrotic cells ............................................. 24

2.11 Immunofluorescence microscopy …............................................................ 24

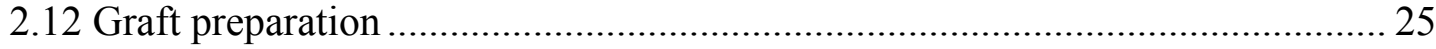

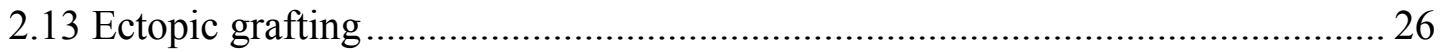

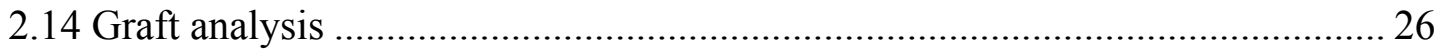

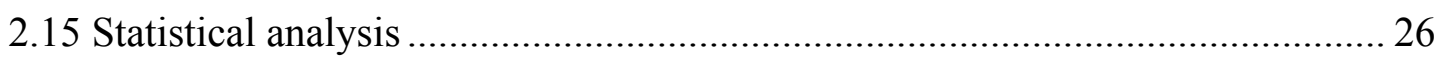

\section{CHAPTER THREE: SPLENIC STROMA SUPPORTS IN VITRO} HEMATOPOIESIS

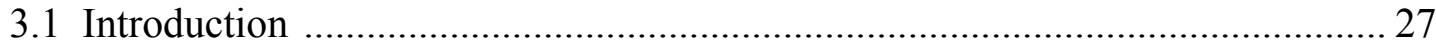

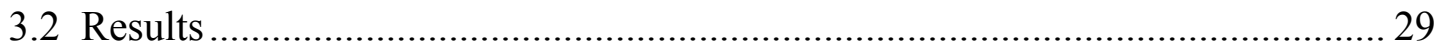

3.2.1 Phenotypic characterisation of splenic stromal lines .............................. 29

3.2.2 5G3 stroma supports myeloid cell production .......................................... 30

3.2.3 Role of 5G3 in signalling hematopoiesis ............................................. 30

3.2.3.1 Imatinib, but not Plerixafor, inhibits $\mathrm{CD} 11 \mathrm{~b}^{\text {hi }}$ cell production ....... 30

3.2.3.2 Effect of the Notch inhibitor, DAPT, on cell production in stromal co-cultures

3.2.3.3 Notch signalling is required for in vitro maintenance of HSC and MPP 33

3.3 Discussion 34

\section{CHAPTER FOUR: CHARACTERISATION OF SPLENIC STROMA WHICH SUPPORTS HEMATOPOIESIS}

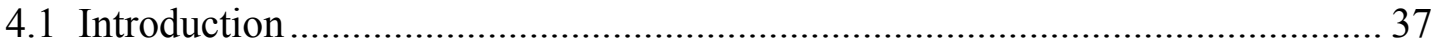

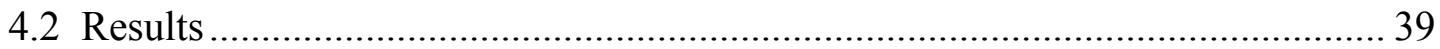

4.2.1 Optimisation of procedures to isolate splenic stromal cells...................... 39

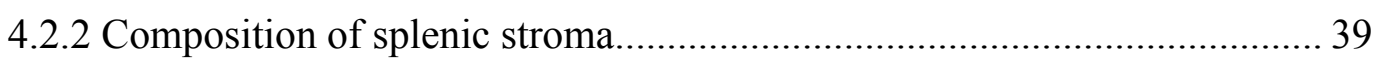

4.2.3 Microscopic examination of cultured stromal fractions............................ 41

4.2.4 Characterisation of stroma on the basis of 2 or 3 markers ........................ 42 
4.2.5 Assessment of hematopoietic support capacity of stromal fractions 42

4.2.6 Fine definition of stromal subsets in spleen............................................ 43

4.2.7 Stromal co-cultures appear to maintain $\mathrm{Lin}^{-}{ }^{\mathrm{c}}-\mathrm{Kit}^{+}$progenitors .................. 45

4.3 Discussion 46

\section{CHAPTER FIVE: IDENTIFICATION OF HSC STROMAL NICHES IN SPLEEN}

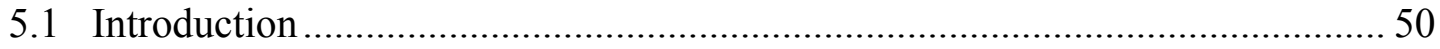

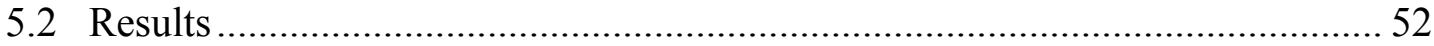

5.2.1 Delineation of splenic regions using regional markers ............................ 52

5.2.2 Identification of different stromal cell subtypes within spleens ................. 53

5.2.3 Optimisation of staining for delineation of HSC in spleens ...................... 54

5.2.4 Localisation of HSC within the spleen architecture................................. 57

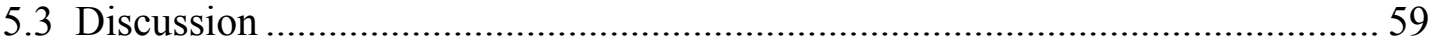

\section{CHAPTER SIX: CAPACITY OF SPLENIC STROMA TO FORM ECTOPIC HSC NICHES}

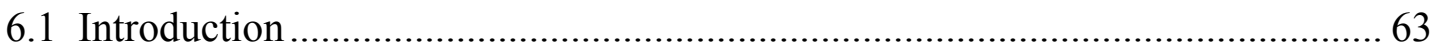

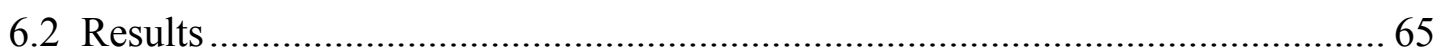

6.2.1 Subcapsular grafting of splenic stroma in kidney .................................... 65

6.2.2 Formation of ectopic grafts following transplantation of 5G3 stroma........ 66

6.2.3 Myelopoiesis is supported within 3B5 stromal grafts .............................. 66

6.2.4 Sorted splenic stromal fractions did not engraft ........................................ 68

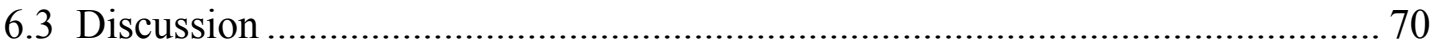

\section{CHAPTER SEVEN: GENERAL DISCUSSION}

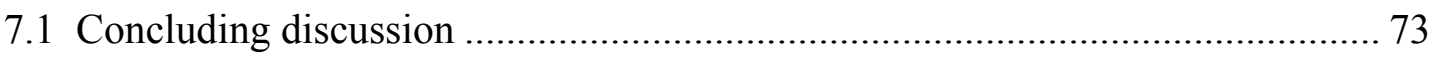

7.2 An in vitro model for hematopoiesis................................................................. 77

7.3 Splenic stroma supports restricted hematopoiesis.......................................... 80

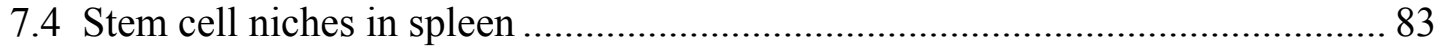

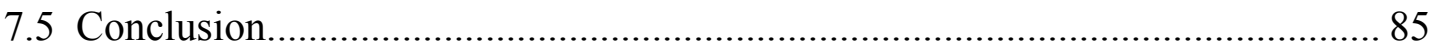

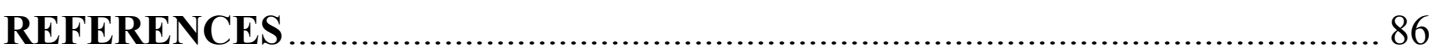

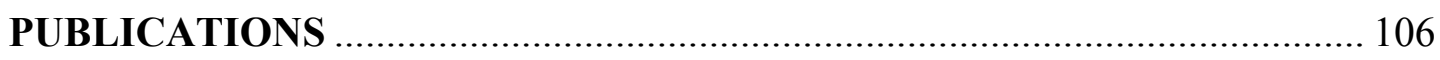




\section{ABBREVIATIONS}

ANGPT1

ANU

$\mathrm{BM}$

BSA

CAR

$\mathrm{cDC}$

CDP

CLP

CMP

CXCR4

CXCL12

DAPI

DC

DCreg

DMEM

EDTA

FACS

FMO

FSC

G-CSF

HSC

ICAM1

IFN

Itagv

JCSMR

LepR

LFA1

Lin

LSK

LTo

LTi

LTC

LT-HSC
Angiopoietin-1

Australian National University

Bone marrow

Bovine serum albumin

CXCL12-abundant reticular cells

Conventional dendritic cells

Common DC progenitors

Common lymphoid progenitor

Common myeloid progenitor

C-X-C Motif receptor 4

C-X-C Motif chemokine ligand 12

4, 6-diamidino-2-phenylindole

Dendritic cells

Regulatory dendritic cells

Dulbecco's Modified Eagle Medium

Ethylenediaminetetraacetic acid

Fluorescence-activated cell sorting

Fluorescence minus one

Forward scatter

Granulocyte colony-stimulating factor

Hematopoietic stem cell

Intracellular adhesion molecule 1

Interferon

Integrin alpha $\mathrm{V}$

John Curtin School of Medical Research

Leptin receptor

Lymphocyte function-associated antigen 1

Lineage

Lin $\cdot \mathrm{Sca}-1^{+} \mathrm{c}-\mathrm{Kit}^{+}$cells

Lymphoid tissue organiser

Lymphoid tissue inducer

Long-term culture

Long-term reconstituting HSC 


\begin{tabular}{|c|c|}
\hline Ly6A & Lymphocyte antigen 6 complex \\
\hline MACS & Magnetic activated cell sorting \\
\hline MAdCAM1 & Mucosal vascular addressin cell adhesion molecular 1 \\
\hline M-CSF & Macrophage colony stimulating factor \\
\hline M-CSFR & Macrophage colony stimulating factor receptor \\
\hline MDP & Macrophage/DC progenitors \\
\hline MFI & Median fluorescence intensity \\
\hline MHC & Major histocompatibility complex \\
\hline mo-DC & Monocyte-derived dendritic cells \\
\hline MPL & Myeloproliferative leukemia virus oncogene \\
\hline MPP & Multipotent progenitors \\
\hline $\mathrm{MSC}$ & Mesenchymal stem cells \\
\hline $\mathrm{pDC}$ & Plasmacytoid dendritic cells \\
\hline $\operatorname{PDGFR} \alpha / \beta$ & Platelet-derived growth factor receptors alpha/beta \\
\hline PBS & Phosphate buffered saline \\
\hline PI & Propidium iodide \\
\hline PPR & PTH-related protein receptor \\
\hline PTH & Parathyroid hormone \\
\hline RANKL & Receptor activator of NF- $\mathrm{NB}$ ligand \\
\hline RPMI & Roswell Park Memorial Institute Medium \\
\hline $\mathrm{RBC}$ & Red blood cell \\
\hline SCF & Stem cell factor \\
\hline sDMEM & Supplemented DMEM \\
\hline SPP1 & Osteopontin \\
\hline $\mathrm{SSC}$ & Side scatter \\
\hline ST-HSC & Short-term reconstituting HSC \\
\hline Thy 1.2 & Thymus cell antigen \\
\hline TEK & Tyrosine kinase \\
\hline THPO & Thrombopoietin \\
\hline VCAM1 & Vascular cell adhesion molecule 1 \\
\hline VEGFR2 & Vascular endothelial growth factor receptor 2 \\
\hline
\end{tabular}


CHAPTER ONE

INTRODUCTION 


\subsection{INTRODUCTION}

Hematopoiesis is the process of blood cell formation from self-renewing, multipotent hematopoietic stem cells (HSC) which are crucial for blood homeostasis of all living organisms (Seita and Weissman, 2010). This developmental process has two distinct phases, primitive and definitive hematopoiesis. In mice, the primitive phase of hematopoiesis occurs in the yolk sac at embryonic (E) day 7.5 (Hirschi, 2012; Ueno and Weissman, 2006; Baron, 2003; Haar and Ackerman, 1971). It results in the production of primitive hematopoietic cells including mainly large, nucleated erythroblasts, some megakaryocytes, and primitive macrophages needed for embryonic growth (Hirschi, 2012; Ueno and Weissman, 2006; Baron, 2003; Haar and Ackerman, 1971). The definitive phase of hematopoiesis in mice begins in the extra-embryonic yolk sac at E8.25 (Hirschi, 2012; Medvinsky and Dzierzak, 1996). Development in this phase is a hierarchical process, with two main lymphoid and myeloid lineages forming, from which all blood cells develop. The lymphoid lineage comprises $\mathrm{T}$ and $\mathrm{B}$ lymphocytes and natural killer cells that arise from a common lymphoid progenitor (CLP). In contrast, the myeloid lineage comprises granulocytes (neutrophils, eosinophils, mast cells and basophils), monocytes, erythrocytes, megakaryocytes, platelets and dendritic cells (DC), all developing from a common myeloid progenitor (CMP). The multipotent HSC resides at the apex of this hematopoietic hierarchy (Doulatov et al., 2012; Seita and Weissman, 2010).

Most of our present knowledge on hematopoiesis stems from decades of research on bone marrow $(\mathrm{BM})$, in part due to the clinical relevance of $\mathrm{BM}$ as the main site for hematopoiesis in adults. However, there is cumulating evidence to suggest that the spleen can adopt extramedullary hematopoiesis in both the steady-state and during disease and inflammation. While very little is understood about extramedullary hematopoiesis, there portends to be huge potential for regenerative medicine if the hematopoietic capacity of spleen could be harnessed. For example, the hematopoietic output of spleen could be experimentally enhanced on BM transplantation using either in vivo or in vitro means. 


\subsection{HEMATOPOIETIC STEM CELLS}

HSC are multipotent adult stem cells, capable of differentiating to give all mature blood cell types, while still maintaining a pool of stem cells due to their unique ability to self-renew (Trumpp et al., 2010). Definitive hematopoiesis in mice occurs at E8.5 and is detected experimentally at E10.5 in the aorta-gonad-mesonephros region of the embryo (Li et al., 2012; Palis et al., 1999; Medvinsky and Dzierzak, 1996; Müller et al., 1994). At E11.5, HSC appear in fetal liver where they exhibit high proliferative and differentiative potential with cell number expansion (Ema and Nakauchi, 2000). HSC appear in fetal spleen at E13-14 and undergo proliferation and differentiation to form mature blood cells (Godin et al., 1999). At E17.5, HSC then proceed to BM, the major hematopoietic site in adults where they are maintained during postnatal life (Dzierzak and Speck, 2008).

HSC in murine BM represent a heterogeneous population characterised phenotypically by the absence of lineage (Lin)-specific markers and high expression of Sca-1, also known as lymphocyte antigen 6 complex (Ly6A), and the c-Kit tyrosine kinase receptor (c-Kit). Within the $\mathrm{Lin}{ }^{-} \mathrm{Sca}-1^{+} \mathrm{c}-\mathrm{Kit}^{+}$cell subset, HSC can be further delineated as $\mathrm{CD} 150^{+} \mathrm{CD} 34^{-} \mathrm{Flt}^{-} \mathrm{CD}^{-} 44^{-} \mathrm{CD} 48^{-}$long-term reconstituting HSC (LT-HSC) and CD150-Flt3 ${ }^{-} \mathrm{CD} 48^{-}$short-term reconstituting HSC (ST-HSC) (Kiel et al., 2005; Yang et al., 2005; Christensen and Weissman, 2001). The adoptive transfer of HSC to reconstitute the hematopoietic system of lethally irradiated mice remains the gold standard assay to distinguish ST-HSC from LT-HSC (Muller-Sieburg et al., 2012). While LT-HSC are able to sustain reconstitution of the hematopoietic system over more than 25 weeks, and even a lifetime (Spangrude et al., 1988), ST-HSC provide short-term reconstitution for only $\sim 6$ weeks (Yang et al., 2005).

\subsection{THE FATE OF HSC}

HSC can adopt several fates throughout the lifetime of an organism, including quiescence, dormancy, self-renewal and differentiation. Quiescence refers to a state of inactivity, whereby most $\mathrm{HSC}$ are in the $\mathrm{G}_{0} / \mathrm{G}_{1}$ phase of cell cycle and are not dividing (Eliasson and Jonsson, 2010). It is believed that keeping HSC in the quiescent state is necessary for long-term maintenance of the HSC compartment, in part due to reduced stress associated with cellular respiration and DNA replication (Eliasson and Jonsson, 
2010). Signalling involving the TGF- $\beta /$ SMAD pathway has been implicated in the maintenance of quiescence in HSC (Sitnicka et al., 1996), and the addition of TGF- $\beta$ to in vitro cultures of LT-HSC can inhibit cell proliferation. The state which involves HSC in long-term quiescence is called dormancy (Wilson et al., 2008). Self-renewal is the process by which HSC undergo symmetrical or asymmetrical cell division to produce one or more daughter stem cells (He et al., 2009). This process leads to expansion of stem cell numbers during development, and restores the stem cell pool after injury (He et al., 2009). Self-renewal, along with quiescence, prevents the depletion of stem cells. Differentiation then involves specialisation of multipotent HSC to give mature blood cells, and is needed to replenish the hematopoietic system since most mature hematopoietic cell types are short-lived.

While the hematopoietic system has a high daily rate of cell turnover, most HSC are quiescent and divide very rarely. This raises the perplexing question of how the hematopoietic system can produce such large numbers of mature blood cells from slowly dividing HSC. The answer lies in the balance between the various HSC fates of quiescence, dormancy, self-renewal and differentiation, such that tight regulation occurs between these fates to ensure that HSC are both maintained for the life of an organism, and sufficient mature blood cells are produced to meet the demands of the organism. The importance of this balance is highlighted in disease states such as leukaemia which result from abnormal HSC development.

\subsection{NICHES FOR HSC}

In the 1970s, Schofield introduced the concept of the HSC 'niche' after observing that once HSC were removed from the BM microenvironment, they quickly lost the capacity to self-renew and to reconstitute the hematopoietic system (Schofield, 1978). The HSC 'niche' involves a microenvironment comprising non-hematopoietic stromal cells, extracellular matrix and soluble regulatory factors that regulate the different fates of HSC (Morrison and Spradling, 2008; Schofield, 1978). To date, three stromal cell types have been found to contribute to the HSC niche, namely endosteal, vascular and perivascular cells (Bianco, 2011; Nagasawa et al., 2011; Kiel and Morrison, 2008). However, it is still not known to what extent these distinct niches function independently of each other, and the extent of hematopoietic support contributed by each cell type is not clear. 
The endosteal niche comprises a heterogeneous group of osteoblastic cells residing close to the endosteal lining of trabecular bone where they interact with HSC. The role of osteoblastic cells in HSC maintenance has been demonstrated in studies which vary the number of osteoblastic cells experimentally (Calvi et al., 2003). In experimental mouse models, it was shown that expression of a constitutively active form of parathyroid hormone (PTH) or the PTH-related protein receptor (PPR) important for calcium regulation under control of the type 1 collagen $\alpha 1$ promoter, gave a marked increase not only in number of osteoblastic cells but also in HSC (Calvi et al., 2003). Osteoblastic cells maintain and regulate HSC through secretion of cytokines like angiopoietin-1 (ANGPT1), thrombopoietin (THPO) and osteopontin (SPP1), which bind to cell surface receptors on HSC, namely endothelial-specific receptor tyrosine kinase (TEK), myeloproliferative leukemia virus oncogene (MPL), and either CD44 or integrins including $\alpha_{4} \beta_{1}, \alpha_{5} \beta_{1}, \alpha_{9} \beta_{1}$, and $\alpha_{4} \beta_{7}$ (Lilly et al., 2011; Qian et al., 2007; Nilsson et al., 2005). A role for THPO and ANGPT1 in HSC maintenance was demonstrated in studies which showed a reduction in the number of HSC in the BM of Thpo $^{-/-}$and Angpt -/- $^{-}$mutant mice (Lilly et al., 2011; Qian et al., 2007; Nilsson et al., 2005). Similarly, Spp1 $1^{-/-}$mice showed a marked increase in the number of HSC cycling, consistent with osteopontin (SPP1) being a negative regulator of HSC proliferation (Nilsson et al., 2005). In addition, osteoblastic cells express Jagged1, which leads to the inhibition of HSC differentiation, and the enhancement of HSC self-renewal when engaged with Notch receptors on HSC (Calvi et al., 2003).

However, the direct involvement of osteoblastic cells as a niche element was challenged when researchers failed to observe a change in HSC numbers after depletion of osteoblasts using ganciclovir treatment or biglycan deficiency (Kiel et al., 2007; Visnjic et al., 2004). In vivo imaging studies also revealed only few HSC in direct contact with osteoblastic cells (Lo Celso et al., 2009). In addition, findings from a genetic modification study further complicate the current understanding of an endosteal niche. That study reported occurrence of myelodysplasia and acute myelogenous leukemia as a result of a deletion of Dicerl in osteolineage cells, but not mature osteocalcin $^{+}$osteoblastic cells (Raaijmakers et al., 2010). Whether osteoblastic cells reflect a key niche element is a question requiring further investigation. 
The vascular niche is an alternative HSC niche located in the vicinity of blood vessels and in close proximity with sinusoids in BM (Kiel et al., 2005). The vascular niche is associated with rapid mobilisation of HSC into the bloodstream after administration of granulocyte colony-stimulating factor (G-CSF) (Kiel et al., 2005). Vascular niches also play an important role during embryogenesis since HSC self-renew and differentiate at a stage of fetal development when BM cavities are not yet formed (Huber et al., 2004). Endothelial cells in the vascular niche express cell surface molecules that allow HSC and immune cells to move between the BM and the periphery (Sipkins et al., 2005). When hematopoietic cells enter tissues, the slow blood flow in the larger sinusoids allows blood-borne cells to interact with sinusoidal endothelial cells via adhesion molecules resulting in movement of cells through the sinus wall and into the extravascular space within BM (Quesenberry and Becker, 1998; Mazo et al., 1998; Frenette et al., 1998).

Sinusoidal endothelial cells express gp130, a cytokine receptor essential for HSC self-renewal (Audet et al., 2001). The importance of endothelial cells expressing gp130 in hematopoiesis was demonstrated in reconstitution studies in mice where BM cells from $\mathrm{gp} 3 \mathrm{O}^{-/-}$mice could reconstitute the hematopoietic system of irradiated wildtype mice, while wild-type BM cells were unable to reconstitute the hematopoietic

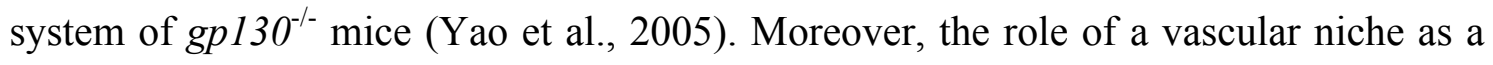
key regulator of hematopoietic integrity was further demonstrated by conditionally deleting the signalling protein vascular endothelial growth factor receptor 2 (VEGFR2) in adult mice (Hooper et al., 2009). This resulted in an inability of sinusoidal endothelial cells to develop after irradiation of mice, thus preventing reconstitution of the hematopoietic system (Hooper et al., 2009). E-selectin expressing endothelial cells in the vascular niche were also shown to promote HSC proliferation. An increase in HSC quiescence and self-renewal was noted in E-selectin knockout $\left(\mathrm{Sele}^{-/}\right)$and in mice treated with an E-selectin antagonist (Winkler et al., 2012).

Three populations of perivascular reticular cells expressing high levels of C-X-C motif chemokine ligand 12 (CXCL12) were initially identified as important perivascular niche elements for HSC in BM. They have been described as CXCL12-abundant reticular (CAR) cells (Sugiyama et al., 2006), nestin-GFP ${ }^{+}$mesenchymal stem cells (Mendez-Ferrer et al., 2010) and leptin receptor (LepR) ${ }^{+}$stromal cells (Ding et al., 2012). CAR cells were characterised as bipotent adipo-osteogenic progenitors, which 
develop around sinusoids (Omatsu et al., 2010; Sugiyama et al., 2006). By conditionally ablating CAR cells using transgenic mice with the diphtheria toxin receptor gene inserted into the $\mathrm{Cxcl12}$ locus, CAR cells were shown to promote HSC proliferation while maintaining them in an undifferentiated state (Omatsu et al., 2010). The absence of CAR cells resulted in a reduction in HSC and progenitors, and early myeloid differentiation of HSC.

Perivascular niches are also defined by nestin ${ }^{+}$mesenchymal stem cells situated near the larger blood vessels in BM (Mendez-Ferrer et al., 2010). These cells were identified in close association with HSC through their nestin expression. When nestin ${ }^{+}$ mesenchymal stem cells were conditionally ablated from mice, the frequency of HSC decreased, indicating the importance of these cells as a perivascular niche element in BM (Mendez-Ferrer et al., 2010). The LepR ${ }^{+}$stromal cells have also been identified as perivascular cells surrounding sinusoids. This subset expresses high levels of CXCL12 and stem cell factor (SCF), and may overlap with other previously described perivascular reticular cell subsets. All three described perivascular subsets are an important source of SCF (Ding et al., 2012) a cytokine that binds to the c-Kit tyrosine kinase receptor expressed on hematopoietic stem/progenitor cells (McNiece and Briddell, 1995). A recent study demonstrated depletion of the HSC pool in $S c f^{/}$mice, highlighting the importance of SCF as well as perivascular cells in HSC maintenance (Ding et al., 2012).

A recent report by Kunisaki et al. (2013) has described two types of perivascular niche cells. First, the Nestin-GFP bright $\mathrm{NG2}^{+} \mathrm{LepR}^{-}$pericytes which surround Sca$1^{\text {hi }}$ VEGFR2 ${ }^{+}$VEGFR $^{-}$arterioles, and secondly, the Nestin-GFP dim NG2-LepR ${ }^{+}$cells which surround sinusoids. While NG2 ${ }^{-}$stromal cells were shown to overlap with earlier described LepR ${ }^{+}$stromal cells (Ding et al., 2012), $\mathrm{NG}^{+}$pericytes are unique niche cells, which are important for HSC quiescence (Kunisaki et al., 2013).

\subsection{SPLEEN AS A HEMATOPOIETIC ORGAN}

The spleen is the largest blood-filtering organ. It also contains structures which support lymphoid cell development and function, and in this respect spleen resembles a lymph node. The spleen is central to both hematopoiesis and immunity. Anatomically, it comprises red pulp, responsible for blood cell removal, and white pulp, which houses $\mathrm{T}$ 
and B lymphocytes in discrete regions (Mebius and Kraal, 2005). Red and white pulp of murine spleen are separated by the marginal zone comprising marginal zone macrophages, B cells and DC, and a marginal sinus where the smallest arterial branches terminate (Mebius and Kraal, 2005). The white pulp is further divided into T cell zones and B cell follicles with germinal centres containing B cells (Mebius and Kraal, 2005). While murine and human spleens are largely similar in terms of their architecture, there are some notable differences (Mebius and Kraal, 2005). Unlike the murine spleen, the marginal sinus is not present in the human spleen, although human spleen does contain a perifollicular region, external to the marginal zone in the red pulp, which is absent in the murine spleen.

\subsubsection{Development of murine spleen}

Spleen organogenesis involves formation of the splanchnic mesodermal plate from lateral plate mesoderm at E9.5 (Brendolan et al., 2007; Hecksher-Sorensen et al., 2004). The splanchnic mesodermal plate comprises epithelial-like cells arranged as an organised plate of cells at the right and left side of the foregut (Brendolan et al., 2007). The initial condensation of mesenchyme within the dorsal pancreatic mesenchyme occurs adjacent to the splanchnic mesodermal plate at E10.5 (Hecksher-Sorensen et al., 2004). By E10.5, there is progressive loss of thickness on the right side of splanchnic mesodermal plate, causing it to be thicker at the left side (Hecksher-Sorensen et al., 2004). In addition, the cells constituting the splenic condensing mesenchyme also acquire splenic cell fate (Brendolan et al., 2007). At the same time, leftward growth of pancreatic mesenchyme and spleen anlagen occur (Brendolan et al., 2007). By E11.5, the spleen anlage proper is formed laterally to the developing stomach (Burn et al., 2008; Brendolan et al., 2007).

While the exact cellular requirements governing development of spleen remain poorly understood, it is widely known that the interaction between the nonhematopoietic $\mathrm{CD} 45^{-} \mathrm{VCAM} 1^{+} \mathrm{ICAM} 1^{+} \mathrm{LT} \beta \mathrm{R}^{+}$lymphoid tissue organiser (LTo) cells and hematopoietic $\mathrm{CD} 45^{+} \mathrm{CD} 3^{-} \mathrm{CD} 4^{+} \mathrm{cKit}^{+} \mathrm{LT}^{+}$lymphoid tissue inducer (LTi) cells is crucial for the development of secondary lymphoid organs such as lymph nodes and Peyer's patches (Randall et al., 2008). This is due to the lymphotoxin LT $\alpha \beta$ signalling, which occurs as a result of binding between lymphotoxin- $\alpha 1 \beta 2\left(\operatorname{Lt} \alpha_{1} \beta_{2}\right)$ expressed on LTi cells and the lymphotoxin- $\beta$ receptor (LT $\beta$ R) on LTo cells (Tan and Watanabe, 
2010). Engagement of $L t \alpha_{1} \beta_{2}$ and LT $\beta R$ induces the activation of two NFKB pathways which promote mesenchymal and endothelial cell differentiation (Dejardin et al., 2002). In addition, increased expression of adhesion molecules like vascular cell adhesion molecule 1 (VCAM1), intracellular adhesion molecule 1 (ICAM1), and mucosal vascular addressin cell adhesion molecule 1 (MAdCAM1), as well as homeostatic chemokines such as CXCL13, CCL19 and CCL21, ensues as part of the differentiation program of mesenchymal cells (Honda et al., 2001). These adhesion molecules and chemokines attract and retain additional hematopoietic cells at the formation site.

The importance of $\operatorname{Lt} \alpha_{1} \beta_{2}$ signalling in secondary lymphoid organ development was first documented after the initial observation that all lymph nodes and Peyer's patches failed to develop in $\mathrm{LT}^{-/-}$mice (De Togni et al., 1994). Identification of what are currently known as LTi cells began with the search for the LT $\alpha \beta$-expressing cell which was first found in developing mesenteric lymph nodes (Mebius et al., 1997). These cells were later characterised as $\mathrm{CD} 45^{+} \mathrm{CD} 3^{-} \mathrm{CD} 4^{+}$cells. Insight into the role of LT $\alpha \beta$-expressing $\mathrm{CD} 45^{+} \mathrm{CD}^{-} \mathrm{CD}^{+}$cells in secondary lymphoid organ development came with the generation of two mutant mice that lacked $\mathrm{CD} 45^{+} \mathrm{CD} 3^{-} \mathrm{CD} 4^{+}$cells (Sun et al., 2000; Yokota et al., 1999). A detailed analysis of these two mutant mice revealed an absence of lymph node and Peyer's patch development. However, the architecture of the T and B cell areas in spleen was unaffected (Zhang et al., 2003; Yokota et al., 1999), suggesting the existence of multiple subsets which provide instructions to splenic stromal cells.

\subsubsection{The red pulp regulates erythrocyte turnover}

The red pulp region has a very specialised function as a blood filter. This region contains many splenic cords formed by red pulp fibroblasts and reticular fibres where blood first enters via the afferent splenic artery (Mebius and Kraal, 2005). Blood then enters venous sinuses lined by endothelium with a discontinuous structure (Mebius and Kraal, 2005; Drenckhahn and Wagner, 1986). Slits formed in the endothelium of the sinuses allow the passage of most blood cells but not aged or damaged platelets and erythrocytes. These are phagocytosed by red pulp macrophages in the cords (Mebius and Kraal, 2005; Bratosin et al., 1998). 
In addition to the filtration of blood, the red pulp is involved in recycling iron. Phagocytosis of aged erythrocytes by splenic macrophages results in release of haem from haemoglobin which is converted into biliverdin and ferrous iron (Mebius and Kraal, 2005; Knutson and Wessling-Resnick, 2003). The resultant iron is either stored or released as ferritins from cells. Plasmablasts and plasma cells are also present in the red pulp for antibody production (Mebius and Kraal, 2005).

\subsubsection{The white pulp facilitates $T$ and $B$ lymphoid responses}

The white pulp of spleen contains the $\mathrm{T}$ cell zones and B cell follicles. In T cell zones, fibroblastic reticular cells encircle the central arterioles and form a network that connects the $\mathrm{T}$ cell zones to the marginal zone (Bajénoff et al., 2008; Anderson and Shaw, 1993). This network serves to guide $\mathrm{T}$ cells in their migration from marginal zone to T cell zones (Bajénoff et al., 2008; Anderson and Shaw, 1993). It is in the T cell zone where $\mathrm{T}$ cells interact with $\mathrm{DC}$ and passing $\mathrm{B}$ cells. In contrast, $\mathrm{B}$ cell follicles comprise activated B cells undergoing clonal expansion, isotype switching and somatic hypermutation. They also house specialised antigen handling cells called follicular dendritic cells which form the architectural framework of the follicles and are involved in retaining and presenting antigens to activated B cells in the germinal centre.

\subsubsection{Multiple subsets of DC exist in spleen}

Dendritic cells are specialised antigen presenting cells that are capable of inducing an adaptive immune response (Shortman and Naik, 2007). They do so by acquiring, processing and presenting antigens on major histocompatibility complex (MHC) molecules to naïve $\mathrm{T}$ cells. While all DC possess the capacity for antigen acquisition, processing and presentation, they are heterogeneous and their subtypes differ in location, migratory pathway, cell surface marker expression and immunological function (Shortman and Naik, 2007). The definition of a DC is therefore not straightforward, although most DC are phenotypically marked by high expression of CD11c and MHC-II (Miloud et al., 2010).

The commonly described DC subsets in murine spleen include conventional DC (cDC), plasmacytoid DC (pDC), regulatory DC (DCreg) and monocyte-derived DC (mo-DC) (Merad et al., 2013; Geissmann et al., 2010). Conventional DC represent 
steady-state, mature DC with CD11 $\mathrm{c}^{\mathrm{hi}} \mathrm{MHC}-\mathrm{II}^{\mathrm{hi}}$ marker expression that can be further classified into $\mathrm{CD} 8 \alpha^{+}$and $\mathrm{CD} 8 \alpha^{-}$subsets (Merad et al., 2013). CD8 $\alpha^{+} \mathrm{CDC}$ are phenotypically distinguishable as $\mathrm{CD} 11 \mathrm{c}^{+} \mathrm{CD} 11 \mathrm{~b}^{-} \mathrm{CD} 8 \alpha^{+} \mathrm{MHC}-\mathrm{II}^{+} \mathrm{B} 220^{-}$cells, while $\mathrm{CD} 8 \alpha^{-} \mathrm{cDC}$ are $\mathrm{CD} 11 \mathrm{c}^{+} \mathrm{CD} 11 \mathrm{~b}^{+} \mathrm{CD} 8 \alpha^{-} \mathrm{MHC}-\mathrm{II}^{+} \mathrm{B} 220^{-}$cells (Merad et al., 2013; Vremec et al., 2000). Plasmacytoid DC exist as less mature DC precursors in the steady-state, producing natural type I interferon (IFN- $\alpha$ ) upon viral exposure. They can be distinguished from other DC subsets by expression of Ly6C, B220, and low expression level of the CD11c marker (Merad et al., 2013; Asselin-Paturel et al., 2001). Under certain inflammatory conditions, monocytes as phagocytic myeloid cells, are induced to differentiate into mo-DC for antigen presentation (Cheong et al., 2010). These cells can be distinguished from other DC by CD64 (FcR) expression.

\subsubsection{Lineage origin of splenic DC}

With high heterogeneity within the DC lineage, an important question is whether each subset is developmentally distinct. Early studies provided direct evidence for a myeloid origin of DC following reconstitution of $\mathrm{CDC}$ and $\mathrm{pDC}$ in the spleen and thymus when mouse BM-derived CMP were transplanted into irradiated recipients (Wu and Liu, 2007). It is now well established that all leukocytes originate from BM-derived HSC. In the early stages of hematopoiesis, successive commitment steps result in the divergence of lymphoid and myeloid lineages, generating CLP and CMP (Liu and Nussenzweig, 2010). The CLP give rise to B, T and natural killer cells, whilst CMP give rise to macrophage/DC progenitors (MDP), identified as $\operatorname{Lin}^{-} \mathrm{CX} 3 \mathrm{CR} 1^{+} \mathrm{CD} 11 \mathrm{~b}^{-}$ $\mathrm{CD} 115^{+} \mathrm{cKit}^{+} \mathrm{CD} 135^{+}$cells (Liu and Nussenzweig, 2010). These subsequently give rise to either common DC progenitors (CDP) or two monocyte subsets distinguishable as Ly6C $^{+}$and Ly6C ${ }^{-}$cells (Geissmann et al., 2010; Liu et al., 2009). In contrast to the developmental flexibility of MDP in terms of ability to produce $\mathrm{cDC}, \mathrm{pDC}$ and monocytes, CDP are restricted to producing cDC and pDC (Liu et al., 2009). It has also been shown that adoptive transfer of either CMP or MDP can give rise to CDP and monocytes, indicating that CDP are downstream of CMP or MDP (Liu and Nussenzweig, 2010).

While monocytes and pDC have been found to exit BM as mature cells, cDC leave as immature precursors that further differentiate and mature within lymphoid organs (Liu et al., 2009). In mouse blood, two populations of DC precursors have been 
described as $\mathrm{CD}_{11} \mathrm{c}^{\text {int }} \mathrm{CD} 11 \mathrm{~b}^{+} \mathrm{CD}_{45 \mathrm{RA}^{-}}$and $\mathrm{CD} 1 \mathrm{c}^{\mathrm{lo}} \mathrm{CD} 11 \mathrm{~b}^{-} \mathrm{CD} 45 \mathrm{RA}{ }^{\text {hi }}$ cells that differentiate to give mature CD8 $\alpha^{-} \mathrm{cDC}$ in the presence of TNF- $\alpha$ and GM-CSF, and IFN- $\alpha$ producing pDC in the presence of GM-CSF and CpG (Naik et al., 2007). CD8 $\alpha^{-}$ cDC are able to stimulate T cells to produce IL-2 in response to microbial stimuli, while pDC weakly stimulate $\mathrm{T}$ cells by producing large quantities of IFN- $\alpha$ (Wu and Liu, 2007). A recent study reported the identification of the most immediate cDC precursors (pre-DC) in spleen with a CD11 $c^{\text {int }} \mathrm{CD} 45 \mathrm{RA}^{\mathrm{lo}} \mathrm{CD} 43^{\text {int }} \mathrm{SIRP}-\alpha^{\text {int }} \mathrm{CD} 4 \mathrm{CD} 8 \alpha^{-}$phenotype (Wu and Liu, 2007). Progenitors in BM give rise to pre-DC which enter the spleen where they differentiate further to give $\mathrm{cDC}$ and p-pre-DC.

\subsection{EXTRAMEDULLARY HEMATOPOIESIS IN SPLEEN}

The spleen can support hematopoiesis, and this finding is based on early evidence documenting the recovery of mice lethally irradiated with a shielded spleen (Rugh and Grupp, 1960). This process is termed extramedullary hematopoiesis since it occurs in sites other than the bone medullary cavity. Extramedullary hematopoiesis can be viewed as an active or a passive process. While extramedullary hematopoiesis is an active natural process during fetal development and also during infection, passive extramedullary hematopoiesis occurs due to impairment of hematopoiesis in the BM (Kim, 2010). An active process is supported by evidence that the low number of hematopoietic stem/progenitor cells present in murine spleen in steady-state increases quickly following inflammation (Massberg et al., 2007; Wolber et al., 2002). The presence of hematopoietic stem/progenitor cells in the steady-state is however not restricted to murine spleen since spleens of pigs, baboons and humans were also found to retain a low number of hematopoietic stem/progenitor cells under steady-state conditions (Dor et al., 2006). Moreover, in cell tracing experiments, spleen cells derived from both neonatal and adult mice were able to provide hematopoietic reconstitution of lethally irradiated host mice following adoptive transfer (Tan and O'Neill, 2012; Tan et al., 2010). These findings confirm that spleen can adopt a role in extramedullary hematopoiesis, at least during times of stress or inflammation. Evidence, which suggests the role of spleen in hematopoiesis, also raises the possibility of a splenic niche that supports the maintenance of HSC in the resting state. 


\subsection{SPLENIC STROMAL CELL NETWORK}

HSC niches in spleen have not been well investigated although at least six distinct stromal cell types have been mapped to different regions of murine spleen. These include gp $38^{+}$fibroblastic reticular cells in the $\mathrm{T}$ cell zones, CD $35^{+}$follicular dendritic cells in the $\mathrm{B}$ cell follicles, MAdCAM1 $1^{+}$marginal reticular cells in the marginal zone, and red pulp fibroblasts, lymphatic endothelial cells and vascular endothelial cells in the red pulp (Mueller and Germain, 2009).

Fibroblastic reticular cells are mesenchymal cells, which along with reticular fibres and fibrous extracellular matrix bundles, are required for the formation of a reticular network that serves as a scaffolding for the three-dimensional structure of secondary lymphoid organs (Gretz et al., 1997). In addition to creating a network in the $\mathrm{T}$ cell areas of spleen which serves to guide $\mathrm{T}$ lymphocytes in their migration from marginal zone to the T cell zones (Bajénoff et al., 2008; Anderson and Shaw, 1993), fibroblastic reticular cells are also involved in creating a conduit system that selectively allows molecules of low molecular mass such as chemokines and antigens to enter the $T$ cell zone (Lokmic et al., 2008; Nolte et al., 2003; Gretz et al., 1997). Large molecules are trapped in the cortical sinuses by subcapsular sinus macrophages (Lokmic et al., 2008; Nolte et al., 2003; Gretz et al., 1997). Such a conduit system offers an opportunity for different types of signals to be delivered in secondary lymphoid organs for optimisation of immunity to different pathogens (Nolte et al., 2003).

In addition to their structural role, fibroblastic reticular cells are also involved in regulation of the immune response. They secrete homeostatic chemokines such as CCL21, CCL19 and CXCL12 which attract naïve T cells expressing the chemokine receptors CCR7 and chemokine C-X-C motif receptor 4 (CXCR4) (Forster et al., 1999). Fibroblastic reticular cells also enhance the survival of naïve $T$ cells in the steady-state by producing interleukin-7. This is important in increasing the probability that naïve $\mathrm{T}$ cells meet cognate antigen presented on antigen presenting cells. A recent study revealed that fibroblastic reticular cells stimulated the activation of cytotoxic $\mathrm{T}$ cells via alarmin secretion during viral infection (Bonilla et al., 2012).

Marginal reticular cells represent a unique subset of stromal cells located in the marginal zone of the spleen. Despite expressing many common stromal cell surface 
markers like ER-TR7, desmin, laminin, VCAM1 and MAdCAM1, marginal reticular cells also specifically express receptor activator of NF-KB ligand (RANKL) and secrete CXCL13 (Katakai et al., 2008). While RANKL has been found to be essential for lymph node development (Dougall et al., 1999), its function in spleen remains elusive. These stromal cells form a conduit system which can capture and deliver antigens to B cell follicles (Katakai et al., 2008).

In the red pulp region, red pulp fibroblasts form the splenic cords necessary for filtration of blood (Mueller and Germain, 2009). They also control splenic blood flow and assist in removal of dead or dying red blood cells (Mueller and Germain, 2009). Additionally, red pulp fibroblasts are involved in the localisation of different cells in the red pulp of spleen through expression of the cell adhesion molecule ICAM1 that binds to lymphocyte function-associated antigen 1 (LFA1), a heterodimeric receptor protein found on lymphocytes (Williams and Barclay, 1988; Hynes, 1987). For instance, ICAM1-LFA1 interaction between red pulp fibroblasts and plasma cells results in movement of plasma cells into the red pulp region for secretion of antibodies into circulation (Ellyard et al., 2005).

\subsection{EVIDENCE THAT SPLENIC STROMA SUPPORTS HEMATOPOIESIS}

Evidence has now been obtained which shows that that spleen contains stromal cells which support in vitro hematopoiesis (Periasamy et al., 2013a; O'Neill et al., 2011; Periasamy et al., 2009; Ni and O'Neill, 1999). In particular, it was found that the stromal monolayer forming in long-term cultures (LTC) of 8-day old murine spleen supports maintenance of small progenitors and the production of a distinct class of large, immature DC, coined 'LTC-DC'. These are produced continuously in LTC over years in the absence of added growth factors and cytokines (Periasamy et al., 2013a; O'Neill et al., 2011; Periasamy et al., 2009; Ni and O'Neill, 1999). When the small progenitors maintained in LTC were specifically sorted and co-cultured over STX3 stroma, large immature dendritic-like cells were produced (Wilson et al., 2000). STX3 stroma was isolated as a stromal line from one splenic LTC which had ceased production of dendritic-like cells after multiple passages, possibly due to the loss of progenitors ( $\mathrm{Ni}$ and O'Neill, 1998). Interestingly, similar dendritic-like cells, termed 'L-DC' were also produced when STX3 was overlaid with lineage-negative (Lin $\left.{ }^{-}\right)$BM cells (Despars and O'Neill, 2006b). L-DC, like LTC-DC, are large cells which express CD11b and CD11c 
but not MHC-II and CD8 $\alpha$ (Periasamy and O'Neill, 2013; Tan et al., 2011). These cells are highly efficient in endocytosis and cross presentation of antigen for $\mathrm{CD}^{+} \mathrm{T}$ cell activation, particularly after exposure to lipopolysaccharide (Periasamy and O'Neill, 2013; Tan et al., 2011).

In order to better understand the cellular composition of the heterogeneous STX3 stroma, the line was cloned to form 102 cloned splenic stromal cell lines (Despars and O'Neill, 2006a). These include the 5G3 clone which is able to support in vitro hematopoiesis, and the 3B5 clone which is a non-supporter. The 5G3 clone supports production of 'L-DC' from hematopoietic progenitors in a highly reproducible and contact-dependent manner similar to the parent line, STX3 (Periasamy and O'Neill, 2013; Periasamy et al., 2009). Transcriptome analysis of 5G3 stroma has revealed high expression of genes including Sca-1, Vcam1, Pdgfro/ $\beta$ and Cxcl12, which are associated with perivascular reticular cells described in the BM (O'Neill lab, data in preparation). In addition, 5G3 was shown to have osteogenic but not adipogenic differentiative capacity (O'Neill lab, data in preparation). This evidence raises the hypothesis that spleen contains a unique perivascular niche comprising mesenchymal stromal cells resembling osteoprogenitors that supports extramedullary hematopoiesis.

The highly reproducible nature of DC production in splenic LTC and in cocultures involving splenic stroma, suggests that a potential equivalent process may exist in vivo. Already there is some evidence for an in vivo equivalent L-DC subset in spleen, which was originally termed 'IVL-DC' (Tan and O'Neill, 2010), this subset was recently more clearly defined and termed L-DC (Hey and O'Neill, 2016). However, the in vivo equivalent stromal supporter cell line has not yet been identified. Moreover, since DC production in splenic stromal co-cultures can be maintained for a long time, it seems likely that the progenitors which are maintained in cultures, are self-renewing. One hypothesis is that the splenic stromal cells maintain self-renewing progenitors through close contact. To test this hypothesis, various progenitor subsets from BM and spleen were sorted and tested for their capacity to seed 5G3 stroma with production of L-DC. 5G3 stromal co-cultures were established with MDP, CDP, ST-HSC or LT-HSC. Since no L-DC production was observed in co-cultures overlaid with MDP and CDP, it was evident that L-DC did not derive from the same progenitors which gave rise to cDC, pDC and monocytes (Petvises and O'Neill, 2014b). When the Flt3 ${ }^{-} \mathrm{c}-\mathrm{Kit}^{+} \mathrm{Lin}^{-} \mathrm{Sca}-{ }^{+}$ subset of LT-HSC from BM, and the Flt $3^{+} \mathrm{c}-\mathrm{Kit}^{+} \mathrm{Lin}^{-} \mathrm{Sca}-1^{+}$subset of ST-HSC were 
overlaid on 5G3 stroma, L-DC production was however supported (Petvises and O'Neill, 2014b; Hinton et al., 2011). In some co-cultures, contact between non-adherent cells and stroma was prevented using a Transwell membrane (Periasamy et al., 2013a). L-DC production occurred for up to 35 days from overlaid HSC, but only in co-cultures where overlaid cells maintained contact with 5G3 stroma (Periasamy et al., 2013a). The development of L-DC is therefore dependent on the interaction between primitive HSC and the competent $5 \mathrm{G} 3$ stroma. The progenitor of L-DC therefore appears to be a subset of HSC, some cells of which express Flt3 and resemble ST-HSC in BM, or the less primitive multipotent progenitors (MPP) (Petvises and O'Neill, 2014b; Periasamy et al., 2013a).

Indeed, it has become clear that L-DC progenitors in vivo reflect HSC endogenous to spleen, and that the process of L-DC development reflects extramedullary hematopoiesis. L-DC progenitors first appear in murine spleen at E18.5, while progenitors of cDC appear after 4 days (Petvises and O'Neill, 2014a). This raises the possibility that hematopoietic progenitors in spleen are laid down during ontogeny, and that hematopoiesis in spleen giving rise to differentiation of dendritic-like L-DC occurs as an active process, independent of inflammatory signalling. One model is that the splenic stromal microenvironment supports the restricted differentiation of endogenous progenitors to give antigen presenting cells unique to the spleen microenvironment. Indeed, studies to date on the in vivo tissue distribution of cells equivalent to L-DC, suggest that L-DC are a novel subset limited in distribution to spleen (Tan et al., 2011). Such a model does not discount the possibility that spleen can also act as a site for extramedullary hematopoiesis under inflammatory conditions. Whether the same stromal microenvironment contributes to both processes remains an unanswered question.

While it is known that hematopoiesis can be driven by inflammation in vivo (Nagai et al., 2006), it is important to consider whether in vitro hematopoiesis in 5G3 co-cultures involves the same mechanism. This laboratory has studied the role of tolllike receptor signalling in the production of L-DC in in vitro co-cultures over 5G3 stroma. Toll-like receptor binding of pathogen components triggers an inflammatory response. Co-cultures established with $\mathrm{BM}$ progenitors derived from mutant mice that lack the adapter proteins MyD88 and TRIF which bind toll-like receptors, were found to be producers of L-DC, suggesting that L-DC production occurs independently of toll- 
like receptor signalling (Periasamy et al., 2013a). L-DC production therefore appears to reflect an active process of steady-state extramedullary hematopoiesis dependent on primitive HSC endogenous to spleen.

\subsection{SIGNIFICANCE}

While spleen has been traditionally viewed as an organ of immunity, recent evidence sheds light on its involvement in hematopoiesis (Yamamoto et al., 2016; Inra et al., 2015; Miwa et al., 2013; Johns and Christopher, 2012; O'Neill et al., 2011; Kim, 2010; Kiel et al., 2005). In this thesis, we have advanced the existence of niches for hematopoiesis in spleen, comprising a perivascular reticular cell type that supports extramedullary hematopoiesis from primitive HSC. Previous evidence in mice and humans suggests that perivascular reticular cells reflect mesenchymal stem/progenitor cells located in close proximity with endothelial cells associated with the vasculature. Since the perivascular cells in BM which constitute the HSC niche surround the sinusoids, it is quite possible that a similar cell type exists in spleen, particularly in the red pulp region, where copious numbers of sinusoids are found. Moreover, transcriptome analysis of spleen-derived 5G3 stroma has revealed a close genetic resemblance between $5 \mathrm{G} 3$ stroma and perivascular cells in the BM (data in preparation). Evidence for the osteogenic nature of $5 \mathrm{G} 3$ cells (O'Neill lab, data in preparation) is also consistent with this finding, suggesting the presence of mesenchymal osteoprogenitors in spleen with ability to support in vitro hematopoiesis.

The possibility that spleen contains perivascular cells which act as niches for hematopoiesis is not without precedence. Perivascular reticular cells present in the red pulp of spleen could provide a niche for maintenance of HSC in the steady-state. Furthermore, restricted hematopoiesis leading to development of only L-DC raises the possibility that the spleen microenvironment may support the production of tissuespecific antigen presenting cells. Their location in red pulp could reflect a specific role in monitoring blood-borne antigens and interacting with migrating lymphoid cells.

The lack of understanding of spleen as a hematopoietic organ has limited clinical application to date. A history of work from this lab has however considered spleen as a site for extramedullary hematopoiesis, with potential for reengineering niches to increase hematopoietic cell production. For example, if these unique stromal 
cells could be isolated and used to expand HSC in vitro, or provided as an ectopic niche in vivo for the same purpose, then the potential exists to enhance hematopoiesis during HSC transplantation. Regeneration or expansion of these niches could represent future therapy for patients undergoing myeloablative treatment, involution of lymphoid tissue with ageing or HSC transplantation.

\subsection{HYPOTHESIS}

The spleen has capacity to support extramedullary hematopoiesis, especially at times of stress, infection and drug treatment (Massberg et al., 2007; Wolber et al., 2002). Here we hypothesise that spleen contains a unique perivascular niche, comprising stromal cells of mesenchymal lineage, which support extramedullary hematopoiesis.

\subsection{AIMS OF THE THESIS}

1. To characterise and demonstrate the role of 5G3 in hematopoietic support

2. To identify the stromal cell type in spleen which supports hematopoiesis

3. To characterise and localise HSC niches in spleen

4. To establish ectopic niches in mouse models using stromal cell lines and isolated splenic stromal subsets 
CHAPTER TWO

MATERIALS AND METHODS 


\section{MATERIALS AND METHODS}

\subsection{Animals}

Specific pathogen-free C57BL/6J $\left(H-2 K^{b}\right)$ mice aged between 4 and 8 weeks, or between 6 and 8 days, and NOD/SCID $\left(H-2 K^{d}\right)$ mice aged between 6 and 9 weeks, were obtained from the John Curtin School of Medical Research (JCSMR: Canberra, Australia). Mice were housed and handled according to protocols approved by the Animal Experimentation Ethics Committee at the Australian National University (ANU: Canberra, Australia).

\subsection{Cell culture}

Cells were cultured in Dulbecco's Modified Eagle Medium (DMEM) supplemented with 4g/L D-glucose, $6 \mathrm{mg} / \mathrm{L}$ folic acid, 36mg/L L-asparagine, $116 \mathrm{mg} / \mathrm{L}$ L-arganine HCL, 10\% heat inactivated fetal calf serum (JRH Biosciences: Lenexa, Kansas, USA), 10mM Hepes (JRH Biosciences), 2mM L-glutamine (JRH Biosciences), $100 \mathrm{U} / \mathrm{mL}$ penicillin (JCSMR), $100 \mu \mathrm{g} / \mathrm{mL}$ streptomycin (JCSMR) and $5 \times 10^{-5} \mathrm{M} 2-$ mercaptoethanol (BDH Ltd: Poole, England), (sDMEM). Cultures were maintained in 5\% $\mathrm{CO}_{2}$ in air, with $95 \%$ humidity at $37^{\circ} \mathrm{C}$.

\subsection{Stromal cell lines}

The establishment of the STX3 splenic stromal line has been previously described (Ni and O'Neill, 1999; Ni and O'Neill, 1997). STX3 was derived from a LTC of murine spleen of $\mathrm{B} 10 . \mathrm{A}(2 \mathrm{R})$ mice which had ceased to produce $\mathrm{DC}$ over time due to loss of hematopoietic cells. In order to maintain the STX3 line, stromal cells were scraped from the surface of the flask and transferred into a new flask.

The derivation of the splenic stromal clones, 5G3, 10C9, 7G10 and 3B5, has been previously described (Despars and O'Neill, 2006a). These lines were cloned from STX3 splenic stroma. Frozen stocks of these cell lines were established from stromal clones which had undergone 2 to 3 passages after cloning and were then stored in liquid nitrogen. In order to establish stroma, each vial of frozen 5G3, 7G10 or 3B5 cells was defrosted rapidly in a $37^{\circ} \mathrm{C}$ water bath for 1 minute and then resuspended in $13 \mathrm{~mL}$ 
sDMEM. Cells were washed twice with $5 \mathrm{~mL}$ sDMEM, with sedimentation between washes using an Allegra 6R centrifuge $\left(300 \mathrm{~g}, 4^{\circ} \mathrm{C}\right.$ for 5 minutes) (Beckman Coulter: Gladesville, NSW, Australia). Cells were then seeded at $5 \times 10^{5}$ cells $/ \mathrm{mL}$ into a $25 \mathrm{~cm}^{2}$ tissue culture flask. After 24 hours, the flask of cells was then passaged after scraping into two $25 \mathrm{~cm}^{2}$ flasks with plating at $3 \times 10^{5}$ cells $/ \mathrm{mL}$ per flask. If necessary, a second cell passage was then performed after 48 hours. To freeze down cells, stromal cells were harvested by trypsinization at $80-90 \%$ confluency. Cells were washed with phosphate buffered saline (PBS) twice prior to trypsinization to completely remove culture medium which would otherwise reduce the efficiency of the trypsinization process. $0.25 \%(\mathrm{~m} / \mathrm{v})$ Trypsin-ethylenediaminetetraacetic acid $[0.02 \%(\mathrm{~m} / \mathrm{v})$ EDTA] (Sigma-Aldrich: Castle Hill, NSW, Australia) was added at $37^{\circ} \mathrm{C}$. Trypsinization was carried out for 1 minute, and the process halted by addition of $5 \mathrm{~mL}$ sDMEM. Harvested cells were washed twice with sDMEM and sedimented between washes by centrifugation $\left(300 \mathrm{~g}, 4^{\circ} \mathrm{C}, 5\right.$ minutes). Cell number and viability were estimated using trypan blue (0.4\%/saline) (Gibco BRL: Grand Island, New York, USA). Viable cells were counted using a haemocytometer. Cells were resuspended to a final concentration of $5 \times 10^{6}$ cells $/ \mathrm{mL}$ in ice-cold freezing medium comprising sDMEM supplemented with $10 \%$ FCS and 10\% dimethyl sulfoxide. Cells were aliquoted (1mL per vial) before placement on a cooling rack above liquid nitrogen for slow freezing. Completely frozen vials were stored in liquid nitrogen.

\subsection{Long-term cultures}

Long-term cultures were established from 5-day-old C57BL/6J spleens which were dissociated as described in Section 2.5. Cells of a single spleen were resuspended in sDMEM and seeded into a $75 \mathrm{~cm}^{2}$ tissue culture flask. Flasks were left undisturbed for 10 days at $37^{\circ} \mathrm{C}$ in $5 \% \mathrm{CO}_{2}$ in air with $97 \%$ humidity. Medium change was carried out 10 days after culture establishment by removal of liquid containing non-adherent cells and centrifugation at $300 \mathrm{~g}, 4^{\circ} \mathrm{C}$ for 5 minutes to pellet non-adherent cells. The cell pellet was resuspended in fresh medium and returned to cultures. Thereafter, LTC were maintained by exchange of half volume of medium every 3-4 days. 


\subsection{Isolation of cells from tissues}

Bone marrow cells were isolated from the femur and tibia of C57BL/6J adult mice by flushing the bone cavity with DMEM using a syringe equipped with a $26 \mathrm{G}$ needle. Cells were dissociated by pressing through a fine mesh sieve. After centrifugation (1200rpm, $4^{\circ} \mathrm{C}, 10$ minutes), cells were resuspended in $5 \mathrm{~mL}$ red blood cell (RBC) lysis buffer [140mM NH $\mathrm{m}_{4} \mathrm{Cl}, 17 \mathrm{mM}$ Tris Base, $\left.\mathrm{pH} 7.5\right]$ for 5 minutes before centrifugation. Cells were then washed twice in sDMEM before resuspension in $1 \mathrm{~mL}$ sDMEM for cell counting as described in Section 2.3.

For isolation of splenocytes, dissected spleen was pressed through a fine mesh sieve. Cells were resuspended into $1 \mathrm{~mL}$ sDMEM and treated with RBC lysis buffer, washed and counted as described for BM cells.

\subsection{Lineage depletion of BM}

Bone marrow cells were isolated as described in Section 2.5 and depleted of known lineage $(\mathrm{Lin})^{+}$cells using a lineage depletion kit containing a cocktail of lineagespecific biotinylated antibodies (Miltenyi Biotec: North Ryde, NSW, Australia). This cocktail contained antibodies specific for CD5, CD45R, CD11b, Ly6C/G, 7-4 and Ter119 (Lineage depletion kit: Miltenyi Biotec) for depletion of all mature hematopoietic cells including B cells, T cells, monocytes/macrophages, neutrophils and granulocytes. Briefly, BM cells were washed twice in $10 \mathrm{~mL}$ magnetic activated cell sorting (MACS) buffer [2mM EDTA/0.5\% bovine serum albumin (BSA) in PBS] by centrifugation $\left(300 \mathrm{~g}, 4^{\circ} \mathrm{C}, 5\right.$ minutes) prior to antibody labelling of cells. The cell pellet was resuspended in $40 \mu \mathrm{L}$ of MACS buffer along with $10 \mu 1$ of biotin-conjugated antibody cocktail per $10^{7}$ cells and incubated for 10 minutes on ice. MACS buffer $\left(30 \mu \mathrm{L}\right.$ per $10^{7}$ cells) and anti-biotin microbeads $\left(20 \mu \mathrm{l}\right.$ per $10^{7}$ cells $)$ were then added to cell suspensions and further incubated for 15 minutes on ice. Cells were then washed with $4 \mathrm{~mL}$ of MACS buffer $\left(300 \mathrm{~g}, 4^{\circ} \mathrm{C}, 5\right.$ minutes) and resuspended in $500 \mu \mathrm{L}$ of the same buffer before loading on to MACS columns (Miltenyi Biotec) previously pre-washed with $500 \mu \mathrm{L}$ of MACS labelling buffer for medium size (MS) columns, or $3 \mathrm{~mL}$ for large size (LS) columns. Columns were washed thrice with $500 \mu \mathrm{L}$ of MACS buffer for MS, or $3 \mathrm{~mL}$ for LS columns. The collected effluent contained hematopoietic progenitors. 


\subsection{Isolation of splenic stromal cells}

Murine adult or neonatal spleens were dissociated between two sterile microscopic slides before filtering through a $70 \mu \mathrm{m}$ cell strainer. The non-suspendable stromal fraction was collected in a tube containing $2 \mathrm{~mL}$ collagenase IV extraction buffer [ $(2 \%$ heat inactivated fetal calf serum, $1 \mathrm{mg} / \mathrm{mL}$ collagenase IV (Sigma-Aldrich: Castle Hill, NSW, Australia) and 40 $\mathrm{g} / \mathrm{mL}$ DNaseI (Sigma-Aldrich: Castle Hill, NSW, Australia) in RPMI] and incubated for 20 minutes at $37^{\circ} \mathrm{C}$ with rotation. Two $\mathrm{mL}$ collagenase D extraction buffer [2\% heat inactivated fetal calf serum, $1 \mathrm{mg} / \mathrm{mL}$

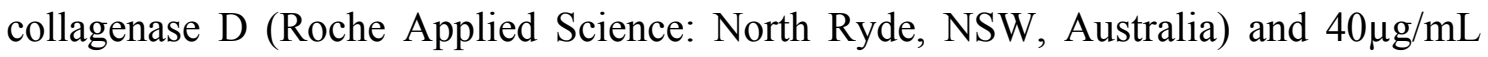
DNaseI in RPMI] was added prior to another 20 -minute incubation at $37^{\circ} \mathrm{C}$ with rotation. An additional $2 \mathrm{~mL}$ of collagenase $\mathrm{D}$ extraction buffer was added and the cell suspension incubated for a further 20 minutes at $37^{\circ} \mathrm{C}$ with rotation. The activity of collagenase was halted by addition of $60 \mu \mathrm{L}$ of $500 \mathrm{mM}$ EDTA to give a final concentration of $5 \mathrm{mM}$. Digested spleens were washed twice with $5 \mathrm{~mL}$ sDMEM (300g, $4^{\circ} \mathrm{C}, 5$ minutes) and viable cell count determined using trypan blue staining as described in Section 2.3. The cell pellet was resuspended in 1mL sDMEM for antibody staining, flow cytometric analysis and cell sorting.

\subsection{Sorted stromal cultures}

Stromal cells sorted by flow cytometry were cultured $\left(5 \% \mathrm{CO}_{2}\right.$ in air with $95 \%$ humidity at $37^{\circ} \mathrm{C}$ ) in a 6 -well plate containing sDMEM for 28 days or until about $90 \%$ confluent. Cells were passaged from 6 -well plates into a $25 \mathrm{~cm}^{2}$ flask and maintained until $90 \%$ confluency was obtained. Cells underwent a second passage from $25 \mathrm{~cm}^{2}$ into $75 \mathrm{~cm}^{2}$ flasks. Cells in the $75 \mathrm{~cm}^{2}$ flasks were either analysed for cell surface marker expression using flow cytometry, or tested for hematopoietic support capacity in coculture assays.

\subsection{Stromal co-culture assays}

Lin $^{-} \mathrm{BM}$ cells were prepared as described in Sections 2.5 and 2.6 and overlaid for co-culture above a near-confluent $5 \mathrm{G} 3$ stromal layer or sorted stromal cells plated at a concentration of $10^{4}$ cells $/ \mathrm{mL}$ in $5 \mathrm{~mL}$ of sDMEM. In some experiments, sorted LTHSC ( $\left.\mathrm{Lin}^{-} \mathrm{Sca}-1^{+} \mathrm{c}-\mathrm{Kit}^{+} \mathrm{F} 1 \mathrm{t} 3^{-} \mathrm{CD} 150^{+}\right)$and MPP ( $\left.\mathrm{Lin}^{-} \mathrm{Sca}^{-} 1^{+} \mathrm{c}-\mathrm{Kit}^{+} \mathrm{Flt} 3^{+} \mathrm{CD} 150^{-}\right)$were 
used as overlaid. Co-cultures were monitored weekly over a period of 4-6 weeks for production of hematopoietic cells through microscopy and flow cytometric analysis of cells produced.

Several potential inhibitors were tested through addition to co-cultures. Imatinib $(10 \mu \mathrm{M}, 1.0 \mu \mathrm{M}$ and $0.1 \mu \mathrm{M})$ and Plerixafor $(1.0 \mu \mathrm{M}, 0.5 \mu \mathrm{M}$ and $0.25 \mu \mathrm{M})$ (Sapphire Bioscience: Waterloo, NSW, Australia) were added directly into stromal co-cultures twice weekly for 42 days. The $\gamma$-secretase indirect Notch inhibitor DAPT $(10 \mu \mathrm{M}$, $1.0 \mu \mathrm{M}$, and $0.1 \mu \mathrm{M}$ ) (Sigma-Aldrich: Castle Hill, NSW, Australia) was added into stromal co-cultures twice weekly for 28 days. In some experiments, inhibitors were added only for the first two weeks and the last two weeks of a 6-week co-culture. Nonadherent cells were collected every 7 days by aspiration and replacement of medium. Non-adherent cells were sedimented $\left(300 \mathrm{~g}, 4^{\circ} \mathrm{C}, 5\right.$ minutes) and resuspended in Fluorescence-activated cell sorting (FACS) buffer (1\% FSC, $0.1 \%$ sodium azide in sDMEM) for flow cytometric analysis of cell surface marker expression.

\subsection{Flow Cytometry}

\subsubsection{Antibodies}

Antibodies used for cell staining were purchased as affinity purified conjugates of either fluorochrome or biotin, along with isotype control antibodies and secondary fluoresceinated conjugates. These are listed in Tables 2.1 and 2.2. All antibodies were titrated before use on splenocytes or BM cells to determine the concentration required to give minimum saturation binding.

\subsubsection{Antibody staining of cells}

Both multicolour and single colour staining protocols were utilised. For single colour staining, $5 \times 10^{5}-1 \times 10^{6}$ cells were sedimented into the wells of a 96-well polystyrene microtitre plate (Corning: New York, USA) by centrifugation (1300 rpm, 4 ${ }^{\circ} \mathrm{C}, 5$ minutes) using an Allegra 6R centrifuge equipped with microtitre plate carriers (Beckman Coulter: Gladesville, NSW, Australia). Supernatant was discarded and cells resuspended in 25 $\mathrm{L}$ anti-CD16/32 (FcBlock) (Biolegend: San Diego, CA, USA) at $5 \mu \mathrm{g} / \mathrm{mL}$ with incubation on ice for 15 minutes. The plate was centrifuged (1300 rpm, 
Table 2.1A List of primary antibody conjugates and isotype controls used in flow cytometry

\begin{tabular}{|c|c|c|c|c|c|}
\hline Specificity & Conjugation $^{a}$ & $\begin{array}{l}\text { Clone of } \\
\text { origin }\end{array}$ & Isotype & $\begin{array}{c}\text { Final } \\
\text { Concentration } \\
(\mu \mathrm{g} / \mathrm{mL})\end{array}$ & Source $^{b}$ \\
\hline $\mathrm{CD} 3 \varepsilon$ & Alexa488 & $145-2 \mathrm{C} 11$ & $\begin{array}{c}\text { Armenian } \\
\text { Hamster IgG }\end{array}$ & 2.5 & 1 \\
\hline $\mathrm{CD} 3 \varepsilon$ & Biotin & $145-2 \mathrm{C} 11$ & $\begin{array}{c}\text { Armenian } \\
\text { Hamster IgG }\end{array}$ & 1.25 & 1 \\
\hline CD3 $\varepsilon$ & $\begin{array}{c}\text { Brilliant Violet } \\
421\end{array}$ & $145-2 \mathrm{C} 11$ & $\begin{array}{c}\text { Armenian } \\
\text { Hamster IgG }\end{array}$ & 2 & 1 \\
\hline $\mathrm{CD} 8 \alpha$ & $\mathrm{PE}$ & $53-6.7$ & Rat $\operatorname{IgG}_{2 \mathrm{a}, \mathrm{K}}$ & 0.5 & 1 \\
\hline CD11b & PE-Cy7 & $\mathrm{M} 1 / 70$ & RatIgG $2 \mathrm{~b}, \mathrm{~K}$ & 0.2 & 1 \\
\hline CD11b & Biotin & $\mathrm{M} 1 / 70$ & RatIgG $_{2 \mathrm{~b}, \mathrm{~K}}$ & 0.5 & 2 \\
\hline CD11c & APC & N418 & Hamster IgG & 0.8 & 1 \\
\hline CD11c & Biotin & N418 & HamsterIgG $_{1, \lambda}$ & 1 & 2 \\
\hline CD19 & $\mathrm{PE}$ & $6 \mathrm{D} 5$ & Rat $\operatorname{IgG}_{2 \mathrm{a}, \mathrm{K}}$ & 1 & 1 \\
\hline CD19 & Biotin & $6 \mathrm{D} 5$ & Rat $\operatorname{IgG}_{2 \mathrm{a}, \mathrm{K}}$ & 0.5 & 1 \\
\hline CD29 & PE & НМ $\beta 1-1$ & $\begin{array}{c}\text { Armenian } \\
\text { Hamster IgG }\end{array}$ & 2 & 1 \\
\hline CD29 & Biotin & НМ $\beta 1-1$ & $\begin{array}{c}\text { Armenian } \\
\text { Hamster IgG }\end{array}$ & 2.5 & 1 \\
\hline CD31 & $\mathrm{PE}$ & 390 & Rat $\operatorname{IgG}_{2 \mathrm{a}, \mathrm{K}}$ & 0.5 & 1 \\
\hline CD31 & Alexa488 & 390 & Rat $\operatorname{IgG}_{2 \mathrm{a}, \mathrm{K}}$ & 2.5 & 1 \\
\hline CD31 & Biotin & 390 & Rat $\operatorname{IgG}_{2 \mathrm{a}, \mathrm{K}}$ & 2.5 & 1 \\
\hline CD41 & Alexa488 & MWReg30 & Rat $\operatorname{IgG}_{1, \mathrm{~K}}$ & 1.25 & 1 \\
\hline CD45.2 & Pacific Blue & 104 & $\begin{array}{c}\text { Mouse (SJL) } \\
\operatorname{IgG}_{2 \mathrm{a}} \\
\end{array}$ & 2.5 & 1 \\
\hline CD45.2 & Biotin & 104 & $\begin{array}{c}\text { Mouse (SJL) } \\
\operatorname{IgG}_{2 \mathrm{a}} \\
\end{array}$ & 2.5 & 1 \\
\hline CD48 & Alexa488 & HM48-1 & $\begin{array}{c}\text { Armenian } \\
\text { Hamster IgG }\end{array}$ & 1.25 & 1 \\
\hline CD51 & $\mathrm{PE}$ & RMV-7 & Rat $\operatorname{IgG}_{1, \mathrm{~K}}$ & 0.5 & 1 \\
\hline CD51 & Biotin & RMV-7 & Rat $\operatorname{IgG}_{1, \mathrm{~K}}$ & 2.5 & 1 \\
\hline CD54 & $\mathrm{PE}$ & YN1/1.7.4 & Rat $\operatorname{IgG}_{2 \mathrm{~b}, \mathrm{~K}}$ & 0.2 & 1 \\
\hline CD105 & $\mathrm{PE}$ & MJ7/18 & Rat $\operatorname{IgG}_{2 \mathrm{a}, \mathrm{K}}$ & 2 & 1 \\
\hline CD105 & Alexa488 & $\mathrm{MJ} 7 / 18$ & Rat $\operatorname{IgG}_{2 \mathrm{a}, \mathrm{K}}$ & 10 & 1 \\
\hline CD140a & $\mathrm{PE}$ & APA5 & Rat $\operatorname{IgG}_{2 \mathrm{a}, \mathrm{K}}$ & 2 & 1 \\
\hline CD140b & APC & APA5 & Rat $\operatorname{IgG}_{2 \mathrm{a}, \mathrm{K}}$ & 4 & 1 \\
\hline CD146 & FITC & ME-9F1 & Rat $\operatorname{IgG}_{2 \mathrm{a}, \mathrm{K}}$ & 1.25 & 1 \\
\hline CD150 & PE & TC15-12F12.2 & Rat $\operatorname{IgG}_{2 \mathrm{a}, \mathrm{K}}$ & 1 & 1 \\
\hline B220 & $\mathrm{PE}$ & RA3-6B2 & Rat $\operatorname{IgG}_{2 \mathrm{a}, \mathrm{K}}$ & 0.5 & 1 \\
\hline c-Kit & PE-Cy7 & 2B8 & RatIgG $\mathrm{G}_{2 \mathrm{~b}, \mathrm{~K}}$ & 1 & 1 \\
\hline ER-TR7 & FITC & sc-73355 & Rat $\operatorname{IgG}_{2 \mathrm{a}, \mathrm{K}}$ & 10 & 3 \\
\hline Flt3 & $\mathrm{APC}$ & A2F10 & Rat $\operatorname{IgG}_{2 \mathrm{a}, \mathrm{K}}$ & 2 & 1 \\
\hline $\mathrm{F} 4 / 80$ & Biotin & Cl: A3-1 & Rat $\operatorname{IgG}_{2 \mathrm{~b}, \mathrm{~K}}$ & 1.25 & 1 \\
\hline $\mathrm{F} 4 / 80$ & $\begin{array}{c}\text { Brilliant Violet } \\
421 \\
\end{array}$ & BM8 & Rat $\operatorname{IgG}_{2 \mathrm{a}, \mathrm{K}}$ & 2 & 2 \\
\hline Gr-1 (Ly6G) & Biotin & RM6-8C5 & Rat $\operatorname{IgG}_{2 \mathrm{~b}, \mathrm{~K}}$ & 1.25 & 2 \\
\hline $\mathrm{H}-2 \mathrm{~K}^{\mathrm{K}}$ & Alexa647 & $36-7-5$ & $\begin{array}{c}\text { Mouse (A.TL) } \\
\operatorname{IgG}_{2 \mathrm{a}, \mathrm{K}} \\
\end{array}$ & 2.5 & 1 \\
\hline Ly6G & $\mathrm{PE}$ & IA8 & Rat $\operatorname{IgG}_{2 \mathrm{a}, \mathrm{K}}$ & 1 & 1 \\
\hline MAdCAM1 & Alexa488 & MECA-367 & Rat $\operatorname{IgG}_{2 \mathrm{a}, \mathrm{K}}$ & 5 & 1 \\
\hline $\begin{array}{c}\text { MHC-I (H- } \\
\left.2 \mathrm{~K}^{\mathrm{b}}\right)\end{array}$ & Biotin & AF6-88.5 & $\begin{array}{c}\text { Mouse }(B A L B / c) \\
\operatorname{IgG}_{2 a, K}\end{array}$ & 1.25 & 1 \\
\hline $\begin{array}{c}\text { MHC-I (H- } \\
\left.2 \mathrm{~K}^{\mathrm{k}}\right)\end{array}$ & Biotin & $36-7-5$ & Mouse $\operatorname{IgG}_{2 \mathrm{a}}$ & 1.25 & 1 \\
\hline MHC-II (IAb) & Alexa488 & AF6-120.1 & Mouse $\operatorname{IgG}_{2 \mathrm{a}, \mathrm{K}}$ & 1.25 & 1 \\
\hline
\end{tabular}




\begin{tabular}{|c|c|c|c|c|c|}
\hline MHC-II (IAb) & Biotin & $25-9-17$ & Mouse $\operatorname{IgG}_{2 \mathrm{a}, \mathrm{K}}$ & 1.25 & 1 \\
\hline NK1.1 & Biotin & PK136 & Mouse $\operatorname{IgG}_{2 \mathrm{a}}$ & 0.5 & 2 \\
\hline $\begin{array}{l}\text { Podoplanin } \\
\text { (gp38) }\end{array}$ & $\mathrm{PE}$ & 8.1 .1 & $\begin{array}{c}\text { Syrian Hamster } \\
\text { IgG }\end{array}$ & 0.5 & 1 \\
\hline $\begin{array}{l}\text { Podoplannin } \\
\text { (gp38) }\end{array}$ & Alexa488 & 8.1 .1 & $\begin{array}{l}\text { Syrian Hamster } \\
\text { IgG }\end{array}$ & 5 & 1 \\
\hline $\begin{array}{c}\text { Sca-1 } \\
(\mathrm{Ly} 6 \mathrm{~A} / \mathrm{E})\end{array}$ & Pacific Blue & D7 & Rat $\operatorname{IgG}_{2 \mathrm{a}, \mathrm{K}}$ & 2.5 & 1 \\
\hline $\begin{array}{c}\text { Sca-1 } \\
(\mathrm{Ly} 6 \mathrm{~A} / \mathrm{E})\end{array}$ & APC & D7 & Rat $\operatorname{IgG}_{2 \mathrm{a}, \mathrm{K}}$ & 1 & 2 \\
\hline Ter119 & Biotin & TER119 & Rat $\operatorname{IgG}_{2 b, K}$ & 1 & 2 \\
\hline Thy 1.2 & APC-Cy7 & $30-\mathrm{H} 12$ & Rat $\operatorname{IgG}_{2 \mathrm{~b}, \mathrm{~K}}$ & 2 & 1 \\
\hline Thy 1.2 & Biotin & $30-\mathrm{H} 12$ & Rat $\operatorname{IgG}_{2 \mathrm{~b}, \mathrm{~K}}$ & 0.5 & 1 \\
\hline VCAM1 & Alexa488 & $\begin{array}{c}429 \\
\text { (MVCAM.A) }\end{array}$ & Rat $\operatorname{IgG}_{2 \mathrm{a}, \mathrm{K}}$ & 2.5 & 1 \\
\hline
\end{tabular}

Table 2.1B List of secondary detection conjugates used in flow cytometry

\begin{tabular}{|c|c|c|c|}
\hline Specificity & Conjugation $^{\mathrm{a}}$ & $\begin{array}{c}\text { Final } \\
\text { Concentration } \\
(\mu \mathrm{g} / \mathrm{mL})\end{array}$ & Source $^{\mathrm{b}}$ \\
\hline Streptavidin & APC & 0.5 & 1 \\
\hline Streptavidin & FITC & 5 & 2 \\
\hline Streptavidin & PE-Cy7 & 1 & 1 \\
\hline Streptavidin & PE & 0.2 & 1 \\
\hline Streptavidin & Alexa780 & 0.2 & 1 \\
\hline Streptavidin & APC-Cy7 & 0.2 & 1 \\
\hline
\end{tabular}

a APC, allophycocyanin; Alexa780, Alexafluor 780; APC-Cy7 allophycocyanin-Cy7; Alexa488, Alexafluor 488; FITC, fluorescein isothiocyanate; PE, phycoerythrin; PE-Cy7, phycoerythrin-Cy7

b 1: Biolegend (San Diego,CA,USA), 2: eBioscience (Parkville, VIC, Australia), 3: Santa Cruz Biotechnology (Dallas, TX, USA) 
Table 2.2A List of primary antibody conjugates and isotype controls used in immunohistochemistry

\begin{tabular}{|c|c|c|c|c|c|}
\hline Specificity & Conjugation $^{\mathrm{a}}$ & $\begin{array}{l}\text { Clone of } \\
\text { origin }\end{array}$ & Isotype & $\begin{array}{l}\text { Final } \\
\text { Conc. } \\
(\mu \mathrm{g} / \mathrm{ml})\end{array}$ & Source ${ }^{b}$ \\
\hline $\mathrm{CD} 3 \varepsilon$ & APC & $145-2 \mathrm{C} 11$ & $\begin{array}{c}\text { Armenian } \\
\text { Hamster IgG }\end{array}$ & 4 & 1 \\
\hline CD3e & Biotin & $145-2 \mathrm{C} 11$ & $\begin{array}{c}\text { Armenian } \\
\text { Hamster IgG }\end{array}$ & 5 & 1 \\
\hline CD11b & Biotin & $\mathrm{M} 1 / 70$ & RatIgG ${ }_{2 b, K}$ & 5 & 2 \\
\hline CD11c & Biotin & N418 & HamsterIgG $_{1, \lambda}$ & 5 & 1 \\
\hline CD19 & Biotin & $6 \mathrm{D} 5$ & Rat $\operatorname{IgG}_{2 \mathrm{a}, \mathrm{K}}$ & 5 & 1 \\
\hline CD29 & $\mathrm{PE}$ & НМ $\beta 1-1$ & $\begin{array}{c}\text { Armenian } \\
\text { Hamster IgG }\end{array}$ & 2 & 1 \\
\hline CD31 & Alexa647 & 390 & Rat $\operatorname{IgG}_{2 \mathrm{a}, \mathrm{K}}$ & 5 & 1 \\
\hline CD41 & Alexa488 & MWReg30 & Rat $\operatorname{IgG}_{1, \mathrm{~K}}$ & 1.25 & 1 \\
\hline CD45.2 & Pacific Blue & 104 & $\begin{array}{c}\text { Mouse (SJL) } \\
\operatorname{IgG}_{2 \mathrm{a}} \\
\end{array}$ & 2.5 & 1 \\
\hline CD45.2 & Biotin & 104 & $\begin{array}{c}\text { Mouse (SJL) } \\
\operatorname{IgG}_{2 \mathrm{a}}\end{array}$ & 2.5 & 1 \\
\hline CD48 & Alexa488 & HM48-1 & $\begin{array}{c}\text { Armenian } \\
\text { Hamster IgG }\end{array}$ & 5 & 1 \\
\hline CD51 & $\mathrm{PE}$ & RMV-7 & Rat $\operatorname{IgG}_{1, \mathrm{~K}}$ & 2 & 1 \\
\hline CD54 & $\mathrm{PE}$ & YN1/1.7.4 & Rat $\operatorname{IgG}_{2 \mathrm{~b}, \mathrm{~K}}$ & 2 & 1 \\
\hline CD105 & $\mathrm{PE}$ & MJ7/18 & Rat $\operatorname{IgG}_{2 \mathrm{a}, \mathrm{K}}$ & 2 & 1 \\
\hline CD105 & Alexa488 & $\mathrm{MJ} 7 / 18$ & Rat $\operatorname{IgG}_{2 \mathrm{a}, \mathrm{K}}$ & 10 & 1 \\
\hline CD140a & $\mathrm{PE}$ & APA5 & Rat $\operatorname{IgG}_{2 \mathrm{a}, \mathrm{K}}$ & 2 & 1 \\
\hline CD140b & $\mathrm{APC}$ & APA5 & Rat $\operatorname{IgG}_{2 \mathrm{a}, \mathrm{K}}$ & 4 & 1 \\
\hline CD146 & FITC & ME-9F1 & Rat $\operatorname{IgG}_{2 \mathrm{a}, \mathrm{K}}$ & 1.25 & 1 \\
\hline CD150 & Purified & TC15-12F12.2 & Rat $\operatorname{IgG}_{2 \mathrm{a}}$ & 5 & 1 \\
\hline B220 & $\mathrm{PE}$ & RA3-6B2 & Rat $\operatorname{IgG}_{2 \mathrm{a}, \mathrm{K}}$ & 2 & 1 \\
\hline c-Kit & PE-Cy7 & $2 \mathrm{~B} 8$ & RatIgG $2 \mathrm{~b}, \mathrm{~K}$ & 1 & 1 \\
\hline Flt3 & $\mathrm{APC}$ & $\mathrm{A} 2 \mathrm{~F} 10$ & Rat $\operatorname{IgG}_{2 \mathrm{a}, \mathrm{K}}$ & 2 & 1 \\
\hline $\mathrm{F} 4 / 80$ & Alexa488 & BM8 & Rat $\operatorname{IgG}_{2 \mathrm{a}}$ & 5 & 1 \\
\hline $\mathrm{F} 4 / 80$ & $\begin{array}{c}\text { Brilliant } \\
\text { Violet } 421\end{array}$ & BM8 & Rat $\operatorname{IgG}_{2 \mathrm{a}, \mathrm{K}}$ & 2 & 2 \\
\hline Gr-1 (Ly6G) & Biotin & RM6-8C5 & Rat $\operatorname{IgG}_{2 \mathrm{~b}, \mathrm{~K}}$ & 5 & 2 \\
\hline $\mathrm{H}-2 \mathrm{~K}^{\mathrm{K}}$ & Alexa647 & $36-7-5$ & $\begin{array}{c}\text { Mouse (A.TL) } \\
\operatorname{IgG}_{2 \mathrm{a}, \mathrm{K}}\end{array}$ & 5 & 1 \\
\hline MAdCAM1 & Alexa488 & MECA-367 & Rat $\operatorname{IgG}_{2 \mathrm{a}, \mathrm{K}}$ & 5 & 1 \\
\hline MHC-II (IAb) & Alexa488 & AF6-120.1 & Mouse $\operatorname{IgG}_{2 \mathrm{a}, \mathrm{K}}$ & 1.25 & 1 \\
\hline MHC-II (IAb) & Biotin & $25-9-17$ & Mouse $\operatorname{IgG}_{2 \mathrm{a}, \mathrm{K}}$ & 5 & 1 \\
\hline NK1.1 & Biotin & PK136 & Mouse $\operatorname{IgG}_{2 \mathrm{a}}$ & 5 & 2 \\
\hline $\begin{array}{l}\text { Podoplanin } \\
\text { (gp38) }\end{array}$ & $\mathrm{PE}$ & 8.1 .1 & $\begin{array}{l}\text { Syrian Hamster } \\
\text { IgG }\end{array}$ & 5 & 1 \\
\hline Sca-1 (Ly6A/E) & APC & D7 & Rat $\operatorname{IgG}_{2 \mathrm{a}, \mathrm{K}}$ & 2 & 2 \\
\hline Ter119 & Biotin & TER119 & Rat $\operatorname{IgG}_{2 \mathrm{~b}, \mathrm{~K}}$ & 5 & 2 \\
\hline Thy1.2 & Alexa647 & $30-\mathrm{H} 12$ & Rat $\operatorname{IgG}_{2 \mathrm{~b}, \mathrm{~K}}$ & 5 & 1 \\
\hline VCAM1 & Alexa488 & $\begin{array}{c}429 \\
\text { (MVCAM.A) }\end{array}$ & Rat $\operatorname{IgG}_{2 \mathrm{a}, \mathrm{K}}$ & 2.5 & 1 \\
\hline
\end{tabular}


Table 2.2B List of secondary detection conjugates used in immunohistochemistry

\begin{tabular}{|c|c|c|c|c|}
\hline Host & Specificity & Conjugation $^{\mathrm{a}}$ & $\begin{array}{c}\text { Final } \\
\text { Concentration } \\
(\mu \mathrm{g} / \mathrm{mL})\end{array}$ & Source $^{\mathrm{b}}$ \\
\hline Goat & Anti mouse IgG & Alexa594 & 5 & 1 \\
\hline Goat & Anti mouse IgG & Alexa647 & 5 & 1 \\
\hline- & Streptavidin & Alexa488 & 5 & 1 \\
\hline
\end{tabular}

a APC, allophycocyanin; Alexa647, Alexafluor647; Alexa780, Alexafluor 780; APC-Cy7 allophycocyanin-Cy7; Alexa488, Alexafluor 488; FITC, fluorescein isothiocyanate; Alexa594, Alexafluor 594; PE, phycoerythrin; PE-Cy7, phycoerythrin-Cy7

b 1: Biolegend (San Diego,CA,USA), 2: eBioscience (Parkville, VIC, Australia) 
$4^{\circ} \mathrm{C}, 5$ minutes) and the supernatant discarded. Cells were then resuspended in $25 \mu 1$ of diluted primary antibody and incubated on ice for 25 minutes. Cells were washed twice with $150 \mu 1 / 10^{6}$ cells FACS buffer with centrifugation (1300rpm, $4^{\circ} \mathrm{C}, 5$ minutes) between each wash. Where necessary, $25 \mu \mathrm{L}$ of diluted secondary antibody or conjugate was added to each well and cells incubated on ice for 25 minutes. Cells were then washed again using the washing procedure described above before resuspension in $50 \mu 1$ FACS buffer and transfer to FACS cluster tubes (Corning) for analysis.

For multicolour staining, a similar procedure was adopted, except that the primary antibody staining step involved up to five different primary antibodies. Where necessary, propidium iodide (PI: $1 \mu \mathrm{g} / \mathrm{mL}$ ) was added for dead cell discrimination on the flow cytometer.

\subsubsection{Flow cytometric analysis of cell surface marker expression}

Cells labelled with fluorochrome-labelled antibodies specific for markers of interest in single and multicolour staining formats were analysed flow cytometrically using an LSRII flow cytometer (Becton Dickinson: Franklin Lakes, New Jersey, USA). Voltage parameters and event counts were preset using FACSDIVA software (Becton Dickson). For multicolour analysis, compensation was carried out manually using single colour controls to prevent fluorescence emission of one fluorochrome leaking into another detection channel. Isotype control antibodies were used to determine the background binding of each specific antibody used and to set gates for delineation of positively stained cells. Live cells were discriminated from dead cells by exclusion of propidium iodide (PI). Analysis of data was performed using FACSDiva and Flow Jo software (Tristar: Phoenix, Arizona, USA). For each sample, $5 \times 10^{4}-1 \times 10^{6}$ cells were analysed and data presented as histogram plots or bivariate plots of side scatter (SSC), fluorescence or forward scatter (FSC). Both percent positive cells and median fluorescence intensity (MFI) were calculated using Flow Jo software (Tristar). Median fluorescence intensity shift (MFIS) was calculated as the net change in marker expression obtained by subtracting MFI for isotype controls from MFI of the specific antibody. 


\subsubsection{Cell sorting}

Fluorescence-activated cell sorting was used to sort cell subsets based on marker expression. Hematopoietic progenitors were prepared as described in Section 2.6. HSC $\left(\mathrm{Lin}^{-} \mathrm{Sca}-1^{+} \mathrm{c}-\mathrm{Kit}^{+} \mathrm{Flt} 3^{-} \mathrm{CD} 150^{+}\right)$and MPP $\left(\mathrm{Lin}^{-} \mathrm{Sca}^{-}{ }^{+}{ }^{+} \mathrm{c}-\mathrm{Kit}^{+} \mathrm{Flt} 3^{+} \mathrm{CD} 150^{-}\right)$were sorted in accordance with the procedure described by Petvises and O'Neill (2014b). Collagenase isolated splenic stromal cells were prepared as described in Section 2.7 and stained with antibodies as described in Section 2.10.2. Sorting was performed on a BD FACSAria ${ }^{\mathrm{TM}}$ II cell sorter (Becton Dickinson).

\subsubsection{Detection of apoptotic and necrotic cells}

The annexin V-FITC apoptosis detection kit (Sigma-Aldrich) was used to detect early apoptotic and necrotic cells. Stromal cells, either as in vitro grown 5G3 or 3B5, or ex vivo isolated splenic stroma, were collected as described in Sections 2.3 and 2.7, respectively. Cells were washed twice with PBS and sedimented $\left(300 \mathrm{~g}, 4^{\circ} \mathrm{C}, 5\right.$ minutes) between washes. Supernatant was discarded and cells resuspended in binding buffer $\left[10 \mathrm{mM}\right.$ HEPES/NaOH, $140 \mathrm{mM} \mathrm{NaCl}, 2.5 \mathrm{mM} \mathrm{CaCl}_{2}$ ] to a concentration of $1 \times 10^{6}$ cells $/ \mathrm{mL}$. $500 \mu \mathrm{L}$ of the cell suspension was then transferred to an Eppendorf tube. Annexin V-FITC $(0.5 \mu \mathrm{g} / \mathrm{mL})$ and PI $(1 \mu \mathrm{g} / \mathrm{mL})$ were added and incubated in the dark at room temperature for 10 minutes before transfer to FACS cluster tubes for flow cytometric analysis.

Annexin V and PI staining of cells was detected using the LSRII flow cytometer (Becton Dickinson). Annexin V and PI staining was used to detect necrotic cells as $\mathrm{PI}^{+}$ annexin $\mathrm{V}^{+}$cells, early apoptotic cells as $\mathrm{PI}^{-}$annexin $\mathrm{V}^{+}$, and live cells as $\mathrm{PI}^{-}$annexin $\mathrm{V}^{-}$.

\subsection{Immunofluorescence microscopy}

Whole C57BL/6J adult or neonatal murine spleen was embedded in Tissue-Tek $\mathrm{OCT}^{\mathrm{TM}}$ compound [10.24\% polyvinyl alcohol, $4.26 \%$ polyethylene glycol, $85.50 \%$ nonreactive ingredient]. Sections of $10 \mu \mathrm{m}$ thickness were then prepared using a ReichertJung 2800 Frigocut cryostat (Reichert-Jung: Depew, New York, USA). Spleen sections were then fixed in acetone for 15 minutes at $4{ }^{\circ} \mathrm{C}$ and air dried for an hour before storage 
at $-80^{\circ} \mathrm{C}$. Frozen slides were left to thaw at room temperature before staining for immunofluorescence microscopy.

For antibody staining, tissue sections were first blocked with $10 \%$ heat inactivated fetal calf serum in PBS for 45 minutes at room temperature to prevent nonspecific binding of antibodies. Sections were then stained with fluorochrome-labelled primary antibodies specific to antigens of interest for 45 minutes at room temperature. Slides were then washed thrice by immersion in three consecutive chambers containing PBS for 5 minutes each. Secondary antibodies were used to stain sections where necessary (for 45 minutes) and washed again as above. Nuclear DNA was stained with 4, 6-diamidino-2-phenylindole (DAPI; Sigma-Aldrich) for 5 minutes and washed thrice with PBS as above to delineate individual cell nuclei. Stained sections were examined using a Leica TCS SP5 Confocal microscope (Leica Microsystems: North Ryde, NSW, Australia).

\subsection{Graft preparation}

Isopore membrane/collagen sponge method: In vitro grown stromal cells were harvested by trypsinization and filtered through a $70 \mu \mathrm{m}$ cell strainer to obtain a single cell suspension. Cell count and viability were determined using trypan blue exclusion as described in Section 2.3. About $1 \times 10^{4}-1 \times 10^{6}$ cells per graft were sedimented $(300 \mathrm{~g}$, $4^{\circ} \mathrm{C}, 5$ minutes) and resuspended in $20 \mu \mathrm{L}$ sDMEM per graft using a P20 pipette tip. The opening of the pipette tip was sealed using Parafilm before centrifugation $\left(300 \mathrm{~g}, 4^{\circ} \mathrm{C}\right.$, 10 minutes). The cell pellet formed in the pipette was carefully released on to an isopore membrane/collagen sponge construct soaked with $400 \mu \mathrm{L}$ sDMEM. The isopore membrane/collagen sponge construct was placed in one well of the 6-well plate. The rest of the wells were filled with PBS to keep the graft moist during incubation at $37^{\circ} \mathrm{C}$ ( $5 \% \mathrm{CO}_{2}$ in air with $95 \%$ humidity).

Matrigel method: In vitro grown stromal cells were harvested and filtered as described above. Sorted ex vivo or in vitro grown stromal cells were pelleted and resuspend in 10-20 $\mu \mathrm{L}$ Matrigel (Corning: New York, USA, Matrigel ${ }^{\circledR}$ Matrix, standard formulation, $8-12 \mathrm{mg} / \mathrm{mL}$ protein concentration). Matrigel-cell mix was withdrawn into 1-10 $\mu \mathrm{L}$. Wiretrol capillary micropipettes (Drummond: Broomall, PA, USA), and allowed for gel solidification at room temperature before injection. 


\subsection{Ectopic grafting}

Prior to the grafting procedure, mice were anaesthetized with $3.5 \%$ isofluorane in oxygen. A small skin incision of $20-25 \mathrm{~mm}$ was made in the region of the left kidney using a pair of scissors and ring tweezers. The left kidney was exteriorized by application of pressure on both sides of the abdomen. In order to introduce the cell pellet which had been incubated overnight into the kidney subcapsular space, a $2-4 \mathrm{~mm}$ incision was carefully made in the kidney capsule using curved fine forceps. To open the kidney subcapsular space between the capsule and the underlying parenchyma, the fine tip of the curved fine forceps was carefully slid between the layers. The graft was implanted into the space formed under the kidney capsule with a pair of curved fine forceps. For introduction of Matrigel into the subcapsular space, a 1-2mm incision was carefully made in the kidney capsule, using the tip of curved fine forceps. A Wiretrol capillary micropipette containing Matrigel-cell mix was carefully inserted into that incision site. Small left-right movements were gently made while inserting the Wiretrol, in order to open the kidney subcapsular space. Once within the kidney subcapsular

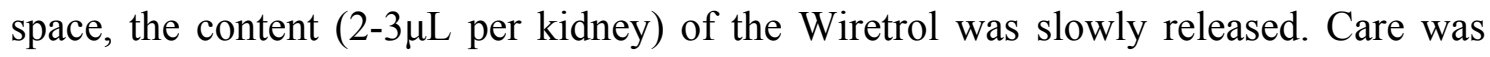
taken to ensure that kidney was kept moist during surgery by wetting with PBS. Upon completion, the kidney was returned into the body cavity. Sutures and skin staples were used to close the incision wounds.

\subsection{Graft analysis}

Grafts were carefully dissected out from the renal capsule at either 2 or 4 weeks after grafting. The graft was cut into smaller pieces before treatment with collagenase tissue were stained with fluorochrome-conjugated antibodies and analysed by flow cytometry. This procedure was described in Section 2.10.

\subsection{Statistical analysis}

Data are presented as mean \pm standard error (SE) for sample size $n \geq 2$. Where a normal distribution could be assumed, the Student's $t$-test was used to assess significance $(\mathrm{p} \leq 0.05)$ using Prism 5.0 software (GraphPad Software, San Diego, California, USA). 
CHAPTER THREE

SPLENIC STROMA SUPPORTS IN VITRO

HEMATOPOIESIS 


\subsection{INTRODUCTION}

Mesenchymal stem cells (MSC) in the BM are multipotent stromal cells, first characterised in $\mathrm{BM}$ as non-hematopoietic cells which adhere to plastic and have trilineage differentiation potential to give osteogenic, chondrogenic and adipogenic cells (Dominici et al., 2006). In addition, they express the CD105, Thy 1.2 and STRO-1 cell surface markers and not hematopoietic markers. The MSC population in BM has been identified as nestin ${ }^{+}$cells in contrast with MSC in association with large blood vessels which do not express nestin (Mendez-Ferrer et al., 2010). In addition to the MSC population, two other stromal cell subsets have been identified in BM. These include CAR cells (Omatsu et al., 2010; Sugiyama et al., 2006), and LepR ${ }^{+}$stromal cells, which are also described as perivascular reticular cells (Ding et al., 2012). These have now been detected in both humans and mice (Corselli et al., 2013; Ding et al., 2012; Sugiyama et al., 2006).

Multiple molecular interactions occur between HSC and the stromal niche environment in BM, many of which are essential triggers for hematopoiesis. Knowledge of these molecular interactions is still incomplete, although some receptor-ligand signalling events have been defined. These include SCF/c-KIT, CXCL12/CXCR4, and Notch signalling (Corselli et al., 2013; Ding et al., 2012; Ogawa et al., 1991; Leary et al., 1992). Both SCF and CXCL12 are produced by perivascular reticular cells in BM and are important for HSC maintenance (Ding et al., 2012; Sugiyama et al., 2006). The role of Notch in hematopoiesis is inconclusive, although in one study, inhibition of Notch in co-cultures of $\mathrm{CD}_{146^{+}}$perivascular cells and human HSC resulted in decreased numbers of HSC and increased B cell development, suggesting a role for Notch in maintaining HSC, so preventing their differentiation (Corselli et al., 2013). The mechanism of Notch signalling involves the binding of Notch receptors (NOTCH1-4 in mammals) to their ligands, DELTA (DLL1, DLL3 and DLL4) and JAGGED (JAG1 and JAG2) (Pajcini et al., 2011). Two successive ligand-induced proteolytic events occur as a result of ligand-receptor binding (Pajcini et al., 2011). Firstly, the extracellular domain of the Notch receptor is cleaved by ADAM10, a metalloprotease. Secondly, the transmembrane domain is then cleaved by $\gamma$-secretase, releasing the Notch intracellular domain which then translocates into the nucleus to activate specific genes (Pajcini et al., 2011). 
This laboratory previously reported a murine splenic stromal cell line 5G3 which supports in vitro hematopoiesis (Periasamy et al., 2009). Similar stromal cell lines have also been isolated from humans (Petvises et al, in preparation). The 5G3 clonal line was shown to support production of 'L-DC' in vitro in the absence of added growth factors and cytokines (Periasamy et al., 2009). Another splenic stromal cell line, named 3B5, is a non-supporter of in vitro hematopoiesis. Recent results from O'Neill Lab (unpublished) indicate that 5G3 and 3B5 splenic stroma do not resemble endothelial cells or fibroblastic cells in terms of gene expression, but do have a mesenchymal stem/progenitor phenotype since cells can undergo osteogenesis under mineralization conditions (O’Neill, unpublished data). These cell lines were therefore investigated further for marker expression to determine their lineage origin. Flow cytometry and specific antibody staining has been used to investigate cell surface marker expression on 5G3 and 3B5 stroma. Cell surface phenotype can be informative for interpretation of lineage origin, and for phenotypic comparison with other described stromal cells populations.

This chapter also investigates the hematopoietic support capacity of the splenic stromal line $5 \mathrm{G} 3$ in terms of signals which control hematopoiesis, in particular the production of myeloid cells including L-DC as well as progenitor cells. The identity of $5 \mathrm{G} 3$ and 3B5 as perivascular reticular cells in BM is confirmed, and stromal interactions with HSC involving c-Kit and Notch, but not CXCR4 are shown to be important in regulating in vitro hematopoiesis. 


\subsection{RESULTS}

\subsubsection{Phenotypic characterisation of splenic stromal lines}

Frozen stocks of 5G3 and 3B5 stroma were used to establish stromal cultures. Cells were passaged twice before harvesting at near confluence by trypinisation. Harvested cells were then incubated with propidium iodide (PI) and Annexin V to differentiate necrotic, early apoptotic and viable cells as shown by the gating protocol in Figure 3.1C. In order to characterise the lineage origin of 5G3 and 3B5 stroma, harvested cells were stained with fluorochrome-conjugated antibodies specific for cell surface markers of MSC, CAR cells, endothelial cells and cells of hematopoietic lineage. Antibody-labelled cells were analysed flow cytometrically to determine median fluorescence intensity (MFI) as shift in fluorescence intensity above background for each marker. A profile of cell surface marker expression for 5G3 and 3B5 stroma was generated estimating MFI of marker expression for multiple stainings (Table 3.1).

Both 5G3 and 3B5 stroma were shown to have a close phenotypic resemblance with mesenchymal stem/progenitor cells and CAR cells (Table 3.1). Both stroma expressed CD105, CD29, Sca-1 and Thy1 in common with MSC. They also expressed VCAM1, CD51 and CD140a, which are markers of perivascular reticular cells. They also stained for gp38, which is a known marker of fibroblastic reticular cells and lymphatic endothelial cells. Significantly higher expression of VCAM1, CD140a, Sca-1 and Thy 1.2 was seen for 5G3 over 3B5 (Table 3.1). 5G3 and 3B5 expressed no markers of hematopoietic cells including CD11b (myeloid cells) (Springer et al., 1979), CD11c (dendritic cells), F4/80 (red pulp macrophages) (Austyn and Gordon, 1981), Ly6G (neutrophils) (Fleming et al., 1993), B220 (B cells) (Gerberick et al., 2002), CD48 (lymphoid cells) (McArdel et al., 2016), CD150 (HSC), MHC II (antigen presenting cells) (Harding and Unanue, 1990), CD45.2 (all hematopoietic cells) (Cupedo et al., 2004) and CD3 (T cells) (Clevers et al., 1988). These markers were all shown to be expressed by subsets of spleen cells used as controls (data not shown). 5G3 and 3B5 do not reflect endothelial cells in that do not express CD31 or CD54. 
Table 3.1 Summary of cell surface makers and their localisation on different cell types

\begin{tabular}{|c|c|c|c|}
\hline Cell surface marker & Cell specificity* & MFI** & MFI** \\
\hline Marker name & & 5 G3 & $3 B 5$ \\
\hline \multicolumn{4}{|c|}{ Mesenchymal stem cells } \\
\hline CD105 & $\begin{array}{l}\text { MSC, MRC, RPF (Oh and Kwon } \\
2010 \text { ) }\end{array}$ & $493 \pm 80.9$ & $464 \pm 140$ \\
\hline $\mathrm{CD} 29$ & $\begin{array}{l}\text { MSC, FRC, RPF (Mueller and } \\
\text { Germain 2009; Oh and Kwon } \\
\text { 2010) }\end{array}$ & $2070 \pm 243$ & $2520 \pm 450$ \\
\hline Sca-1† & $\begin{array}{l}\text { MSC, CAR cells (Oh and Kwon } \\
\text { 2010; Nagasawa et al. 2011) }\end{array}$ & $3160 \pm 579$ & $279 \pm 83.3$ \\
\hline Thy $1.2 \dagger$ & $\begin{array}{l}\text { MSC, fibroblastic cells, T cells } \\
\text { (Garg et al. 2013; Nagasawa et al. } \\
\text { 2011; Dominici et al. 2006; } \\
\text { Spangrude et al. 1988) }\end{array}$ & $6730 \pm 457$ & $2640 \pm 446$ \\
\hline \multicolumn{4}{|c|}{ CXCL12-Abundant Reticular cells } \\
\hline CD51 & CAR cells (Nagasawa et al. 2011) & $294 \pm 51.0$ & $299 \pm 94.5$ \\
\hline VCAM1† & $\begin{array}{l}\text { MSC, FRC, CAR cells, MRC (Oh } \\
\text { and Kwon 2010; Mueller and } \\
\text { Germain 2009; Nagasawa et al. } \\
\text { 2011) }\end{array}$ & $448 \pm 47.3$ & $179 \pm 29.5$ \\
\hline CD140at & $\begin{array}{l}\text { CAR cells, FRC, RPF (Mueller and } \\
\text { Germain 2009; Nagasawa et al. } \\
\text { 2011) }\end{array}$ & $403 \pm 160$ & $123 \pm 48.9$ \\
\hline
\end{tabular}




\begin{tabular}{|l|l|l|l|}
\hline Endothelial cells & $\begin{array}{l}\text { FRC, MRC, LEC, RPF (Mueller } \\
\text { and Germain 2009) }\end{array}$ & 9 & 7 \\
\hline CD54 & LEC (Mueller and Germain 2009) & 13 & 13 \\
\hline CD31 & $\begin{array}{l}\text { FRC, LEC (Mueller and Germain } \\
\text { 2009) }\end{array}$ & $6720 \pm 839$ & $4110 \pm 814$ \\
\hline Lin38† & T cells (Clevers et al. 1988) & 0 & 0 \\
\hline CD3 & B cells (Gerberick et al. 2002) & 2 & 4 \\
\hline B220 & $\begin{array}{l}\text { Hematopoietic stem cells (Kiel et } \\
\text { al. 2005) }\end{array}$ & 2 & 0 \\
\hline CD150 & $\begin{array}{l}\text { All hematopoietic cells except } \\
\text { Neutrophils (McArdel et al. 2016) }\end{array}$ & 6 & 1 \\
\hline CD48 & $\begin{array}{l}\text { Myeloid cells (Springer et al. } \\
1979)\end{array}$ & 1 & 0 \\
\hline CD11b & $\begin{array}{l}\text { Antigen presenting cells, B cells, } \\
\text { Thymic epithelial cells }\end{array}$ & 71 & 28 \\
\hline MHC II & $\begin{array}{l}\text { Macrophages (Austyn and Gordon } \\
1981)\end{array}$ & 0 & 1 \\
\hline F4/80 & Dendritic cells (Sadhu et al. 2007) & 0 & 2 \\
\hline CD11c & Neutrophils (Fleming et al. 1993) & 5 & 6 \\
\hline Ly6G & $\begin{array}{l}\text { Hematopoietic cells (Cupedo et al. } \\
\text { 2004) }\end{array}$ & 36 & 36 \\
\hline CD45.2 & & & \\
\hline
\end{tabular}

† These markers were expressed at significantly higher levels in 5G3 over 3B5

*MSC, mesenchymal stem cells; CAR, CXCL-12 abundant reticular cells; FRC, fibroblastic reticular cells; MRC, marginal reticular cells; LEC, lymphatic endothelial cells; RPF, red-pulp fibroblasts.

** Median fluorescent intensity was found by subtracting median fluorescence intensity (MFI) for control antibodies from that of specific antibodies. Data are shown as mean $\pm S E, n=4$ in all cases except for CD140a where $n=3$. 


\subsubsection{G3 stroma supports myeloid cell production}

The hematopoietic support capacity of $5 \mathrm{G} 3$ stroma was demonstrated by overlay of lineage depleted BM cells on to near-confluent stroma and co-culture over time (Figure 3.1A). This process was described originally by Periasamy et al. (2009). Nonadherent cells were collected from the supernatant of co-cultures and stained with fluorochrome-conjugated antibodies specific for CD11b, CD11c, MHC-II and F4/80 for flow cytometric analysis and identification of myeloid cell types produced. On the basis of cell surface marker staining, L-DC were gated as $\mathrm{CD} 11 \mathrm{~b}^{\mathrm{hi}} \mathrm{CD} 11 \mathrm{c}^{\mathrm{lo}} \mathrm{F} 4 / 80^{+} \mathrm{MHC}-\mathrm{II}^{-}$

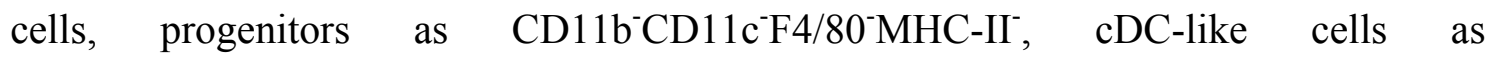

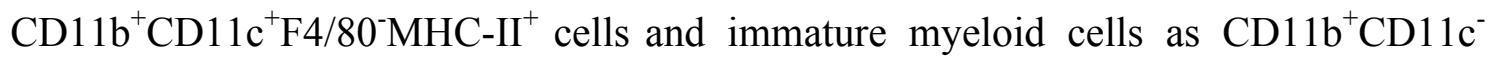
F4/80'MHC-II' (Figure 3.1A). A diagrammatic representation of cells produced in stromal co-cultures overlaid with $\mathrm{Lin}^{-} \mathrm{BM}$ is shown in Figure 3.1B.

After 14 days, L-DC reflected $61.3 \%$ of cells, with cDC-like cells (13.2\%) and myeloid cells (12.3\%) as minor populations. A distinct population of L-DC was evident by 21 days, representing $92.6 \%$ of cells, with minor populations of myeloid cells (4.2\%) and progenitors $(10.4 \%$ ) (Figure 3.1A). cDC-like cells and myeloid cells are produced only transiently from precursors present in $\operatorname{Lin}^{-} \mathrm{BM}$ (Periasamy et al., 2009).

\subsubsection{Role of $5 \mathrm{G3}$ in signalling hematopoiesis}

\subsubsection{Imatinib, but not Plerixafor, inhibits $\mathrm{CD}_{11} \mathrm{~b}^{\text {hi }}$ production}

Previously, gene profiling using Affymetrix genechips (this laboratory) revealed expression of $S c f$ and $C x c l 12$ genes by $5 \mathrm{G} 3$ stroma, which was also confirmed by qPCR (Periasamy and O'Neill, unpublished data). These genes encode the soluble factors SCF and CXCL12, known to be expressed by perivascular cells in BM, which are directly involved in the maintenance of HSC (Ding et al., 2012; Sugiyama et al., 2006). In order to investigate a possible role for SCF and CXCL12 in myeloid cell production in stromal co-cultures, Imatinib, a selective tyrosine kinase inhibitor of the c-Kit receptor for SCF and Plerixafor, an antagonist inhibitor of the CXCR4 receptor for CXCL12 were titrated into co-cultures established with Lin $^{-} \mathrm{BM}$ cells. Inhibitors were replenished bi-weekly over 42 days as described in Section 2.9. Non-adherent cells were collected from cultures every 7 days, stained for CD11b, CD11c, MHC-II and F4/80, and 
Figure 3.1 Characterisation of cells produced in stromal co-cultures. (A) Co-cultures were established by overlay of lineage depleted bone marrow cells over confluent 5G3 stroma. Production of non-adherent cells was evident at 14 and 21 day above a monolayer. Non-adherent cells were collected from the supernatant of co-cultures and stained with fluorochrome-conjugated antibodies specific for CD11b, CD11c, MHC-II and F4/80. Stained cells were analysed flow-cytometrically to delineate the subset type of cells produced. Propidium iodide (PI; $1 \mu \mathrm{g} / \mathrm{mL})$ was added to discriminate live (PI') from dead cells and large cells were gated using forward scatter (FSC) versus side scatter (SSC) analysis (not shown). Stained cells were analysed flow-cytometrically to delineate cell types produced. On the basis of cell surface marker staining, $\mathrm{L}_{-} \mathrm{DC}$ were gated as $\mathrm{CD} 11 \mathrm{~b}^{+} \mathrm{CD} 11 \mathrm{c}^{+} \mathrm{F} 4 / 80^{+} \mathrm{MHC}-\mathrm{II}^{-}$

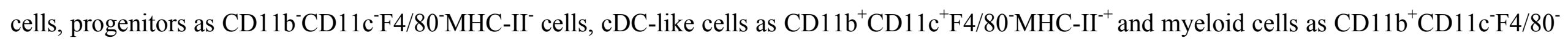
MHC-II' cells. A Co-culture representative of one experiment is shown. (B) Diagrammatic representation of cell types produced in stromal co-cultures comprising Lin ${ }^{-}$bone marrow overlaid on 5G3 stroma. (C) 5G3 and 3B5 stromal cells were harvested by trypinisation at near confluence, stained with Annexin V and PI to distinguish cells based on viability. Based on the uptake of Annexin V and PI, live cells were gated as Annexin $\mathrm{V}^{-} \mathrm{PI}{ }^{-}$(Q4), apoptotic cells as Annexin $\mathrm{V}^{+} \mathrm{PI}(\mathrm{Q} 1)^{-}$, and necrotic cells as Annexin $\mathrm{V}^{+/} \mathrm{PI}^{+}$(Q2 \& Q3), respectively. Gated cells were then plotted as overlays of cell populations distributed on a side scatter (SSC) plot versus forward scatter (FSC). This distribution allows the live population of 5G3 and 3B5 to be gated on FSC and SSC parameters in all future experiments. 

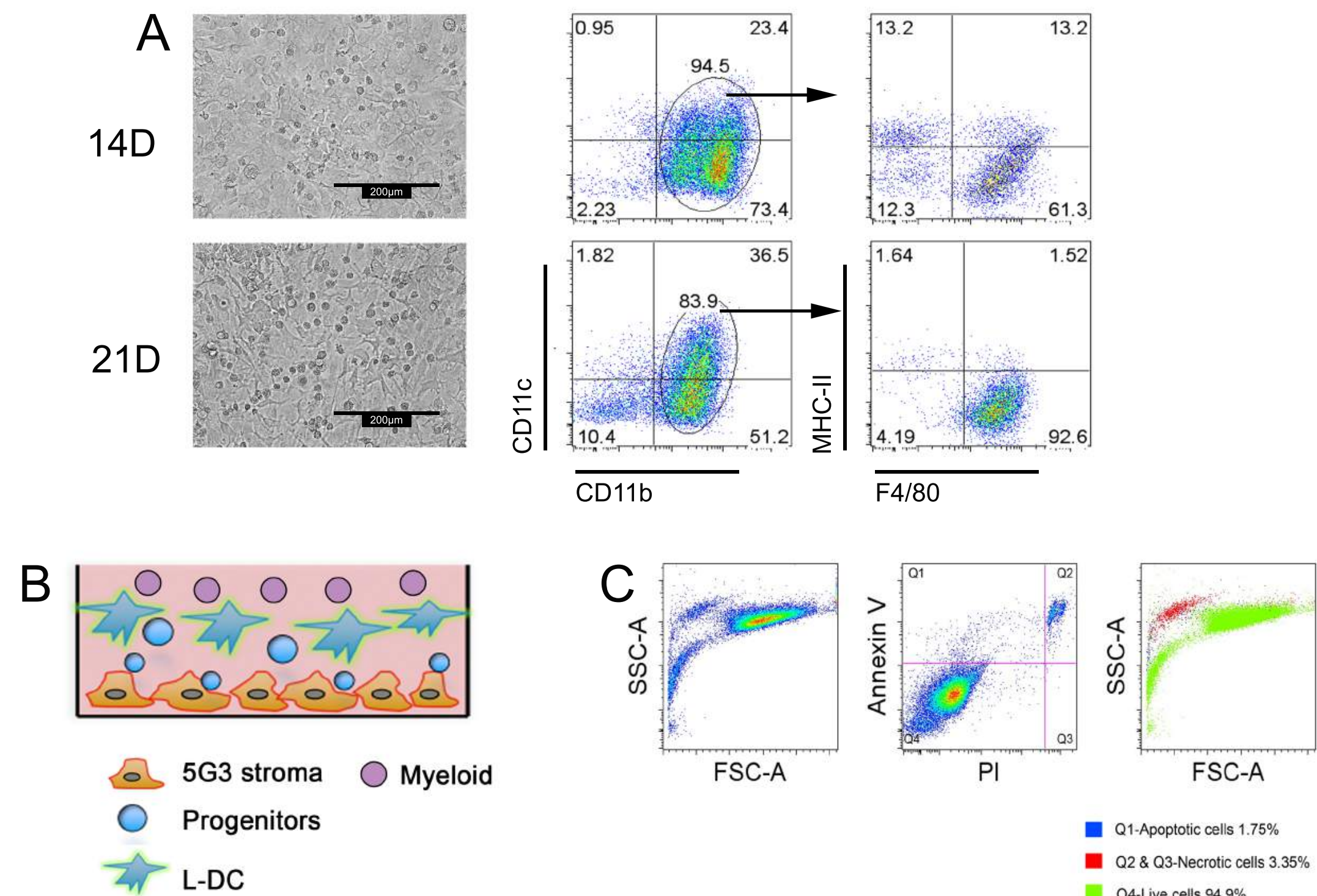

Q1-Apoptotic cells $1.75 \%$

Q2 \& Q3-Necrotic cells 3.35\%

Q4-Live cells $94.9 \%$ 
analysed using flow-cytometry to delineate $\mathrm{CD} 11 \mathrm{c}^{+} \mathrm{CD} 11 \mathrm{~b}^{\text {hi }}$ cells. In some co-cultures, an exclusion period between 14 to 28 days after co-culture establishment was included to determine if cell production would resume after a period of inhibition, questioning whether progenitors were still maintained and able to differentiate.

Flow cytometric analysis of cells produced in co-cultures treated with Plerixafor gave continuous cell production in all treated co-cultures compared with control cocultures across a wide concentration range $(1.0 \mu \mathrm{M}, 0.5 \mu \mathrm{M}$ and $0.25 \mu \mathrm{M})$. Reduction in cell production was minor, and the effect of Plerixafor was not distinctive or significant. The removal of drug after 14 days of co-culture had no noticeable effect on cell production. This suggested that CXCL12 binding to CXCR4 was not essential for myelopoiesis in stromal co-cultures. In contrast, addition of Imatinib at concentrations of $10 \mu \mathrm{M}$ and $0.1 \mu \mathrm{M}$, noticeably reduced the production of cells in stromal co-cultures. By 14 days, cultures treated with $10 \mu \mathrm{M}$ Imatinib showed cell production at $10-20 \%$ of control levels (Figure 3.2). This suggests that Imatinib acts to slow cell development, at the level of progenitors, perhaps inhibiting self-renewal, maintenance or survival. This effect was not reversed through a period of drug withdrawal. However, drug effects were biphasic, such that a concentration of $1.0 \mu \mathrm{M}$ had no overall effect on production of $\mathrm{CD} 11 \mathrm{c}^{+} \mathrm{CD} 11 \mathrm{~b}{ }^{\text {hi }}$ cells, while treatment with $0.1 \mu \mathrm{M}$ gave a partial effect (Figure 3.2). Such a concentration effect suggests that more than one cell type may be a target for the drug. When 1.0 $\mu \mathrm{M}$ Imatinib treatment was suspended across 14-28 days of treatment, an increase in $\mathrm{CD} 11 \mathrm{c}^{+} \mathrm{CD} 11 \mathrm{~b}{ }^{\text {hi }}$ cell production was seen compared with cultures where drug treatment was continued. One explanation for this could be that c-Kit is not only expressed by progenitors but also by downstream progeny eg. dendritic cell precursors. The effect of blocking c-Kit on downstream cells could alter their development, perhaps by making them more responsive to other differentiation factors produced by $5 \mathrm{G} 3$, for example macrophage colony stimulating factor (M-CSF) (Periasamy, unpublished data), which could induce proliferation of myeloid precursors. One would then argue that the inhibition seen at $0.1 \mu \mathrm{M}$ is due to a partial effect on progenitors or precursors and perhaps no secondary effect on downstream progeny cells as proposed above. 
Figure 3.2 Imatinib is an effective inhibitor of in vitro hematopoiesis. Co-cultures of Lin ${ }^{-}$bone marrow overlaid on $5 \mathrm{G} 3$ stroma were established for 42 days. Imatinib, an inhibitor of c-Kit, and Plerixafor which blocks CXCR4 binding CXCL12, were added from Day 0 at several concentrations to assess their effects on cell production. Inhibitors were replaced twice weekly at medium change. Non-adherent cells were collected every 7 days from 14 days of co-culture, stained with fluorochrome-conjugated antibodies specific for CD11b, CD11c, MHC II and CD8a, and cells analysed flow cytometrically. Stained cells were incubated with propidium iodide (PI) $(1 \mu \mathrm{g} / \mathrm{ml})$ for gating live (PI') cells and, large live cells (FSC $\left.{ }^{-}\right)$were gated on the basis of a side scatter (SSC) and forward scatter (FSC) data (not shown). Isotype control antibodies were used to set gates. \%CD11 $\mathrm{c}^{+} \mathrm{CD} 11 \mathrm{~b}^{\mathrm{hi}}$ cells amongst the total live cell population was calculated for: (A) Imatinib treatment at $10.0 \mu \mathrm{M}, 1.0 \mu \mathrm{M}$ and $0.1 \mu \mathrm{M}$, with an exclusion period across 14 to 28 days when inhibitors were not replenished (shaded area); (B) Continuous Imatinib treatment at $10.0 \mu \mathrm{M}, 1.0 \mu \mathrm{M}$ and $0.1 \mu \mathrm{M}$; (C) Plerixafor treatment at $1.0 \mu \mathrm{M}, 0.5 \mu \mathrm{M}$ and $0.25 \mu \mathrm{M}$ with an exclusion period across 14 to 28 days when inhibitors were not replenished (shaded area); (D) Continuous Plerixafor treatment at $1.0 \mu \mathrm{M}, 0.5 \mu \mathrm{M}$ and $0.25 \mu \mathrm{M}$. Cells did not stain for MHC-II or CD8 $\alpha$ (data not shown). Control cultures contained no added inhibitors. 
A Imatinib treatment (with exclusion)

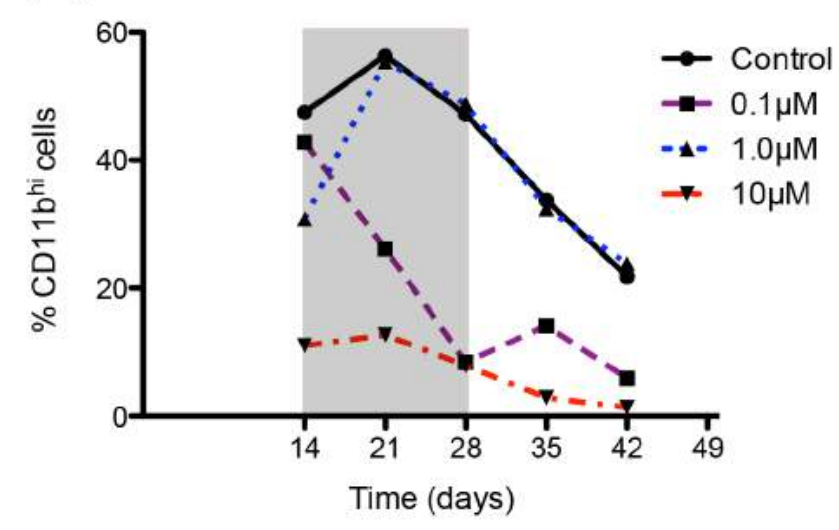

B Imatinib treatment

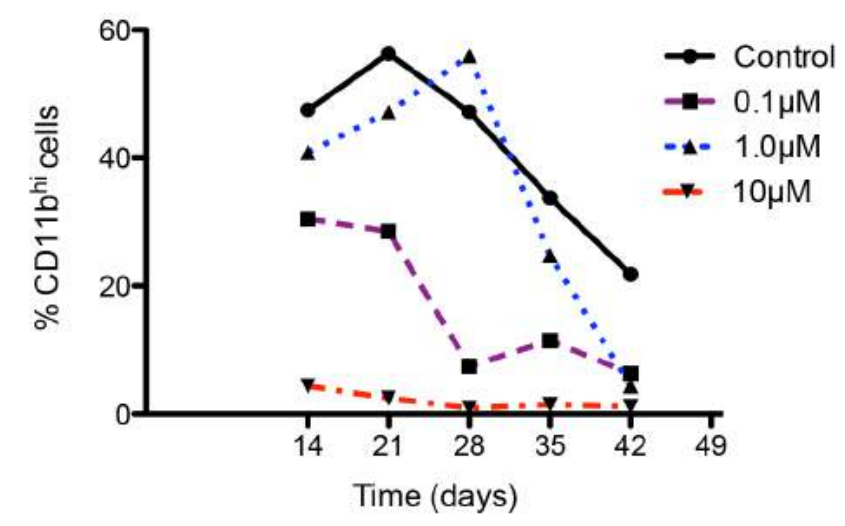

C Plerixafor treatment (with exclusion)

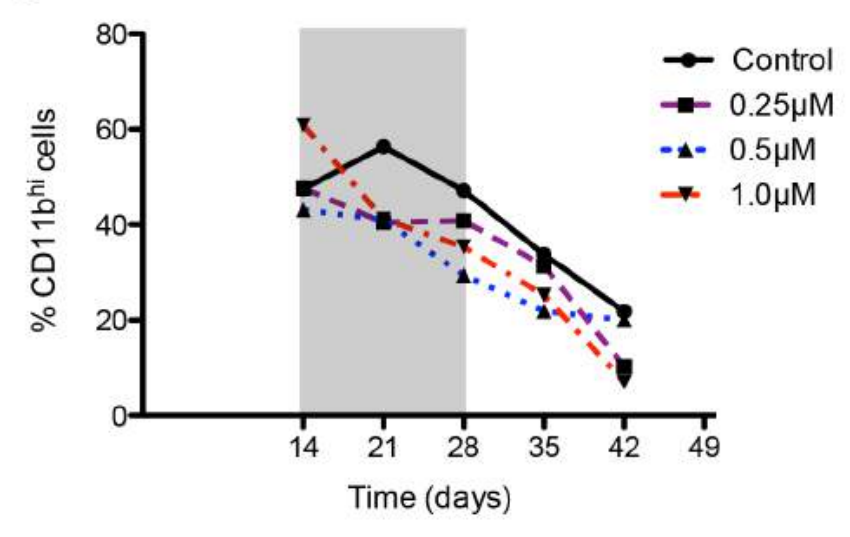

D Plerixafor treatment

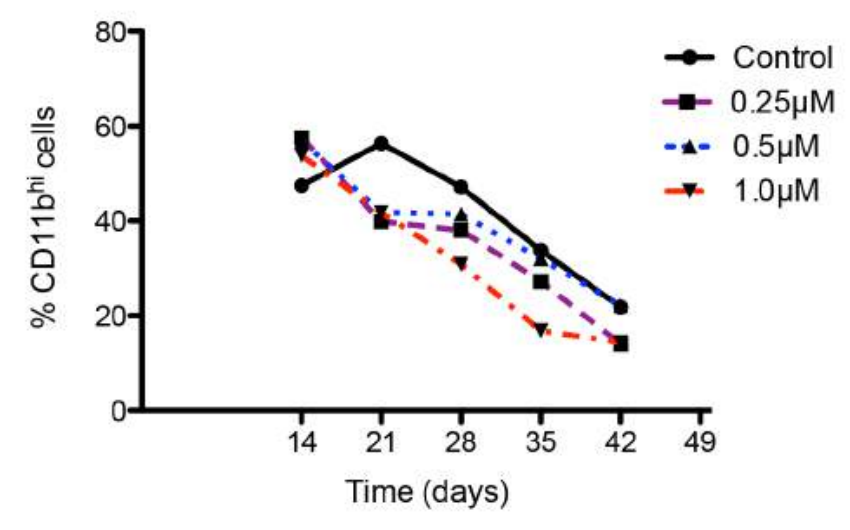




\subsubsection{Effect of the Notch inhibitor, DAPT, on cell production in stromal co-} cultures

Previous experiments from this laboratory showed that hematopoiesis in 5G3 co-cultures is stroma contact-dependent, although the controlling receptor-ligand interactions have not been identified (Periasamy et al., 2013a). Previously, the Notch and Wnt pathways have been identified as important in the maintenance of HSC (Benveniste et al., 2014; Corselli et al., 2013; Duncan et al., 2005). Recently, Corselli et al. (2013) used DAPT at a concentration of $10.0 \mu \mathrm{M}$ to investigate the role of Notch activation in the maintenance of $\mathrm{HSC}$ by $\mathrm{CD} 146^{+}$perivascular reticular cells. The role of Notch signalling in in vitro hematopoiesis was therefore investigated here, using the same loss-of-function approach. The $\gamma$-secretase indirect Notch inhibitor, DAPT, was used to abolish Notch signalling and to assess the effect on cell production in 5G3 cocultures.

DAPT was added into co-cultures of lineage-depleted BM cells over 5G3 stroma with bi-weekly addition for 28 days. To ascertain the optimum concentration of DAPT, co-culture assays were compared with addition of $0.1 \mu \mathrm{M}, 1.0 \mu \mathrm{M}$ and $10.0 \mu \mathrm{M}$ of DAPT. Non-adherent cells were harvested every 7 days and analysed flow-cytometrically to assess cell production and effectiveness of inhibition. L-DC were gated as

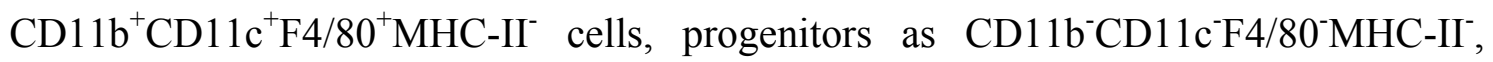
cDC-like cells as $\mathrm{CD} 11 \mathrm{c}^{+} \mathrm{F} 4 / 80^{-} \mathrm{MHC}^{-\mathrm{II}^{-+}}$and immature myeloid cells as

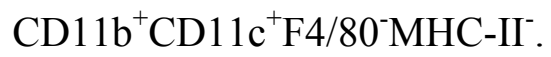

The number of L-DC and progenitor cells produced was consistently higher in co-cultures treated with DAPT at $10.0 \mu \mathrm{M}$. At this concentration, addition of DAPT noticeably enhanced the production of L-DC and progenitors. Production of L-DC peaked at day 14 and progenitor numbers peaked at day 21 (Figure 3.3A). The number of cDC-like cells progressively decreased to near zero by day 14. The myeloid cell population decreased to near zero levels by 14 days with a late increase by 28 days. Notch may be an important regulator of HSC quiescence, so that inhibition leads to both increased self-renewal of HSC and their direct differentiation to give L-DC as shown by Petvises and O'Neill (2014b). Notch would not seem to have any effect on precursors of myeloid or cDC-like cells. Conclusions based on changes in absolute cell number were also supported by proportional changes in cell type (Figure 3.3B) 


\section{Figure 3.3 Effect of Notch inhibitors on in vitro hematopoiesis}

$\mathrm{Lin}^{-}$bone marrow was co-cultured over 5G3 stroma for a period of 28 days. DAPT, a $\gamma$-secretase (Notch) inhibitor, was added twice weekly to cultures at medium change using concentrations of $10.0 \mu \mathrm{M}, 1.0 \mu \mathrm{M}$ and $0.1 \mu \mathrm{M}$. Controls were given DMSO diluent only $(0.0 \mu \mathrm{M}$ DAPT) or nothing (NIL). Non-adherent cells were collected every 7 days and stained with fluorochrome-conjugated antibodies specific for CD11b, CD11c, MHC-II and F4/80. Prior to flow cytometry, cells were incubated with propidium iodide (PI) $(1 \mu \mathrm{g} / \mathrm{ml})$ for gating live ( $\left.\mathrm{PI}^{-}\right)$cells, and large live cells $\left(\mathrm{FSC}^{\text {hi }}\right)$ were then gated on side scatter (SSC) versus forward scatter (FSC) (data not shown). Fluorescence minus one controls were used to set gates. (A) The production

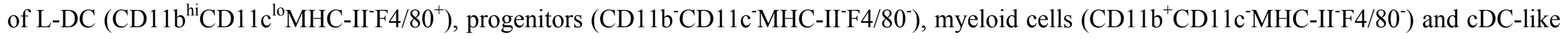
cells $\left(\mathrm{CD} 11 \mathrm{~b}^{+} \mathrm{CD} 11 \mathrm{c}^{+} \mathrm{MHC}-\mathrm{II}^{+} \mathrm{F} 4 / 80^{-}\right)$was calculated over a period of 28 days. (B) The proportional representation of L-DC, progenitors, myeloid cells and cDC-like cells amongst non-adherent cells collected from co-cultures was also calculated. 
A
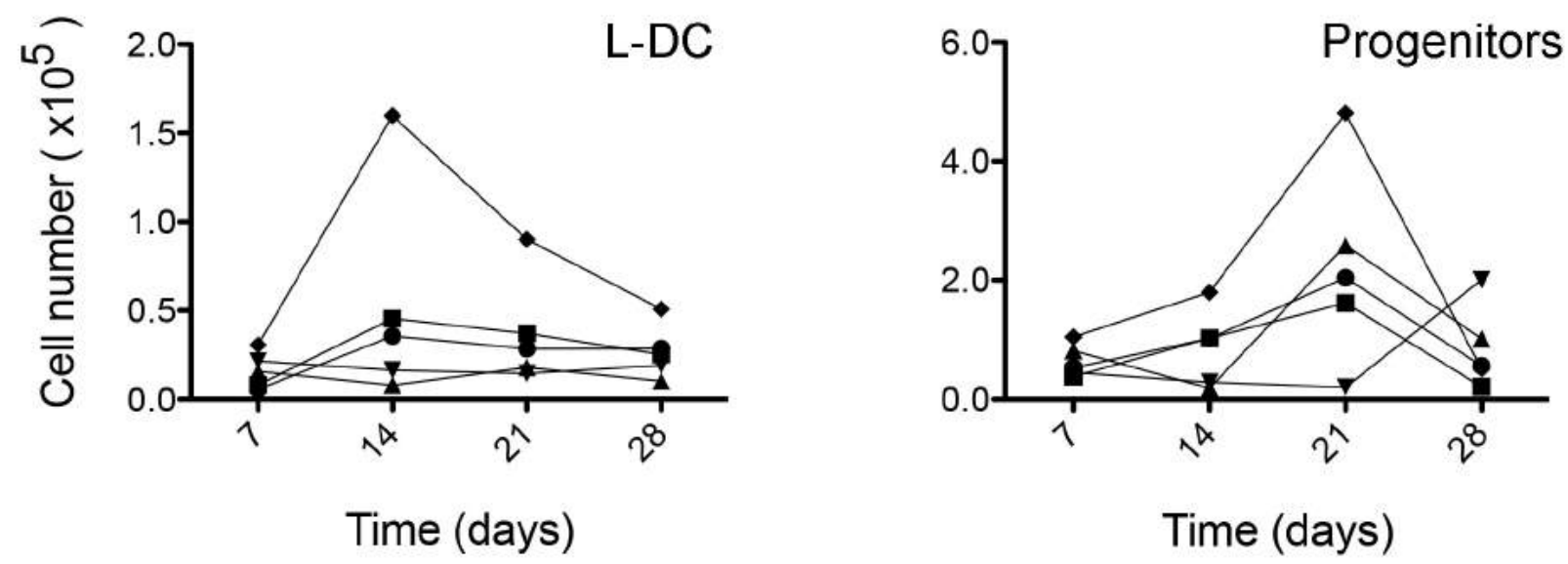

- Control

- $0 \mu \mathrm{MDAPT}$

- $0.1 \mu \mathrm{M}$ DAPT

₹ $1.0 \mu \mathrm{MDAPT}$

$\checkmark 10.0 \mu \mathrm{M}$ DAPT
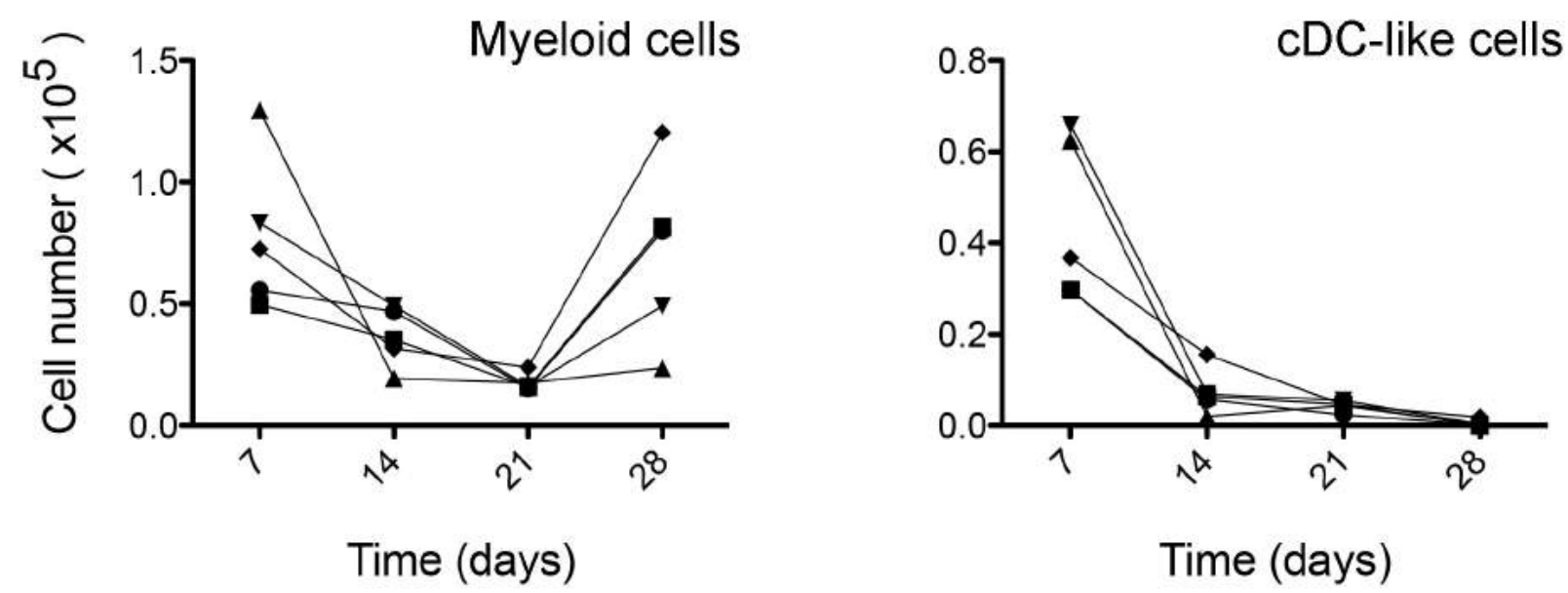

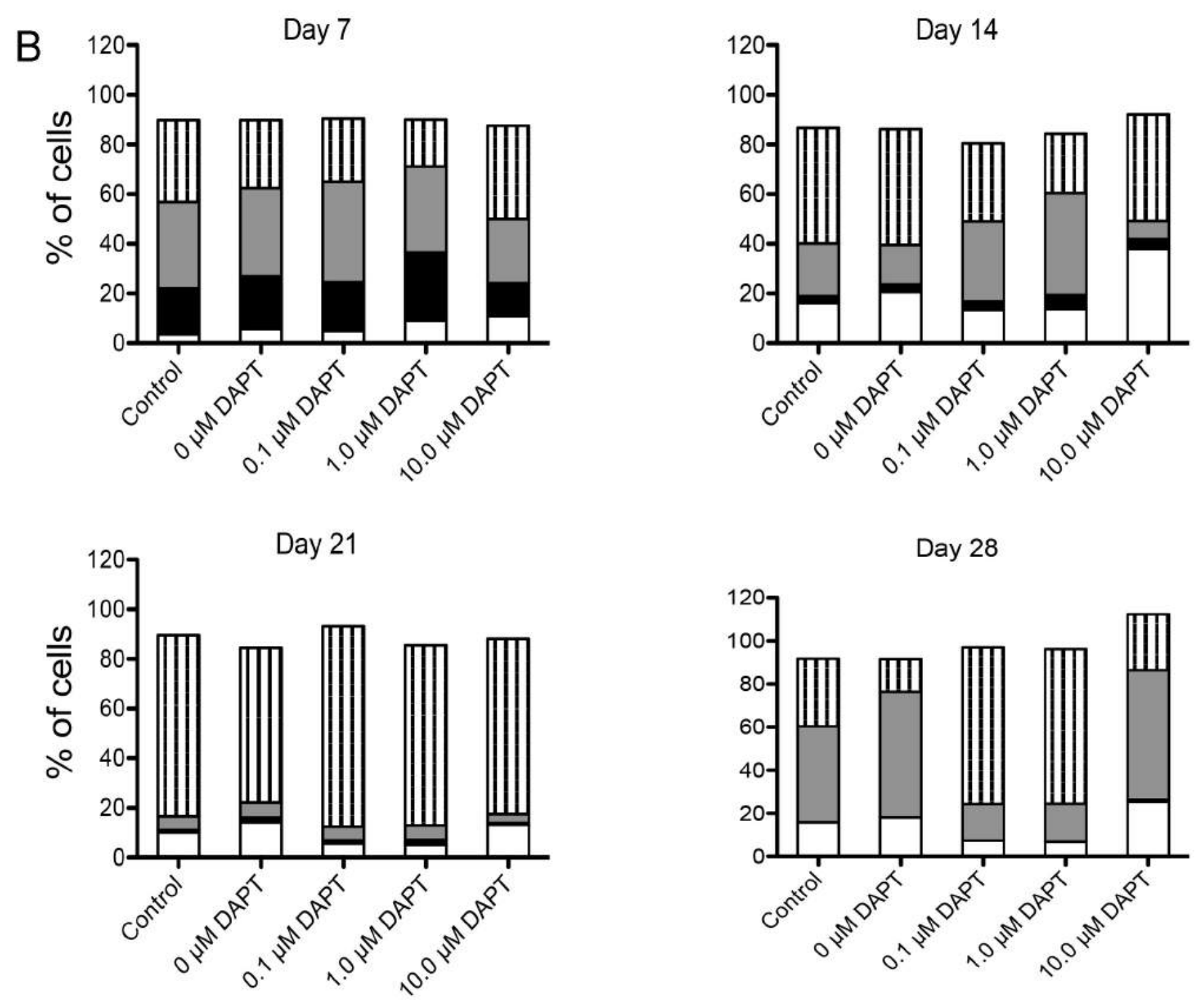

$\square$ L-DC

CDC

$\square$ Myeloid

II Progenitor 


\subsubsection{Notch signalling is required for in vitro maintenance of HSC and MPP}

Lineage-depleted BM contains low numbers of HSC and MPP which are known progenitors of L-DC (Petvises and O'Neill, 2014). As a further test that Notch signalling drives hematopoiesis in co-cultures, purified HSC or MPP were used to establish co-cultures. Purified HSC and MPP were sorted from BM and used to prepare co-cultures for DAPT inhibition. As previously, DAPT was added into co-cultures biweekly for 21 days and non-adherent cells harvested from cultures every 7 days. Control cultures contained either no inhibitors, or DMSO diluent alone. Flow-cytometry was used to assess the effectiveness of inhibition. Co-cultures established with HSC and MPP produce only L-DC and progenitors (Petvises and O'Neill, 2014b). L-DC were

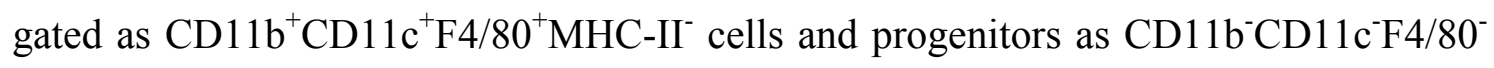
MHC-II' cells respectively.

Flow cytometric analysis revealed significantly higher production of L-DC in MPP co-cultures supplemented with $10.0 \mu \mathrm{M}$ DAPT compared with control co-cultures, DAPT inhibition of Notch leads to increased differentiation of MPP to give L-DC (Figure 3.4). This is in agreement with an explanation for enhanced differentiation of progenitors as a result of inhibition of Notch signalling. Notch, along with Wnt signalling is necessary to maintain HSC and MPP in an undifferentiated state (Duncan et al., 2005). An increase in L-DC and progenitor production was also noted in HSC cocultures, although this increase was not statistically significant. The observed increase in L-DC production in MPP co-cultures suggests that Notch signalling is required for maintenance of MPP. However, differentiation in MPP following Notch inhibition results in only L-DC production with no increase in progenitors. 


\section{Figure 3.4 The specific effect of Notch inhibition on hematopoiesis in vitro}

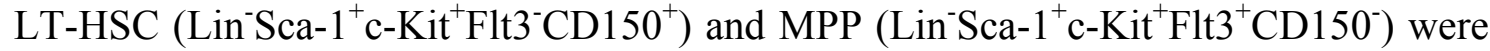
sorted from murine bone marrow and co-cultured above 5G3 stroma for a period of 21 days. Co-cultures were supplemented twice weekly with DAPT a $\gamma$-secretase inhibitor and also an indirect inhibitor of Notch $(10 \mu \mathrm{M})$ in DMSO diluent, DMSO diluent alone, or nothing (NIL). Non-adherent cells were collected after 21 days and stained with fluorochrome-conjugated antibodies specific for CD11b, CD11c, MHC-II and F4/80 to delineate subsets produced. Prior to flow cytometry, cells were incubated with propidium iodide (PI) $(1 \mu \mathrm{g} / \mathrm{ml})$ for gating live $(\mathrm{PI})$ cells. Large cells $\left(\mathrm{FSC}^{\text {hi }}\right)$ were gated on a side scatter (SSC) versus forward scatter (FSC) plot (data not shown). Fluorescence minus one (FMO) controls were used to set gates. Significant differences $(\mathrm{p} \leq 0.05)$ in cell production in DAPT treated co-cultures $(10 \mu \mathrm{M})$ compared with diluent controls is shown by *. (A) The proportional representation of L-DC $\left(\mathrm{CD} 11 \mathrm{~b}^{\mathrm{hi}} \mathrm{CD} 11 \mathrm{c}^{\mathrm{lo}} \mathrm{MHC}-\mathrm{II}^{-} \mathrm{F} 4 / 80^{+}\right)$and progenitors (CD11b-CD11 $\left.\mathrm{c}^{-} \mathrm{MHC}-\mathrm{II}^{-} \mathrm{F} 4 / 80^{-}\right)$was calculated. (B) The absolute number of L-DC (CD11b $\left.{ }^{\text {hi }} \mathrm{CD} 11 \mathrm{c}^{\mathrm{lo}} \mathrm{MHC}-\mathrm{II}-\mathrm{F} 4 / 80^{+}\right)$and progenitors $\left(\mathrm{CD}^{2} 1 \mathrm{~b}^{-} \mathrm{CD} 11 \mathrm{c}^{-} \mathrm{MHC}-\mathrm{II}^{-} \mathrm{F} 4 / 80^{-}\right)$was calculated. Data reflect mean $\pm \mathrm{SE}$ of replicate experiments prepared from three separate cell sorts. 
A
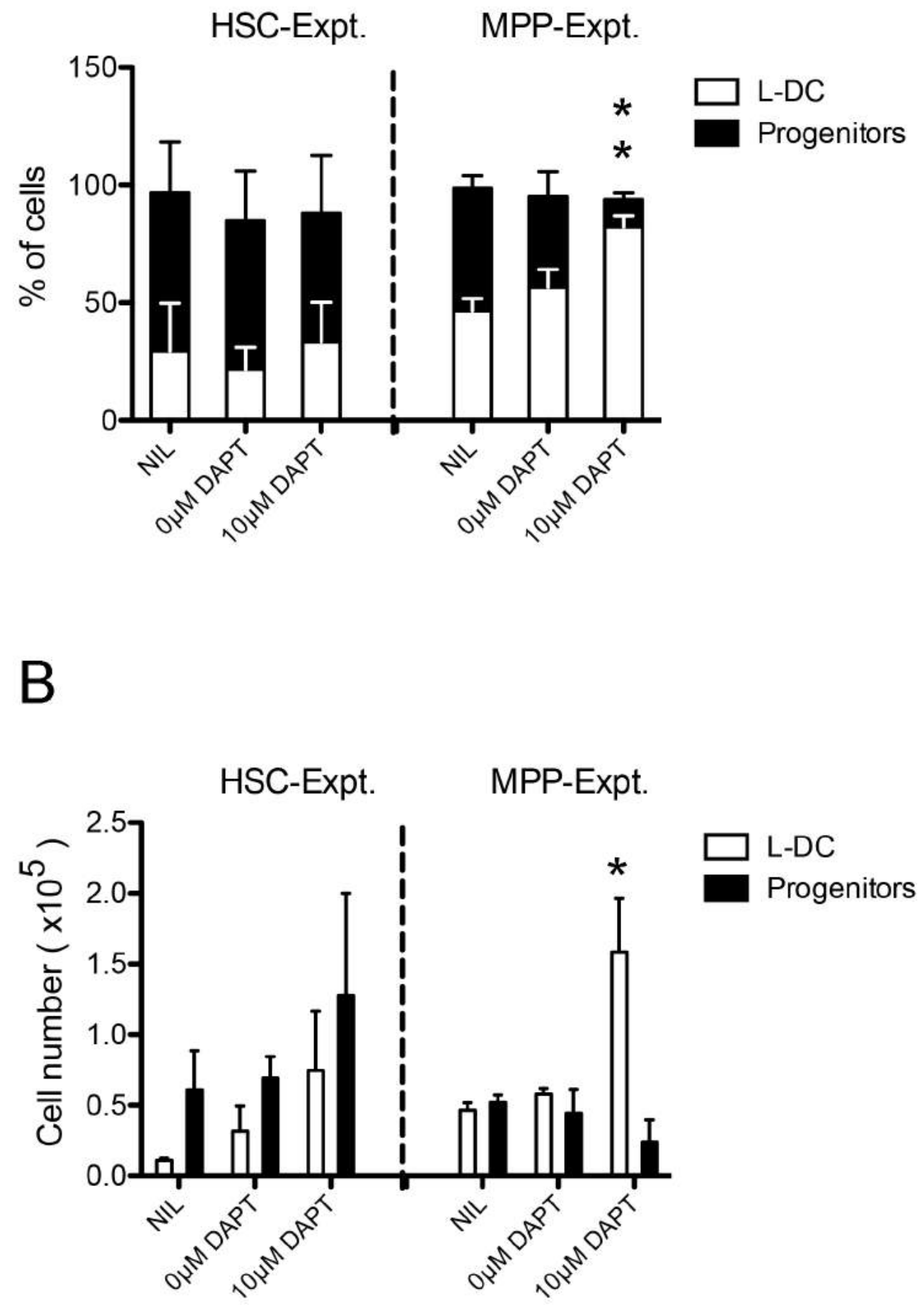


\subsubsection{DISCUSSION}

Previously, this laboratory uncovered a splenic stromal cell line derived from a long-term neonatal splenic culture, named 5G3, which supports in vitro hematopoiesis (Periasamy et al., 2009). Transcriptome analysis of 5G3 has revealed expression of many genes specific to perivascular reticular cells in BM (data in preparation), raising the possibility of a unique perivascular niche in spleen which supports extramedullary hematopoiesis. Current understanding of extramedullary hematopoiesis in spleen is incomplete and this extends to both characterisation of stromal cell niches which support hematopoiesis, and the nature and number of hematopoietic stem/progenitor cells which colonise these niches.

The work presented in this chapter investigates 5G3 and 3B5 as stromal line models for HSC niches in spleen. It provides clear evidence of the lineage origin of 5G3 and 3B5 stromal cell lines through immunophenotyping. These stromal cell lines clearly express mesenchymal cell markers like CD105, Thy1.2 and CD140a, and lack expression of lineage-specific hematopoietic and endothelial markers. The phenotype of 5G3 and 3B5 closely matches that of CAR cells and MSC (Sugiyama et al., 2006), suggesting a common mesenchymal lineage. Consistent with this result is unpublished evidence from the O'Neill lab describing the osteogenic potential of 5G3 stromal cells, following culture under mineralisation conditions, and revealed by Alizarin Red $\mathrm{S}$ staining of cells. This was also confirmed by measuring alkaline phosphatase production and expression of genes related to osteogenesis (unpublished data). In addition, 5G3 stroma shares many markers commonly expressed by other splenic stromal cell types. These include CD29, VCAM1 and CD140a, which are found on the surface of fibroblastic reticular cells, marginal reticular cells and red pulp fibroblasts (Mueller and Germain, 2009). This redundancy could be due to the sharing of a common ancestry with several spleen stromal cell types.

It is worth noting that while the phenotype of cultured cells might differ from that of their in vivo counterparts, the phenotype as a whole, and taken in context, provides important information. However, caution has to be applied in extrapolating information obtained with in vitro grown cells into the in vivo cell counterpart. As commonly noted in the literature, cell subsets that are not defined by a unique marker are often characterised by a combination of less specific markers (Wetzig et al., 2013; 
Lindner et al., 2010). Therefore, the phenotypic characterisation of 5G3 stroma provides a good reference for further characterisation of an equivalent stromal cell population in spleen which supports hematopoiesis.

Restricted in vitro hematopoiesis was demonstrated in this study using a coculture system involving 5G3 stroma. It was shown that dendritic-like cells, termed 'LDC', were produced as early as day 14 after co-cultures were established from progenitors in the lineage-depleted BM population. L-DC are large cells found to be highly endocytic with the ability to activate $\mathrm{CD} 8^{+} \mathrm{T}$ cells, but not $\mathrm{CD} 4^{+} \mathrm{T}$ cells, through cross presentation of antigen (Periasamy et al., 2013a; Tan et al., 2011). The functional capacity of 5G3 in supporting restricted in vitro hematopoiesis is consistent with previously published evidence. In particular, Periasamy et al. (2013) reported that the in vitro hematopoiesis support mediated by $5 \mathrm{G} 3$ stroma is cell contact-dependent, although the exact molecular mechanism has not been elucidated (Periasamy et al., 2013a). In an attempt to have a clearer understanding of the molecular interactions involved, inhibition assays were attempted here. Previously, it was found that in vitro production of L-DC was dependent on FMS-like tyrosine kinase-3 (Flt3) but independent of macrophage colony-stimulating factor receptor (M-CSFR) signalling (Petvises and O'Neill, 2014b). Here an important role for SCF and Notch signalling but not CXCL12 is defined.

SCF and CXCL12 are highly expressed by 5G3 stroma, so the importance of these signalling molecules was investigated. Inhibitors Imatinib and Plerixafor were used to disrupt the receptor-ligand interactions occurring in stromal co-cultures. Specifically, Imatinib blocks SCF/c-KIT interaction by binding to the c-KIT receptor, and Plerixafor interacts with the CXCR4 receptor to disrupt the CXCL12/CXCR4 interaction. Disruption of the SCF/c-KIT interaction, but not the CXCL12/CXCR4 interaction, resulted in decreased in vitro cell production, suggesting a role of SCF in co-cultures in vitro. Indeed, the effect of Imatinib mirrors the in vitro inhibitory effect reported previously for $\mathrm{CD}^{+} 4^{+}$stem/progenitor cells, where Imatinib caused a significant reduction in production of $\mathrm{CD}^{+} 4^{+}$cells (Bartolovic et al., 2004). The biphasic concentration effect noted in our study is thought to relate to a possible counter-inhibitory effect on more mature precursors as well as on progenitors. Proof of this theory, however, will require further experimental investigation. 
Notch signalling was also considered to be a potential regulatory mechanism controlling in vitro hematopoiesis. The distinct enhancing effect of the $\gamma$-secretase Notch inhibitor, DAPT, was noted for cell production in co-cultures overlaid with lineage-depleted BM cells, suggesting that Notch signalling could be an important regulator of HSC quiescence. While no significant effect was found in co-cultures overlaid with HSC, this study showed a distinctive enhancing effect on cell production in co-cultures overlaid with MPP. This could suggest that Notch signalling may be required for maintenance of MPP rather than HSC. This phenomenon has also been reported by other groups (Corselli et al., 2013; Varnum-Finney et al., 2011). In a study using a gain-of-function approach, it was reported that the addition of Notch ligand inhibited myeloid cell differentiation (Varnum-Finney et al., 2011). One explanation for the lack of significant effect on HSC co-cultures could be due to signalling redundancy in in vitro system, such that $5 \mathrm{G} 3$ stroma provides an array of signalling molecules, which HSC can respond to. In contrast, MPP may have a more restricted signalling repertoire and be largely dependent on Notch signalling for maintenance. Therefore, blocking Notch signalling could have a profound effect on L-DC production.

This chapter has investigated the first stromal co-culture using the well characterised 5G3 stromal cell line which demonstrates restricted hematopoiesis in vitro. Earlier studies from this laboratory characterised this system as an in vitro system supporting dendritic cell development. Indeed, with recent identification of the dendritic-like 'L-DC' in vivo (Hey et al., 2015), the co-culture system is now thought to reflect a normal spleen microenvironment that physiologically mimics the splenic environment in vivo. Here, we have extended the application of this splenic stromal coculture system to investigate molecular signals driving hematopoiesis in vitro. These show results reflective of similar HSC niches described in BM. Future work could entail assessment of other factors to enhance understanding of hematopoiesis in vitro. In addition, 5G3 stroma represents a valuable cell line, which should allow further characterisation of splenic stromal niches for hematopoiesis. 
CHAPTER FOUR

CHARACTERISATION OF SPLENIC STROMA WHICH SUPPORTS HEMATOPOIESIS 


\subsection{INTRODUCTION}

Stroma is a supporting cellular network comprising non-hematopoietic cells of mesenchymal lineage. It forms the basement layer in tissue and contributes to organ architecture. Previously, stromal cells were thought to play only a supporting role in the three-dimensional structure of an organ (Roozendaal and Mebius, 2011). In the case of spleen, they organise tissue into different regions including red pulp, white pulp and marginal zone. However, in recent years, stromal cells have been found essential in supporting organ function (Roozendaal and Mebius, 2011; Mueller and Germain, 2009). For instance, splenic fibroblastic reticular cells assist in regulating immune responses through secretion of chemokines like CCL19 and CCL21 (Luther et al., 2000). To date, several distinct stromal subsets have been clearly described in spleen, including gp $38^{+}$ fibroblastic reticular cells, MadCAM1 ${ }^{+}$marginal reticular cells, $\mathrm{CD} 35^{+}$follicular dendritic cells, $\mathrm{CD} 105^{+}$red pulp fibroblasts and $\mathrm{CD} 31^{+}$vascular endothelial cells (den Haan et al., 2012; Mueller and Germain, 2009).

While extensive studies have been carried out to investigate the function of splenic stroma in immune regulation (Malhotra et al., 2013), there have been limited studies addressing hematopoietic support capacity. This could be a reflection of the perception that extramedullary hematopoiesis in spleen is only associated with stress or disease, and that spleen does not apparently support steady-state hematopoiesis (Johns and Christopher, 2012; Kim, 2010). While a role for spleen in hematopoiesis has been clearly defined in mice, but is less clear for humans, a role for spleen in hematopoiesis offers tremendous clinical potential. The substantial knowledge of BM hematopoiesis can be easily redirected to the study of hematopoiesis in spleen. One of the challenges facing the identification of splenic stroma is the lack of specific cell surface markers. The classification of many splenic stromal subsets has been extrapolated from the phenotype of cells found in lymph nodes. There is therefore a need to perform an indepth analysis of splenic stroma, and to identify specific markers for spleen.

Using phenotypic information on 5G3 described in Chapter 3, stromal cells in spleen have been analysed in order to identify the in vivo equivalent stromal cell subset through phenotype analysis, cell fractionation, cell growth and testing of hematopoietic support capacity in vitro. This study identifies markers that define stromal subsets which grow in vitro and form stromal monolayers resembling 5G3 in phenotype. It also 
identifies those stromal subsets which support hematopoiesis, and represent candidate niche elements in spleen. Identification of these cells in spleen will lead to studies to localise stromal cells within splenic compartments, and to question which stromal cell types reside in close proximity to HSC, myeloid cells or other hematopoietic cells, thus reflecting the presence of niches for hematopoiesis in steady-state spleen. 


\subsection{RESULTS}

\subsubsection{Optimisation of procedures to isolate splenic stromal cells}

Splenic stromal cells were isolated, using methodology dependent on collagenase, and developed and tested by Dr Jonathan Tan (Bond University). Collagenase treatment is generally harsh on cells leading to cell death. If treatment kills cells selectively, then isolated splenic stroma may poorly represent the in vivo stromal cell population. In order to counteract this problem, the incubation time for collagenase treatment was optimised for highest cell recovery.

Adult and neonatal murine spleens were prepared by mashing tissue between two microscopic slides and then filtering the cell suspension through a cell strainer to remove most hematopoietic cells and red blood cells. The isolated stromal tissue lump was then incubated with collagenase for $60 \mathrm{~min}$, during which time live cell counting was performed at 20 min intervals using trypan blue exclusion to detect live cells. The optimum incubation time was found to be 40 minutes for adult spleen and at least 60 minutes for neonatal spleen (Figure 4.1). The maximum number of viable cells recovered from collagenase treated stroma isolated from one adult murine spleen was $(2.09 \pm 0.22) \times 10^{7}$ cells after 40 minutes incubation (Figure 4.1). For 10 neonatal spleens, this number was $(1.89 \pm 0.49) \times 10^{7}$ cells.

\subsubsection{Composition of splenic stroma}

In order to investigate the cellular composition of splenic stroma, dissociated stromal cells were fractionated using flow cytometry on the basis of cell surface markers to enrich or deplete cells expressing a particular marker(s). The initial choice of cell surface markers was based on the phenotype of the control 5G3 stromal cell line, as well as the phenotype of mesenchymal lineage cells (Chapter 3). A high proportion of splenic stromal cells $(90.35 \pm 4.05 \%)$ analysed by flow cytometry was found to express CD29, also known as integrin beta-1 (Table 4.1). CD29 is a widely expressed integrin on splenic stroma and this marker was considered important in further stromal cell characterisation. In contrast, markers like Sca-1, CD31, gp38, CD140a, CD51, ER-TR7, Thy1.2, CD146, MadCAM1 and VCAM1 were expressed by minority populations of stromal cells (1-3\%) (Table 4.1). CD105 ${ }^{+}$cells represented $\sim 13 \%$ of stromal cells in 
Figure 4.1 Viable cell recovery after collagenase treatment of splenic stroma. An adult or 10 neonatal murine spleens were mechanically teased apart, filtered through a wire mesh grid to separate stroma from leukocytes and red cells, and the remaining stromal fraction treated with a combination of collagenase IV and collagenase D for different times up to 60 minutes. Viable cells recovered were counted using trypan blue exclusion at 20 minute intervals. Data shown reflect mean $\pm \mathrm{SE}$ of three replicate experiments. 


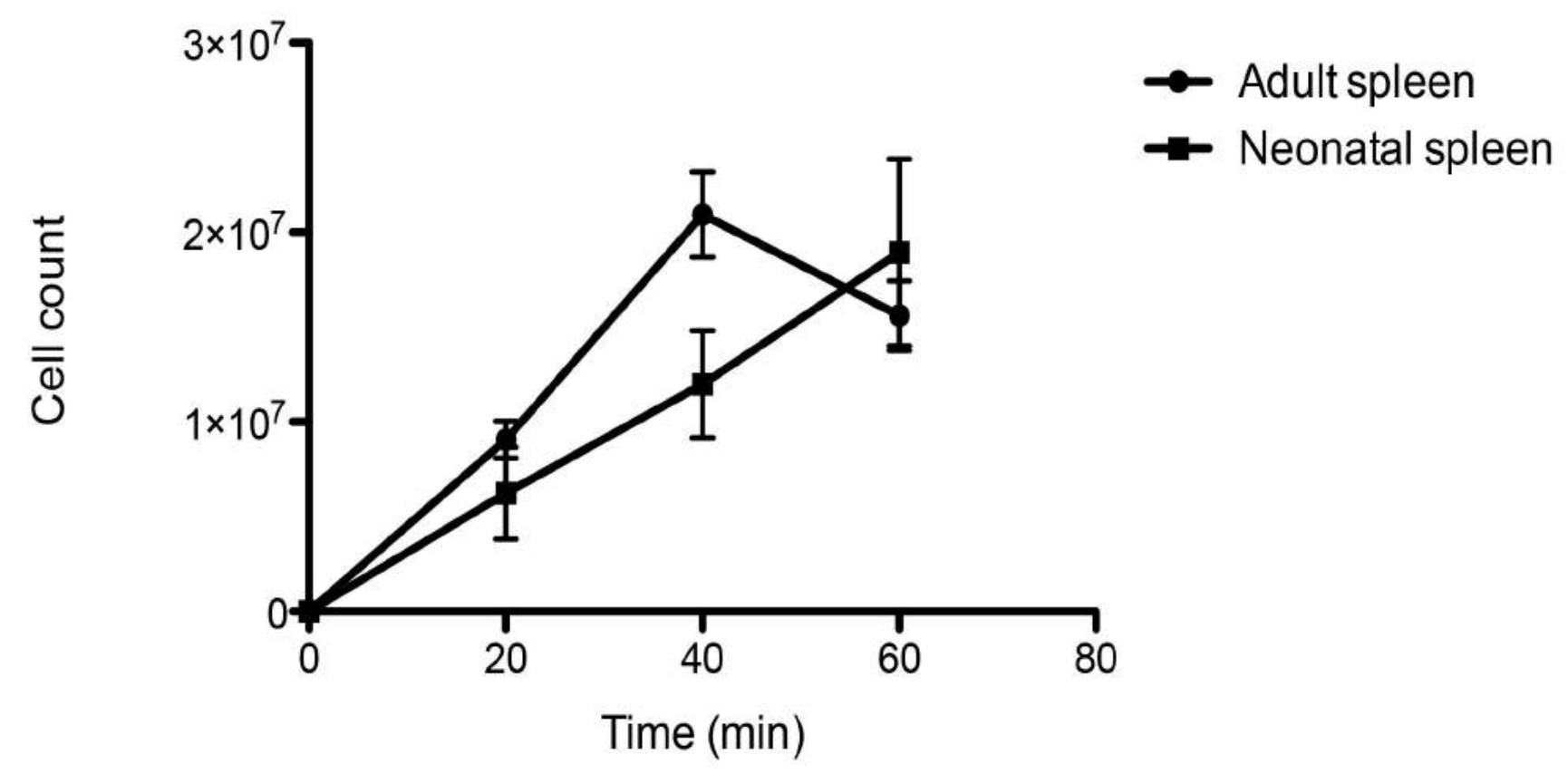


Table 4.1 Proportion of cells in stromal fractions

\begin{tabular}{|c|c|c|c|}
\hline Spleen fraction & $\%$ cells $\dagger$ & Spleen fraction ${ }^{*}$ & $\%$ cells $\dagger$ \\
\hline $\mathrm{CD}^{2} 9^{-}$ & $9.65 \pm 4.05$ & $\mathrm{CD}_{29^{+}}$ & $90.35 \pm 4.05$ \\
\hline Sca-1 ${ }^{-}$ & $98.43 \pm 0.50$ & Sca- $^{+}$ & $1.57 \pm 0.50$ \\
\hline $\mathrm{CD} 31^{-}$ & 99.15 & $\mathrm{CD} 31^{+}$ & 0.85 \\
\hline gp38- & $99.01 \pm 0.32$ & gp38 & $0.99 \pm 0.32$ \\
\hline $\mathrm{CD} 105^{-}$ & $86.93 \pm 1.26$ & $\mathrm{CD} 105^{+}$ & $13.07 \pm 1.26$ \\
\hline $\mathrm{CD}_{140 \mathrm{a}^{-}}$ & $98.24 \pm 0.67$ & $\mathrm{CD} 140 \mathrm{a}^{+}$ & $1.76 \pm 0.67$ \\
\hline $\mathrm{CD}^{-} 1^{-}$ & 97.79 & $\mathrm{CD} 51^{+}$ & 2.21 \\
\hline ER-TR7 ${ }^{-}$ & $98.48 \pm 0.40$ & ${\mathrm{ER}-\mathrm{TR} 7^{+}}^{+}$ & $0.60 \pm 0.53$ \\
\hline Thy $1.2^{-}$ & $99.82 \pm 0.19$ & Thy $1.2^{+}$ & $0.19 \pm 0.19$ \\
\hline CD146- & $98.67 \pm 0.36$ & $\mathrm{CD}_{146}^{+}$ & $1.33 \pm 0.36$ \\
\hline MAdCAM1 $^{-}$ & $99.65 \pm 0.06$ & $\mathrm{MAdCAM}^{+}$ & $0.35 \pm 0.06$ \\
\hline VCAM1 $^{-}$ & 97.28 & $\mathrm{VCAM}^{+}$ & 2.72 \\
\hline
\end{tabular}

"Stromal cells were isolated from neonatal murine spleen using collagenase treatment. Cells were labelled with fluorochrome-conjugated antibodies, and flow cytometry used to separate marker positive and marker negative fractions for quantification.

†Data are presented as mean $\pm \mathrm{SE}(\mathrm{n}=3)$ for replicated data except for $\mathrm{CD} 29^{+/}$, $\mathrm{ERTR}^{+/-}$and Thy $1.2^{+/-}$where mean $\pm \mathrm{SE}(\mathrm{n}=2)$. Data represent a single experiment. 
spleen. Due to the small size of different subsets, splenic stromal cell characterisation was considered challenging, requiring investigation and isolation of rare stromal cells expressing markers of interest.

Our approach to analysis was to increase the number of spleens used in the experiment and to couple analysis of the enriched marker positive subset with analysis of the marker depleted subset. One option was to expand stromal subsets through in vitro culture, testing their independent growth capacity and aiming to expand the number of cells. This involved growing stromal cells in sDMEM with twice weekly medium change. This procedure also allowed assessment of the growth capacity of stromal fractions where cells were grown under controlled and constant conditions over 28 days. Assessment was made on whether the stromal cell fraction survived and proliferated in culture, as well as the phenotype of the stromal cells that grew out after 28 days.

The growth data shows that only fractions enriched for, but not depleted of CD29, gp38, CD105, Thy1.2 and CD140a, were able to reach confluent growth by 28 days (Tables 4.2A \& 4.2B). This suggests that these markers, which are also reflective of mesenchymal cells, might be important markers of stromal cells that can replicate in culture. Interestingly, only fractions depleted of, but not enriched for CD31 and VCAM1 resulted in confluent growth by 28 days suggesting that endothelial cells do not survive the in vitro growth conditions. (Tables 4.2A \& 4.2B). Cell surface markers including Sca-1, CD51 and ER-TR7 do not seem to be critical markers for growth capacity because fractions enriched for, or depleted of these markers, were equally able to attain confluent growth (Tables $4.2 \mathrm{~A} \& 4.2 \mathrm{~B}$ ).

Cells which grew out of 28-day cultures established from growth-competent stromal fractions were also mesenchymal in terms of cell surface phenotype (Tables 4.2A and 4.2B). For all stromal fractions tested for growth, cells growing after 28 days of culture expressed Sca-1 (50-80\% of cells), with most expressing Thy1, CD51 and gp38 (50-80\%), but with some cultures showing $<50 \%$ expression of the latter markers. The expression of CD105 was variable, with some cultures showing no expression. CD140a expression was weak to negative, with only $0-10 \%$ of cells expressing this marker. None of the cultures showed expression of the fibroblastic marker ER-TR7. 
Table 4.2A Phenotype of marker-positive stromal fractions after culture

\begin{tabular}{|c|c|c|c|c|c|c|c|c|c|}
\hline Cell fractions & Cell number plated $^{\#}$ & Growth $\dagger$ & & & Phenoty & of $28 \mathrm{~d}$ & stroma $^{\S}$ & & \\
\hline & & & Sca1 & gp38 & CD51 & CD105 & ERTR7 & CD140a & Thy1.2 \\
\hline $\mathrm{CD}_{29}{ }^{+}$ & $(1.6 \pm 0.3) .10^{6}(n=2)$ & $* *$ & +++ & +++ & +++ & +++ & - & + & +++ \\
\hline Sca- $1^{+}$ & $(1.7 \pm 1.3) \cdot 10^{4}(n=3)$ & $*$ & +++ & ++ & +++ & + & - & - & +++ \\
\hline $\mathrm{CD} 1^{+}$ & $9.6 .10^{3}$ & - & & & & & & & \\
\hline $\mathrm{gp} 38^{+}$ & $(1.1 \pm 0.4) \cdot 10^{4}(n=5)$ & $*$ & +++ & +++ & ++ & ++ & - & ++ & ++ \\
\hline CD105 ${ }^{+}$ & $(2.8 \pm 4.3) \cdot 10^{4}(n=5)$ & $*$ & +++ & +++ & ++ & +++ & - & + & ++ \\
\hline $\mathrm{CD}_{140 \mathrm{a}^{+}}$ & $(2.2 \pm 1.4) \cdot 10^{4}(n=5)$ & $*$ & ++ & +++ & ++ & - & - & - & ++ \\
\hline $\mathrm{CD} 1^{+}$ & $1.08 .10^{4}$ & $*$ & +++ & +++ & +++ & + & - & + & +++ \\
\hline ER-TR7 $^{+}$ & $(1.6 \pm 0.5) \cdot 10^{4}(n=2)$ & $*$ & +++ & ++ & +++ & - & - & - & +++ \\
\hline Thy $1.2^{+}$ & $(1.4 \pm 1.0) \cdot 10^{4}(n=3)$ & $*$ & ++ & + & + & + & - & ++ & +++ \\
\hline $\mathrm{CD} 146^{+}$ & $(2.0 \pm 0.8) \cdot 10^{4}(n=4)$ & - & & & & & & & \\
\hline $\mathrm{MadCAM}^{+}$ & $(3.4 \pm 2.4) \cdot 10^{3}(n=3)$ & - & & & & & & & \\
\hline $\mathrm{VCAM}^{+}$ & $1.6 .10^{4}$ & - & & & & & & & \\
\hline
\end{tabular}

\$ Stromal cells were isolated from murine spleen using collagenase treatment and cells stained with antibodies specific for CD45.2 to separate out the hematopoietic cells and either CD29, Sca-1, CD31, gp38, CD105, CD140a, CD51, ER-TR7, Thy1.2, CD146 or MAdCAM1. Separate sorting experiments were conducted, and number of cells plated shown by mean \pm SE (n). Sorted cell subsets were cultured in SDMEM for 28 days before dissociation of cells and staining to identify marker expression.

\# $5 \times 10^{4}$ cells was considered minimal to achieve growth, but in some cases, lower numbers were also found to be productive.

$\dagger$ Cell growth: confluent by 10 days (**), confluent by 28 days $(*)$, no confluence (-), cells died (X).

$\S$ Cells were trypsinised and stained with antibodies to determine phenotype.,$+++>80 \%$ cells expressing;,$++ 50-80 \% ;+, 10-$

$50 \% ;-,<10 \%$. 
Table 4.2B Phenotype of marker-negative stromal fractions after culture

\begin{tabular}{|c|c|c|c|c|c|c|c|c|c|}
\hline Cell fractions ${ }^{+}$ & Cell number plated $^{\#}$ & Growth $\uparrow$ & \multicolumn{7}{|c|}{ Phenotype of 28 day stroma ${ }^{\S}$} \\
\hline & & & Sca-1 & gp38 & CD51 & CD105 & ERTR7 & CD140a & Thy1.2 \\
\hline $\mathrm{CD}^{29^{-}}$ & $(1.6 \pm 0.7) \cdot 10^{5}(\mathrm{n}=2)$ & $\mathrm{X}$ & & & & & & & \\
\hline Sca-1- & $(1.6 \pm 0.9) \cdot 10^{6}(\mathrm{n}=3)$ & $*$ & +++ & ++ & +++ & + & - & - & ++ \\
\hline $\mathrm{CD}^{2} 1^{-}$ & $8.30 .10^{5}$ & $* *$ & ++ & + & ++++ & - & - & + & + \\
\hline gp38- & $(1.7 \pm 0.4) \cdot 10^{6}(\mathrm{n}=5)$ & - & & & & & & & \\
\hline CD105 & $(1.5 \pm 0.2) \cdot 10^{6}(\mathrm{n}=5)$ & - & & & & & & & \\
\hline $\mathrm{CD}_{140 \mathrm{a}^{-}}$ & $(1.9 \pm 0.3) \cdot 10^{6}(\mathrm{n}=5)$ & - & & & & & & & \\
\hline $\mathrm{CD}^{2} 1^{-}$ & $8.3 .10^{5}$ & $*$ & +++ & +++ & +++ & ++ & - & - & +++ \\
\hline ER-TR7 ${ }^{-}$ & $(1.3 \pm 7.5) \cdot 10^{6}(\mathrm{n}=2)$ & $*$ & +++ & +++ & ++ & +++ & - & - & - \\
\hline Thy1.2- & $(1.18 \pm 1.2) \cdot 10^{6}(\mathrm{n}=3)$ & $\mathrm{X}$ & & & & & & & \\
\hline CD146- & $(1.81 \pm 0.4) \cdot 10^{6}(n=4)$ & - & & & & & & & \\
\hline MAdCAM1- $^{-}$ & $(1.41 \pm 0.7) \cdot 10^{6}(\mathrm{n}=3)$ & - & & & & & & & \\
\hline VCAM1 $^{-}$ & $6.8 .10^{5}$ & $*$ & +++ & +++ & +++ & +++ & - & - & +++ \\
\hline
\end{tabular}

\$ Stromal cells were isolated from murine spleen using collagenase treatment and stained with antibodies specific for CD45.2 to separate out hematopoietic cells and either CD29, Sca-1, CD31, gp38, CD105, CD140a, CD51, ER-TR7, Thy1.2, CD146 or MAdCAM1. Separate sorting experiments were conducted, and number of cells plated shown by mean \pm SE (n). Sorted cell subsets were cultured in SDMEM for 28 days before dissociation of cells and staining to identify marker expression.

\# $5 \times 10^{4}$ cells considered minimal to achieve growth, but in some cases, lower numbers were also found to be productive.

$\uparrow$ Cell growth: confluent by 10 days $(* *)$, confluent by 28 days $(*)$, no confluence $(-)$, cells died $(\mathrm{X})$.

$\S$ Cells were trypsinised and stained with antibodies to determine phenotype.,$+++>80 \%$ cells expressing;,$++ 50-80 \% ;+, 10-50 \%$; ,$-<10 \%$. 
These data need to be interpreted with caution, taking into consideration the artificial conditions of growth which can moderate or enhance expression of markers, leading to false phenotypic assignment. Similar consideration must be applied to the 5G3 and 3B5 stromal cell lines described in Chapter 3, although it is important to note the similarity between the phenotypes of those cell lines, and the cell types which grow out of stromal cultures prepared by many different fractionation regimes. The data indicate that a small number of variant lines of distinct mesenchymal type can be cultured, noting variability particularly in expression of CD105 and CD140a.

\subsubsection{Microscopic examination of cultured stromal fractions}

In general, stromal cell monolayers were heterogeneous showing a mix of spindle-shaped fibroblastic cells and cuboidal cells possibly reflecting endothelial cells. The extent of confluency also varied even after 28 days of culture. Depletion of cells expressing VCAM1 or CD31 from splenic stroma led to confluent growth of spindleshaped stromal cells, while subsets of $\mathrm{VCAM}^{+}$and $\mathrm{CD} 31^{+}$cells would not grow

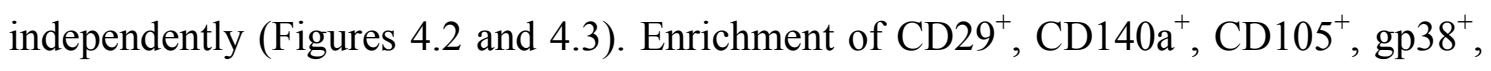
$\mathrm{CD} 1^{+}$and to a lesser extent Thy $1.2^{+}$cells, gave confluent, extensive stroma comprising largely spindle-shaped cells (Figure 4.3). These were reflective of mesenchymal cells. Depletion of cells expressing CD51 or Sca-1 still gave a sparse, heterogeneous stroma, suggesting that the remaining stromal populations were largely mesenchymal (Figure 4.2). Similarly, enrichment for Sca- $1^{+}$cells gave a very mixed population of cuboidal and spindle-shaped cells, consistent with CD29 as a marker of $\sim 90 \%$ of stromal cells in spleen (Table 4.1) (Figure 4.3). The extensive heterogeneity within the $\mathrm{CD} 29^{+}$fraction was revealed by culturing CD29 expressing cells as three independent subcultures (A, B and C) for 28 days. Stromal cells in each of A, B and C subcultures showed very different growth rates and morphologies (Figure 4.4). A reflects spindle-shaped cells, B sparse cuboidal cells, and $\mathrm{C}$ a confluent mixture of cell types.

ER-TR7 is a marker of fibroblasts and the ER-TR7 $7^{+}$population was an active grower (Figure 4.3). Following depletion of ER-TR7 ${ }^{+}$cells, a network of spindleshaped cells remained however, confirming the extensive in vitro growth capacity of the mesenchymal cell fractions in spleen. 
Figure 4.2 Morphology of spleen stromal cells. Stromal cells were isolated from murine spleen using collagenase treatment, stained with antibodies and sorted by flow cytometry. Stromal fractions were cultured in SDMEM, and photographed after 28 days using a camera attached to an inverted phase microscope. Cultured cells represent stromal fractions depleted of cells expressing (A) VCAM1, (B) CD51, (C) CD31, (D) Sca-1 and (E) ERTR7. 


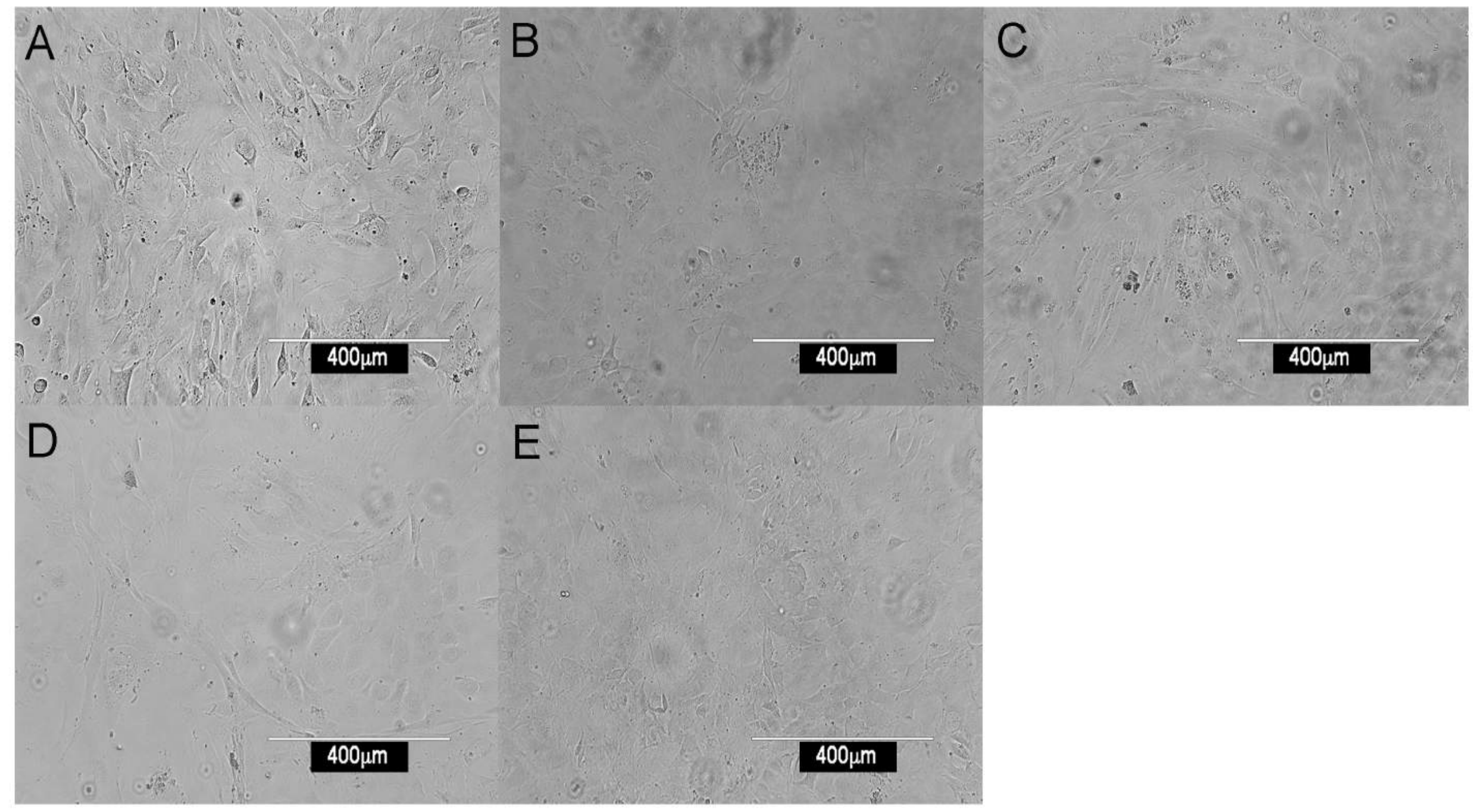


Figure 4.3 Morphology of splenic stromal fractions. Stromal cells were isolated from murine spleen using collagenase treatment, stained with antibodies to identify specific subsets, and cells sorted using a flow cytometer. Stromal cells were cultured in sDMEM, and photographed after 28 days using a camera attached to an inverted phase microscope. Stromal fractions tested for in vitro growth were sorted on the basis of a single marker. (A) CD29, (B) Sca-1, (C) CD140a, (D) CD105, (E) gp38, (F) ERTR7, (G) CD51 and (H) Thy1.2. 


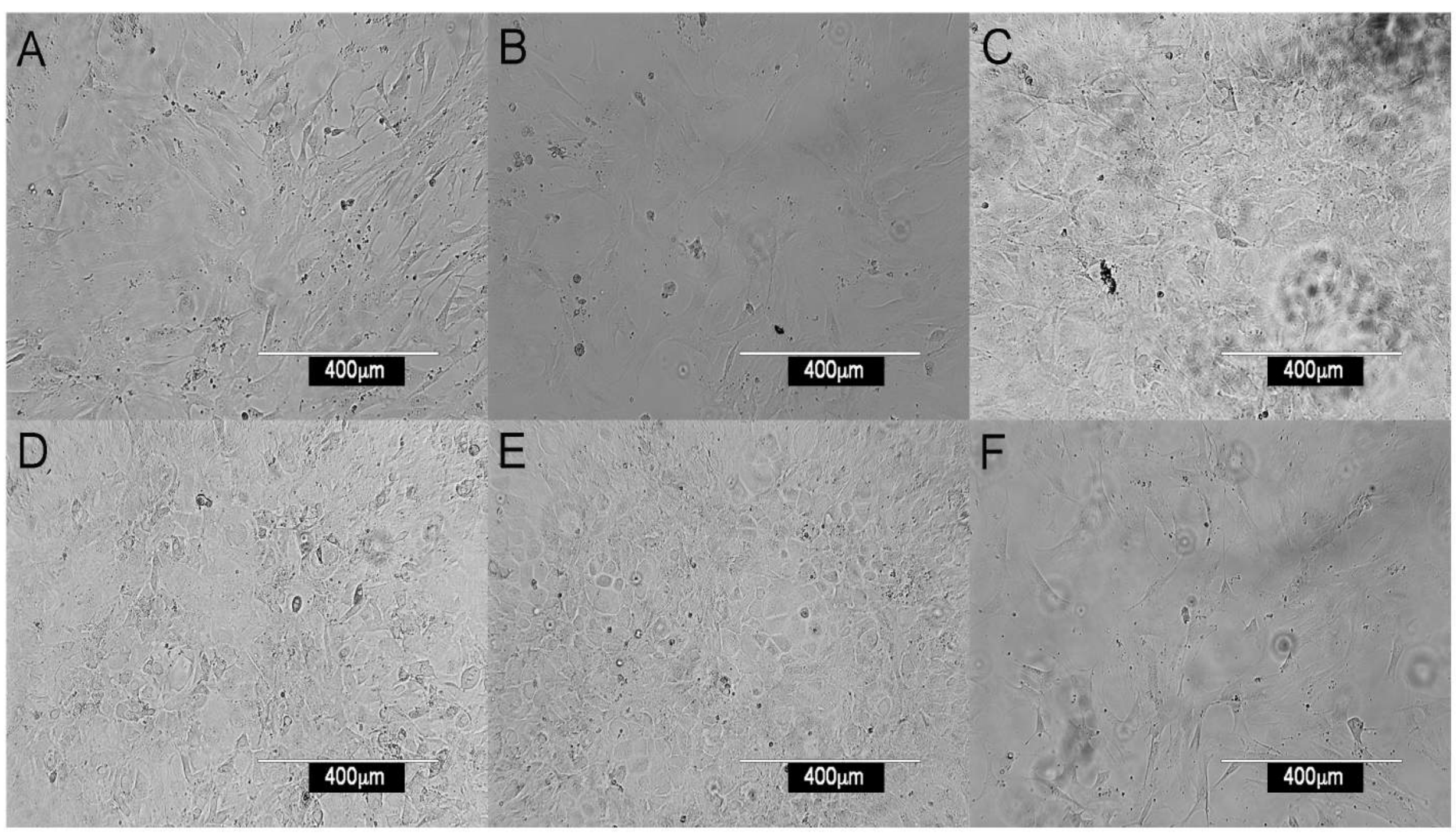




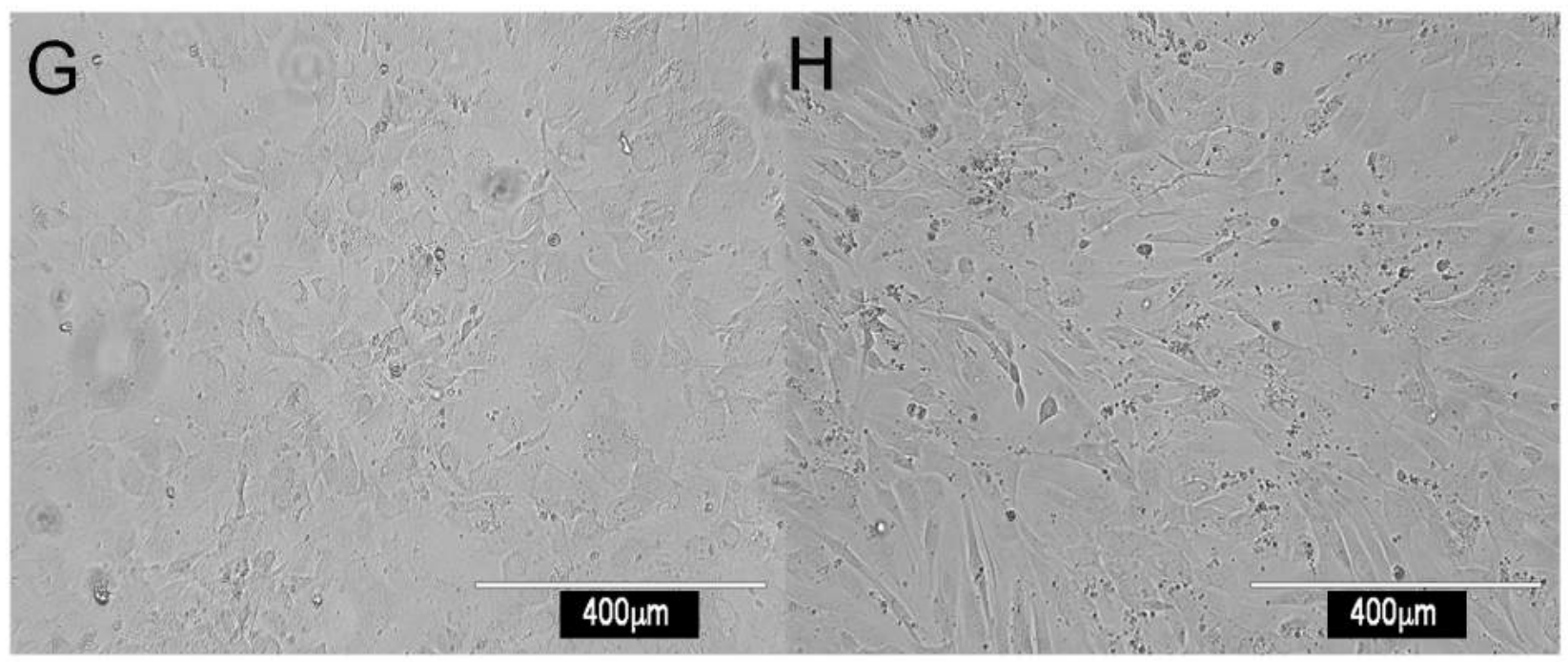


Figure 4.4 Morphology of passaged CD29 ${ }^{+}$stroma. Stromal cells were isolated from murine spleen using collagenase treatment, stained with antibodies to select specific subsets, and cells sorted using a flow cytometer. Stromal cells were cultured in sDMEM, and photographed after 28 days using a camera attached to an inverted phase microscope. The $\mathrm{CD} 29^{+}$stromal fraction was passaged to give three different cultures, and each tested for in vitro growth. These are labeled $\mathrm{A}, \mathrm{B}$ and $\mathrm{C}$. 


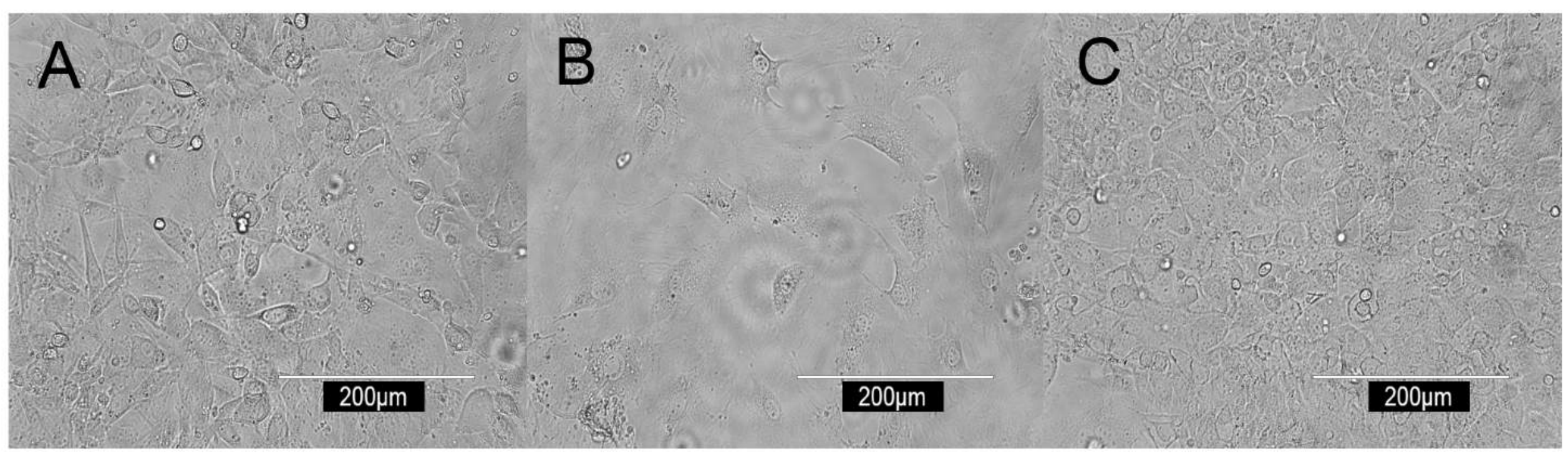




\subsubsection{Characterisation of stroma on the basis of 2 or 3 markers}

Since CD $29^{+}$cells reflected $90 \%$ of stroma, subfractions of those cells were compared for growth based on expression of the mesenchymal markers CD105, Sca-1 and the gp38 marker of fibroblastic reticular cells. In general, stromal fractions that expressed either CD29 or gp38 grew well (Table 4.3). Microscopic examination of stromal cells growing after 28 days showed outgrowth of all CD29 ${ }^{+}$fractions: with $\mathrm{CD} 29^{+}$gp $38^{-}$cells forming sparse, spindle-shaped cells, CD $29^{+} \mathrm{CD} 105^{+}$cells growing well but showing heterogeneity with both spindle-shaped and cuboidal cells present; $\mathrm{CD} 29^{+} \mathrm{CD} 105^{-}$cells, showing sparse spindle-shaped cells; and $\mathrm{CD} 29^{+} \mathrm{gp} 38^{+} \mathrm{Sca}-1^{-}$cells showing poor growth of predominately spindle-shaped cells (Figure 4.5).

Again, the phenotype of stromal cells which grew out of 28 day cultures was consistently found to be Sca $-1^{+}$gp $38^{+}$Thy $1.2^{+} \mathrm{CD} 29^{+} \mathrm{CD} 51^{+}$, with some variability in expression of CD105 and CD140a (Table 4.3), as seen previously for stroma fractionated on the basis of one marker (Tables 4.1A and 4.2B). One explanation for this outcome is that one or a small number of mesenchymal subsets exist in spleen which are readily cultured in vitro. These are identifiable as a CD29 ${ }^{+}$Sca$1^{+} \mathrm{Thy}^{+} \mathrm{CD} 51^{+} \mathrm{gp} 38^{+}$population. Sorting cell fractions on the basis of one or more of these markers will enrich for the presence of in vitro growing cells, and with time in culture, these particular cells grow out preferentially.

\subsubsection{Assessment of hematopoietic support capacity of stromal fractions}

To assess the capacity of stromal cell fractions to support hematopoiesis, confluent monolayers were grown for 28 days and used to establish co-cultures by overlay of lineage-depleted BM cells isolated from CD45-allotype distinct mice. The production of cells including progenitors, myeloid cells and dendritic cells was measured at 21 days after co-culture establishment as described in Chapter 3. Analysis involved harvest of non-adherent cells from culture and staining with a range of fluorescence-conjugated antibodies. Progenitors were identified as the CD11 b CD11c ${ }^{-}$

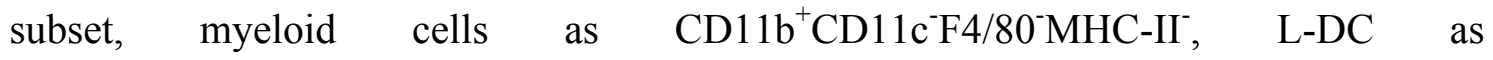

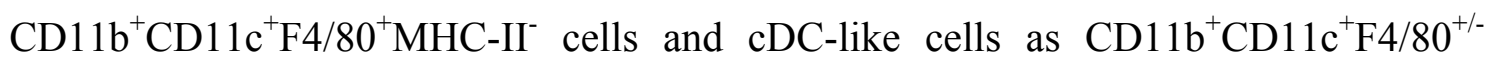
MHC-II ${ }^{+}$. Prior to flow cytometry, cells were stained with propidium iodide to discriminate live cells $\left(\mathrm{PI}^{-}\right)$for analysis. Large cells were then gated based on forward 


\section{Table 4.3 Phenotype of stromal subsets after culture}

\begin{tabular}{|c|c|c|c|c|c|c|c|c|c|c|}
\hline Cell fractions & Cell number plated & Growth $\dagger$ & & & & otype of & day str & $\mathrm{aa}^{\S}$ & & \\
\hline & & & Sca-1 & gp38 & CD51 & CD105 & CD29 & ERTR7 & CD140a & Thy 1.2 \\
\hline $\mathrm{CD}^{2} 9^{-} \mathrm{CD} 105^{-}$ & $2.2 .10^{5}$ & - & & & & & & & & \\
\hline $\mathrm{CD}^{2} 9^{+} \mathrm{CD} 105^{+}$ & $8.2 .10^{5}$ & $*$ & +++ & +++ & + & - & ++ & - & + & +++ \\
\hline $\mathrm{CD}^{2} 9^{+} \mathrm{CD} 105^{-}$ & $9.6 .10^{4}$ & * & +++ & +++ & ++ & - & +++ & - & - & +++ \\
\hline $\mathrm{CD}^{2} 05^{-} \mathrm{gp} 38^{-}$ & $9.7 .10^{8}$ & - & & & & & & & & \\
\hline $\mathrm{CD}^{2} 05^{+} \mathrm{gp} 38^{-}$ & $1.4 .10^{5}$ & - & & & & & & & & \\
\hline $\mathrm{CD}^{2} 9^{+} \mathrm{gp} 38^{+}$ & $1.74 .10^{3}$ & - & & & & & & & & \\
\hline $\mathrm{CD}^{2} 9^{+}{\mathrm{gp} 38^{-}}^{-}$ & $3.0 .10^{5}$ & * & +++ & +++ & + & + & +++ & - & + & +++ \\
\hline $\mathrm{CD}^{2} 9^{-} \mathrm{gp} 38^{-}$ & $4.4 .10^{4}$ & - & & & & & & & & \\
\hline 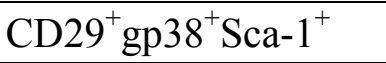 & $2.2 .10^{5}$ & $*$ & +++ & +++ & +++ & ++ & +++ & - & ++ & +++ \\
\hline 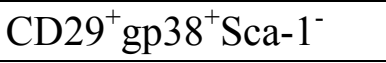 & $5.6 .10^{4}$ & $*$ & +++ & +++ & +++ & +++ & +++ & - & + & +++ \\
\hline $\mathrm{CD}_{29}{ }^{+} \mathrm{Sca}-1^{+} \mathrm{CD} 105^{+}$ & $2.0 .10^{4}$ & - & & & & & & & & \\
\hline $\mathrm{CD}^{2} 9^{+} \mathrm{Sca}-1^{+} \mathrm{CD} 105^{-}$ & $1.0 .10^{3}$ & - & & & & & & & & \\
\hline
\end{tabular}

\$ Stromal cells were isolated from murine spleen using collagenase treatment and stained with antibodies specific for CD45.2 to separate out the hematopoietic cells and antibodies specific for either CD29, Sca-1, CD31, gp38, CD105, CD140a, CD51, ER-TR7, Thy1.2, CD146 or MAdCAM1. Sorted subsets were cultured in SDMEM for 28 days before dissociation of cells and staining to identify marker expression.

\# $5 \times 10^{4}$ cells was considered minimal to achieve growth, but in some cases, lower numbers were also found to be productive.

$\dagger$ Cell growth: confluent by 10 days $(* *)$, confluent by 28 days $(*)$, no confluence $(-)$, cells died (X).

$\S$ Cells were trypsinised and stained with antibodies to determine phenotype.,$+++>80 \%$ cells expressing;,$++ 50-80 \% ;+, 10-50 \% ;-,<10 \%$. 
Figure 4.5 Morphology of defined stromal splenic fractions. Stromal cells were isolated from murine spleen using collagenase treatment, stained with multiple antibodies to select specific subsets, and cells sorted using a flow cytometer. Stromal cells were cultured in sDMEM, and photographed after 28 days using a camera attached to an inverted phase microscope. Stromal fractions tested for in vitro growth included (A) CD29 ${ }^{+}$gp $38^{-}$, (B) $\mathrm{CD} 29^{+} \mathrm{CD} 105^{+}$, (C) $\mathrm{CD} 29^{+} \mathrm{CD} 105^{-}$, and (D) CD29 ${ }^{+}$gp $38^{+}$Sca- $1^{-}$. 


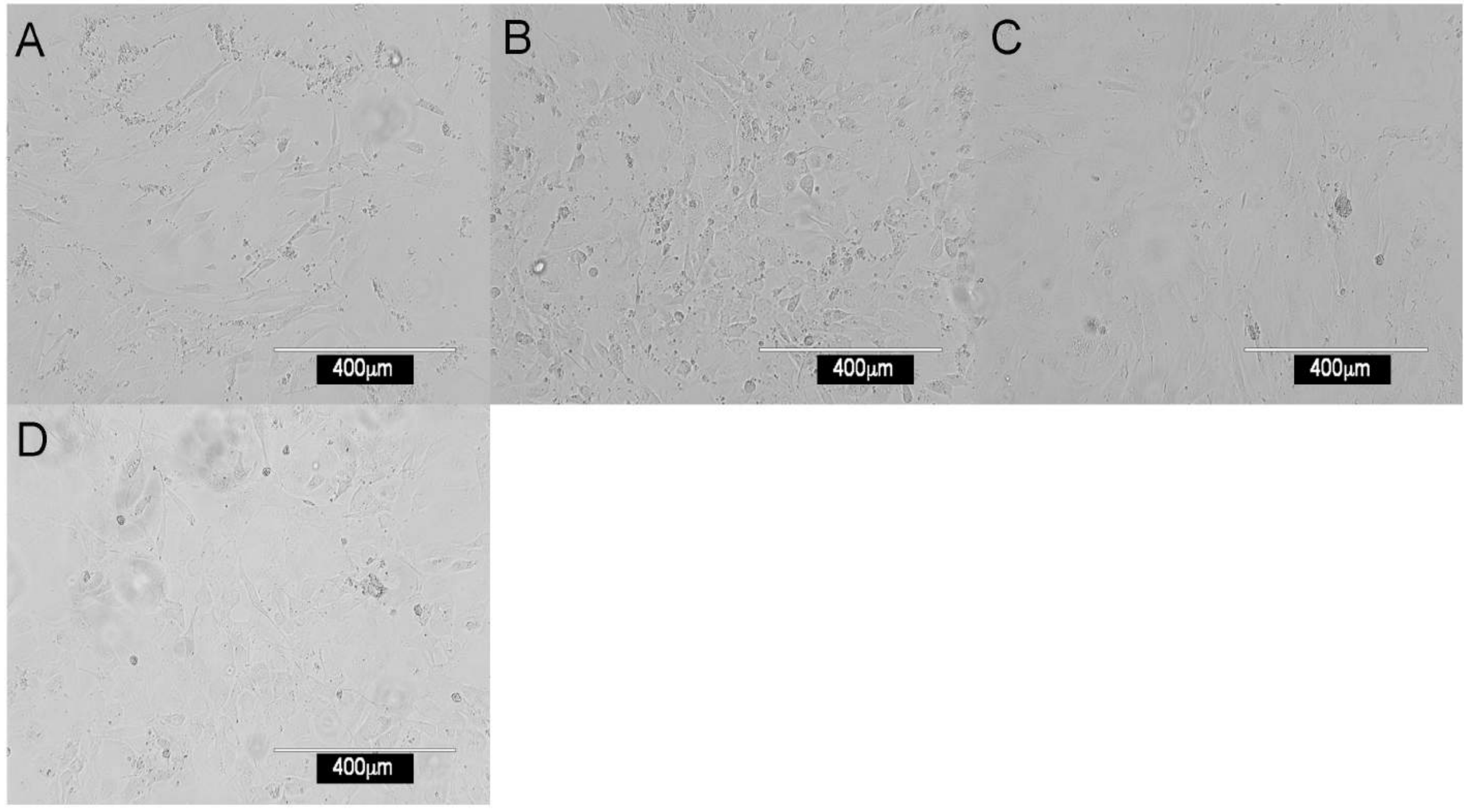


scatter versus side scatter analysis. Live large cells were identified as CD45.2, and then analysed for their CD11b and CD11c expression in the first instance.

Initial studies involved stromal cell fractions separated on the basis of a single marker. Analysis revealed a population of L-DC in most tested co-cultures by 21 days after co-culture establishment, although the proportion of L-DC varied considerably amongst the different stroma tested. Multiple experiments were performed to test various stromal fractions always using 5G3 as a co-culture control. Most co-cultures established were low cell producers in comparison with 5G3 (Figure 4.6), and these included co-cultures established with the stromal fractions of $\mathrm{CD}_{105}{ }^{+}, \mathrm{CD} 51^{+}, \mathrm{gp} 38^{+}$,

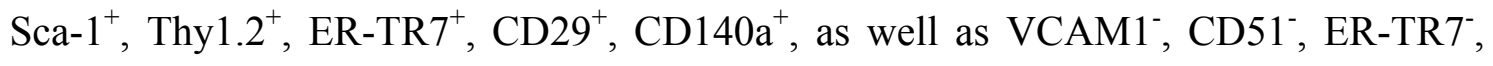
Sca- $1^{-}$and $\mathrm{CD} 31^{-}$. As expected, co-cultures containing CD29 ${ }^{+}$cells passaged from A, B and $\mathrm{C}$ wells exhibited different hematopoietic support capacity, which further supported the heterogeneity noted previously within this fraction (Figure 4.4). Some selected cocultures were replicated, but most replicated co-cultures exhibited variation in their capacity to support hematopoiesis (Figure 4.6). The hematopoietic support ability of a culture is ultimately dependent on the outgrowth of a particular stromal population, so that over a period of time, heterogeneous stromal populations could give variable results.

However, all stroma did produce some hematopoietic cells, with most at levels much lower than 5G3. These, however, contained cells representative of 5G3 cocultures, with production of L-DC, progenitors and myeloid cells, although no cDC-like cells. One outlier was the $\mathrm{CD}^{+} 9^{+}$A stroma which grew very well (Figure 4.4) and gave equal production of cells as did 5G3 in EXPT 7 (Figure 4.6). Some stromal subsets isolated on the basis of two or more markers including CD29, also gave cell production equivalent to $5 \mathrm{G} 3$. These included $\mathrm{CD} 29^{+}$gp $38^{+} \mathrm{Sca}-1^{+}$and $\mathrm{CD} 29^{+}$gp $38^{+}$Sca- $1^{-}$subsets in EXPT 7 (Figure 4.6). Notably, the $\mathrm{CD}^{-} 5^{-} \mathrm{CD} 31^{-}$mesenchymal subset was also a poor supporter of hematopoiesis, despite enrichment of mesenchymal cells (Figure 4.6). All of these data reinforce the importance of a mesenchymal cell type, but one representing a rare subset amongst the whole mesenchymal cell population.

\subsubsection{Fine definition of stromal subsets in spleen}

On the basis of knowledge of marker expression on splenic stromal cell subsets which could be cultured in vitro, splenic stroma was characterised more fully using five 
Figure 4.6 In vitro hematopoietic support capacity of stromal cell fractions. Stromal cells of different marker phenotype were sorted and cultured for 28 days until confluent. Lin $^{-}$BM was then overlaid above stroma. Non-adherent cells were collected after 21 days and stained with antibodies to CD11b, CD11c, MHC-II and F4/80 to delineate myeloid/dendritic cell production. Flow cytometric analysis was used to identify subsets of progenitors $\left(\mathrm{CD} 11 \mathrm{~b}^{-} \mathrm{CD} 11 \mathrm{c}^{-}\right)$, myeloid cells $\left(\mathrm{CD} 11 \mathrm{~b}^{+} \mathrm{CD} 11 \mathrm{c}^{-} \mathrm{F} 4 / 80^{-} \mathrm{MHC}-\mathrm{II}^{-}\right), \mathrm{L}-\mathrm{DC}\left(\mathrm{CD} 11 \mathrm{~b}^{+} \mathrm{CD} 11 \mathrm{c}^{+} \mathrm{F} 4 / 80^{+} \mathrm{MHC}^{-} \mathrm{II}^{-}\right)$and $\mathrm{cDC}-\mathrm{like} \mathrm{cells}\left(\mathrm{CD} 11 \mathrm{~b}^{+/-} \mathrm{CD} 11 \mathrm{c}^{+} \mathrm{F} 4 / 80^{-}\right.$ $\mathrm{MHC}^{-} \mathrm{II}^{+}$) amongst non-adherent cells produced in co-cultures. Nine individual self-controlled experiments were conducted, each comparing cell production by a specific stromal fraction in comparison with 5G3. The yield of cells varied with each co-culture, and this was evident by differences in cell production in 5G3 co-cultures. Both total number of cells produced, and proportional representation of subsets, is shown for each experiment. P9 and P10 reflect subsets identified in Figure 4.7. 

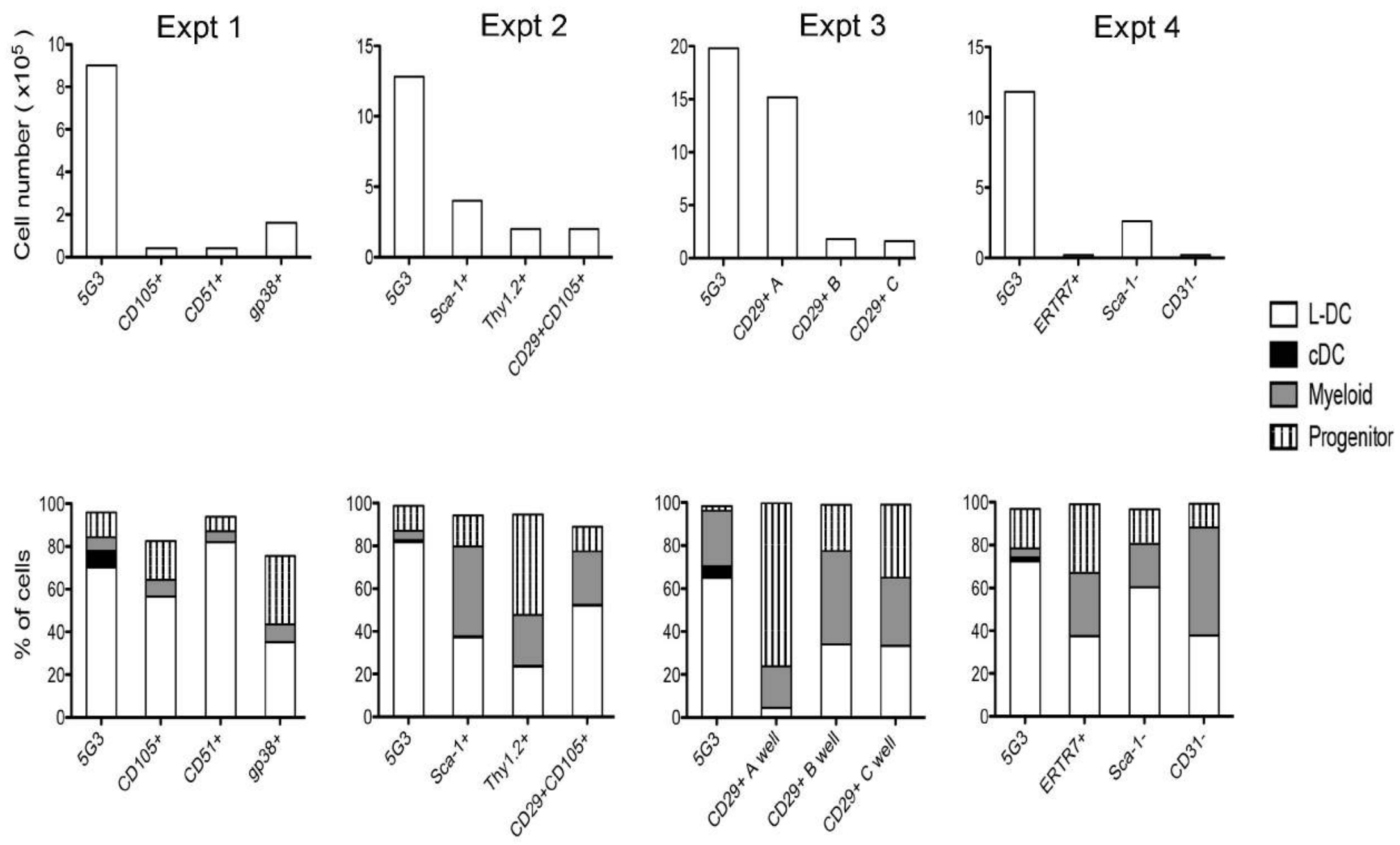

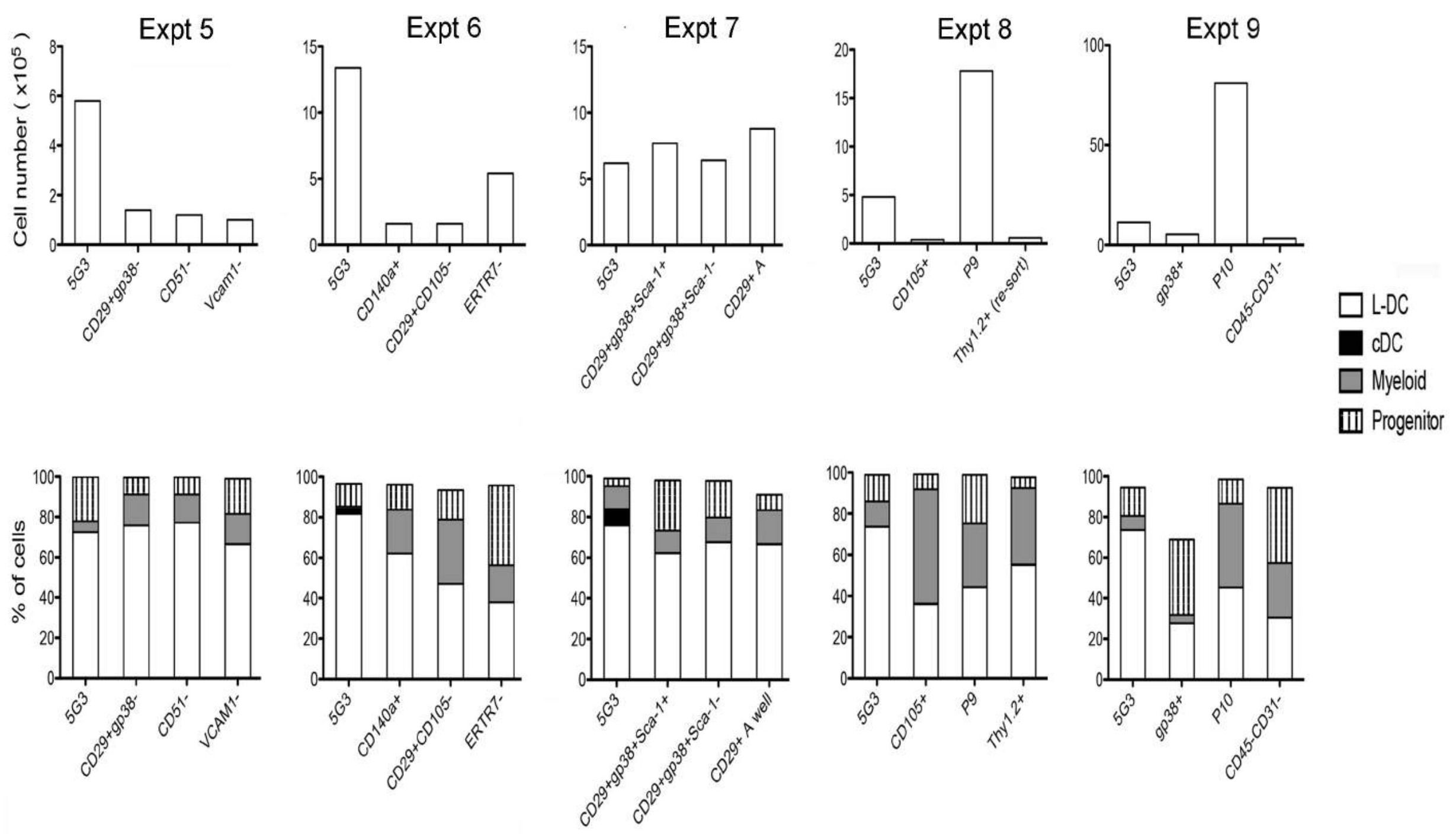
cell surface markers to delineate subsets amongst the total ex vivo splenic stromal cell population. The panel of markers comprised Thy1.2, Sca-1, CD105, CD51 and CD140a, informed by the 5G3 phenotype, as well as data collected on the growth and hematopoietic support function of stromal fractions. Splenic stromal cells were prepared from 6-day old murine neonatal spleens using collagenase treatment, and cells stained with fluorochrome-conjugated antibodies specific for CD45.2, Thy1.2, Sca-1, CD105, CD51 and CD140a.

Flow cytometric analysis of live cells revealed a subset of non-hematopoietic (CD45.2 ) stromal cells, which was investigated further for expression of markers of interest. Further analysis of this subset showed three distinct populations based on level of Sca-1 expression (Figure 4.7). Three populations were distinguished as Sca- ${ }^{\text {hi }}$, Sca$1^{\text {lo }}$ and Sca- $1^{-}$cells (Figure 4.7). These subsets were subsequently analysed for Thy 1.2, CD105, CD51 and CD140a expression (Figure 4.7). The subset of Sca- ${ }^{\text {hi }}$ was found to contain a population of Thy $1.2^{-} \mathrm{CD} 105^{+} \mathrm{CD} 51{ }^{\mathrm{lo}} \mathrm{CD} 140 \mathrm{a}^{-}$cells $(\mathrm{P} 8)$, while the subset of Sca- $1^{\text {lo }}$ contained three populations including Thy $1.2^{+} \mathrm{CD} 105^{+} \mathrm{CD} 51^{+} \mathrm{CD} 140 \mathrm{a}^{+}$cells (P9), Thy $1.2^{-} \mathrm{CD} 105^{+} \mathrm{CD} 51^{10} \mathrm{CD} 140 \mathrm{a}^{\text {lo }}$ cells $(\mathrm{P} 10)$, and Thy $1.2^{-} \mathrm{CD} 105^{-} \mathrm{CD} 51^{+} \mathrm{CD} 140 \mathrm{a}^{\text {lo }}$ cells (P11) (Figure 4.7). The Sca- $1^{-}$subset was found to contain three populations of Thy $1.2^{+} \mathrm{CD} 105^{10} \mathrm{CD} 51^{+} \mathrm{CD} 140 \mathrm{a}^{\text {lo }}$ cells (P12), Thy $1.2^{-} \mathrm{CD} 105^{+} \mathrm{CD} 51^{+} \mathrm{CD} 140 \mathrm{a}^{-}$cells (P13), and Thy1.2 ${ }^{-} \mathrm{CD} 105^{-} \mathrm{CD} 51^{-} \mathrm{CD} 140 \mathrm{a}^{-}$cells (P14) (Figure 4.7). Over 3 replicate experiments, the proportional representation of these subsets amongst splenic culture was measured. P10 was the most predominant cell type, although all were representative of $<1 \%$ of stromal cells in spleen (Table 4.4 ).

Stromal subsets P8, P9, P10 and P11 expressed markers consistent with 5G3 and cell types defined previously, and so were sorted from collagenase treated neonatal spleen for further study following expansion in culture. Only P9 and P10 proved competent to produce confluent stromal monolayers after 28 days in culture. While these cells grew, they expressed a Sca $-1^{+} \mathrm{gp} 38^{+} \mathrm{CD} 29^{+}$Thy $1.2^{+}$phenotype, but did not express CD105 or CD140a (Table 4.5). These subsets were later tested for their hematopoietic support capacity in co-culture assays involving overlay of Lin $^{-} \mathrm{BM}$ cells. P9 and P10 gave high total cell production after 21 days of co-culture (Figure 4.7). While P9 and P10 were high cell producers, they produced less than 50\% of L-DC in cultures, due to a higher production of myeloid cells (Figure 4.6). 
Figure 4.7 Full definition of stromal subsets in spleen. Stromal cells were isolated from murine spleen using collagenase treatment and cells stained with antibodies specific for CD45.2, Sca-1, Thy1.2, CD105, CD51 and CD140a. Prior to flow cytometry, cells were incubated with propidium iodide (PI) $(1 \mu \mathrm{g} / \mathrm{ml})$ for gating live (PI-) cells using PI versus SSC analysis. Singlets were then selected on the basis of FSC-H and FSC-A staining. Cells were then gated on the basis of FSC to eliminate red blood cells. Multicolour analysis was then used to detect subsets amongst the CD45.2 population of non-hematopoietic stromal cells. Fluorescence minus one (FMO) controls were used to delineate specific antibody binding, and to set gates. Numbers in quadrants, or by circle gates, represent \% specific binding of cells. Subsets identified as P8. P9, P10 and P11 reflect cells expressing marker profiles of interest. 


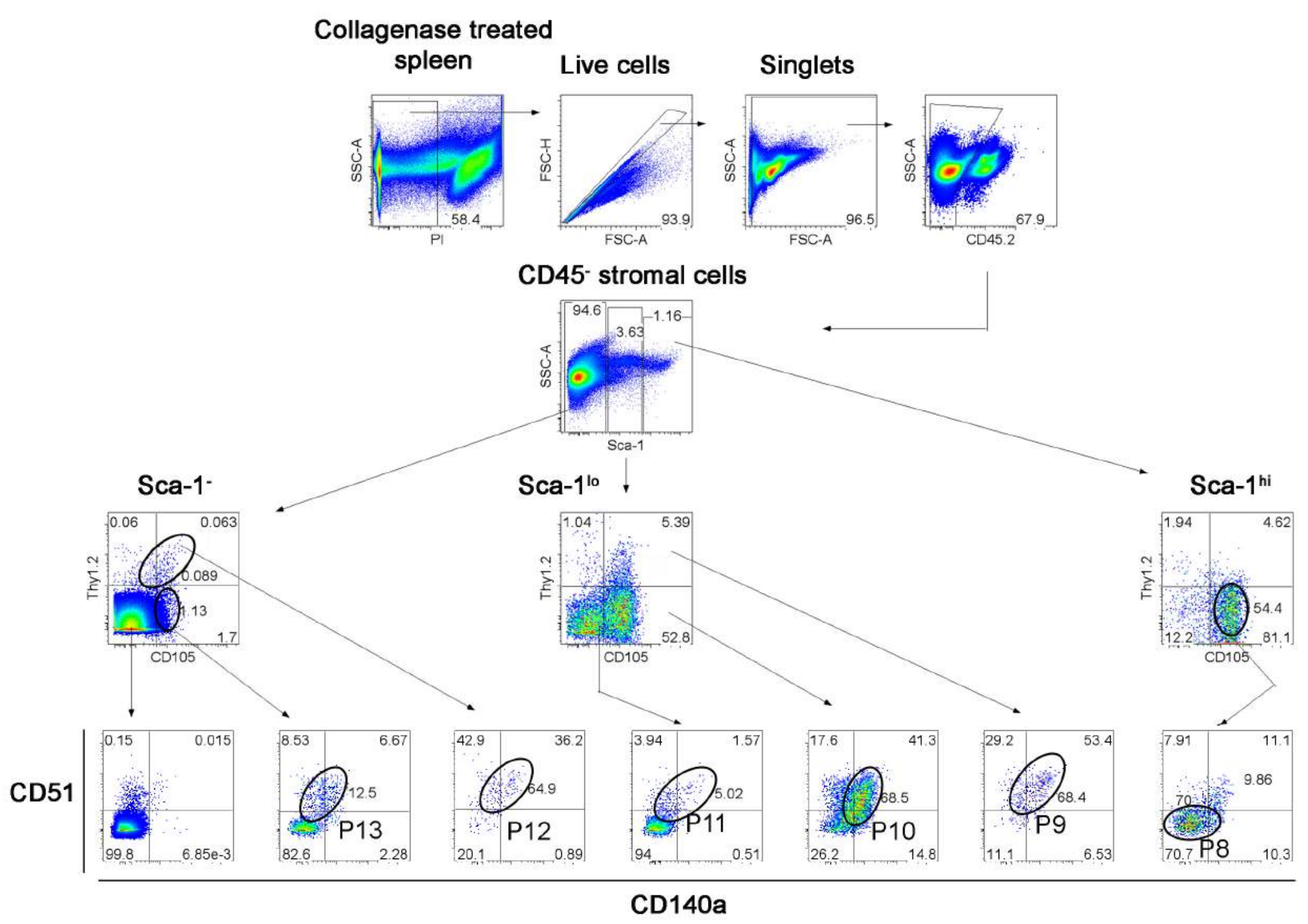


Table 4.4 Representation of specific subsets amongst the spleen stromal fraction

\begin{tabular}{|c|c|c|}
\hline Subset & Designation* & $\%$ cells $^{\dagger}$ \\
\hline Sca- $1^{\text {hi }}$ Thy $1.2^{-} \mathrm{CD} 105^{+} \mathrm{CD} 51^{\mathrm{lo}} \mathrm{CD} 140 \mathrm{a}^{-}$ & P8 & $0.17 \pm 0.068$ \\
\hline Sca- $1^{10}$ Thy $1.2^{10} \mathrm{CD} 105^{+} \mathrm{CD} 51^{+} \mathrm{CD} 140 \mathrm{a}^{+}$ & P9 & $0.06 \pm 0.021$ \\
\hline Sca- $1^{10}$ Thy $1.2^{-} \mathrm{CD} 105^{+} \mathrm{CD} 51^{10} \mathrm{CD} 140 \mathrm{a}^{\mathrm{lo}}$ & $\mathrm{P} 10$ & $0.52 \pm 0.190$ \\
\hline Sca- $1^{10}$ Thy $1.2^{-} \mathrm{CD} 105^{-} \mathrm{CD} 51^{+} \mathrm{CD} 140 \mathrm{a}^{\mathrm{lo}}$ & P11 & $0.04 \pm 0.006$ \\
\hline Sca-1 $1^{-}$Thy $1.2^{\text {lo }} \mathrm{CD} 105^{\text {lo }} \mathrm{CD} 51^{+} \mathrm{CD} 140 \mathrm{a}^{\text {lo }}$ & $\mathrm{P} 12$ & $0.03 \pm 0.007$ \\
\hline Sca-1-Thy $1.2^{-} \mathrm{CD} 105^{+} \mathrm{CD} 51^{+} \mathrm{CD} 140 \mathrm{a}^{\text {lo }}$ & P13 & $0.06 \pm 0.017$ \\
\hline
\end{tabular}

$\dagger \%$ cells amongst stromal the fraction of neonatal (6D) spleen isolated by collagenase digestion, and then delineated through flow cytometric gating of CD45 cells. Data reflect mean $\pm \operatorname{SE}(n=3)$.

"Subset designation is shown in Figure 4.7. 
Table 4.5 Phenotype of cells cultured out of stromal subsets

\begin{tabular}{|c|c|c|}
\hline Subset & $\begin{array}{l}\text { Cell number } \\
\text { plated }\end{array}$ & Phenotype of 28 day stroma ${ }^{\S}$ \\
\hline P8 & $\begin{array}{l}(2.8 \pm 0.5) \cdot 10^{4} \\
(\mathrm{n}=5)\end{array}$ & No growth \\
\hline P9 & $\begin{array}{l}(7.6 \pm 1.5) \cdot 10^{3} \\
(\mathrm{n}=5)\end{array}$ & Sca- $1^{+}$gp $38^{+} \mathrm{CD} 51^{10} \mathrm{CD} 105^{-} \mathrm{CD} 29^{+}$ER-TR7 CD140a ${ }^{-}$Thy $1.2^{+}$ \\
\hline P10 & $\begin{array}{l}(9.8 \pm 1.6) \cdot 10^{3} \\
(\mathrm{n}=5)\end{array}$ & Sca- $1^{+}$gp $38^{+}$CD $51^{-} \mathrm{CD} 105^{-} \mathrm{CD} 29^{+}$ER-TR7 CD140a Thy $1.2^{+}$ \\
\hline P11 & $\begin{array}{l}(1.3 \pm 9 \cdot 6) \cdot 10^{2} \\
(\mathrm{n}=5)\end{array}$ & No growth \\
\hline
\end{tabular}

$\S$ Cells were trypsinised and stained with antibodies to determine phenotype.

*Subset designation is shown in Figure 4.7. 


\subsubsection{Stromal co-cultures appear to maintain Lin $^{-} \mathrm{c}-\mathrm{Kit}^{+}$progenitors}

To determine if stromal co-cultures maintain $\mathrm{Lin}^{-} \mathrm{c}-\mathrm{Kit}^{+}$progenitors, co-cultures established for at least 35 days were trypsinised for cell harvest to ensure isolation of any stem cell/progenitors adherent to stroma. Harvested cells were stained with fluorescence-conjugated antibodies specific for lineage markers (CD3, CD19, CD11b, CD11c, MHC-II, Gr-1, NK1.1 and Ter-119), CD45.2, Sca-1 and c-Kit to delineate stem/progenitor cell populations. Flow cytometry revealed a small population of Lin'c$\mathrm{Kit}^{+}$progenitors in $\mathrm{CD} 45^{-}$and $\mathrm{CD} 140 \mathrm{a}^{+}$stromal co-cultures but not in $5 \mathrm{G} 3$ co-cultures (Figure 4.8). One explanation could be that the 5G3 stroma is more efficient than $\mathrm{CD}_{140 \mathrm{a}^{+}}$and $\mathrm{CD}^{-} 5^{-}$stroma in promoting rapid differentiation of progenitors to L-DC so that very few are detectable following cell isolation and analysis. A similar explanation could also explain the lower production of L-DC in CD140a ${ }^{+}$and CD $45^{+}$ stromal co-cultures if the maintenance of progenitors is more efficient giving lower differentiation to L-DC (Figure 4.8). 
Figure 4.8 Attempts to identify progenitors in co-cultures. Co-cultures were prepared as described in Figure 3.4, and analysed for the presence of hematopoietic progenitors after 35 days. Cultures were first trypsinised for cell harvest to ensure isolation of any progenitors adherent to stroma. Harvested cells were stained with fluorescence-conjugated antibodies specific for lineage (Lin) and CD45.2, as well as c-Kit and Sca-1, to delineate progenitor cell populations. Fluorescence minus one (FMO) controls were used to set gates. 5G3 stroma was used as a control (A), and compared with the $\mathrm{CD}^{-} 5^{-}(\mathrm{B})$ and $\mathrm{CD} 140 \mathrm{a}^{+}$(C) stromal fractions used to establish co-cultures. 


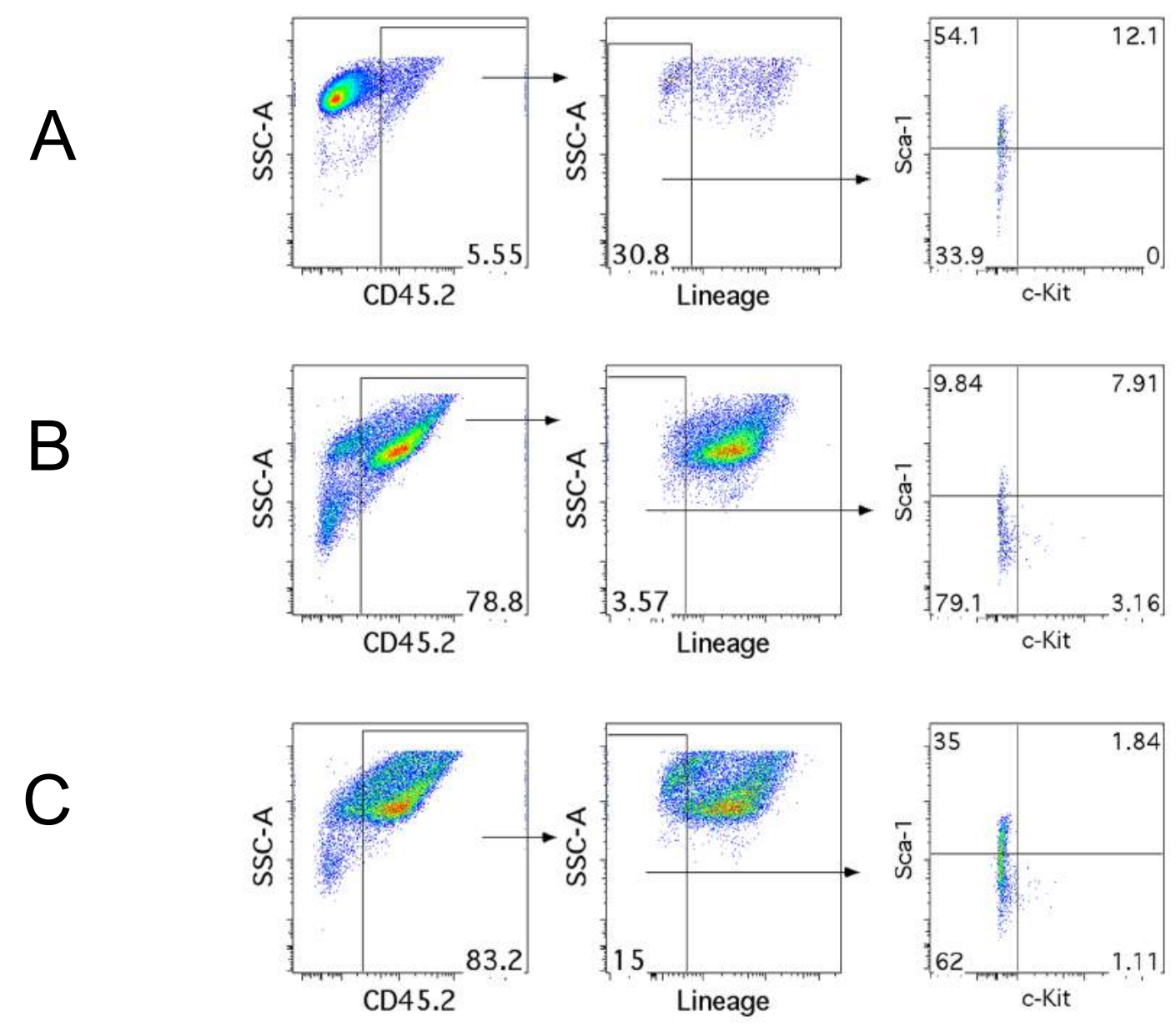




\subsection{DISCUSSION}

This study represents the first comprehensive characterisation of splenic stroma as a hematopoietic niche. Traditionally, the spleen is viewed as an immune organ which also supports erythropoiesis and turnover of red blood cells (Cesta, 2006; Mebius and Kraal, 2005). However the spleen also plays an active role in extramedullary hematopoiesis during times of stress, infection and inflammation (Yamamoto et al., 2016; Johns and Christopher, 2012; Cesta, 2006). In this study, we have studied steadystate spleen and used a reductionist approach in order to better understand the composition of splenic stroma, its heterogeneity and its ability to support hematopoiesis. By using fluorescent-activated cell sorting, fractionation of collagenase treated splenic stroma was initially carried out using single markers, followed subsequently by two or more markers to improve the fractionation procedure. The ability of fractionated stromal cells to grow in culture was then assessed, and hematopoietic support capacity evaluated using Lin $^{-} \mathrm{BM}$ as an overlay. In addition to characterising the capacity of splenic stroma to support hematopoiesis, this study aimed to investigate the marker phenotype of stromal subsets which can grow and support in vitro hematopoiesis.

The ability of fractionated stromal cells to grow and expand to form a monolayer was regarded as a necessary step, although a bottleneck in the in vitro characterisation of stromal cell capacity to support hematopoiesis. It is widely understood that growing fresh, untransformed mammalian cells in culture is time-consuming and difficult (Despars and O'Neill, 2006a; Smith, 2005). Moreover, the isolation and sorting process to obtain cell fractions could also be selectively traumatic to some cell subsets. In order to ensure the reliability of the growth assay, the use of collagenase in cell isolation was optimised for highest cell recovery. In addition, stromal cells were cultured in SDMEM under uniform growth conditions to promote optimal cell growth.

Plastic adherence has been used as a criterion for isolation of MSC and has also been used by others to evaluate the growth capacity of fractionated stromal cells (Lindner et al., 2010). Growth of cells in vitro on plastic has been used here for isolation of splenic stromal subsets in this study. Since the hypothesis is that the spleen contains perivascular reticular cells of mesenchymal lineage which support hematopoiesis, preliminary evaluation of plastic adherence and cell growth was undertaken using multiple splenic stromal fractions. Our results confirm that the splenic stromal 
population is highly heterogeneous, evidenced by mixed cellular morphology in adherent cultures, as opposed to a uniform cuboidal morphology of cells of the cloned 5G3 stromal line. The majority of splenic stromal cells express CD29 which is one of the cell surface markers used to isolate and characterise MSC (Lindner et al., 2010). Since CD29 is widely expressed by stromal cells in spleen, it was not unexpected to find a range of cells exhibiting different morphology within the CD29 ${ }^{+}$stromal subset. It should however be noted that morphological examination of growing cell isolates provides only limited information on cell type, and is in the main a demonstration of the degree of heterogeneity within a growing cell population.

While cell morphological examination alone was not definitive, it has been used here in combination with cell phenotype, growth capacity and hematopoietic support capacity. Stromal cell growth analysis has revealed that stromal fractions depleted of cells expressing CD29, gp38, CD105, Thy1.2 or CD140a failed to establish monolayers in culture. These cell surface markers are therefore important markers of cells which show capacity for in vitro adherence and growth. In addition, these markers also reflect the phenotype that defines MSC, consistent with the hypothesis that a mesenchymal cell present in spleen forms a niche for hematopoiesis in vitro. Notably, stromal cells that grow out of 28 -day cultures consistently show a Sca- $1^{+}$gp $38^{+}$Thy $1.2^{+} \mathrm{CD} 29^{+} \mathrm{CD} 51^{+}$ phenotype with some variability in expression of CD105 and CD140a. This phenotype is indicative of cells of mesenchymal lineage, present in spleen, and readily expanded in vitro. Caution should be exercised with regard to marker expression since culturing conditions can lead to changes in surface maker expression on cells (Pevsner-Fischer et al., 2011).

In Chapter 3, a co-culture assay involving overlay of Lin $^{-} \mathrm{BM}$ cells above 5G3 stroma was extensively described. Here, we use a similar strategy to test the hematopoietic support capacity of cultured stromal fractions and defined splenic stromal subsets. It was found that most established stroma support the production of hematopoietic cells equivalent to those produced in control $5 \mathrm{G} 3$ co-cultures, although cell production levels were much lower and more variable than found in 5G3 cocultures. An exception would be the specifically defined stromal subsets, P9 and P10.

Heterogeneity of splenic stroma appears to contribute to variability in hematopoietic support capacity. This would be consistent with a model whereby 
specific cells, perhaps defined by the P9 and P10 subsets identified here, have the best hematopoietic support function, while others have weaker or different capacity. Indeed, variability in hematopoietic support noted in this study parallels that seen amongst clonal cell line derivatives of the original parental STX3 splenic stroma (Periasamy et al., 2009; Despars and O'Neill, 2006a). In that study, it was found that cloned stromal lines including 2A8, 5G3 and 10C9 were good, although variable supporters, whereas 3B5 was a non-supporter, despite having originated from the same parental STX3 stromal line (Periasamy et al., 2009).

Taken together, this chapter has found the Sca $-1^{+} \mathrm{gp} 38^{+}$Thy $1.2^{+} \mathrm{CD} 29^{+} \mathrm{CD} 51^{+}$ cell phenotype to be defining of stroma which grow in vitro and support hematopoiesis. However, cells with this phenotype did not support cell production to the level achieved with 5G3 stroma. It is likely that $5 \mathrm{G} 3$ has been selected by continuous culture over time for enhanced in vitro growth capacity and perhaps for in vitro hematopoietic support capacity. Since the markers, which define the stromal subset are not specific, heterogeneity is still expected within the Sca- $1^{+}$gp $38^{+}$Thy $1.2^{+} \mathrm{CD} 29^{+} \mathrm{CD} 51^{+}$cell subset. These markers will be used in the next chapter to delineate the stromal population using immunohistochemistry of spleen sections, to determine stroma which co-localise with HSC so forming a niche for HSC maintenance.

Importantly, analyses of growth capacity of stromal cells indicated the importance of CD140a and CD105 as markers defining of subsets with in vitro growth and hematopoietic support capacity. However, these are also elusive markers which show variability and sometimes weak expression, so may not be reliable markers of important cells of interest. Based on these findings, CD140a and CD105 markers will also be used to localise HSC niches in the next chapter. While expression of CD140a and CD105 varied on stroma that grew in vitro, we cannot ignore the possibility that expression of these markers is subject to growth conditions. Variability in hematopoietic support noted within replicates of the same stromal co-cultures was also noticed and could also be caused by variability in the $\operatorname{Lin}^{-} \mathrm{BM}$ population used as overlay cells. Different preparations of these cells could contain different numbers of progenitors which could add to variability in the co-culture responses seen. Therefore, future work will entail testing the hematopoietic support capacity of clonal isolates of stromal cells using highly purified sorted HSC/MPP cell populations as described previously for the $5 \mathrm{G} 3$ cell line (Chapter 3 ). In addition, it will be possible to support in 
vitro studies with in vivo tests of stromal cell function. Stromal cell types can be transplanted in vivo under the kidney capsule, so forming ectopic niches which support the growth and development of hematopoietic cells, providing an ectopic splenic niche environment. This would be an ultimate test of the capacity of the stromal subset to act as a niche for HSC. 


\section{CHAPTER FIVE IDENTIFICATION OF HSC STROMAL NICHES IN SPLEEN}




\section{$5.1 \quad$ INTRODUCTION}

HSC niches refer to a microenvironment comprising non-hematopoietic cells which interact with HSC via juxtacrine and paracrine signalling to regulate their selfrenewal and differentiation as well as their proliferation and quiescence (Boulais and Frenette, 2015). In the BM, known HSC niches reflect endosteal, vascular and perivascular microenvironments, involving osteoblasts, endothelial cells and perivascular reticular cells (Ugarte and Forsberg, 2013; Ding et al., 2012; MendezFerrer et al., 2010; Sugiyama et al., 2006; Kiel et al., 2005; Nilsson et al., 2005; Calvi et al., 2003). The main cell subsets of the perivascular niche in the BM have been described as nestin ${ }^{+}$mesenchymal stem cells, LepR $^{+}$stromal cells and CAR cells (Ding and Morrison, 2013; Ding et al., 2012; Mendez-Ferrer et al., 2010; Sugiyama et al., 2006). These stromal subsets have been shown by immunofluorescence imaging to be localised adjacent to arterioles/sinusoids (Ding and Morrison, 2013; Ding et al., 2012; Mendez-Ferrer et al., 2010) and to lie in close proximity with HSC (Ding et al., 2012; Mendez-Ferrer et al., 2010; Sugiyama et al., 2006).

While HSC niches in BM have been extensively studied, limited knowledge is available on niches for HSC in spleen. Previous studies in this laboratory have determined that a stromal cell derivative of a murine, neonatal splenic long-term culture, termed 5G3, supports restricted in vitro hematopoiesis (Periasamy and O'Neill, 2013; Periasamy et al., 2013a; Periasamy et al., 2009). In addition, stromal fractions isolated from neonatal spleens were shown in Chapter 4 to support in vitro hematopoiesis when overlaid with lineage-negative BM cells, albeit at lower levels than achieved with the 5G3 stromal cell line. In murine spleen undergoing extramedullary hematopoiesis, HSC were localised in close contact with sinusoids in the red pulp region (Inra et al., 2015; Kiel et al., 2005). Recently, Inra et al. (2015) reported the existence of a perisinusoidal niche in murine spleen comprising $T c f 21^{+}$stromal cells and endothelial cells supporting extramedullary hematopoiesis. The gene profile and phenotype of 5G3 stroma reflects a mesenchymal cell expressing genes common to perivascular reticular cells like Cxcl12, Scf, Pdgfrb, Pdgfra, Endoglin (also known as CD105), Itagv (Integrin alpha V, also known as CD51), Sca-1 and Thy1.2, so that it may overlap with $T c f 21^{+}$cells described by Inra et al (2015), as mesenchymal cells which form the perisinusoidal niche in the red pulp region of spleen. All data to date support the possibility that the spleen might contain HSC niches, similar to that of the BM whereby HSC are supported by both 
mesenchymal perivascular cells and endothelial cells in sinusoids. Whether the same niches support HSC under steady-state conditions and under physiological stress leading to extramedullary hematopoiseis, is not yet known.

In this chapter, immunofluorescence imaging has been used to localise HSC in spleen and to determine their spatial relationship with known stromal cell types. Investigation was carried out to compare spleens of 4-6 week old and 6-day old C57BL/6J mice. Models for extramedullary hematopoiesis were also studied since these are associated with higher numbers of HSC and HSC niches in spleen. Pregnant C57BL/6J mice (E18.5) were analysed (Nakada et al, 2014) along with Fms-like tyrosine kinase (Flt)-3 ligand (Flt3L) treated C57BL/6J mice. The latter treatment is known to mobilise HSC into blood and spleen (Robinson et al., 2000; Neipp et al., 1998; Brasel et al., 1996).

Spleen sections were stained with markers which define stoma in different regions of spleen, including CD29, a marker of mesenchymal cells (also hematopoietic cells) in spleen (Mueller and Germain, 2009; Oh and Kwon, 2010), CD105 which marks angiogenic vasculature, marginal reticular cells and red pulp fibroblasts in spleen (Tan and Watanabe, 2014; Duff et al., 2003), CD31 which identifies mature endothelial cells in both the red and white pulp regions of spleen (Mueller and Germain, 2009; Newman, 1997), and gp38 which identifies lymphatic endothelial cells in the lymph node, fibroblastic reticular cells (Mueller and Germain, 2009; Farr et al., 1992), and follicular dendritic cells in spleen (Mueller and Germain, 2009; Yu et al., 2007). Further markers were used to identify cells resembling perivascular reticular cells or CAR cells. These included CD140a/b which identifies fibroblastic reticular cells, red pulp fibroblasts, CAR cells and MSC (Mueller and Germain 2009; Nagasawa et al. 2011), CD51 which identifies CAR cells (Nagasawa et al., 2011), as well as Thy1 which identifies T cells and MSC (Garg et al., 2013; Nagasawa et al., 2011; Dominici et al., 2006; Spangrude et al., 1988). By using a combination of markers for stromal and hematopoietic cell types, it has been possible to localise different stromal cell subtypes in relation to hematopoietic stem/progenitor cells. 


\subsection{RESULTS}

\subsubsection{Delineation of splenic regions using regional markers}

The architecture of the spleen is uniquely arranged in a way that best reflects its functional capacity in erythropoiesis and immunity. In order to visualise specific regions of the spleen, frozen sections were prepared using a cryostat and stained with antibodies specific for markers known to be expressed by specific stromal subsets of spleen (Mueller and Germain, 2009). Three main regions can be delineated including B cell follicles, $\mathrm{T}$ cell zones and red pulp regions, using antibodies specific for the B220, CD3 and F4/80 markers, respectively.

Staining for the B220 marker on B cells revealed distinct B cell follicles in both adult and neonatal sections (Figure 5.1), where activated B cells undergo clonal expansion resulting in isotype switching and somatic hypermutation (Mebius and Kraal, 2005). Dense staining indicates that B cells are in abundance in these follicles (Figure 5.1). Multiple $\mathrm{T}$ cell zones in adult and neonatal sections revealed by CD3 staining, also showed dense staining, indicative of $\mathrm{T}$ cell-rich regions (Figure 5.1). In these sites, naïve $\mathrm{T}$ cells are activated on encounter with specific antigens presented by dendritic cells with subsequent differentiation into effector T cells (Mebius and Kraal, 2005). Multicolour staining showed T cell zones in close proximity with B cell follicles in both adult and neonatal spleen sections (Figure 5.1). This close proximity increases the possibility of naïve $\mathrm{B}$ cells encountering their specific effector T cells.

A comparison of architecture of neonatal and adult spleen revealed differences in architecture, notable by smaller regions of $\mathrm{T}$ and $\mathrm{B}$ cells in neonatal spleen. The $\mathrm{B}$ cell follicles and $\mathrm{T}$ cell zones appeared larger and more developed in adult than in neonatal spleen (Figure 5.1). Moreover, the red pulp region of neonatal spleen appeared more extensive than that of adult spleen, reflected by the distribution of $\mathrm{F} 4 / 80^{+}$ macrophages although less dense in terms of myeloid cell numbers (Figure 5.1). While the red pulp region contains a substantial fraction of red pulp macrophages, it also contains other cell types including plasma cells, dendritic cells and red blood cells (Cesta, 2006; Mebius and Kraal, 2005). Ter-119, a marker found almost exclusively on red blood cells, could also be used as an alternative red pulp region marker to F4/80 (Ikuta et al., 1990). In sum, neonatal spleen has a similar but distinct architecture to 
Figure 5.1 Architecture of adult and neonatal spleen. Acetone-fixed frozen sections were stained with specific fluorochrome-conjugated antibodies. Images representative of 3 mice are shown: Adult and neonatal spleens showing T cell zones (T) (CD3-blue), B cell follicles (B) (B220-red), central arteriole (CA) and red pulp macrophages (RP) (F4/80-green) at low magnification (scale bar: $250 \mu \mathrm{m})$. 
Adult

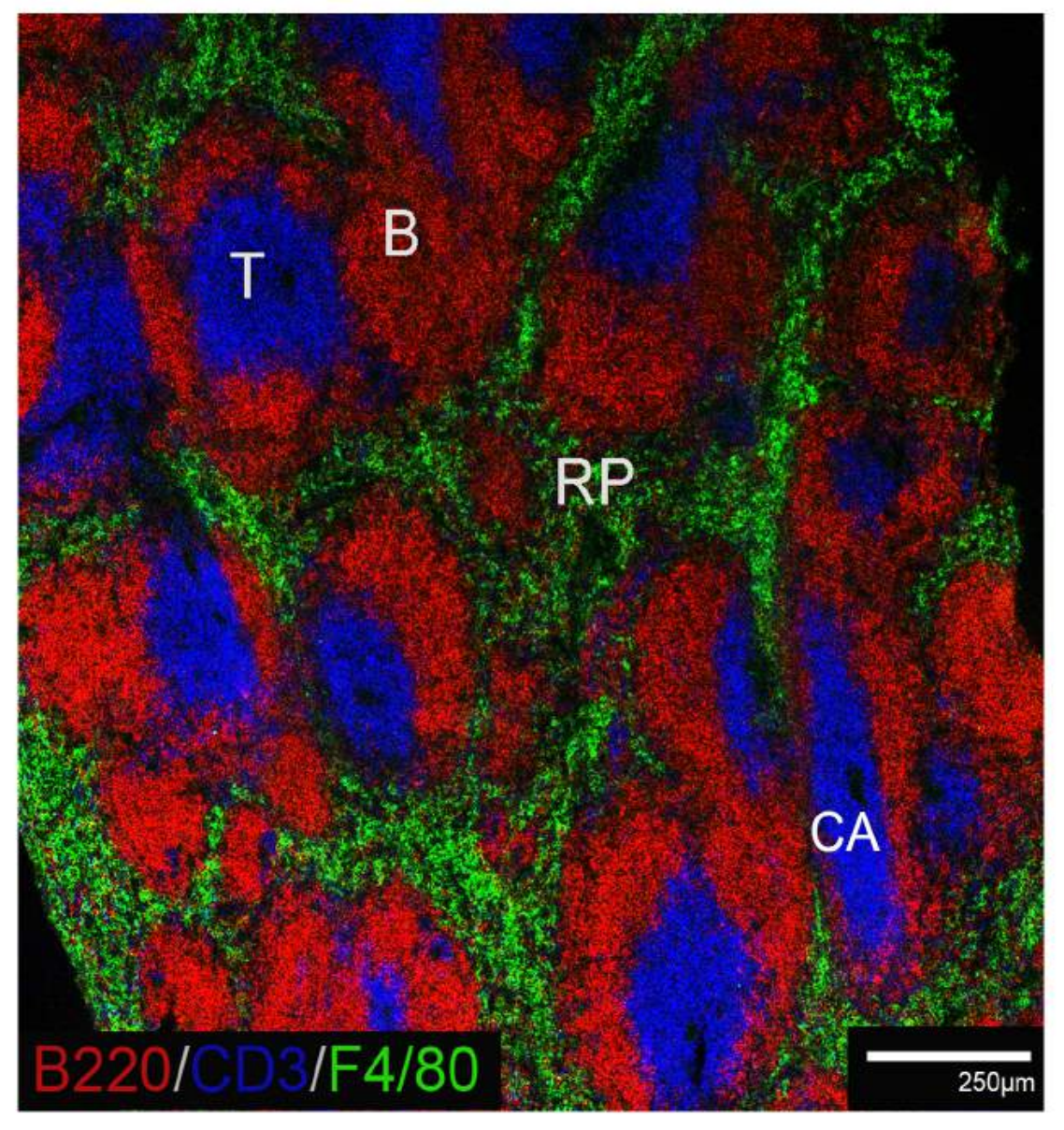

Neonatal

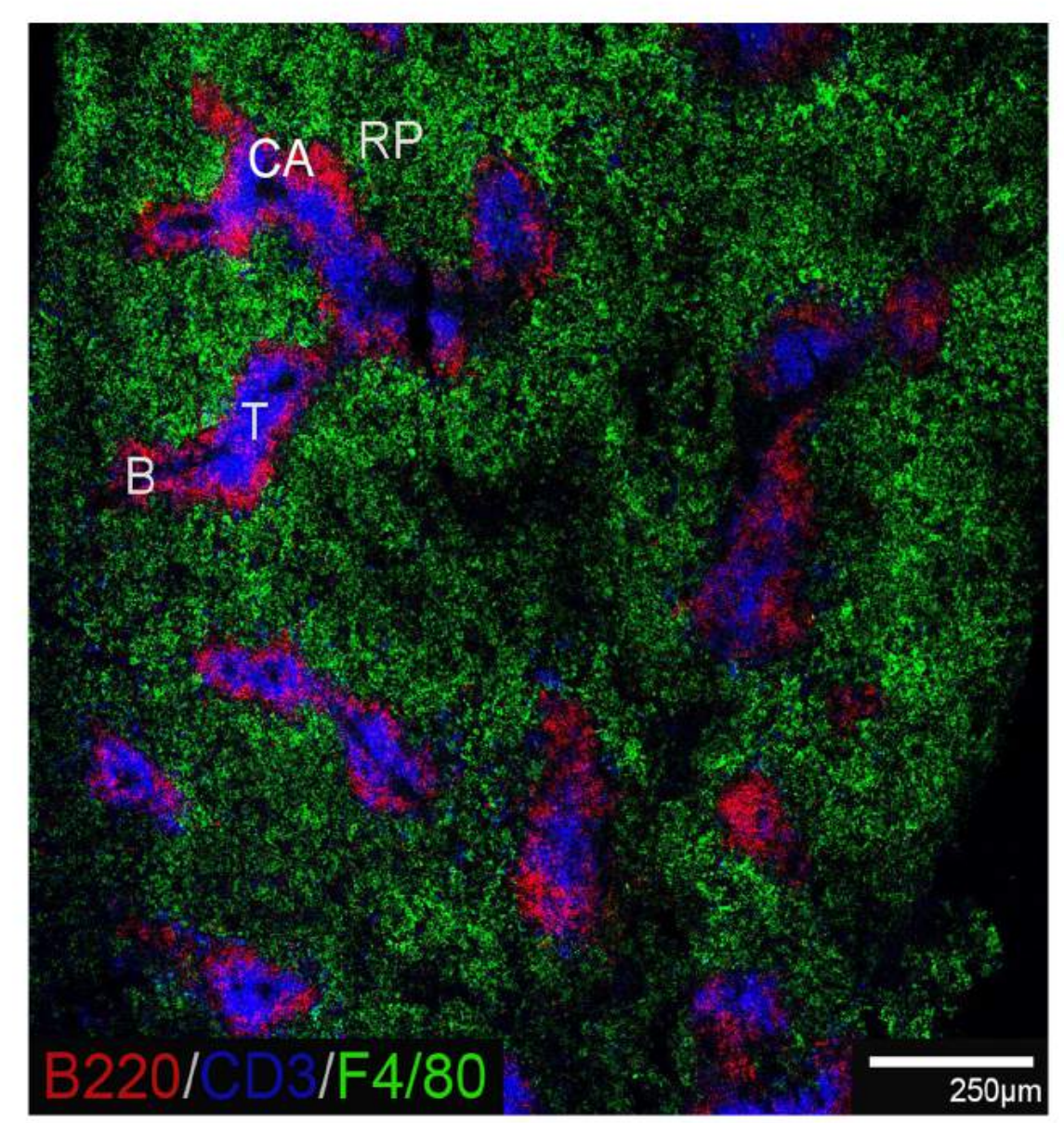


adult spleen, reflected in lower numbers of hematopoietic cells arranged within an extensive red pulp matrix.

\subsubsection{Identification of different stromal cell subtypes within spleens}

The spleen contains large numbers of non-hematopoietic stromal cells. To localise the different stromal cell types in adult and neonatal spleens, antibodies specific for the cell surface markers CD29, CD31, CD105, gp38, Thy1.2, CD140a/b and CD51 were used initially. Staining for the CD29 marker showed continuous distribution of stromal cells in the red pulp of both adult pregnant and neonatal spleens, albeit more densely in adults than neonatal spleens (Figure 5.2A). The distribution of CD29 ${ }^{+}$cells in adult and neonatal spleen is consistent with evidence that CD29-expressing stromal cells are distributed in the red pulp. Some CD29 ${ }^{+}$expressing cells reflecting the fibroblastic reticular cells of white pulp (den Haan et al., 2012) were also detected in both adult pregnant and neonatal spleens (Figure 5.2A).

The CD31 marker identifies sinusoidal and vascular endothelial cells which line capillaries, arteries and venous sinuses in red pulp, marginal sinuses in the marginal zone on the edge of the white pulp, and central arterioles in the white pulp of spleen. Adult spleen sections stained with antibody to CD31 marker, revealed extensive distribution of CD31 ${ }^{+}$cells (Figure 5.2C). Co-staining CD31 with F4/80 confirmed the presence of $\mathrm{CD} 31^{+}$cells in the red pulp, white pulp around central arterioles, and in the marginal zone of adult and neonatal spleens (Figure 5.2C). However, CD $31^{+}$cells appeared more densely in the red pulp of adult than neonatal spleens, suggesting more developed vasculature than in neonatal spleens, although this was well formed ahead of hematopoietic cells in neonatal spleens indicated by F4/80 staining.

Spleen Sections stained with antibody to CD105, a marker of angiogenic vasculature, marginal reticular cells and red pulp fibroblasts, showed a similar staining pattern as did CD31 in both adult and neonatal spleens (Figure 5.2B). However, staining with antibody to CD105 predominated over F4/80 staining in red pulp of neonatal than adult spleens, consistent with early formation of $\mathrm{CD} 105^{+}$stromal cells in neonates ahead of full hematopoiesis (Tan and Watanabe, 2014). Localisation of gp $38^{+}$cells was restricted to the white pulp in adult spleens (Figure 5.2D). These gp $38^{+}$cells are likely to be fibroblastic reticular cells in T cell zones and follicular dendritic cells in the B cell 
Figure 5.2 Stromal cell distribution in adult pregnant and neonatal spleens. Acetonefixed frozen sections of adult pregnant (E18.5) and neonatal spleen were stained with specific fluorochrome-conjugated antibodies. Images representative of 3 mice are shown: (A) CD29-expressing cells (red) distributed extensively in the red pulp (RP), but not the

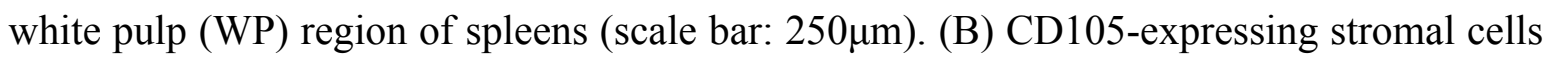
(green) widely distributed in spleens. F4/80 staining marks the myeloid cells throughout the red pulp region (scale bar: $250 \mu \mathrm{m}$ ). (C) CD31-expressing endothelium (green) localised in both RP and WP of spleen (scale bar: $250 \mu \mathrm{m}$ ). (D) gp38-expressing cells restricted to the WP regions of adult pregnant spleen (E18.5), but in both the WP and RP regions of neonatal spleen (scale bar: $250 \mu \mathrm{m}$ ). (E) Thy1.2-expressing cells largely restricted to the T cell zones in WP of both pregnant adult and neonatal spleens (scale bar: $250 \mu \mathrm{m}$ ). 


\section{Pregnant}
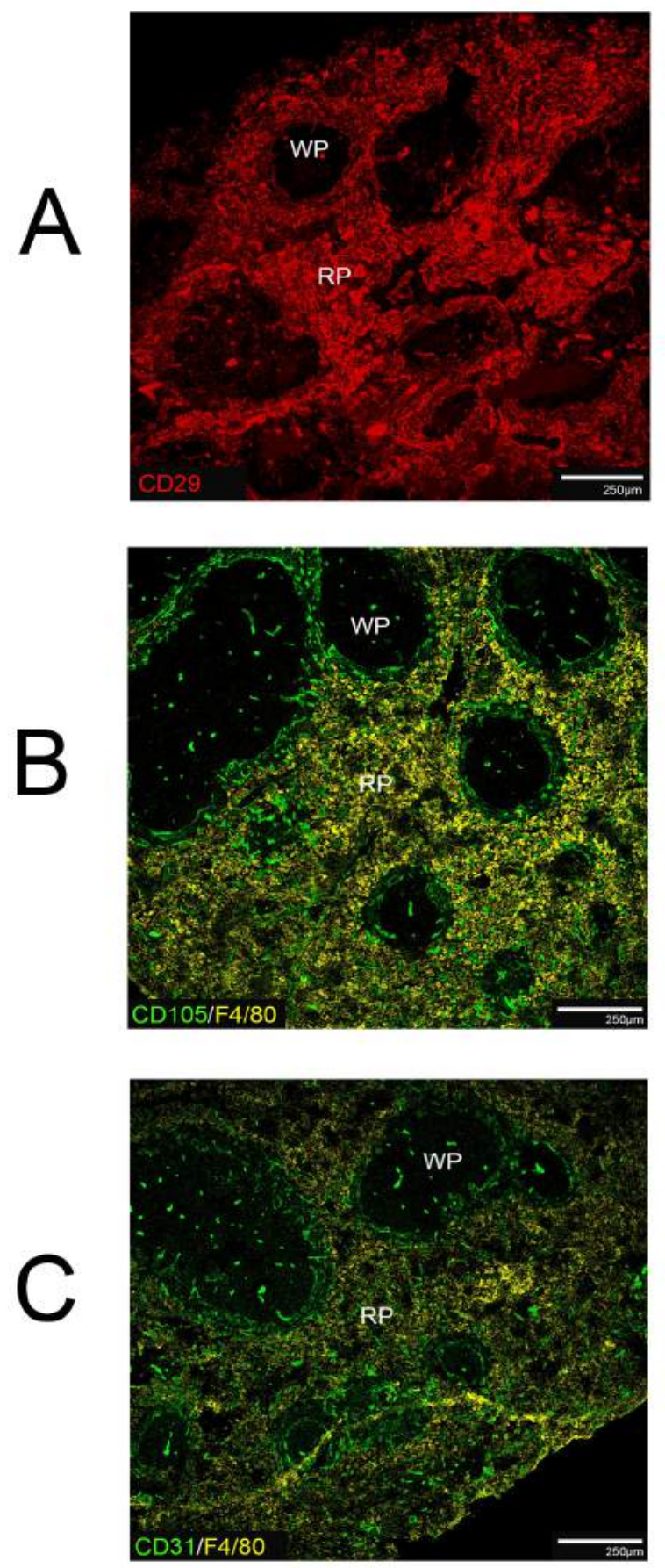

Neonatal
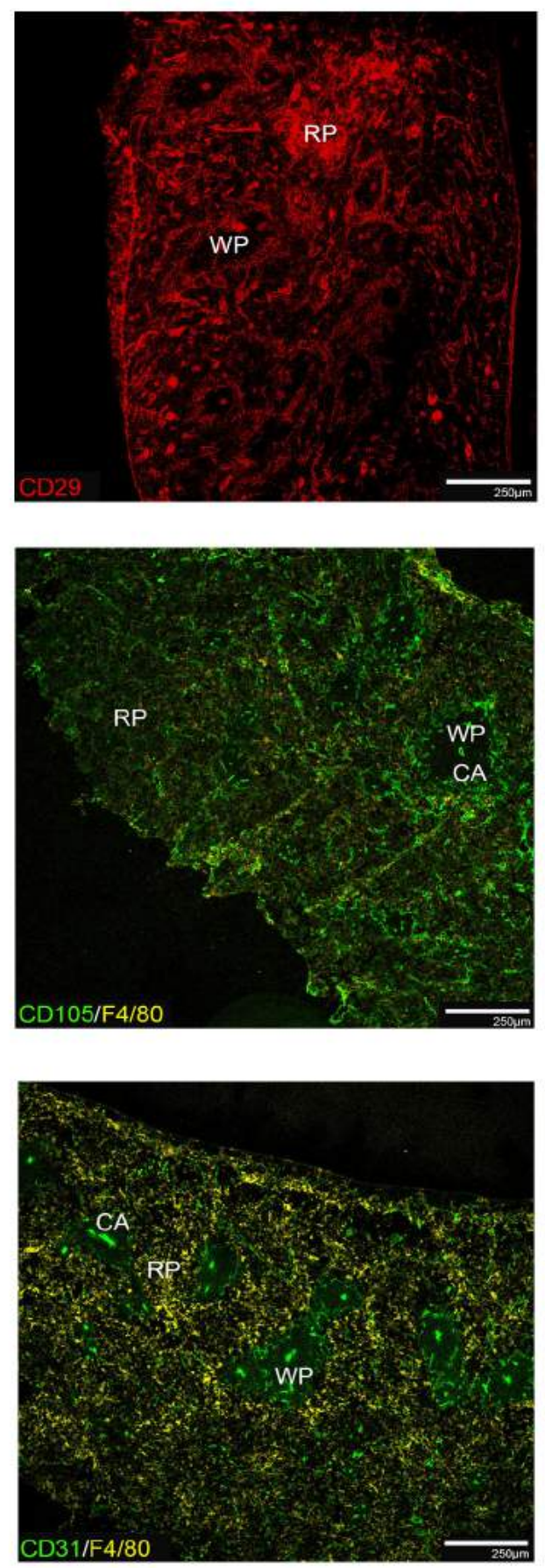


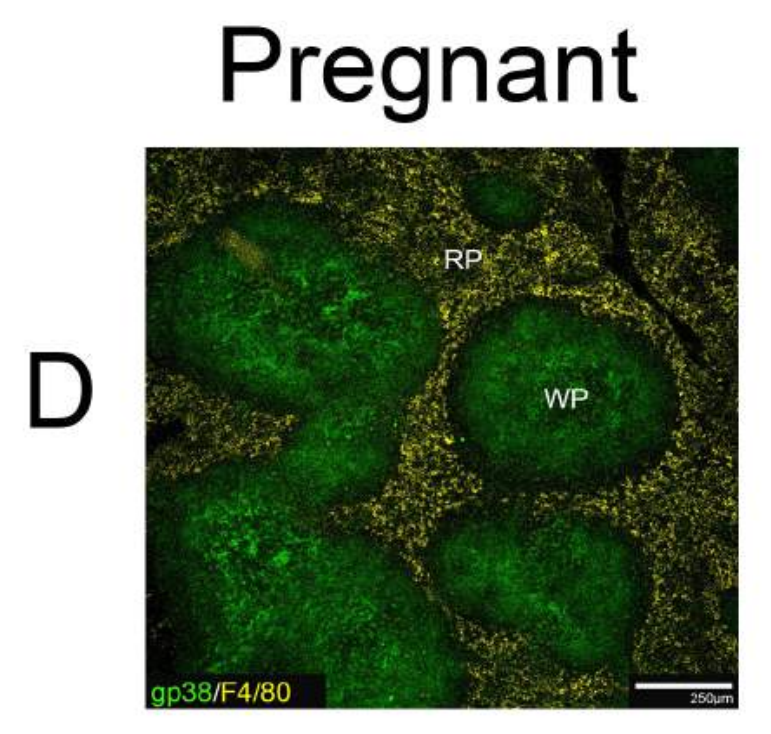

Neonatal
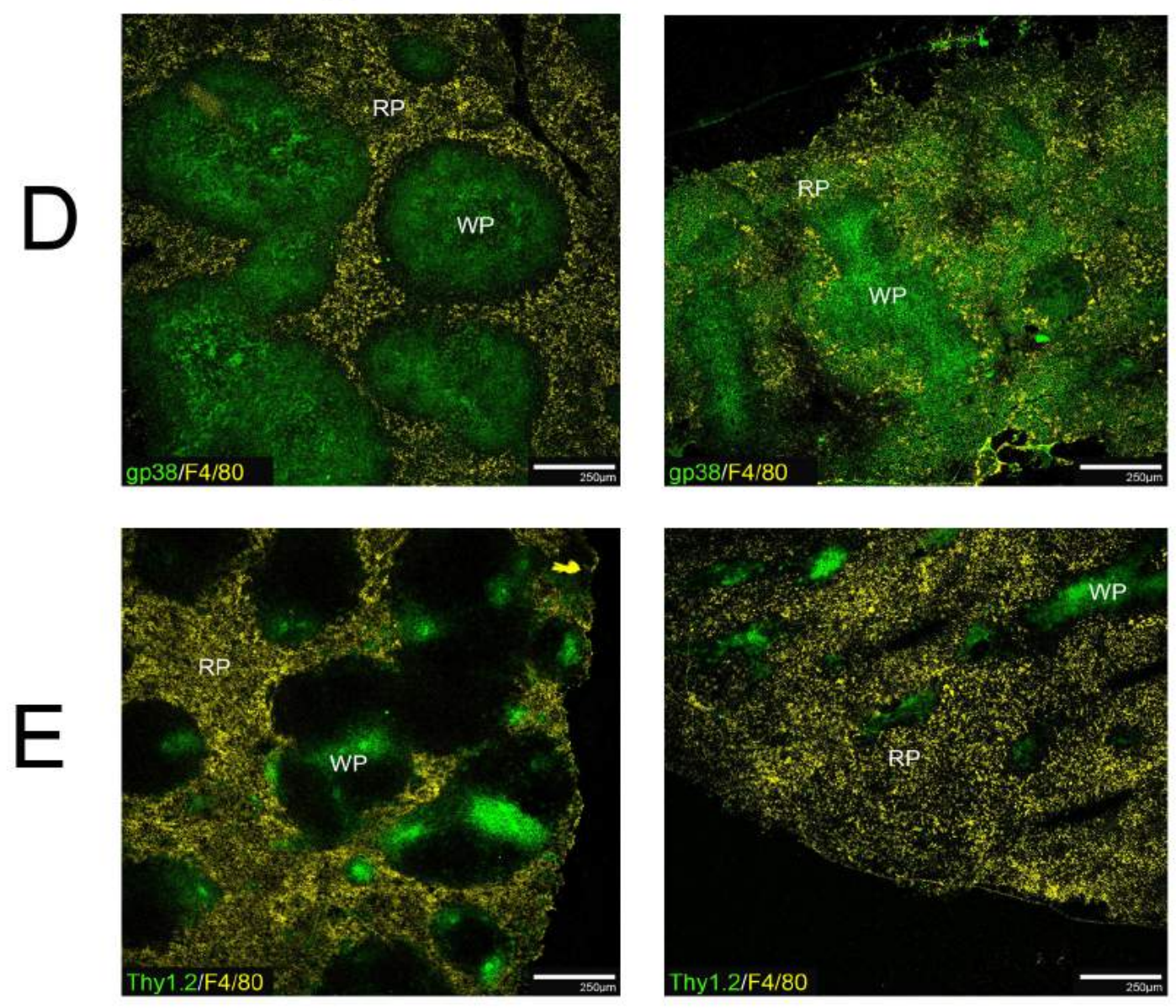
follicles, as previously reported (Mueller and Germain, 2009). In contrast, gp $38^{+}$cells were widely distributed in the neonatal spleens in both the red and white pulp regions, suggesting quite distinct stromal architecture in neonates in relation to adult spleen. Staining for Thy 1.2 revealed restricted distribution of T cells, mainly in the white pulp regions of adult and neonatal spleens. While Thy1.2 has been reported to be a Pan-T cell marker, several other cell types including HSC, mesenchymal stem cells and fibroblastic cells are also known to express this marker (Garg et al., 2013; Nagasawa et al., 2011; Dominici et al., 2006; Spangrude et al., 1988). These cells are rare however, and it was not possible to distinguish them using immunohistochemical staining of frozen sections. More specific methods of cell identification will be needed to test for the presence of these cell types. Unfortunately, staining for CD140a/b and CD51 on spleen sections was unsuccessful despite multiple attempts made. The antibodies used were of APA5 clone from Biolegend (San Diego, CA, USA) which are probably not capable of detecting markers following fixation of tissue.

\subsubsection{Optimisation of staining for delineation of HSC in spleens}

While Sca-1 and c-Kit, along with lineage markers have been routinely used in flow cytometry to delineate BM HSC, a report by Morita and colleagues (2011) has now confirmed that BM HSC are phenotypically similar to splenic HSC. Therefore, antibodies to Sca-1 and c-Kit were used initially to delineate splenic HSC on sections, along with the F4/80 marker of myeloid cells to delineate red pulp through detection of red pulp macrophages. Adult spleen sections stained with antibody for Sca-1, c-Kit and F4/80 showed minimum staining for $\mathrm{Sca}-1^{+} \mathrm{c}-\mathrm{Kit}^{+}$cells with $\mathrm{Sca}-1^{+}$cells reflective of activated lymphocytes present in white pulp, but very few c-Kit ${ }^{+}$cells overall (Figure 5.3C). This is not unexpected since adult murine spleen is known to harbour very low levels of Sca- $1^{+} \mathrm{c}-\mathrm{Kit}^{+} \mathrm{HSC}$ under steady-state or normal physiological conditions (Dor et al., 2006; Wolber et al., 2002). HSC staining was also tested on neonatal spleen sections (Figure 5.3A). Extensive distribution of ${\mathrm{c}-\mathrm{Kit}^{+}}^{+}$cells was detected in the red pulp of neonatal spleen, with many of these cells expressing Sca1. This suggested the presence of HSC in the red pulp of neonatal spleen. Small numbers of c-Kit ${ }^{+}$cells were also found in the white pulp, but these could reflect dendritic cells, since some dendritic cell subsets are known to express c-Kit ${ }^{+}$(Pulendran et al., 1997) (Figure 5.3A). This confirmed that the antibody for c-Kit cell surface marker was working. Co-staining of Sca- ${ }^{+} \mathrm{c}-\mathrm{Kit}^{+}$cells was confirmed by high power microscopy, although a distinct 
Figure 5.3 Staining for HSC in spleen. Acetone-fixed frozen sections were stained with specific fluorochrome-conjugated antibodies for Sca-1 (blue), c-Kit (red), and F4/80 (green). Cells were localised in relation to red pulp (RP) and white pulp (WP) using F4/80 staining of myeloid cells in RP. Representative images are shown for: (A) C57BL/6J neonatal spleen at low magnification (scale bar: 250 $\mu \mathrm{m}$ ). (B) C57BL/6J neonatal spleen at high magnification (scale bar: 50 $\mu \mathrm{m}$ ). (C) C57BL/6J adult spleen (scale bar: $250 \mu \mathrm{m}$ ). Images representative of 2 mice are shown. 
A

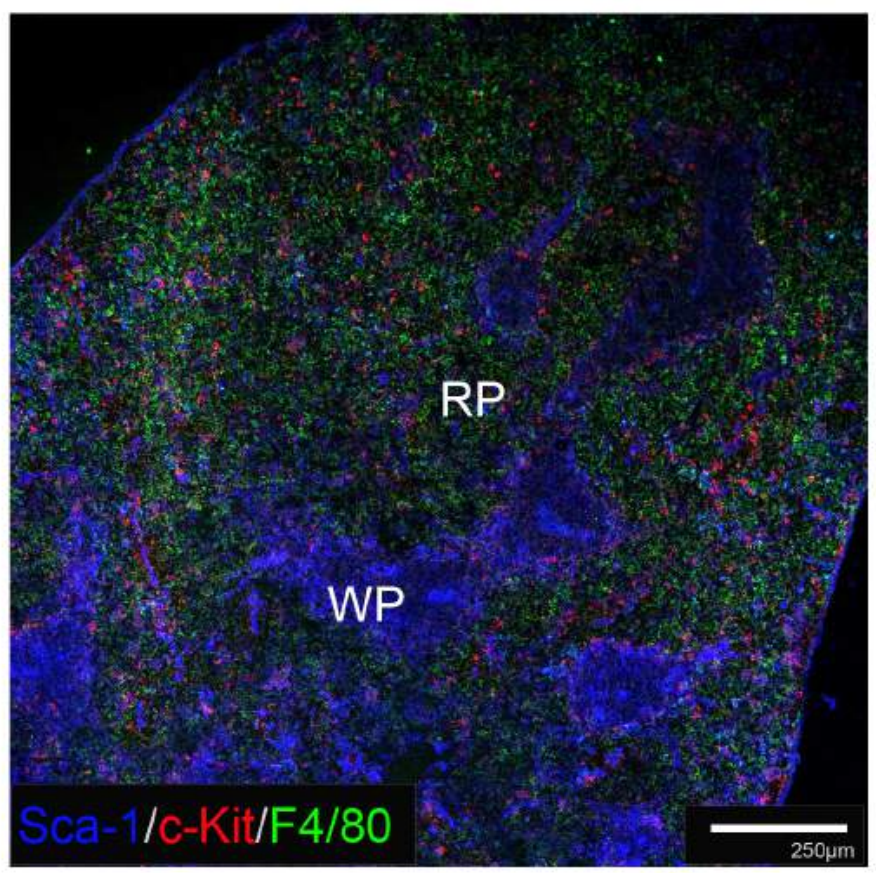

B

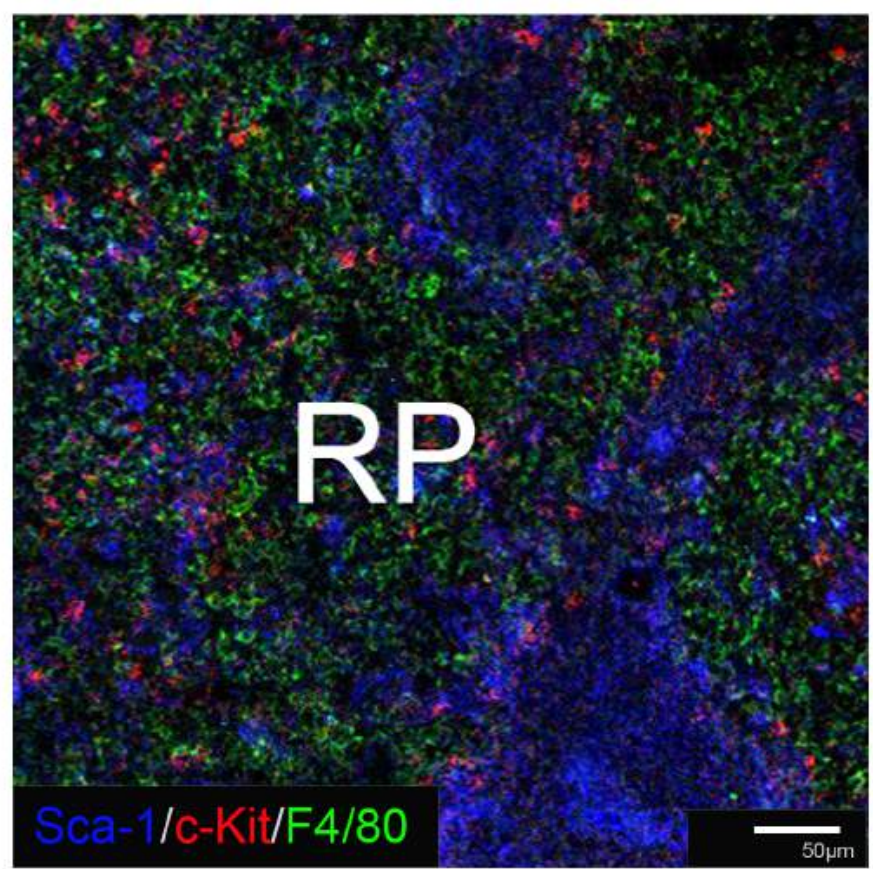




\section{C}

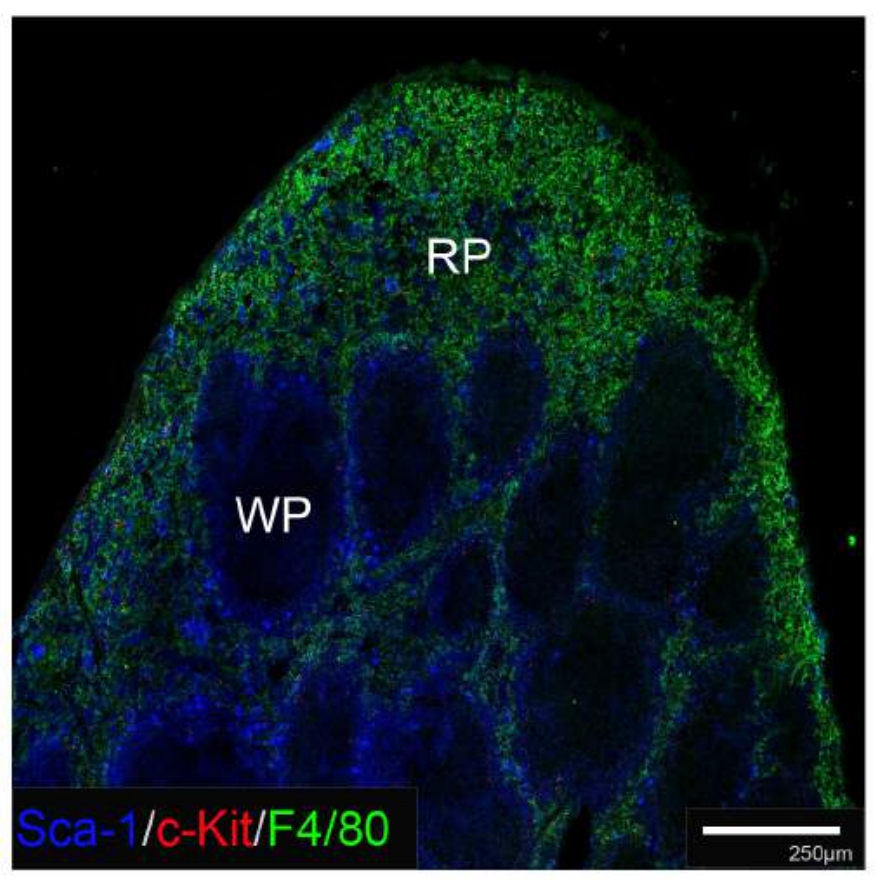


population of $\mathrm{c}-\mathrm{Kit}^{+}$cells was also detected (Figure 5.3B). Flow cytometry confirmed the presence of $\mathrm{Lin}^{-} \mathrm{Sca}-1^{+} \mathrm{c}-\mathrm{Kit}^{+}$cells in neonatal spleen, although $\mathrm{Lin}^{-} \mathrm{c}-\mathrm{Kit}^{+}$, or $\mathrm{Lin}^{-}$ Sca- $1^{+} \mathrm{c}-\mathrm{Kit}^{+}$cells, were not visibly present in normal adult spleen using immunofluorescent staining of spleen sections (Table 5.4; Figure 5.3C and Figure 5.7).

One consideration with section staining is that rare cells may not be detectable due to the bluntness of the technique and the fact that only a slice of spleen can be stained for study. To increase the possibility of detecting HSC in spleen, mobilisation of HSC from BM into blood and spleen was induced by treating mice with Flt3L. This factor was previously shown to expand and mobilise hematopoietic progenitors in BM and spleen when administered to mice (Robinson et al., 2000; Brasel et al., 1996). In this study, mice were given an inoculum of B16-Flt3L melanoma cells which secrete Flt3L (Mora et al., 2003). After 7 days mice were sacrificed for analysis of HSC present in spleen. Two staining protocols were used to detect HSC in spleen. Staining for detection of $\mathrm{Lin}^{-} \mathrm{Sca}-\mathrm{1}^{+} \mathrm{c}-\mathrm{Kit}^{+}$cells reflects the total but heterogeneous population of HSC (Ogawa et al., 1991; Spangrude et al., 1988). Staining for detection of Lin ${ }^{-}$ $\mathrm{CD} 150^{+} \mathrm{CD} 41^{-} \mathrm{CD} 48^{-}$cells is an alternative procedure which is more specific for primitive or long-term HSC, but which also detects a heterogeneous population (Kiel et al., 2005).

Small numbers of both subsets of HSC could be detected in treated and untreated mice (Figure 5.4). In control mice, the number of HSC detected by the two stainings was approximately the same (Tables 5.1 and 5.2). However, in mobilised mice, the number of $\mathrm{Lin}^{-} \mathrm{Sca}-1^{+} \mathrm{c}-\mathrm{Kit}^{+}$HSC increased by $\sim 8$-fold, the number of $\mathrm{Lin}^{-}$ $\mathrm{CD} 150^{+} \mathrm{CD} 41^{-} \mathrm{CD} 48^{-} \mathrm{HSC}$ decreased by $\sim 10$-fold (Tables 5.1 and 5.2; Figures 5.4). An explanation for these disparate results could lie in the different cell types detected by the different staining protocols used. Primitive LT-HSC were more enriched amongst the $\mathrm{Lin}^{-} \mathrm{CD} 150^{+} \mathrm{CD} 41^{-} \mathrm{CD} 48^{-}$compartment than the $\mathrm{Lin}^{-} \mathrm{Sca}-1^{+} \mathrm{c}-\mathrm{Kit}^{+}$subset, such that mobilisation of hematopoietic stem/progenitors, rather than primitive long-term reconstituting HSC, would occur into spleens of Flt3L treated mice. Section staining of spleens from mobilised mice using antibodies to Sca-1 and c-Kit confirmed co-staining of these two markers on some spleen cells in mobilised mouse spleen although not in control mice (Figure 5.5A). Lineage staining in Figure 5.5B confirmed that the c-Kit expressing cells did not express lineage markers also consistent with the hypothesis that HSC have localised into spleen on mobilisation. 
Table 5.1 Impact of Flt3L treatment on HSC numbers in spleen

\begin{tabular}{|c|c|c|c|}
\hline Mice & Cell subset $t$ & $\begin{array}{c}\% \text { cells } \\
\text { amongst } \\
\text { Lin }^{-} \text {spleen }\end{array}$ & $\begin{array}{l}\text { Absolute } \\
\text { cell number }\end{array}$ \\
\hline $\begin{array}{c}\text { Control } \\
\text { C57BL/6J }\end{array}$ & $\mathrm{HSC}\left(\mathrm{Lin}^{-} \mathrm{Sca}-1^{+} \mathrm{c}-\mathrm{Kit}^{+}\right)$ & 1.38 & 4140 \\
\hline $\begin{array}{l}\text { Flt3L-treated } \\
\text { C57BL/6J }\end{array}$ & $\mathrm{HSC}\left(\mathrm{Lin}^{-} \mathrm{Sca}-1^{+} \mathrm{c}-\mathrm{Kit}^{+}\right)$ & 4.63 & 32410 \\
\hline
\end{tabular}

$\dagger$ Adult mice were given B16-Flt3L expressing cells subcutaneously at 7 days prior to isolation of spleen.

t Lin splenocytes were prepared and stained with antibodies to identify HSC through gating to detect Lin $^{-}$cells expressing Sca-1 and c-Kit (Figure 5.4A). Data reflect one experiment. 
Table 5.2 Impact of Flt3L treatment on numbers of primitive HSC in spleen

\begin{tabular}{|c|c|c|c|}
\hline Mice & Cell subset $\ddagger$ & $\begin{array}{c}\% \text { cells } \\
\text { amongst } \\
\text { Lin }^{-} \text {spleen }\end{array}$ & $\begin{array}{c}\text { Absolute } \\
\text { cell number }\end{array}$ \\
\hline $\begin{array}{c}\text { Control } \\
\text { C57BL/6J }\end{array}$ & HSC $\left(\mathrm{Lin}^{-} \mathrm{CD} 150^{+} \mathrm{CD}^{-} 1^{-} \mathrm{CD}^{-}\right)$ & 0.96 & 2880 \\
\hline $\begin{array}{c}\text { Flt3L-treated } \\
\mathrm{C} 57 \mathrm{BL} / 6 \mathrm{~J}^{\dagger}\end{array}$ & $\mathrm{HSC}\left(\mathrm{Lin}^{-} \mathrm{CD} 150^{+} \mathrm{CD}^{-} 1^{-} \mathrm{CD}^{-} 8^{-}\right)$ & 0.034 & 238 \\
\hline
\end{tabular}

${ }^{\dagger}$ Adult mice were given B16-Flt3L expressing cells subcutaneously at 7 days prior to isolation of spleen.

+ Lin ${ }^{-}$splenocytes were prepared and stained with antibodies to identify HSC through gating to detect Lin $^{-}$cells expressing Sca-1 and c-Kit. LT-HSC were then delineated through differential expression of CD150 and Flt3, followed by staining to ensure cells did not express CD41 and CD48 (Figure 5.4A).

Data reflect a single experiment. 
Table 5.4 Changes in HSC numbers in spleen during ontogeny

\begin{tabular}{|c|c|c|c|}
\hline $\begin{array}{l}\mathrm{C} 57 \mathrm{BL} / 6 \mathrm{~J} \\
\text { mice }\end{array}$ & Cell subset $\div$ & $\begin{array}{c}\% \text { cells } \\
\text { amongst } \\
\text { Lin }^{-} \text {spleen } \\
\end{array}$ & $\begin{array}{l}\text { Absolute } \\
\text { cell number }\end{array}$ \\
\hline $\begin{array}{l}\text { Pregnant } \\
\text { adult } \\
(\mathrm{E} 18.5)\end{array}$ & $\begin{array}{c}\mathrm{HSC} \\
\left(\mathrm{Lin}^{-} \mathrm{Sca}^{+} \mathrm{1}^{+} \mathrm{c}-\mathrm{Kit}^{+} \mathrm{CD} 150^{+} \mathrm{Flt3}^{-}\right. \\
\left.\mathrm{CD}^{-} 1^{-} \mathrm{CD} 48^{-}\right)\end{array}$ & 0.123 & $4.06 \times 10^{4}$ \\
\hline $\begin{array}{l}\text { Neonatal } \\
\text { (6 days) }\end{array}$ & $\begin{array}{c}\mathrm{HSC} \\
\left(\mathrm{Lin}^{-} \mathrm{Sca}-1^{+} \mathrm{c}-\mathrm{Kit}^{+} \mathrm{CD} 150^{+} \mathrm{Flt3}^{-}\right. \\
\left.\mathrm{CD}^{-} 1^{-} \mathrm{CD} 48^{-}\right)\end{array}$ & 0.244 & $7.32 \times 10^{3}$ \\
\hline $\begin{array}{c}\text { Adult (4-6 } \\
\text { weeks) }\end{array}$ & $\begin{array}{c}\mathrm{HSC} \\
\left(\mathrm{Lin}^{-} \mathrm{Sca}-1^{+} \mathrm{c}-\mathrm{Kit}^{+} \mathrm{CD} 150^{+} \mathrm{Flt3}^{-}\right. \\
\left.\mathrm{CD} 41^{-} \mathrm{CD} 48^{-}\right)\end{array}$ & 0.014 & $4.09 \times 10^{3}$ \\
\hline
\end{tabular}

+ Lin ${ }^{-}$splenocytes were prepared and stained with antibodies to identify HSC through gating to detect Lin ${ }^{-}$cells expressing Sca-1 and c-Kit, followed by differential expression of CD150 and Flt3, and absence of expression of CD41 and CD48 (Kiel et al., 2005) (Figure 5.7). Data reflect one experiment. 
Figure 5.4 Flow cytometric detection of $\mathrm{Lin}^{-} \mathrm{Sca}-1^{+} \mathrm{c}-\mathrm{Kit}^{+}$and $\mathrm{Lin}^{-} \mathrm{CD} 150^{+} \mathrm{CD}^{-} \mathrm{CD}^{-} \mathrm{C8}^{-} \mathrm{HSC}$ in spleens of Flt3L mobilised mice. Spleen cells from B16Flt3L-treated C57BL/6J adult spleen (a) and untreated controls (b) were prepared for antibody staining by mechanical dissociation, filtering single cells to remove stroma and lysis of red blood cells. Lineage depletion then employed the magnetic-activated cell separation procedure to obtain a population of cells enriched for hematopoietic progenitors. The resultant cell suspension was labelled with antibodies specific for lineage (CD11c, CD11b, MHC-II, Gr-1, CD19, CD3, NK1.1 and Ter119) markers, Sca-1, c-Kit, Flt3, CD150, CD41 and CD48 to detect the (A) $\mathrm{Lin}^{-} \mathrm{Sca}-1^{+} \mathrm{c}-\mathrm{Kit}^{+}$(LSK) and $\mathrm{Lin}^{-} \mathrm{CD} 150^{+} \mathrm{CD} 41^{-} \mathrm{CD} 48^{-} \mathrm{HSC}$ fractions. (B) Extensive analysis on LT-HSC (Lin

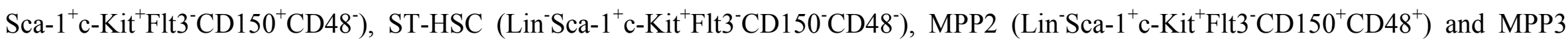
$\left(\right.$ Lin $\left.{ }^{-} \mathrm{Sca}-1^{+} \mathrm{c}-\mathrm{Kit}^{+} \mathrm{Flt} 3^{-} \mathrm{CD} 150^{-} \mathrm{CD} 48^{+}\right)$fractions was also made. 
A Lin-Sca- $1^{+} \mathrm{C}-\mathrm{Kit}^{+}$
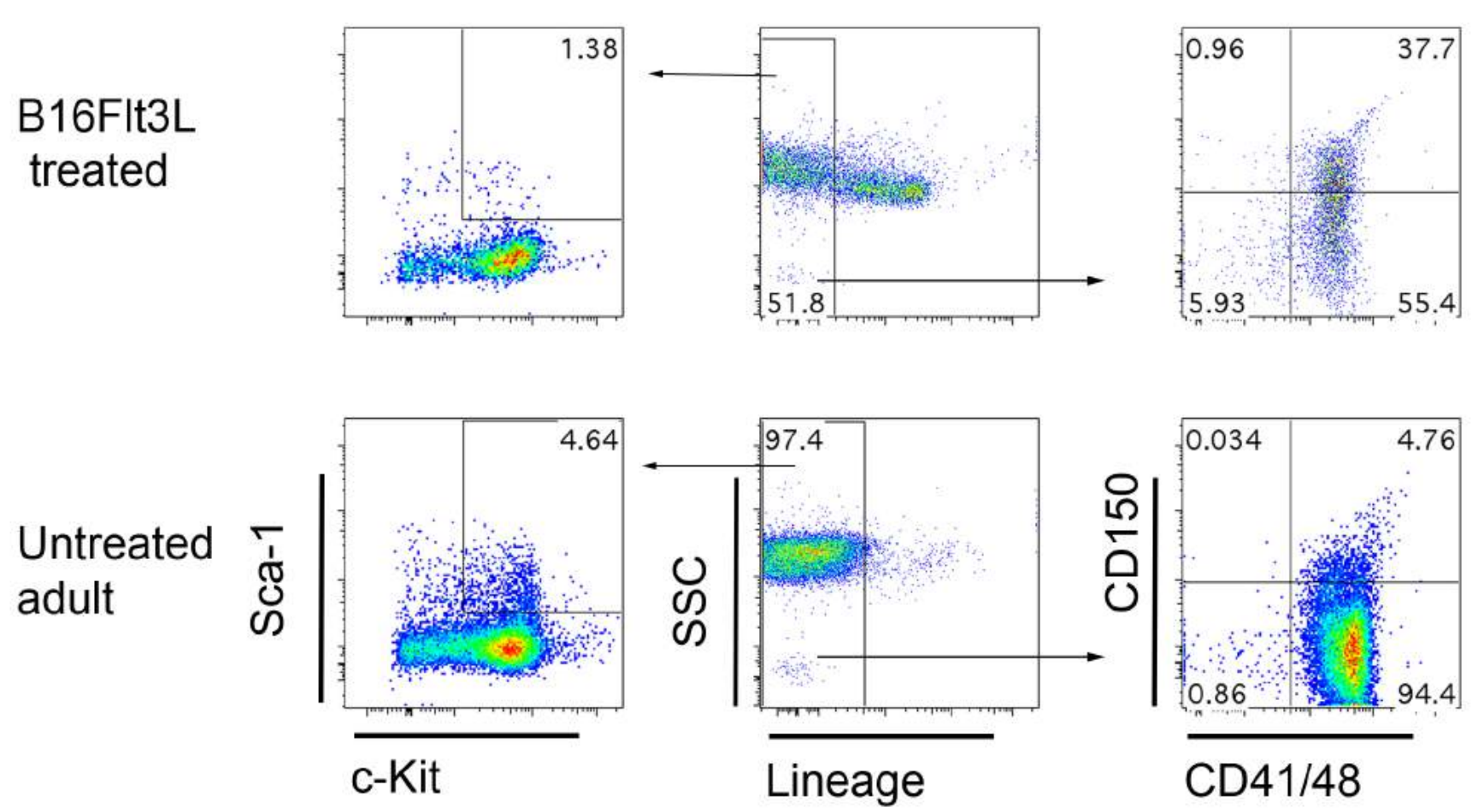

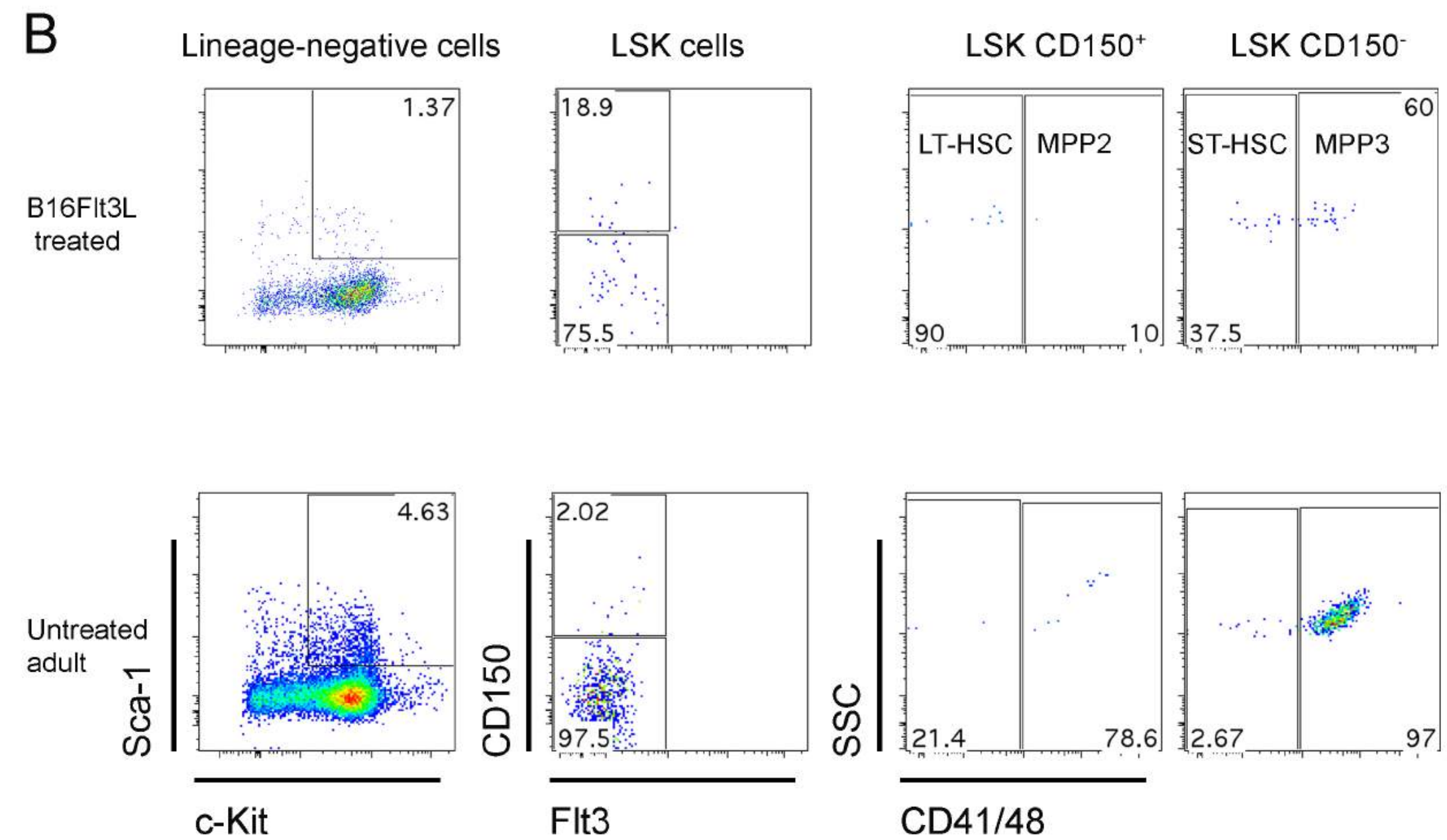
Figure 5.5 Identification of Sca-1 ${ }^{+} \mathbf{c}-\mathrm{Kit}^{+} \mathrm{HSC}$ in mobilised adult spleen. Acetone-fixed frozen sections of spleens collected from Flt3Ltreated mice were stained with specific fluorochrome-conjugated antibodies to detect HSC. Representative images are shown for: (A) Sca- $1^{+}$ and $\mathrm{c}-\mathrm{Kit}^{+}$staining showing some costaining (pink) (scale bar: $\left.50 \mu \mathrm{m}\right),(\mathrm{B})$ lineage ${ }^{+}$and $\mathrm{c}-\mathrm{Kit}^{+}$staining showing no costaining cells (scale bar: $25 \mu \mathrm{m})$. Results are representative of two animals studied. 
A

B

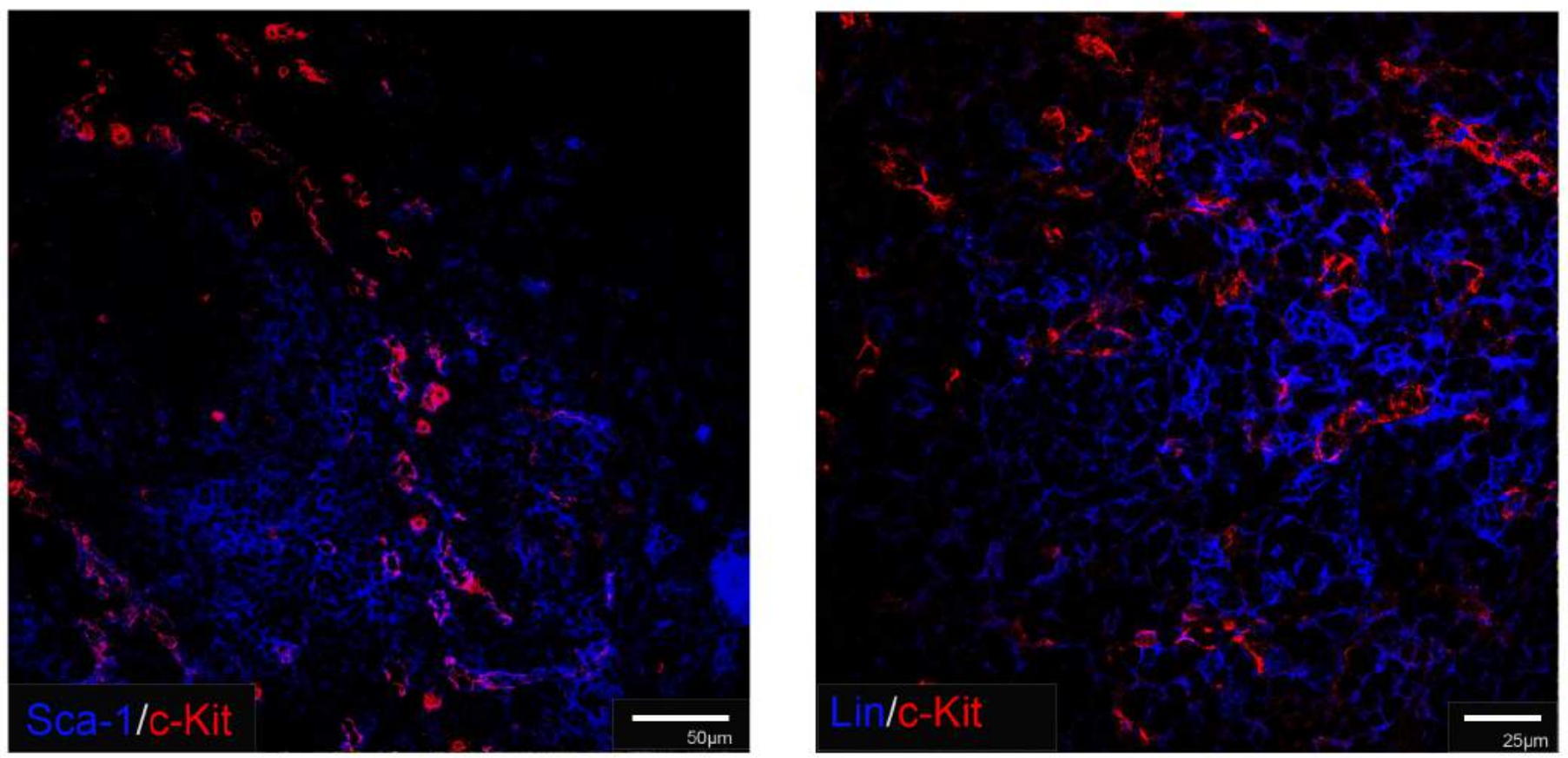




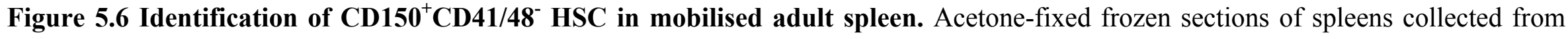
Flt3L-treated mice, and control C57BL/6J mice, for staining with fluorochrome-conjugated antibodies specific for CD150 (blue), CD41 (red) and CD48 (red) in order to detect HSC delineated as CD150 CD41/48- cells (blue staining). Representative images of 2 animals are shown for: (A) C57BL/6J adult, and (B) Flt3L-treated C57BL/6J adult spleen. (scale bar: $100 \mu \mathrm{m}$ ). 
A

B
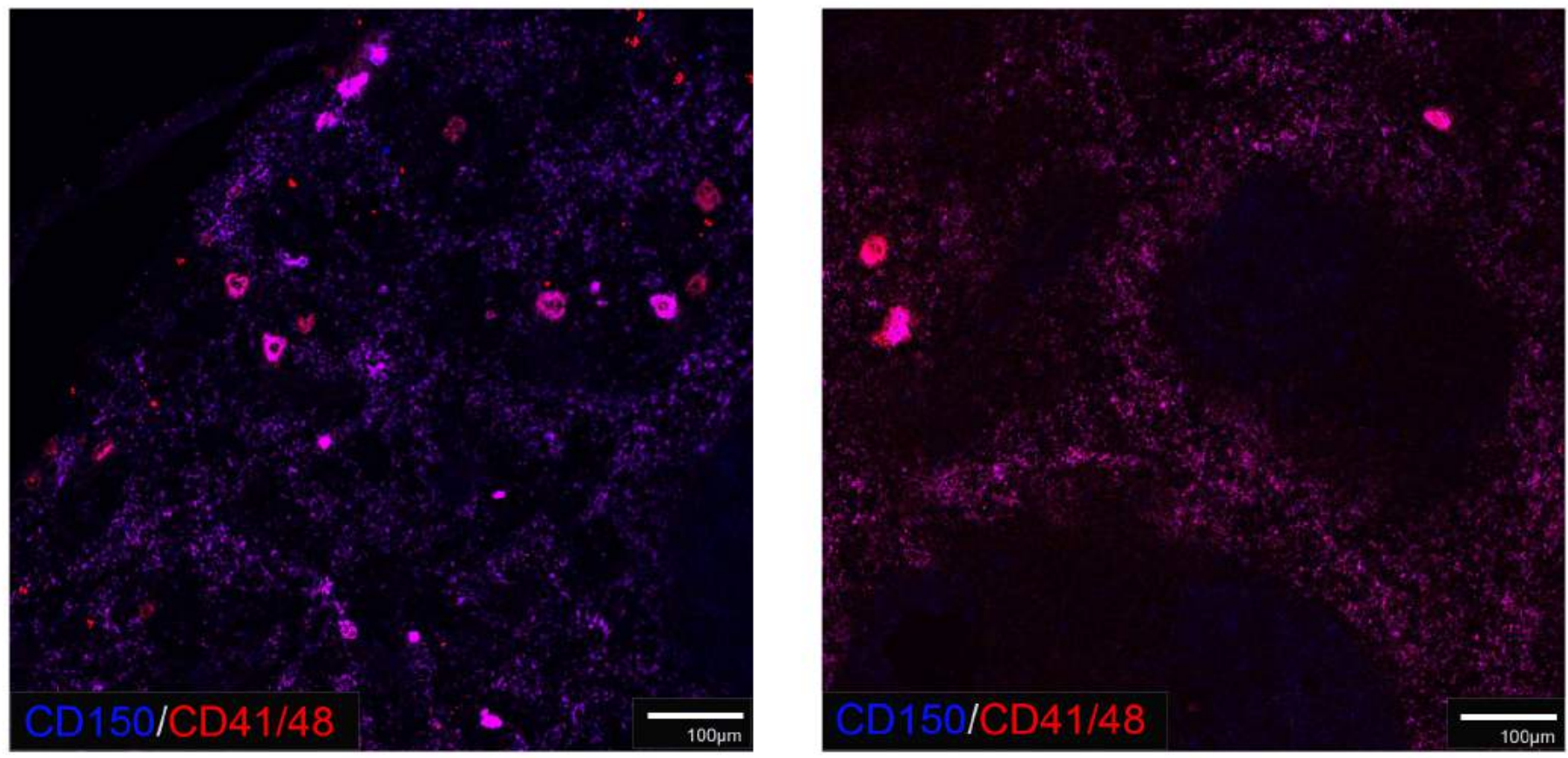


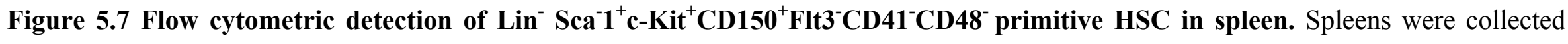
from C57BL/6J mice, either normal adults, neonatals or pregnant adults, and cells mechanically separated, filtered to obtain a stroma-free single cell suspension and exposed to red blood cell lysis. Cells were then subjected to a magnetic-activated cell separation procedure to deplete lineage cells which was then labelled with antibodies specific for lineage (CD11c, CD11b, MHC-II, Gr-1, CD19, CD3, NK1.1 and Ter119) markers, Sca-1, c-Kit, CD150, Flt3, CD41 and CD48 to detect primitive (or longterm reconstituting) HSC as a Lin ${ }^{-S c a}{ }^{-}{ }^{+}{ }^{-}-$

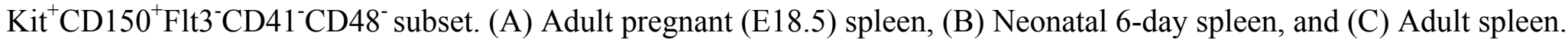




\section{Pregnant (E18.5)}

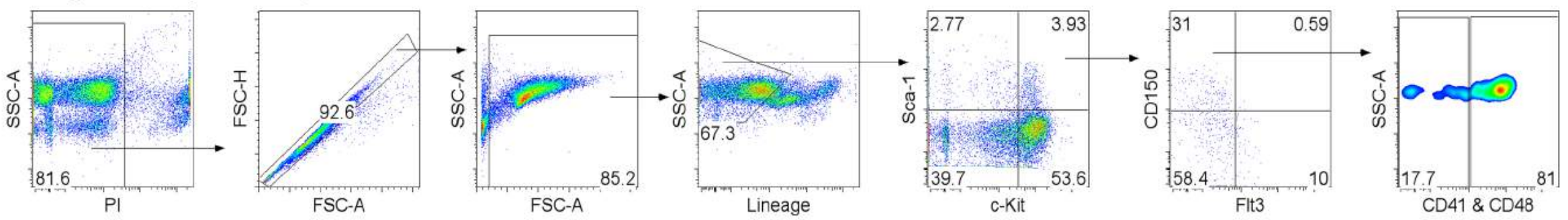

Neonatal
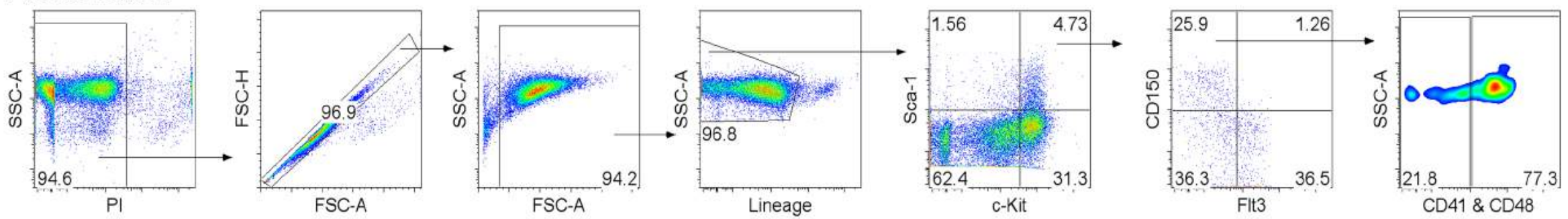

\section{Adult}
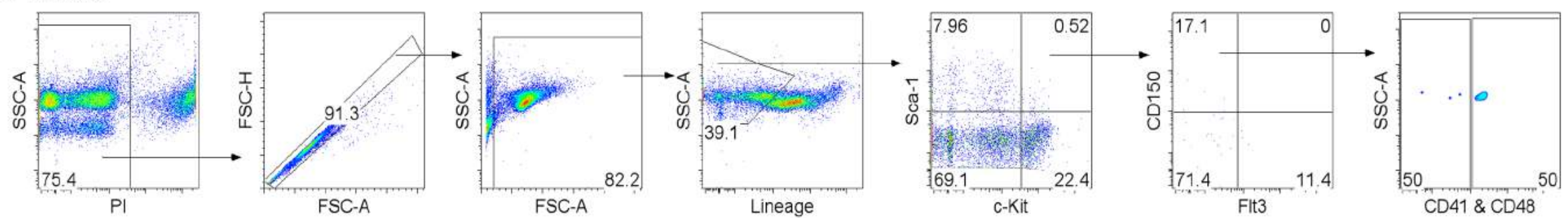
In order to determine the types of hematopoietic stem/progenitors which were increased within the $\mathrm{Lin}{ }^{-} \mathrm{Sca}-1^{+} \mathrm{c}-\mathrm{Kit}^{+}$subset in Flt3L-treated mice, a comprehensive analysis of defined progenitors including LT-HSC, ST-HSC, MPP2 and MPP3 cell subsets within the $\mathrm{Lin}{ }^{-} \mathrm{Sca}-1^{+} \mathrm{c}-\mathrm{Kit}^{+}$subset was performed in treated and untreated mice (Table 5.3; Figure 5.4B). Antibody staining to delineate ST-HSC and subsets amongst MPP have been defined previously (Pietras et al., 2015; Oguro et al., 2013). ST-HSC differs from their LT-HSC counterpart by having a short-term reconstituting capability, while MPP is known to have limited self-renewing ability. MPP are currently described as MPP2, MPP3 and MPP4 based on phenotypic and functional characterisation (Pietras et al., 2015; Oguro et al., 2013). MPP2 and MPP3 are known to have myeloid-biased outputs whereas MPP4 is largely lymphoid-biased (Pietras et al., 2015; Oguro et al., 2013). Analysis of Lin ${ }^{-S c a}-1^{+} \mathrm{c}-\mathrm{Kit}^{+}$cells in experimental mice revealed that numbers of LT-HSC and ST-HSC decreased by $\sim 5$-fold and $\sim 1.3$-fold respectively in treated compared with untreated mice. Conversely, the numbers of MPP2 and MPP3 increased $\sim 6$-fold and $\sim 16$-fold in treated over untreated mice (Table 5.3; Figure 5.4B). These results confirmed that Flt3L induced mobilisation of BM progenitors was selectively directed at increasing the number of MPP3 which entered spleen, with smaller increases in MPP2 numbers. In contrast, LT-HSC numbers in spleen decreased while ST-HSC remained the same. These results are very distinctive, and caution on the need to investigate the specific effects of mobilisation on the movement of different stem/progenitor cell types moving out of BM and entering blood and spleen.

Delineation of HSC was also carried out using a second panel of markers including CD150, CD41, CD48 and lineage markers applied to spleen sections. By comparison with spleens of normal adult mice which showed clear evidence of CD150 ${ }^{+} \mathrm{CD} 41 / 48^{-}$cells (Figure 5.6A), Flt3L treated adult spleen failed to reveal any $\mathrm{CD} 150^{+} \mathrm{CD} 41^{-} \mathrm{CD} 48^{-} \mathrm{HSC}$ (Figure 5.6B). Most cells detected in both normal adults and Flt3L treated adult spleens were $\mathrm{CD} 150^{+} \mathrm{CD} 41^{+} / \mathrm{CD} 48^{+}$reflecting mature hematopoietic cells (Figure 5.6). This result is consistent with the flow cytometry data shown in Figure 5.4, which showed lower numbers of $\mathrm{Lin}^{-} \mathrm{CD} 150^{+} \mathrm{CD} 41^{-} \mathrm{CD} 48^{-} \mathrm{HSC}$ in Flt3L treated than normal adult spleens (Table 5.2; Figure 5.4). Since spleens of pregnant (E18.5) mice have been reported to harbour higher numbers of HSC than age-matched controls (Nakada et al., 2014), these animals were compared for the presence of Lin $^{-}$ $\mathrm{CD} 150^{+} \mathrm{CD} 41^{-} \mathrm{CD} 48^{-}$HSC. Sections were stained with antibodies for CD150, CD41, CD48 and lineage markers. This study revealed the presence of rare $\mathrm{CD} 150^{+} \mathrm{CD} 41^{-}$ 
Table 5.3 Impact of FIt3L treatment on numbers of HSC and MPP in spleen

\begin{tabular}{|c|c|c|c|}
\hline Mice & Cell subset $\downarrow$ & $\begin{array}{c}\% \text { cells } \\
\text { amongst } \\
\text { Lin }^{-} \text {spleen }\end{array}$ & $\begin{array}{l}\text { Absolute } \\
\text { cell number }\end{array}$ \\
\hline \multirow{4}{*}{$\begin{array}{l}\text { Control } \\
\text { C57BL/6J }\end{array}$} & $\begin{array}{c}\text { LT-HSC } \\
\left(\text { Lin }^{-} \text {Sca- } 1^{+} \mathrm{c}^{-\mathrm{Kit}^{+}}{ }^{\mathrm{F}} \mathrm{lt} 3^{-\mathrm{CD}} 150^{+} \mathrm{CD} 48^{-}\right) \\
\end{array}$ & 0.23 & 699 \\
\hline & $\begin{array}{c}\text { ST-HSC } \\
\left(\text { Lin }^{-} \text {Sca- } 1^{+} \text {c-Kit }^{+} \text {Flt3 }{ }^{-} \text {CD } 150^{-} \mathrm{CD}^{-}\right)\end{array}$ & 0.40 & 1164 \\
\hline & $\begin{array}{c}\text { MPP2 } \\
\left(\text { Lin }^{-} \text {Sca- } 1^{+} \text {c-Kit }{ }^{+} \text {Flt3 } 3^{-} \mathrm{CD} 150^{+} \mathrm{CD} 48^{+}\right)\end{array}$ & 0.03 & 78 \\
\hline & $\begin{array}{c}\text { MPP3 } \\
\left(\mathrm{Lin}^{-} \mathrm{Sca}-\mathrm{1}^{+} \mathrm{c}-\mathrm{Kit}^{+}{ }^{\mathrm{Flt}} 3^{-\mathrm{CD}} 150^{-} \mathrm{CD} 48^{+}\right)\end{array}$ & 0.62 & 1863 \\
\hline \multirow{4}{*}{$\begin{array}{l}\text { Flt3L-treated } \\
\text { C57BL/6J }\end{array}$} & $\begin{array}{c}\text { LT-HSC } \\
\left(\text { Lin }^{-} \text {Sca- } 1^{+} \mathrm{c}-\mathrm{Kit}^{+}{ }^{+} \text {Flt3-CD } 150^{+} \mathrm{CD} 48^{-}\right)\end{array}$ & 0.02 & 140 \\
\hline & $\begin{array}{c}\text { ST-HSC } \\
\left(\text { Lin }^{-} \text {Sca- } 1^{+} \mathrm{c}^{-K i t}{ }^{+} \text {Flt3 }{ }^{-} \mathrm{CD} 150^{-} \mathrm{CD} 48^{-}\right)\end{array}$ & 0.12 & 840 \\
\hline & $\begin{array}{c}\text { MPP2 } \\
\left(\text { Lin }^{-} \text {Sca- } 1^{+}{ }^{+}-\text {Kit }^{+} \text {Flt3 } 3^{-} \mathrm{CD} 150^{+} \mathrm{CD}_{4} 8^{+}\right)\end{array}$ & 0.07 & 518 \\
\hline & $\begin{array}{c}\text { MPP3 } \\
\left(\text { Lin }^{-} \text {Sca- } 1^{+} \mathrm{c}-\mathrm{Kit}^{+} \mathrm{Flt} 3^{-} \mathrm{CD} 150^{-} \mathrm{CD} 48^{+}\right)\end{array}$ & 4.38 & 30660 \\
\hline
\end{tabular}

${ }^{\dagger}$ Adult mice were given B16-Flt3L expressing cells subcutaneously at 7 days prior to isolation of spleen.

\$ Lin ${ }^{-}$splenocytes were prepared and stained with antibodies to identify HSC through gating to detect Lin $^{-}$cells expressing Sca-1 and c-Kit. LT-HSC were then delineated through differential expression of CD150, Flt3 and CD41/48 (Figure 5.4B). Data reflect a single experiment. 
CD48- HSC present in the red pulp of adult pregnant mouse spleen (Figure 5.8). Pregnant mice therefore provide an alternate model for detection of HSC in spleen over Flt3L mobilisation, which can be used to localise more primitive $\mathrm{CD} 150^{+} \mathrm{CD} 41^{-} \mathrm{CD} 48^{-}$ HSC within the red pulp region (Figure 5.8).

Further flow cytometry also confirmed the presence of rare primitive LT-HSC in spleens of pregnant mice in higher numbers than were detected in either neonatal mice or normal adult control mice. This study involved multicolour staining for detection of the rare primitive $\mathrm{Lin}^{-} \mathrm{Sca}^{-} 1^{+} \mathrm{c}-\mathrm{Kit}^{+} \mathrm{CD} 150^{+} \mathrm{Flt3}^{-} \mathrm{CD} 41^{-} \mathrm{CD} 48^{-} \mathrm{HSC}$ subset described recently (Shin et al., 2014). Initial studies have indicated $\sim 10$-fold increase in the size of this population over normal adult spleen, and $\sim 5$-fold increase in neonatal spleen over adult spleen (Table 5.4; Figure 5.7). While it has been possible to replicate section staining in multiple animals, flow cytometry results are indicative of only one experiment and further replication is needed to confirm the numbers reported here. The fact that the same result can be confirmed, however, using two different staining methods, is important.

\subsubsection{Localisation of HSC within the spleen architecture}

In Figures 5.3 and 5.5, we showed evidence that HSC could be detected amongst dissociated spleen cells of neonatal mice, Flt3L mobilised mice and pregnant mice using antibodies commonly used in flow cytometry. We also showed in Figure 5.7 that primitive HSC could be detected in spleen cell suspensions as a $\operatorname{Lin}^{-} \mathrm{Sca}^{-} 1^{+} \mathrm{c}-$ $\mathrm{Kit}^{+} \mathrm{CD} 150^{+} \mathrm{Flt3}^{-\mathrm{CD}} 41^{-\mathrm{CD}} 48^{-}$subset of cells. It has also been possible to identify HSC in sections of adult normal and pregnant mice (Figures 5.6 and 5.8). In order to localise HSC in spleen in relation to splenic architecture and stromal cell types, a series of section staining experiments were conducted. When a stroma-specific antibody was combined with antibodies that delineate HSC, it was possible to show that HSC localise in the red pulp region of spleen. Antibody to F4/80, which delineates red pulp macrophages, was commonly used to delineate the red pulp region and could be clearly seen in red pulp of spleens of pregnant mice (Figure 5.8). In addition, HSC were found to lie in close proximity with $\mathrm{F} 4 / 80^{+}$red pulp macrophages (Figure 5.8). It is also likely that the subset of $\mathrm{F} 4 / 80^{+}$red pulp macrophage overlaps with the $\mathrm{VCAM} 1^{+}$red pulp macrophages described by Dutta and colleagues (2015), which retain HSC in spleen via VCAM1 (Dutta et al., 2015). The models of neonatal and adult pregnant mice were 
Figure 5.8 HSC are localised in the red pulp of pregnant (E18.5) spleens. Acetone-fixed frozen spleen sections from adult pregnant (E18.5) mice were stained with fluorochrome-conjugated antibodies specific to CD150 (blue), CD41 (red), CD48 (red), Lineage (red), CD3 (green) and F4/80 (yellow). In A) red pulp (RP), T cell zones (T), and B cell follicles (B) are identified. In B) white pulp (WP) and red pulp (RP) are identified. HSC ( Lin $\left.^{-} \mathrm{CD} 150^{+} \mathrm{CD} 41^{-} \mathrm{CD} 48^{-}\right)$are identified as blue cells by white arrows in the RP. Images representative of 3 mice are shown at: (A) lower magnification (scale bar: $250 \mu \mathrm{m}$ ), (B) higher magnification (scale bar: $50 \mu \mathrm{m}$ ). 
A

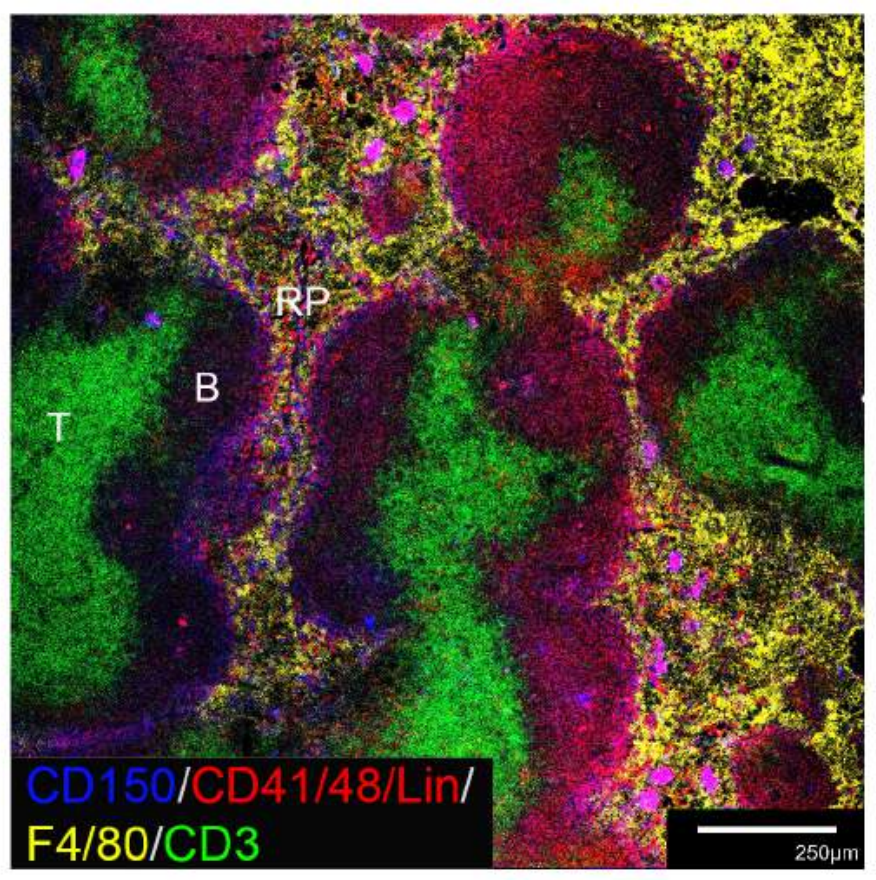

B

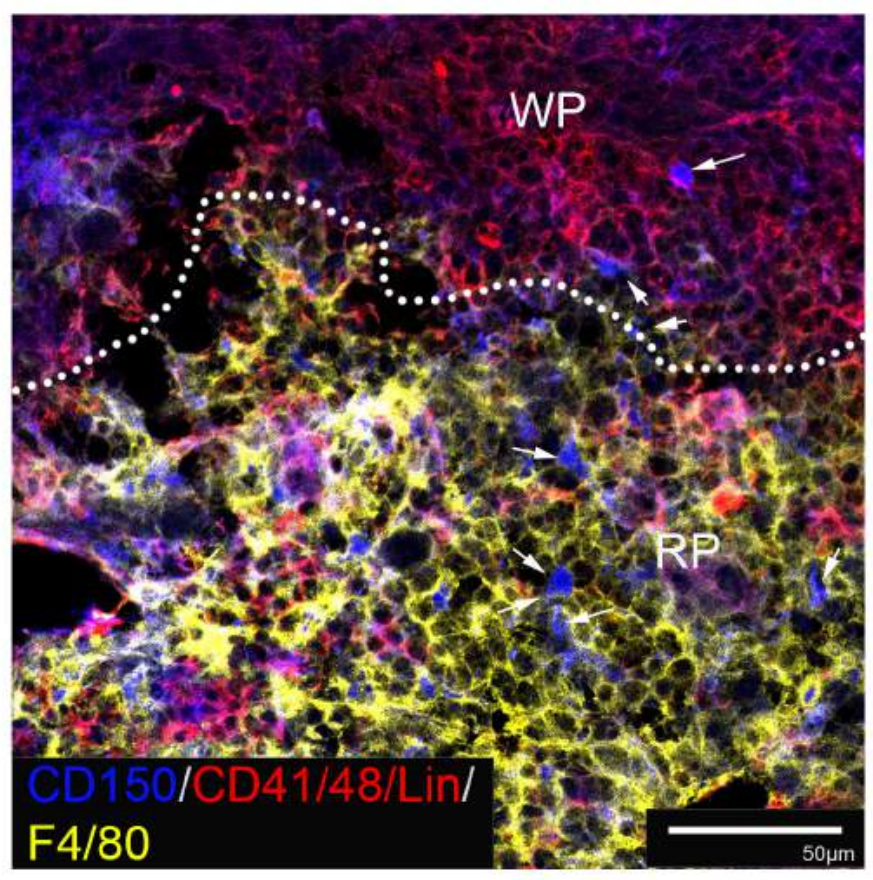


found most useful in these studies since they have the highest number of HSC within spleen.

We next asked whether HSC associate with spleen stromal cell types bearing markers identified in Chapter 4 (Figures 5.1 and 5.2). In a series of experiments, sections of spleen from both neonatal and adult pregnant mice were stained with a cocktail of antibodies to detect $\mathrm{HSC}$ as $\mathrm{Lin}^{-} \mathrm{CD} 150^{+} \mathrm{CD} 41^{-} \mathrm{CD} 48^{-}$cells, along with an antibody specific for different stromal cell types. These included CD31 specific for endothelial cells, CD105 specific for angiogenic vasculature, marginal reticular cells and red pulp fibroblasts, gp38 specific for fibroblastic reticular cells in T cell zones and follicular dendritic cells in the B cell follicles, and Thy1.2 specific for T cells and also mesenchymal stem/progenitor cells. HSC detectable in the red pulp regions of both neonatal and pregnant mouse spleen did not co-localise with $\mathrm{CD} 31^{+}$cells, suggesting no close association of HSC with sinusoidal endothelial cells (Figures 5.9 and 5.10). Antibody to CD105 was used to detect red pulp fibroblasts, marginal reticular cells and angiogenic endothelial cells in neonatal spleens. Cells which stained for this marker had no association with HSC, in line with evidence obtained for CD31 staining cells (Figure 5.11). In further studies, gp $38^{+}$stromal cells were identified in the red pulp region of neonatal but not pregnant mouse spleens (Figure 5.12 and 5.13). In these studies, some but not all HSC in neonatal mice appeared to associate with gp $38^{+}(\%$ association: 32.50 \pm 22.98 ) or Lin $^{+}$cells (Figure 5.12). In contrast, HSC in pregnant spleens appeared to associate with $\mathrm{F} 4 / 80^{+}$myeloid cells or $\mathrm{Lin}^{+}$cells in the red pulp of spleen, in the presence of far fewer gp $38^{+}$cells (Figure 5.13). A final study involved Thy1.2 staining of cells in red pulp of pregnant mouse spleen. This revealed that some HSC were in close alignment with Thy1.2 staining mesenchymal cells (\% association: $26.17 \pm 15.11$ ), as well as F4/80 and Lin staining cells (Figure 5.14). Thy1.2 staining would be consistent with the presence of mesenchymal perisinusoidal cells providing a niche in spleen supportive of HSC as reported by others (Inra et al., 2015). 
Figure 5.9 HSC in the red pulp of neonatal spleen are not associated with sinusoids. Acetone-fixed frozen neonatal spleen sections were stained with fluorochrome-conjugated antibodies specific to CD150 (blue), CD41 (red), CD48 (red), Lineage (red), CD31 (green), and F4/80 (yellow), to delineate red pulp (RP), white pulp (WP) and central arteriole (CA) in A). In B) HSC (arrows: Lin $^{-} \mathrm{CD}^{2} 50^{+} \mathrm{CD}^{\circ}{ }^{\circ} \mathrm{CD} 48^{-}$: blue) were found to be localised independently of sinusoids (CD31 ${ }^{+}$: green) and myeloid cells (F4/80 ${ }^{+}$yellow) in the red pulp region of neonatal spleen. Representative images of 3 mice are shown at: (A) lower magnification (scale bar: $250 \mu \mathrm{m}$ ), (B) higher magnification (scale bar: $50 \mu \mathrm{m})$. 
A

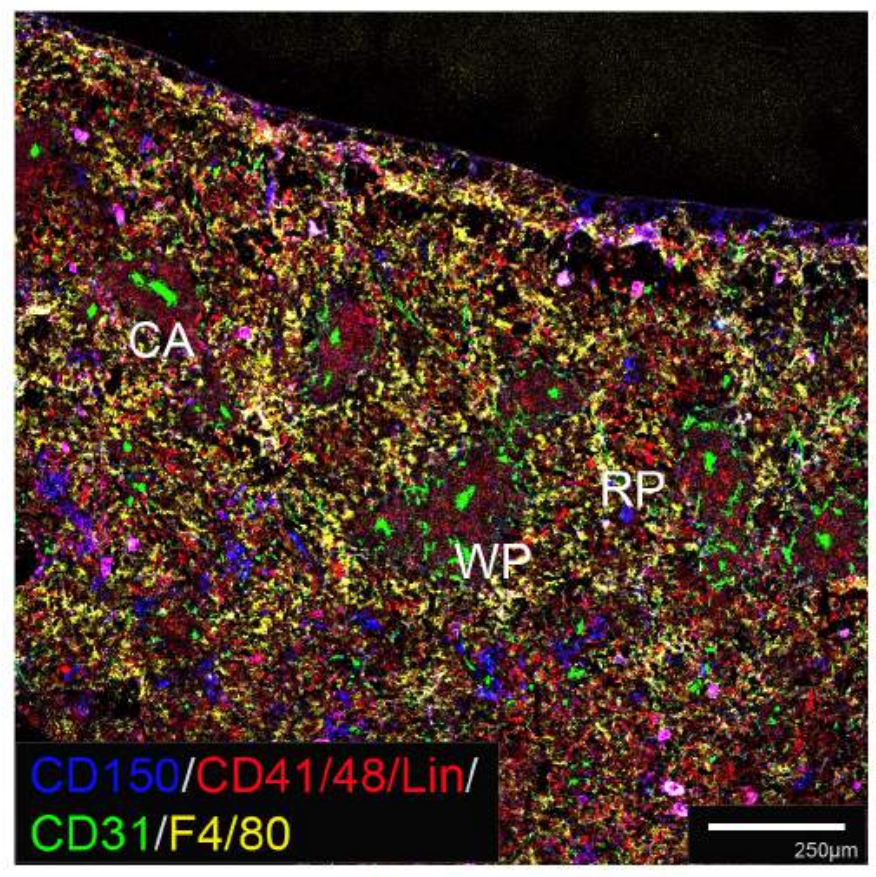

B

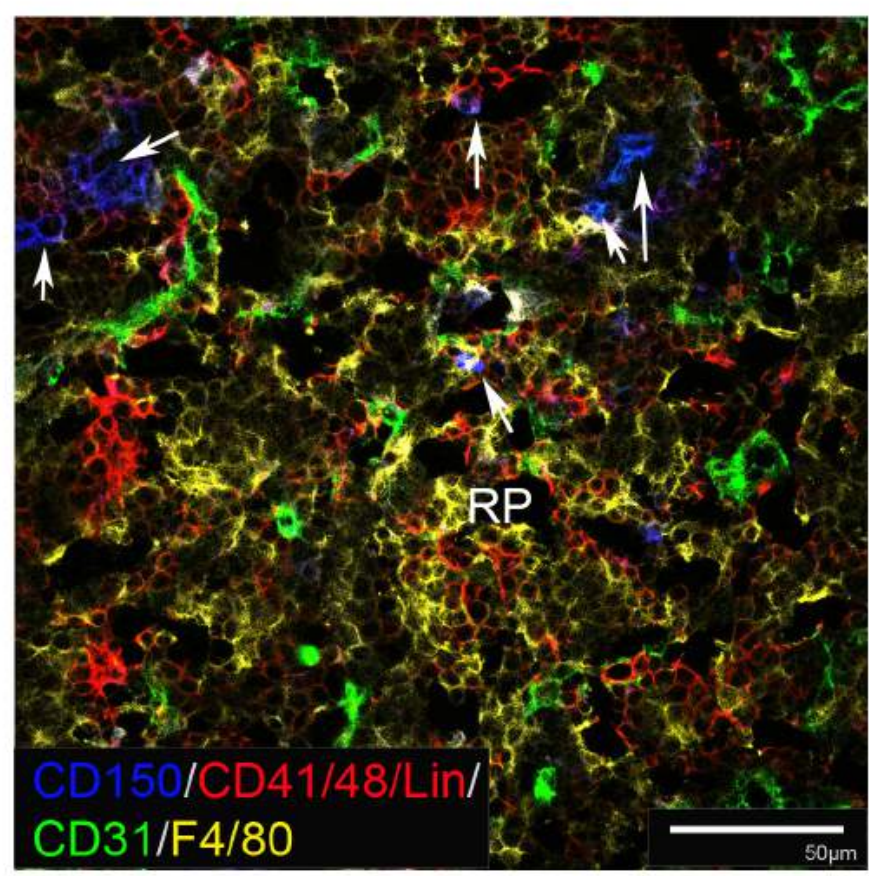


Figure 5.10 Localisation of HSC in relation to sinusoidal endothelial cells in spleens of pregnant (E18.5) mice. Frozen sections of spleen from pregnant (E18.5) mice were fixed with acetone and stained with fluorochrome-conjugated antibodies to CD150 (blue), CD41 (red), CD48 (red), Lineage (red), CD31 (green), and F4/80 (yellow). Images representative of 2 mice are shown. In A) red pulp (RP) and white pulp (WP) regions are delineated (scale bar: $250 \mu \mathrm{m}$ ). In B) HSC (Lin ${ }^{-} \mathrm{CD} 150^{+} \mathrm{CD}^{-} 1^{-} \mathrm{CD} 48^{-}$) were localised in RP but not in association with CD31 staining (green) sinusoidal endothelial cells (scale bar: $50 \mu \mathrm{m}$ ). 
A

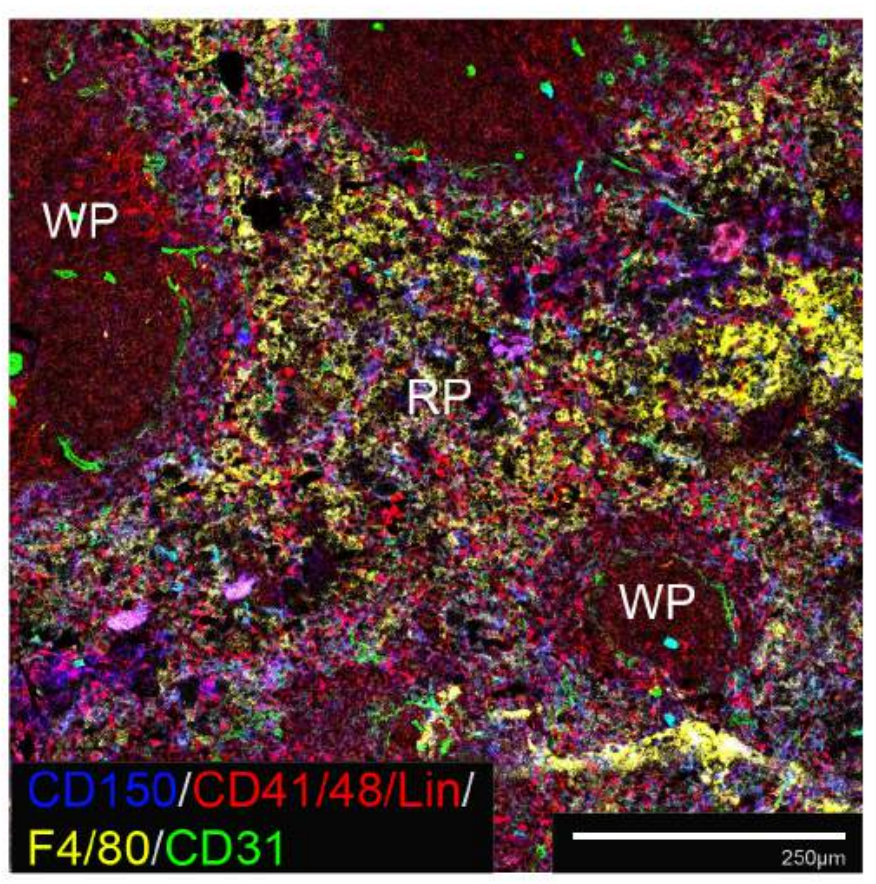

B

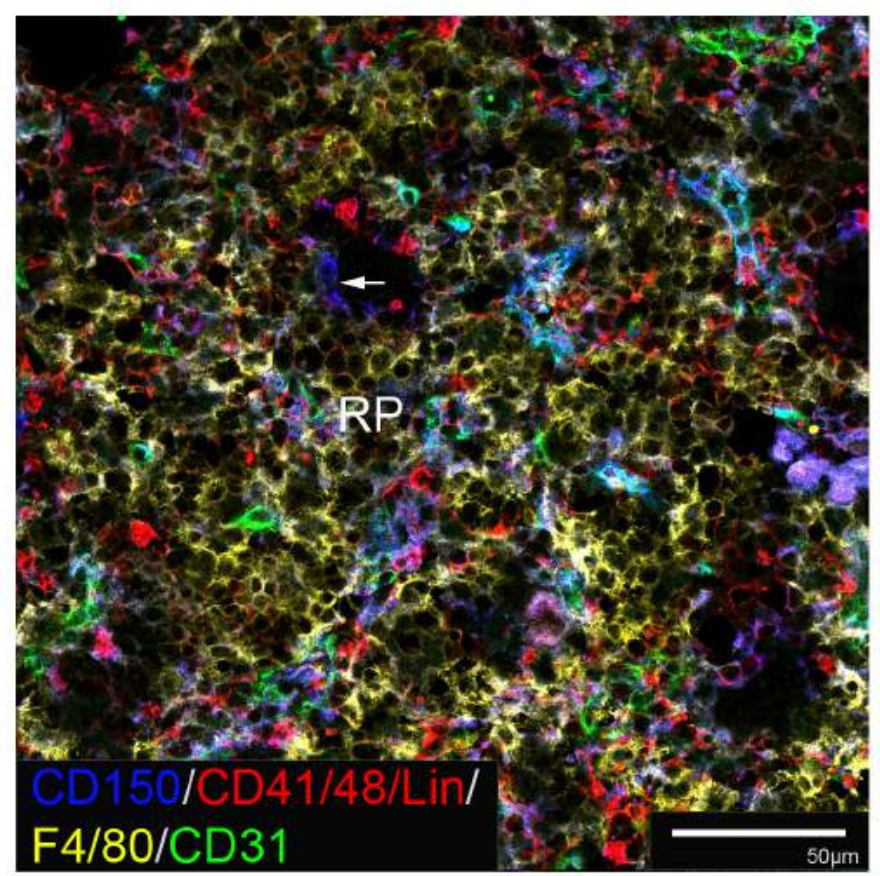


Figure 5.11 HSC in neonatal spleen do not associate with red pulp fibroblasts. Neonatal spleen sections were fixed with acetone and stained with fluorochrome-conjugated antibodies to CD150 (blue), CD41 (red), CD48 (red), Lineage (red), CD105 (green), and F4/80 (yellow). Representative images of 2 mice are shown in: (A) where central arteriole (CA), red pulp (RP), and white pulp (WP) regions were delineated (scale bar: $250 \mu \mathrm{m})$. In (B) HSC ( $\operatorname{Lin}^{-} \mathrm{CD} 150^{+} \mathrm{CD} 41^{-} \mathrm{CD} 48^{-}$: blue) were localised in RP independent of CD105 ${ }^{+}$(green) cells (scale bar: $50 \mu \mathrm{m}$ ). 

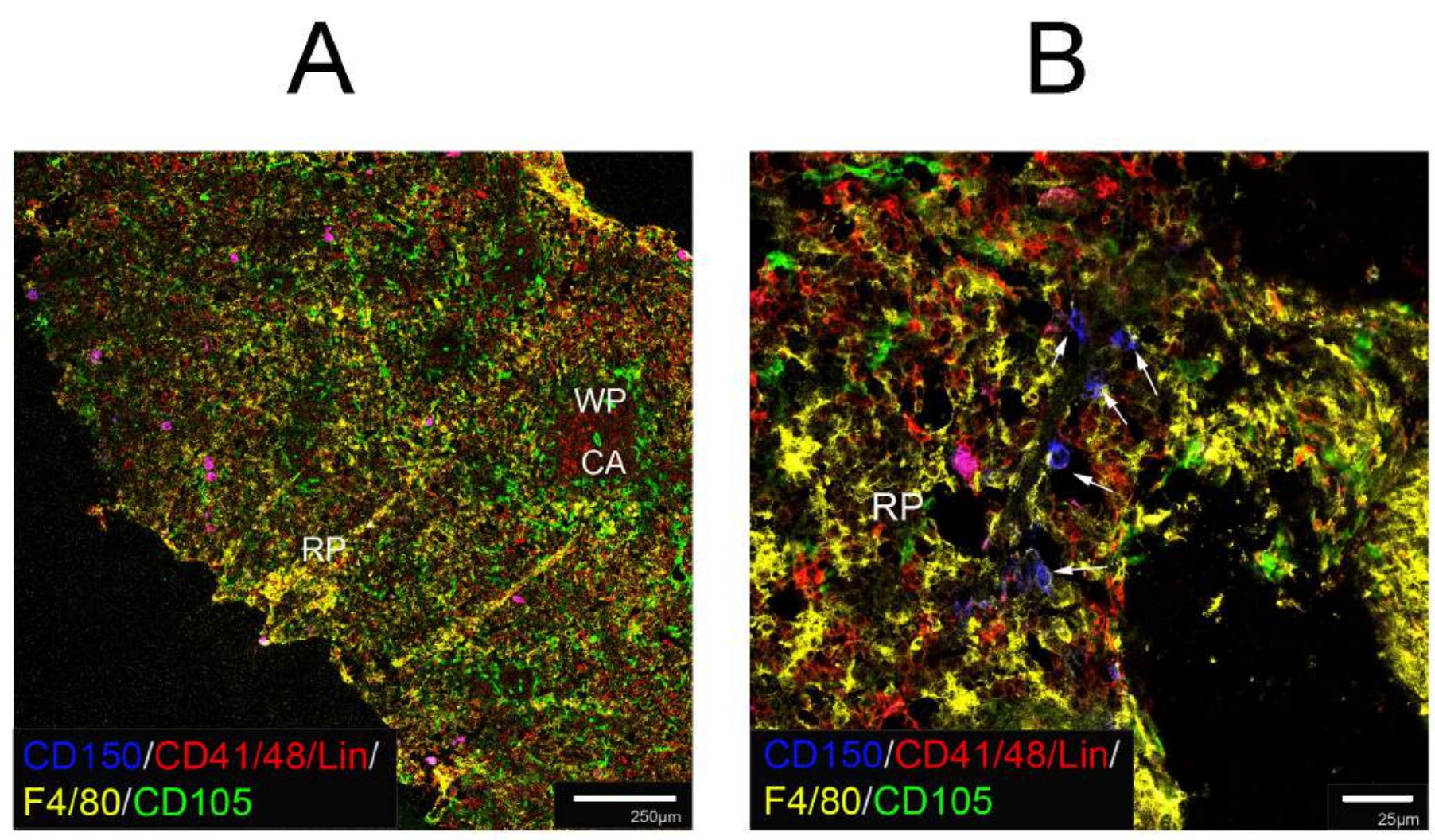
Figure 5.12 Localisation of HSC in relation to gp38-expressing stromal cells in neonatal spleen. Frozen neonatal spleen sections were fixed with acetone and stained with fluorochrome-conjugated antibodies to CD150 (blue), CD41 (red), CD48 (red), Lineage (red), gp38 (green), and F4/80 (yellow). In A) red pulp (RP) and white pulp (WP) regions were delineated (scale bar: $250 \mu \mathrm{m}$. In B) HSC (Lin ${ }^{-}$ $\mathrm{CD} 150^{+} \mathrm{CD} 41^{-} \mathrm{CD} 48^{-}:$blue) were localised in RP, some in close proximity with gp $38^{+}$(green) cells (scale bar: $25 \mu \mathrm{m}$ ). Images representative of 3 mice are shown. 
A

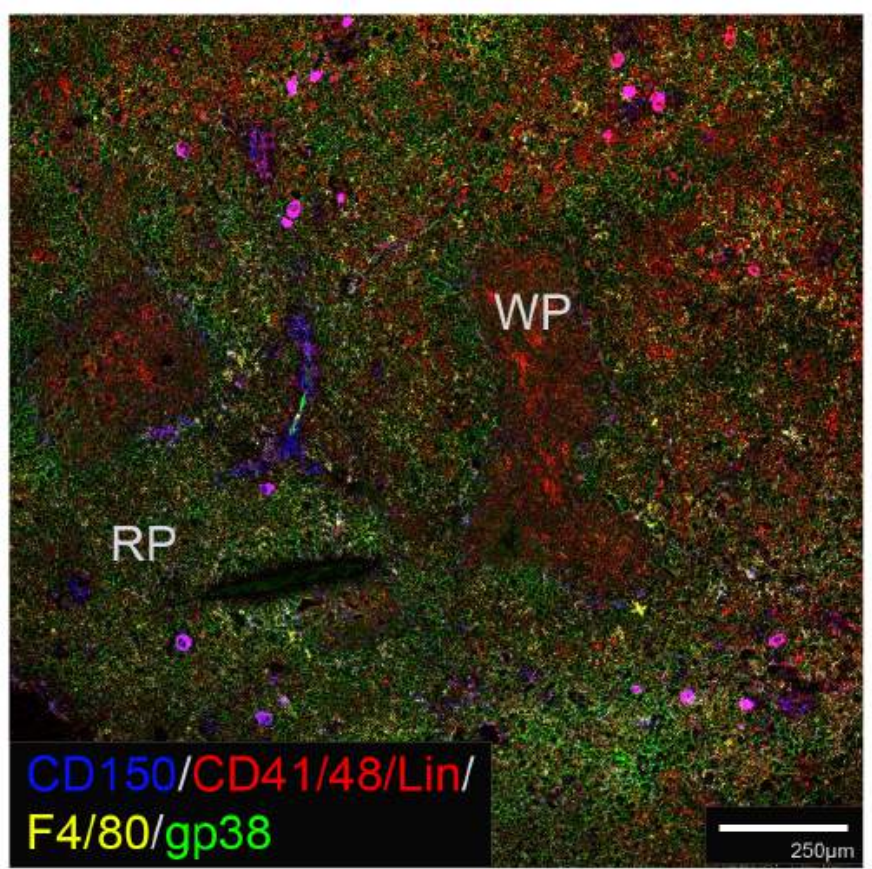

B

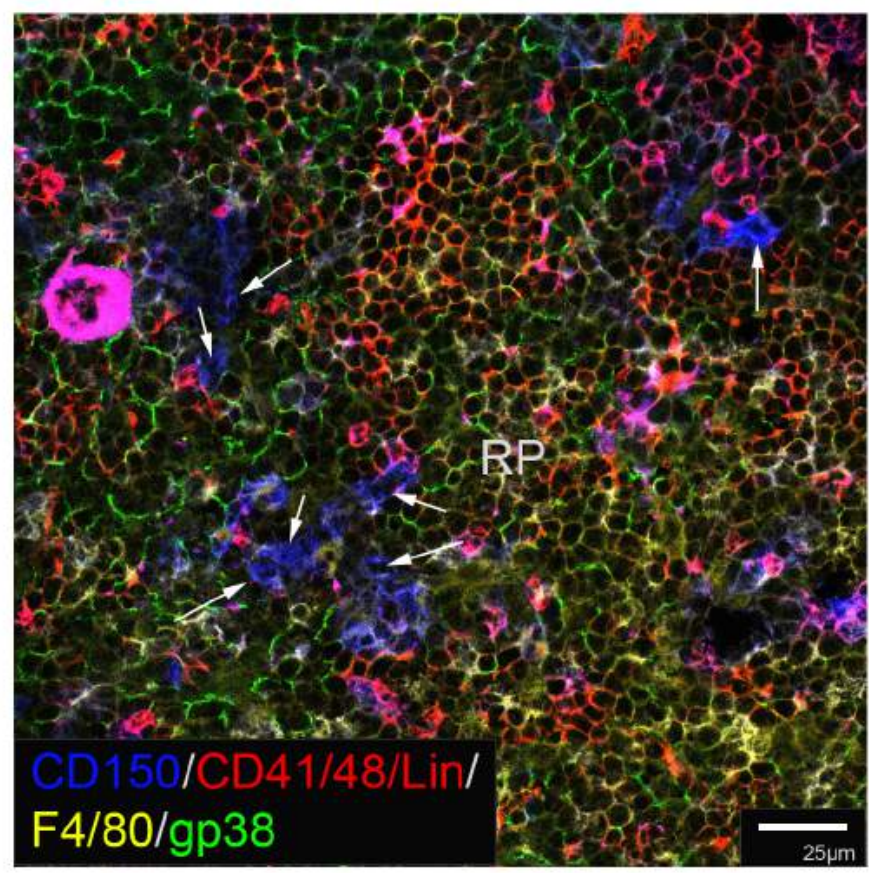


Figure 5.13 Localisation of HSC in relation to gp38-expressing stromal cells in pregnant (E18.5) spleen. Frozen sections from spleens of pregnant (E18.5) mice were fixed with acetone and stained with fluorochrome-conjugated antibodies to CD150 (blue), CD41 (red), CD48 (red), Lineage (red), gp38 (green) and F4/80 (yellow). In A) red pulp (RP) and white pulp (WP) regions are delineated. Gp38 ${ }^{+}$fibroblastic reticular cells (FRC) were localised in the white pulp (scale bar: $250 \mu \mathrm{m})$. In B) HSC (Lin ${ }^{-} \mathrm{CD} 150^{+} \mathrm{CD}^{-} 1^{-} \mathrm{CD}^{-} 8^{-}$: blue) were localised in red pulp in association with $\mathrm{F} 4 / 80^{+}$or Lin $^{+}$cells (scale bar: $25 \mu \mathrm{m}$ ). In C) FRC (green) but not HSC (blue) were localised in white pulp (scale bar: $25 \mu \mathrm{m})$. Images representative of 3 mice are shown. 

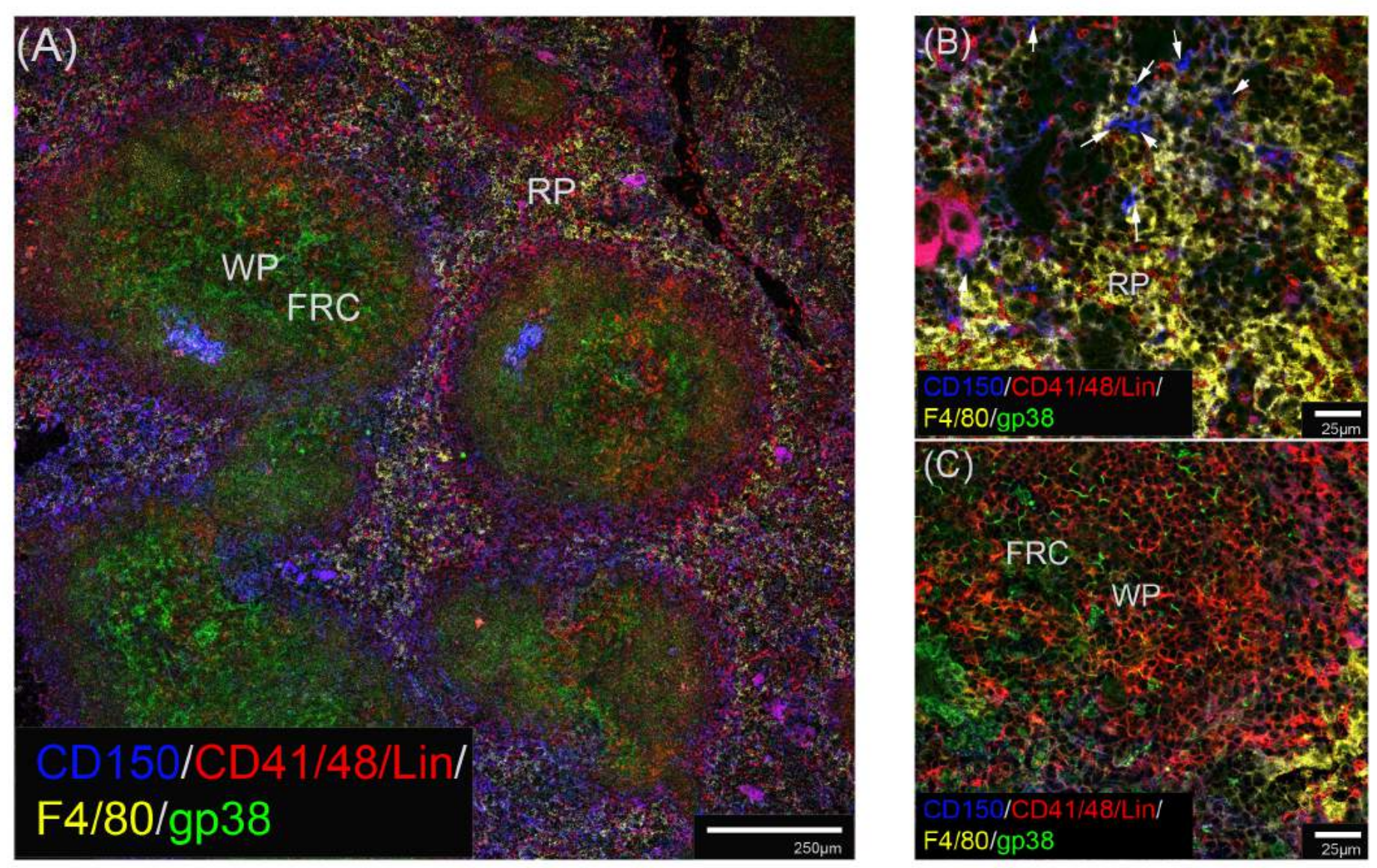
Figure 5.14 Localisation of HSC in relation to Thy1.2-expressing stromal cells in pregnant (E18.5) spleens. Frozen spleens of adult pregnant (E18.5) mice were fixed with acetone and stained with fluorochrome-conjugated antibodies to CD150 (blue), CD41 (red), CD48 (red), Lineage (red), Thy1.2 (green), and F4/80 (yellow). In A) red pulp (RP) and white pulp (WP) regions are delineated. Discrete white pulp regions stained with Thy1.2 reflect T cell zones. (scale bar: $250 \mu \mathrm{m})$. In B) HSC (Lin CD150 ${ }^{+} \mathrm{CD}^{-} 1^{-} \mathrm{CD}^{-} 8^{-}$) were localised in red pulp, with only some of those cells in association with Thy $1.2^{+}$(green) stromal cells. (scale bar: $25 \mu \mathrm{m}$ ). Images representative of 3 mice are shown. 
A

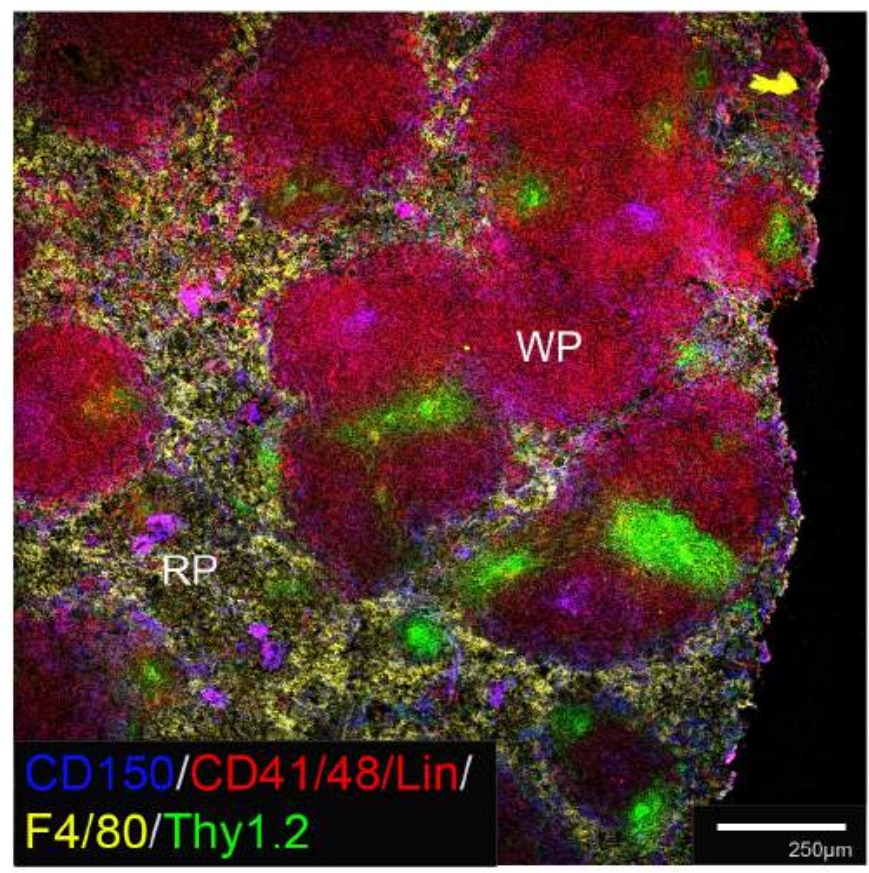

B

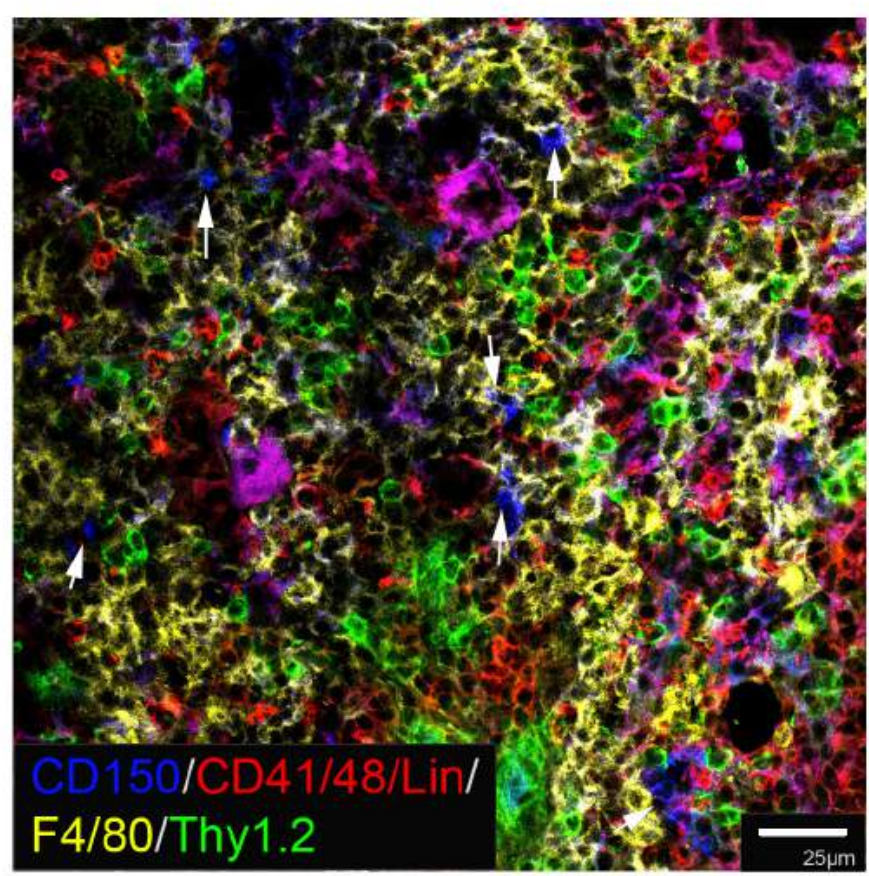




\subsection{DISCUSSION}

While the concept of a HSC niche was developed a few decades ago, it has only been technological advances in the recent past which have permitted experimental investigation at the level of single cell identification and interaction. Indeed, these studies have uncovered multiple niche elements in BM and described possible interplay between distinct cell types. Unfortunately, investigation into HSC niches in spleen is only in its infancy, and made more difficult because of the rarity of HSC in that organ, resulting in very limited information available. In this chapter, information on the phenotypic characteristics of 5G3 stroma developed in Chapter 3, as well as cell surface markers of ex vivo stroma identified in Chapter 4, have been combined for investigation of niches for HSC in spleen.

Previous studies have shown that the adult spleen contains a very small population of HSC capable of long-term hematopoietic reconstitution (Tan and O'Neill, 2010; Wolber et al., 2002). HSC in spleen were also found to be phenotypically and functionally similar to HSC in the BM (Morita et al., 2011). However, since HSC exist in far lower number in adult spleen than that in BM (Morita et al., 2011), it has been extremely challenging to detect HSC in steady-state adult spleen using immunofluorescence imaging. We therefore decided to turn our attention to further models where the numbers of HSC is increased above normal adult levels in order to perfect techniques and staining methods for HSC detection. These models included 6day old neonatal mice, pregnant (E18.5) mice and Flt3L-mobilised mice. There are two main reasons for the choice of the neonatal spleen model. Firstly, it is known that the spleen harbours high numbers of HSC until 2 weeks of age (Christensen et al., 2004; Wolber et al., 2002). Secondly, stroma-dependent splenic LTC were most readily established from 6-day old spleens, producing L-DC which develop in vitro directly from LT-HSC (Petvises and O'Neill, 2014b). The choice to also use the pregnant adult spleen model was based on a recent report showing that pregnant spleen contains more HSC than non-pregnant adult spleen, consistent with a need for increased erythropoiesis and myelopoiesis during pregnancy (Inra et al., 2015). In addition, the documented effect of Flt3L on HSC mobilisation from BM to peripheral blood and spleen (Robinson et al., 2000; Neipp et al., 1998; Brasel et al., 1996) has been the main reason for the choice of Flt3L mobilisation model. 
In this study, success was achieved in localising Lin $^{-} \mathrm{CD} 150^{+} \mathrm{CD}^{-} 1^{-} \mathrm{CD} 48^{-} \mathrm{HSC}$ within the red pulp of neonatal spleen using section staining, even though cells were present in low numbers. Data collected here therefore parallel a recent report showing that HSC in spleen can be readily detected following stress-induced induction of extramedullary hematopoiesis (Inra et al., 2015). In that report, Inra and coworkers induced extramedullary hematopoiesis in spleen using combined administration of cyclophosphamide and G-CSF, a procedure which results in increased numbers of HSC migrating into spleen (Inra et al., 2015; Kiel et al., 2005; Wright et al., 2001; Morrison et al., 1997). In that study, immunofluorescence imaging was used effectively to localise HSC within spleen red pulp. That same group also showed that extramedullary hematopoiesis was prominent in spleens of pregnant mice (Nakada et al., 2014). Consistent with their findings, we have shown that the number of $\operatorname{Lin}^{-} \mathrm{CD} 150^{+} \mathrm{CD} 41^{-}$ CD48- HSC in pregnant adult mice is $\sim 10$-fold greater than in non-pregnant adult spleen (Table 5.4), with the majority of these cells present in the red pulp region (Figure 5.8). These results are consistent with increased erythropoiesis and myelopoiesis occurring in spleen during pregnancy dependent on an increased supply of hematopoietic stem/progenitor cells present in that organ (Inra et al., 2015; Nakada et al., 2014).

A detailed comparison amongst of several models used for splenic hematopoiesis has revealed that pregnant adult mice model are superior to 6-day old neonatal and Flt3L mobilised adult models mice in terms of number of Lin $^{-}$ $\mathrm{CD} 150^{+} \mathrm{CD} 41^{-} \mathrm{CD} 48^{-} \mathrm{HSC}$ in spleen. The exact mechanisms leading to these differences are not known and will be a complex problem to sort out. During development, hematopoiesis in neonatal spleen progressively decreases to a steady-state level as the BM takes over as the main hematopoietic organ. In the case of Flt3L-mobilised mice, Flt3L treatment led to a specific increase in the number of MPP3, myeloid-biased MPP present in spleen (Table 5.3; Figure 5.4B). Another important question is whether differentiation of HSC to MPP occurs prior to mobilisation or within the splenic microenvironment. There are many questions yet to be addressed in relation to the entry, or development of HSC within spleen. However, that issue is not the main focus of this chapter. The study here was focused on localising HSC in spleen and with them the HSC niches which support hematopoiesis in that organ.

This study has gone some way towards identifying the stromal cells which are associated with HSC forming niches within spleen. Multiple cell surface markers 
including CD31, gp38, CD105 and Thy1.2 were used in this study. Some markers of interest could not be used since available antibodies were not suitable for immunofluorescent staining of fixed sections. In particular, it was not possible to use $\mathrm{CD} 140 \mathrm{a} / \mathrm{b}$ for immunofluorescence staining of spleen sections, a marker which has been associated previously with perivascular reticular cells in BM (Zhou et al., 2014). Amongst those markers tested successfully, no association with HSC was observed for CD31 and CD105 staining cells in either neonatal or pregnant spleens (Figures 5.9, 5.10 and 5.11). Neonatal spleens showed a predominance of gp $38^{+}$stromal cells in red pulp and some HSC appeared to associate with these stromal cells (Figure 5.12). This finding was not repeated for adult pregnant spleen where fewer gp $38^{+}$cells were detected, and very few HSC appeared to co-localise with these cells (Figure 5.13). Thy1.2 staining stromal cells did however lie in close proximity with some HSC in pregnant spleens (Figure 5.14), consistent with a niche involving mesenchymal, perhaps perisinusoidal reticular cells, as described previously by others (Inra et al., 2015).

It was also noted that some HSC were associated with hematopoietic cells. It is possible that hematopoietic cells can act to maintain HSC within the splenic red pulp microenvironment. Splenic macrophages may promote HSC maintenance in spleen, consistent with the role of $\mathrm{CD} 169^{+}$macrophages in HSC maintenance in BM (Chow et al., 2011). Indeed, Dutta and coworkers (2015) recently reported that macrophages retain HSC in spleen through VCAM1 interaction, and that reduction of VCAM1 expression leads to egression of HSC into the circulation (Dutta et al., 2015). Previously it was shown that splenic stroma could promote differentiation of HSC from BM into regulatory DC (Tang et al., 2006). Regulatory DC themselves promote the generation of regulatory $\mathrm{T}$ cells. Recently, FoxP3 regulatory $\mathrm{T}$ cells were reported to provide an immune privileged site for HSC niches in BM (Fujisaki et al., 2011). However in this study no CD3 staining T cells were detected in the red pulp (Figure 5.1).

Although direct contact of HSC with stromal cells is in keeping with a niche model for hematopoiesis, it is still possible that stromal cells could act in a paracrine fashion. We are therefore unable to conclusively interpret the hematopoietic support role of stromal cells which were not in direct contact with HSC without using conditional knock out mice to undertake a complete study. A splenic niche involving $\operatorname{Tcf} 21^{+}$mesenchymal and endothelial cells has been recently reported (Inra et al., 2015). While $T c f 21^{+}$cells were shown to express CD140a/b, we were unable to get good 
staining of CD140a/b $\mathrm{b}^{+}$cells in spleen sections and could not therefore do a direct test of these earlier findings. However, it would be valuable to know if $T c f 21^{+}$cells also express gp38 and Thy1.2 since our staining has shown co-localisation of HSC with these stromal cells. It would also be interesting to speculate that HSC niches present in spleen might change during ontogeny, which would explain the presence of a niche comprising gp $38^{+}$stromal cells in neonatal but not adult, or adult pregnant spleen, based on their association with HSC.

Interestingly, distinct architectural differences were also noted between adult and neonatal spleens in this study. The more developed white pulp region of adult spleen compared with neonatal spleen is consistent with earlier findings that white pulp of murine spleen is poorly organised at birth, and that extensive cellular organisation occurs after birth (Kuper et al., 2016; Golub and Cumano, 2013). This greatly contrasts with human spleen which is apparently fully developed at birth (Steiniger et al., 2007). To this end, we have shown that HSC localise in the red pulp region of neonatal and pregnant spleens. While only gp $38^{+}$stromal cells were found to associate with HSC in neonatal spleens, there appear to be different mesenchymal stromal cell types which form HSC niches in adult spleen. The possibility that endothelial and vascular cells may contribute in a paracrine fashion to aid in the regulation of splenic extramedullary hematopoiesis also needs to be considered. Current research methodology might not be able to adequately address this possibility. 
CHAPTER SIX

CAPACITY OF SPLENIC STROMA TO FORM

ECTOPIC HSC NICHES 


\subsection{INTRODUCTION}

The subcapsular space of the kidney is a commonly used site for ectopic tissue transplantation in rodents since it offers a highly vascularised environment and a large accessible space for transplantation of cells. This environment also permits angiogenesis of grafted tissue, necessary for long-term graft survival. Subcapsular kidney grafting has been successfully used to investigate repopulation of hematopoietic cells and progenitors following transplantation of adult and neonatal spleen capsular tissue (Shatry and Levy, 2004). This technique was also used recently to demonstrate that the regeneration of splenic tissue from neonatal spleen capsule tissue requires lymphotoxin signalling from stromal cells (Tan and Watanabe, 2014). Methodologies described in these two studies were used as a reference for current work involving transplantation of splenic stromal cells with a view to the development of ectopic spleen tissue.

This chapter utilises subcapsular kidney grafting to investigate whether defined ex vivo splenic stromal subsets and cloned stromal cell lines can form ectopic HSC niches in vivo. One of the biggest challenges with transplantation of freshly sorted splenic stromal subsets is the low cell number available. In order to optimise the transplantation outcome, sorted or cultured cells are often mixed with Matrigel, an extracellular matrix comprising laminin, enactin and collagen IV extracted from Englebreth-Holm-Swarm tumours in mice (Hughes et al., 2010; Kleinman et al., 1982; Orkin et al., 1977). Matrigel is commonly used to support cultures of stem cells and has been shown to maintain the self-renewal and pluripotency of stem cells in culture (Hughes et al., 2010).

Chapter 3 of this thesis described stromal cell lines derived from a splenic longterm culture, STX3. The 5G3, but not 3B5, clonal line, was shown to support in vitro hematopoiesis (Periasamy et al., 2009). The difference in hematopoietic support capacity between $5 \mathrm{G} 3$ and $3 \mathrm{~B} 5$ stroma has provided this laboratory with a means to further investigate the molecular signals which drive in vitro hematopoiesis. An important question is therefore whether these two stromal cell lines could exhibit hematopoietic support capacity in vivo. Similar protocols have also been used to assess the capacity of the defined splenic stromal subsets P8, P9, P10 and P11 described in Chapter 4, since at least P9 and P10 were shown to support in vitro hematopoiesis. More recently, this laboratory described the in vivo counterpart of L-DC in both murine 
and human spleen (Petvises et al., 2016; Hey et al., 2015). This finding adds physiological relevance to in vitro cultures for hematopoiesis. Since L-DC were originally described as the main myeloid cell produced in splenic stromal co-cultures in vitro (Periasamy et al., 2009; Ni and O'Neill, 1997), it is therefore, of interest to know whether the splenic stromal subsets and cloned stromal cell lines also support the development of L-DC in stromal cell grafts following their transplantation in vivo. 


\subsection{RESULTS}

\subsubsection{Subcapsular grafting of splenic stroma in kidney}

The kidney subcapsular grafting procedure published by Tan and Watanabe (2014) and Shatry and Levy (2004) was adapted for this study. In an initial study to test the functionality of this technique for investigation of stromal fractions, 3-day old neonatal spleen capsule was prepared in accordance with the procedure used by Tan and Watanabe (2014). In most cases, one spleen capsule was grafted into the kidney subcapsular space, allowed to grow for 4 weeks, and then dissected out for dissociation of cells, followed by antibody staining and flow cytometry to detect subsets present in grafts. The grafting of splenic capsules into the kidney subcapsular space of C57BL/6J mice gave a success rate of $33 \%$ (Table 6.1). Successive grafted tissue showed the infiltration of $\mathrm{T}$ and $\mathrm{B}$ cells (Figure 6.1), suggesting success with the technique, albeit low success rate in graft uptake.

Further experiments tested the grafting technique on immunodeficient NOD/SCID mice as host mice. Grafting with spleen capsules into the kidney subcapsular space of NOD/SCID mice gave a success rate of 33\% (Table 6.1). Replicate grafts showed the presence of myeloid cells based on cell staining for CD11b and CD11c (Figure 6.2). These included myelomonocytic cells $\left(\mathrm{CD} 11 \mathrm{~b}^{+} \mathrm{CD} 11 \mathrm{c}^{-}\right)$and dendritic cells $\left(\mathrm{CD} 11 \mathrm{~b}^{+/-} \mathrm{CD} 11 \mathrm{c}^{+}\right)$. T cells were delineated as $\mathrm{CD}^{+}$cells and $\mathrm{B}$ cells as $\mathrm{CD} 19^{+}$cells (Figure 6.2). No macrophages were detectable indicated by an absence of F4/80 staining.

In order to test whether it was possible to engraft isolated fractionated stromal cells, in a separate experiment $5 \times 10^{4}$ to $1 \times 10^{6}$ capsular cells from spleen were dissociated with collagenase, mixed with Matrigel and grafted into NOD/SCID or C57BL/6J mice. Unfortunately, no successful grafts were recovered at 28 days after grafting isolated stroma (Table 6.1). Based on a series of grafting experiments, it was determined that grafting untreated spleen capsule was more successful than grafting dissociated capsular stromal cells. Mixing cells with Matrigel did not improve graft outcomes. 
Table 6.1 Grafting success using neonatal spleen

\begin{tabular}{|c|c|c|c|}
\hline Grafted cells & No. of hosts & Successful grafts & Success rate (\%) \\
\hline Whole spleen capsule & $3 \ddagger$ & 1 & 33 \\
\hline $\begin{array}{c}5 \times 10^{5}-1 \times 10^{6} \\
\text { capsular cells }\end{array}$ & $4 \ddagger$ & 0 & 0 \\
\hline $\begin{array}{c}\text { Whole spleen capsule } \\
5 \times 10^{4}\end{array}$ & $3 \dagger$ & 1 & 33 \\
\hline capsular cells & $2 \uparrow$ & 0 & 0 \\
\hline
\end{tabular}

* Grafts were derived from 3-day old C57BL/6J spleen, either as a tissue fragment or as collagenase-digested capsular cells.

‡ Host mice were adult C57BL/6J $\left(C D 45.2 . H-2 K^{b}\right)$, which had been splenectomised.

$\dagger$ Host mice were adult NOD/SCID $\left(C D 45.1 . H-2 K^{d}\right)$, which had been splenectomised. 
Figure 6.1 Procedure for grafting into the subcapsular space of kidney. (A) Graft preparation, grafting procedure and graft tissue analysis. Threeday old spleens were crushed and capsular tissue isolated for transplantation into the renal subcapsular space of 6-week-old C57BL/6J mice. In some experiments, capsular tissue was dissociated with collagenase digestion and single cells prepared for transplantation by mixing with Matrigel. Grafted tissues were dissected from kidney at 4 weeks after transplantation, and cells dissociated and filtered through a 100- $\mu \mathrm{m}$ cell strainer to give a single cell suspension. Cells were then stained with antibodies specific for CD3, CD19 and CD45. CD45-expressing cells were gated for further analysis including expression of CD3 and CD19, to detect T and B cells as shown here (B). 

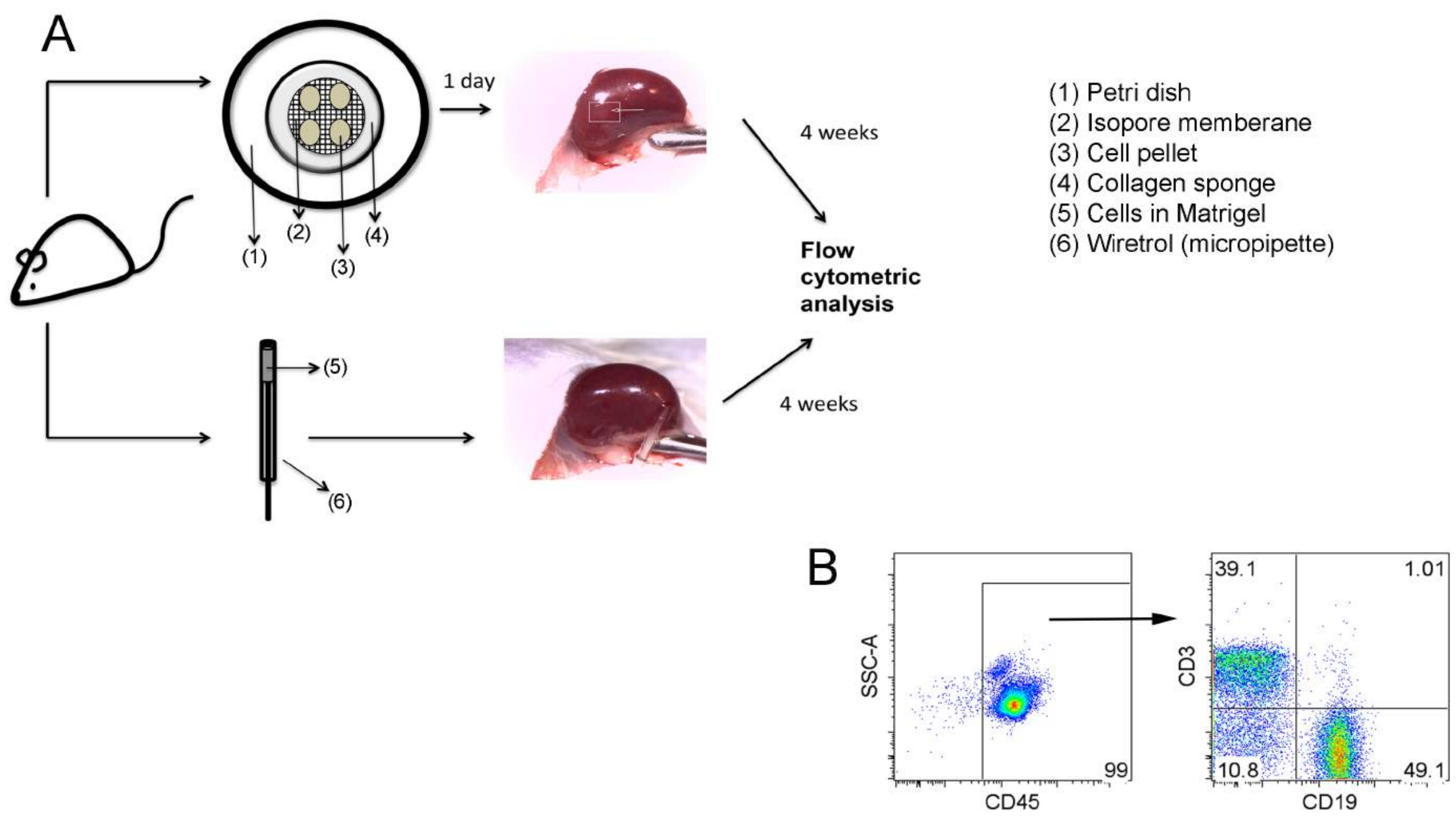
Figure 6.2 Composition of tissue forming from 3-day old spleen capsular graft. Capsular tissue was prepared by mechanical dissociation of spleen, followed by transplantation into the renal subcapsular space of 6-week-old NOD/SCID mice. Grafted tissues were dissected out after 4 weeks, and cells dissociated for staining with antibodies for CD11b, CD11c, CD3, CD19 and F4/80. Live singlets were gated, and staining with CD11b and CD11c used to divide subsets for further analysis of expression of the CD19 and CD3 lymphoid markers. One capsule transplanted under the kidney capsule of a single mouse was analysed. 


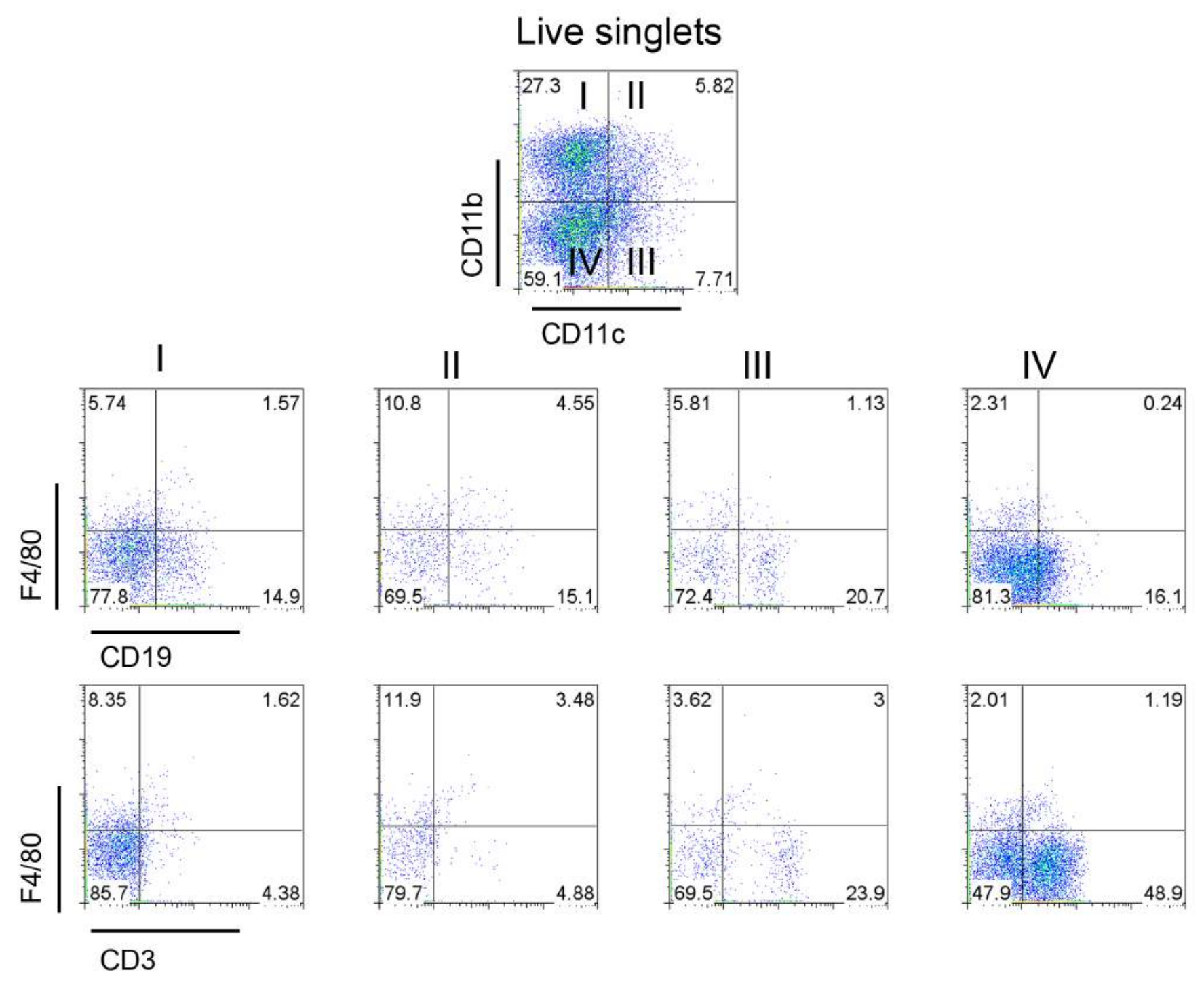




\subsubsection{Formation of ectopic grafts following transplantation of 5 G3 stroma}

Using the same methodology, 5G3 stroma was tested for its ability to form ectopic splenic tissue in vivo following transplantation into the subcapsular space of the kidney of immunodeficient NOD/SCID mice. Generally, 1 or 2 grafts were surgically placed under an individual kidney capsule of multiple mice. Two supporting matrices were used for grafting: an isopore membrane/collagen sponge construct and a Matrigel matrix. Some mice were splenectomised ahead of grafting to test if splenectomised mice would give improved graft formation. In most cases, tissue forming in the graft space was isolated and cells dissociated for flow cytometry at 4 weeks after grafting. In one particular experiment, three distinct grafts established with varying cell numbers $\left(5 \times 10^{4}\right.$, $5 \times 10^{5}$ or $1 \times 10^{6}$ ) were used for analysis of grafted tissue at 1 to 3 weeks after grafting.

Due to the low overall graft success rate $(3 \%)$, it was not possible to assess effectiveness of grafting matrix, cell number, importance of splenectomy, or time past grafting, on the overall success of tissue formation using $5 \mathrm{G} 3$ stromal cells as a graft (Table 6.2). Success was however obtained with one mouse given three separate grafts. Flow cytometric analysis of these grafts showed two distinct subsets of $\mathrm{CD} 11 \mathrm{~b}^{+}$myeloid cells present in the graft (Figure 6.3A). One subset of cells reflected CD11 $\mathrm{c}^{\text {hi }}$ dendritic cells, while the other was a CD11 ${ }^{\text {lo }}$ subset. These cells also expressed CD19 or both

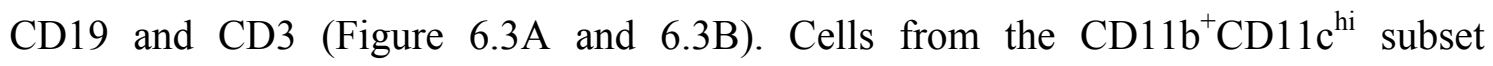
uniformly showed F4/80 staining. In contrast, F4/80 staining was present on $<10 \%$ cells of cells of the $\mathrm{CD} 11 \mathrm{~b}^{+} \mathrm{CD} 11 \mathrm{c}^{\text {lo }}$ subset (Figures 6.3A and 6.3B). The expression of CD3 and CD19 cell surface markers on cells of CD11 $\mathrm{b}^{+} \mathrm{CD} 11 \mathrm{c}^{+}$phenotype was unusual and suggested the possibility of an aberrant cell type forming in 5G3 stromal grafts (Figure 6.3A). In these experiments, control $\mathrm{C} 57 \mathrm{BL} / 6 \mathrm{~J}$ mice showed the expected $\mathrm{T}$ and $\mathrm{B}$ lymphoid cells in spleen which are absent in the NOD/SCID hosts, which instead contained mainly CD11 $\mathrm{b}^{+}$myeloid cells (Figure 6.2A).

\subsubsection{Myelopoiesis is supported within 3B5 stromal grafts}

A similar grafting procedure was carried out using 3B5 stromal cells grafted into NOD/SCID mice. However, in addition to analysis of cells in grafts by flow cytometry, some grafted tissue was isolated whole and frozen for immunohistochemistry. Grafting of 3B5 stroma was very successful, yielding an overall success rate of 73\% (Table 6.2). 
Table 6.2 Success in grafting stromal cell lines

\begin{tabular}{|c|c|c|c|c|}
\hline $\begin{array}{c}\text { Grafted } \\
\text { cells }\end{array}$ & No. of cells grafted & No. of hosts & Successful grafts & Success rate (\%) \\
\hline \multirow{3}{*}{$3 \mathrm{~B} 5$} & $1 \times 10^{6} \S$ & 19 & 13 & 68 \\
\cline { 2 - 5 } & $1 \times 10^{6}: 1 \times 10^{6} \dagger$ & 2 & 2 & 100 \\
\cline { 2 - 5 } & $5 \times 10^{4}: 5 \times 10^{5} \dagger$ & 2 & $1^{1}$ & 50 \\
\hline \multirow{4}{*}{$5 \mathrm{G} 3$} & $1 \times 10^{6} \S$ & $24(4 \ddagger)$ & 1 & 4 \\
\cline { 2 - 5 } & $1 \times 10^{6}$ & 4 & 0 & 0 \\
\cline { 2 - 5 } & $1 \times 10^{6}: 1 \times 10^{6} \dagger$ & 3 & $0^{1}$ & 0 \\
\cline { 2 - 5 } & $5 \times 10^{4}: 5 \times 10^{5} \dagger$ & 1 & $0^{2}$ & 0 \\
\cline { 2 - 5 } & $5 \times 10^{4}: 5 \times 10^{5} \dagger$ & 1 & $0^{3}$ & 0 \\
\hline 10C9 & $1 \times 10^{6}$ & 5 & 3 & 0 \\
\hline STX3 & $1 \times 10^{6}$ & 5 & 0 & 0 \\
\hline 7G10 & $1 \times 10^{6}$ & 5 & & \\
\hline
\end{tabular}

Stromal cell lines derived from B10.A(2R) mouse spleen $\left(C D 45.2, H-2 K^{k}\right)$ were grafted under the kidney capsule of adult NOD/SCID (CD45.1, H-2K ${ }^{\mathrm{d}}$ ) mice. In most cases, cells were mixed with Matrigel ahead of transplant.

$\S$ These cells were grown overnight on a collagen sponge as a matrix for grafting, instead of mixing in Matrigel.

$\$$ These mice were splenectomised ahead of grafting.

$\uparrow$ Two separate grafts were placed on the same kidney.

${ }^{1}$ Graft was analysed 3 weeks after transplantation, instead of the usual 4 weeks.

${ }^{2}$ Graft was analysed at 1 week.

${ }^{3}$ Graft was analysed at 2 weeks. 
Figure 6.3 Limited success with 5G3 stromal cell grafting. A $5 \mathrm{G} 3$ stromal cell pellet was prepared by trypsinising cells in culture flasks and pelleting them onto a collagen sponge followed by overnight culture. The construct was then carefully transplanted into the renal subcapsular space of 6-week-old NOD/SCID mice. Tissues which formed in the graft space were dissected out at 4 weeks and dissociated for staining cells with antibodies specific for CD11b, CD11c, CD3, CD19 and F4/80. Live singlets were gated, and staining with CD11b and CD11c used to divide subsets for further analysis of expression of the CD19 and CD3 lymphoid markers. Three individual grafts transplanted into a single mouse were analysed, and cell composition compared with splenic leukocytes from adult C57BL/6J and NOD/SCID mice. (A) Analysis of myeloid and lymphoid cell subsets. (B) Further analysis of two distinct subsets of cells in terms of myeloid and lymphoid markers. 


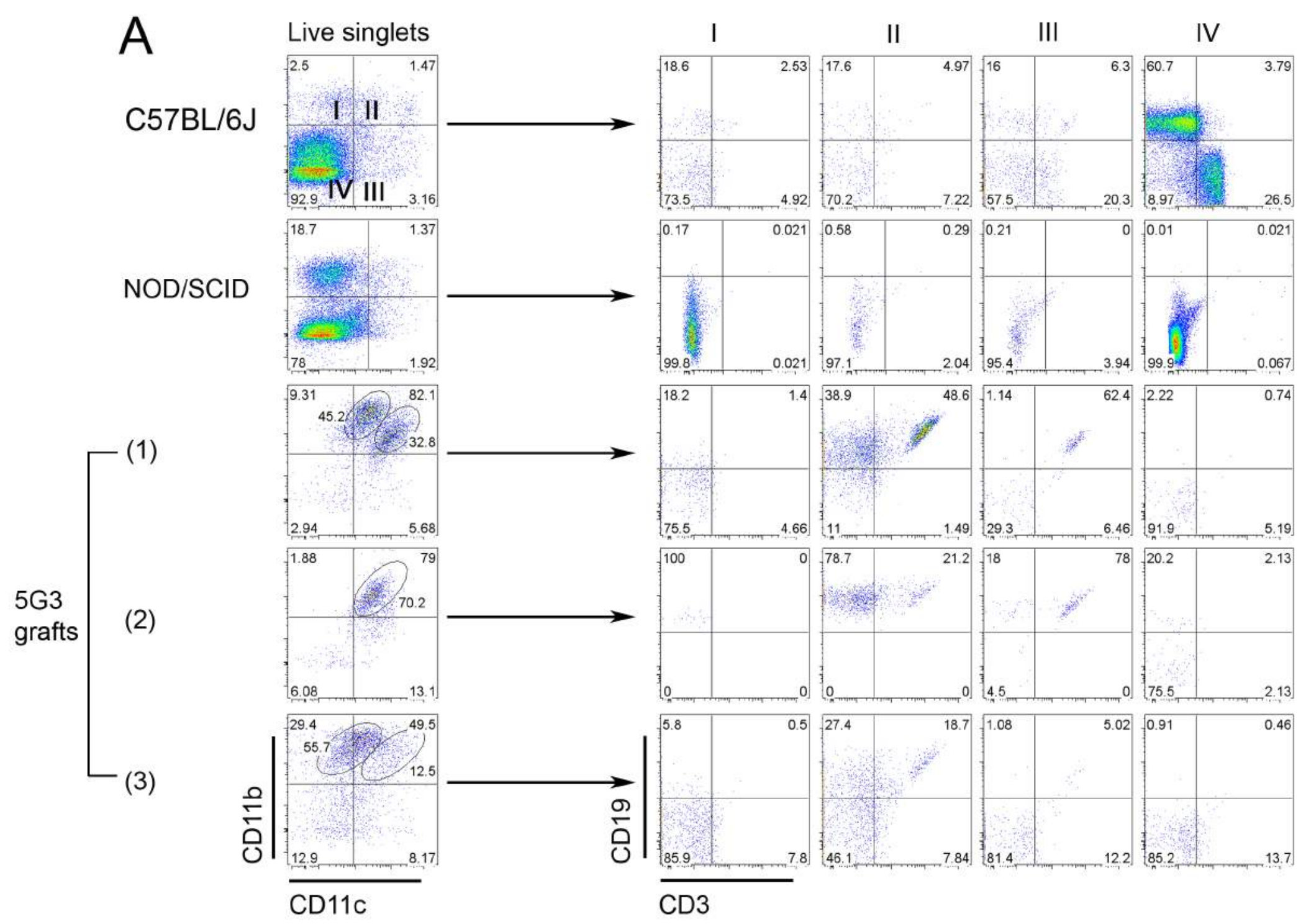




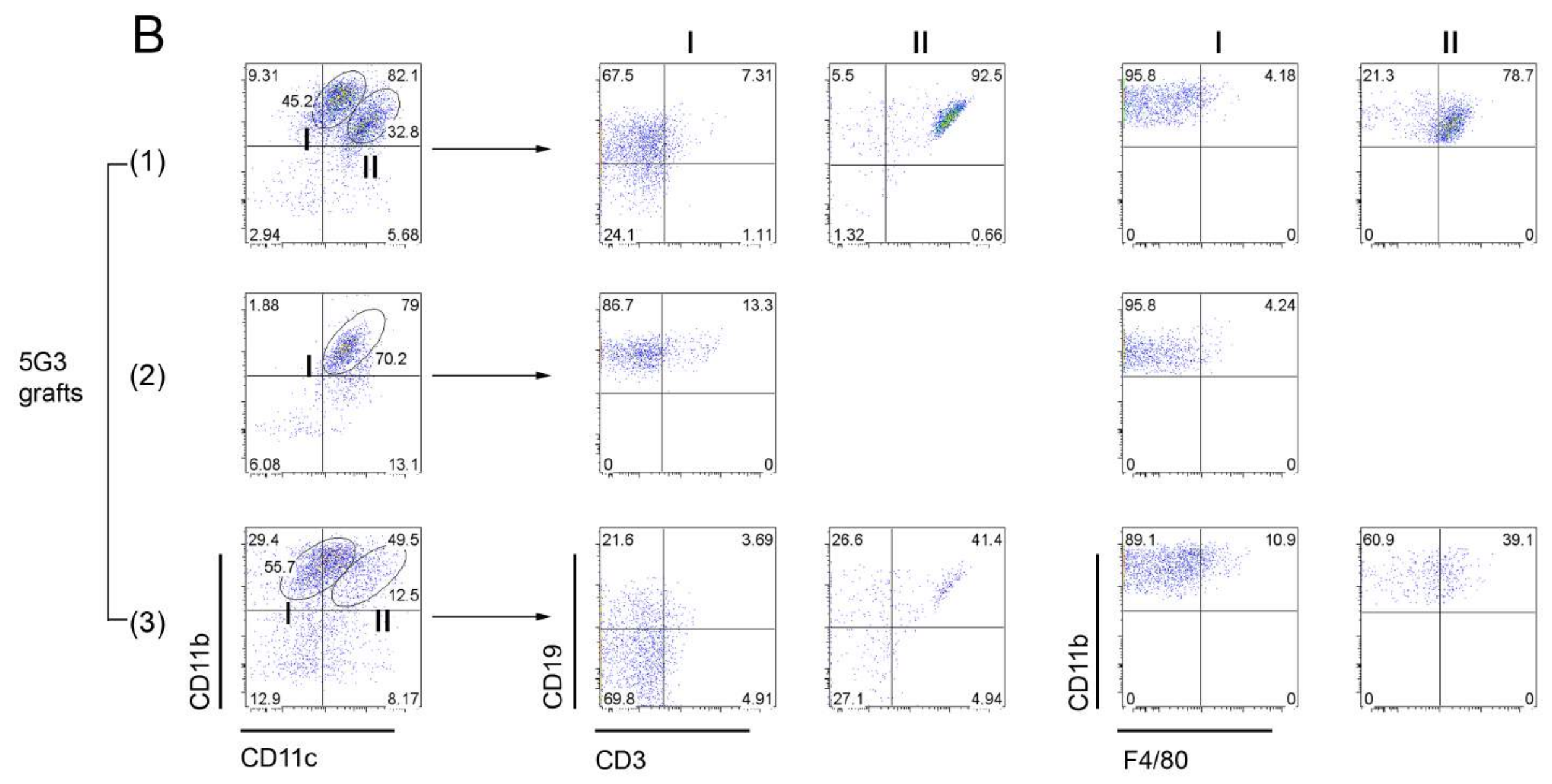


A comparison of the success rate between different experiments indicated that a graft cell number of $1 \times 10^{6}$, with analysis at 4 weeks after grafting, was optimal for 3B5 stroma. Different supporting matrices were not found to have any noticeable effect on the success of 3B5 grafting. Flow cytometry identified a consistent range of hematopoietic cells within all 3B5 grafts based on staining for CD11b, CD11c, F4/80, CD3 and CD19 (Figure 6.4, Table 6.3). Notably, grafts contained myeloid (CD11b ${ }^{+}$) and dendritic cells $\left(\mathrm{CD} 11 \mathrm{c}^{+}\right)$, but lacked lymphoid cells $\left(\mathrm{CD} 19^{+} / \mathrm{CD}^{+}\right)$(Figure 6.4A). A majority (34\%) population of dendritic-like cells was present in all grafts. These cells have a phenotype of $\mathrm{CD} 11 \mathrm{~b}^{+} \mathrm{CD} 11 \mathrm{c}^{10} \mathrm{~F} 4 / 80^{+}$, which is reflective of L-DC (Table 6.3; Figure 6.4A and 6.4B). Monocytes/macrophages were identified as $\mathrm{CD} 11 \mathrm{~b}^{+} \mathrm{CD} 11 \mathrm{c}^{-}$ $\mathrm{F} 4 / 80^{+}$cells, and made up $12 \%$ of the total cell population (Table 6.3). Minor populations of $\mathrm{cDC}$-like cells as $\mathrm{CD} 11 \mathrm{~b}^{-/+} \mathrm{CD} 11 \mathrm{c}^{+} \mathrm{F} 4 / 80^{+}$cells and plasmacytoid DC as $\mathrm{CD} 11 \mathrm{~b}^{-} \mathrm{CD} 11 \mathrm{c}^{+} \mathrm{F} 4 / 80^{-}$cells were also detected. No T cells $\left(\mathrm{CD}^{+}\right)$and $\mathrm{B}\left(\mathrm{CD} 19^{+}\right)$cells were detected in the grafts (Table 6.3; Figure 6.4A and 6.4B).

Further analysis investigated the localisation of hematopoietic cells within 3B5 graft tissue. Frozen sections were made and fixed with acetone before staining with antibodies specific for markers of myeloid (CD11b) and dendritic (CD11c) cells. Antibody to $\mathrm{H}-2 \mathrm{~K}^{\mathrm{k}}$ was included to identify $3 \mathrm{~B} 5$ stromal cells in relation to host NOD/SCID cells which express $\mathrm{H}-2 \mathrm{~K}^{\mathrm{d}}$. Section staining of $3 \mathrm{~B} 5$ grafted tissue revealed mature myeloid $\left(\mathrm{CD} 11 \mathrm{~b}^{+}\right)$and dendritic cells $\left(\mathrm{CD} 11 \mathrm{c}^{+}\right)$scattered within the tissue (Figure 6.5). Moreover, hematopoietic cells were found to be closely aligned with 3B5 stromal cells within the grafted tissue (Figure 6.5). Mature host hematopoietic cells in grafts could have either directly infiltrated the graft, or arose by differentiation from host hematopoietic stem/progenitor cells that had infiltrated the graft. In order to address the source of hematopoiesis, flow cytometry and immunohistochemistry were used to identify any hematopoietic stem/progenitor cells within grafts. These cells were detected by staining for lineage-negative $\left(\mathrm{Lin}^{-}\right)$cells which express Sca-1 and c-Kit (LSK cells), which also express CD150 but not Flt3. This phenotype has been described previously as reflective of LT-HSC in mouse BM (Shin et al., 2014). The LSK $\mathrm{CD} 150^{+} \mathrm{Flt3}^{-}$subset, which is highly enriched for LT-HSC, was detected within two separate 3B5 grafts (Figure 6.6). In addition, immunohistochemical staining for Lin $^{-}$ $\mathrm{CD} 150^{+} \mathrm{CD} 41^{-} \mathrm{CD} 48^{-} \mathrm{HSC}$ on $3 \mathrm{~B} 5$ graft sections using immunohistochemistry has confirmed the presence of HSC amongst other mature hematopoietic cells in the graft (Figure 6.7). These results introduce the possibility that mature hematopoietic cells may 
Figure 6.4 Ectopic 3B5 stromal grafts support hematopoiesis. Grafts of 3B5 stromal cells were prepared and transplanted as described in Figure 6.1 using NOD/SCID mice as hosts. These were dissected from the kidney of NOD/SCID recipient mice at 4 weeks after transplantation, and cells dissociated for staining with antibodies specific for CD11b, CD11c, CD3, CD19 and F4/80. Live singlets were gated, and CD11b and CD11c myeloid cell staining used to divide subsets for further analysis of expression of the lymphoid markers CD19 and CD3. Three individual grafts transplanted under the kidney capsule of a single mouse were analysed, and cell composition compared with spleen cells from adult C57BL/6J and NOD/SCID mice. (A) Expression of lymphoid markers on subsets differing in expression of CD11b and CD11c. (B) Further analysis of two distinct subsets of cells in terms of myeloid and lymphoid markers. 


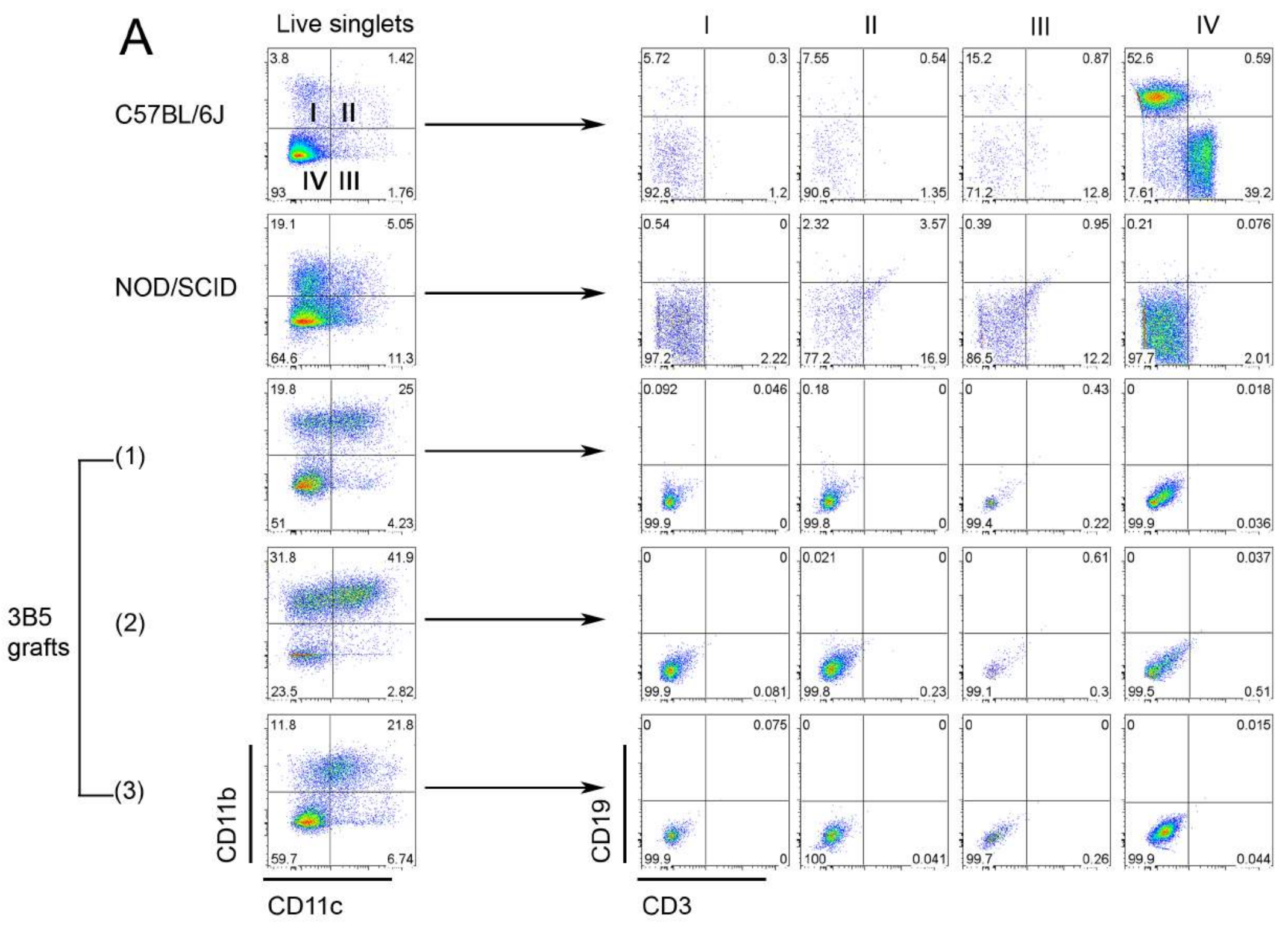



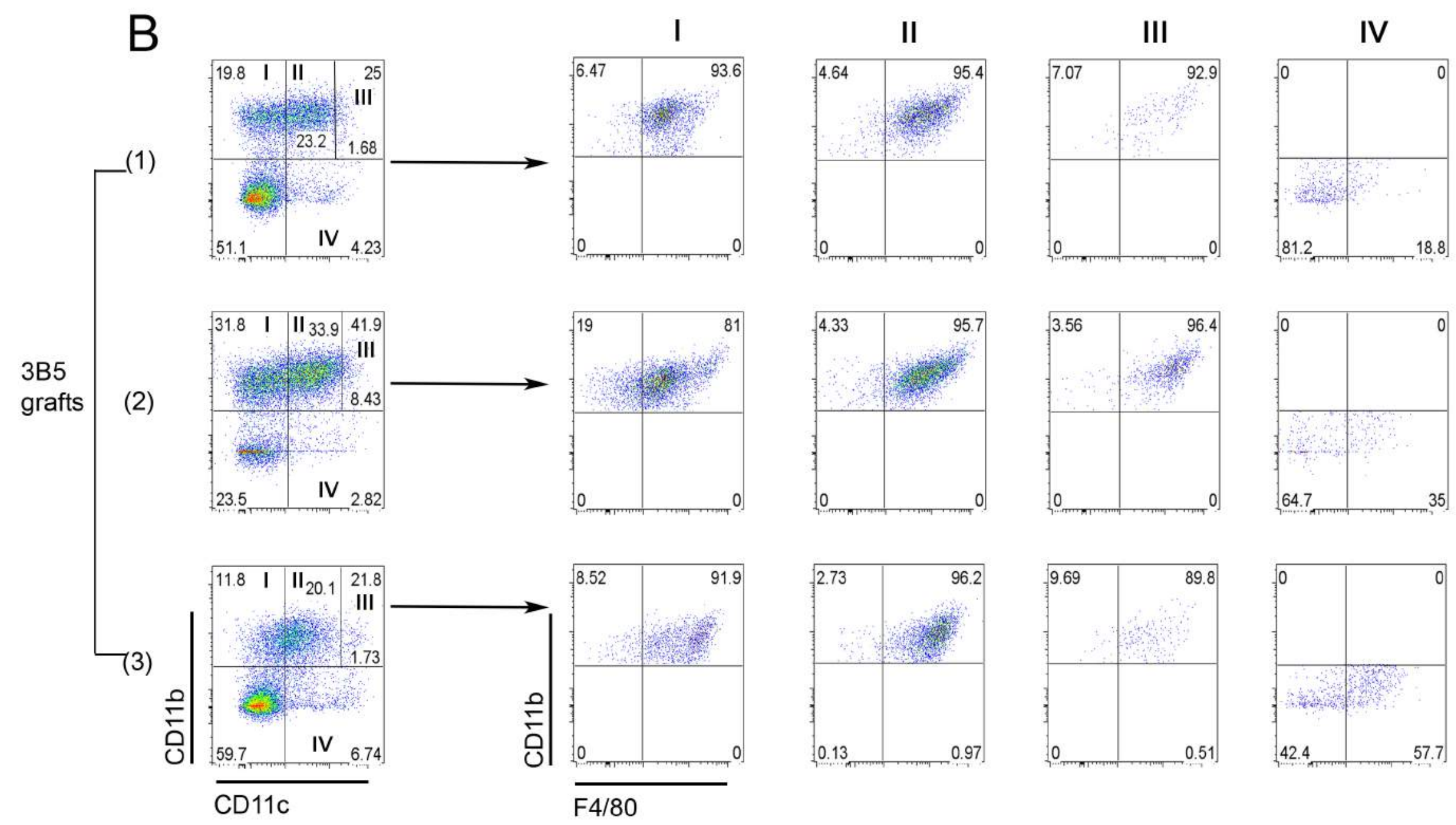
Table 6.3 Representation of hematopoietic cells within 3B5 grafts

\begin{tabular}{|c|c|c|}
\hline Subset identified* & Predicted cell type & $\begin{array}{l}\text { \% cells within } \\
\text { dissociated } \\
\text { graft } * *(n=9)\end{array}$ \\
\hline $\mathrm{CD}^{-11 \mathrm{~b}^{-} \mathrm{CD} 11 \mathrm{c}^{-} \mathrm{F} 4 / 80^{-} \mathrm{CD3}^{+} \mathrm{CD} 19^{-}}$ & T cell & $0.02 \pm 0.01$ \\
\hline $\mathrm{CD} 11 \mathrm{~b}^{-} \mathrm{CD} 11 \mathrm{c}^{-} \mathrm{F} 4 / 80^{-} \mathrm{CD}^{-} \mathrm{CD}^{-} \mathbf{C}^{+}$ & B cell & $0.00 \pm 0.00$ \\
\hline $\begin{array}{c}\mathbf{C D 1 1 b}^{+} \mathbf{C D} \mathbf{C D}^{\mathbf{1 0}} \mathbf{F} 4 / \mathbf{8 0}^{+} \mathrm{CD}^{-} \\
\mathrm{CD}^{-} 9^{-}\end{array}$ & L-DC & $34.41 \pm 8.14$ \\
\hline 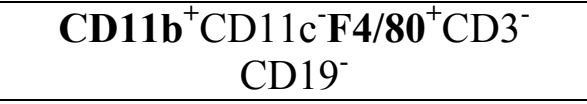 & Monocyte/macrophage & $12.45 \pm 4.15$ \\
\hline $\mathrm{CD}^{2} 1 \mathrm{~b}^{-} \mathrm{CD} 11 \mathrm{c}^{+} \mathrm{F} 4 / 80^{-} \mathrm{CD}^{-\mathrm{CD}} 19^{-}$ & Plasmacytoid DC & $2.95 \pm 0.98$ \\
\hline 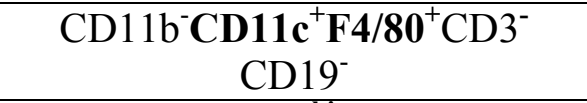 & $\mathrm{CD}^{+} \mathrm{cDC}$ & $1.36 \pm 0.45$ \\
\hline $\begin{array}{c}\mathbf{C D 1 1 b}^{+} \mathbf{C D 1 1 c}^{\mathrm{hi}} \mathbf{F} 4 / \mathbf{8 0}^{+} \mathrm{CD}^{-} \\
\mathrm{CD}^{-} 9^{-}\end{array}$ & $\mathrm{CD}^{-} \mathrm{cDC}$ & $3.21 \pm 1.07$ \\
\hline
\end{tabular}

3B5 stromal cells were grown on a collagen sponge and transplanted under the kidney capsule of NOD/SCID (CD45.1) mice. Grafts were dissected out after 4 weeks and cells dissociated for analysis by antibody staining and flow cytometry.

* Subsets are identified by expressed markers only.

** The remainder of cells in the graft reflect hematopoietic precursors and nonhematopoietic (stromal) cells as verified in Figure 6.6. 
Figure 6.5 Localisation of myeloid cells within 3B5 grafts. 3B5 stromal cells were grown on a collagen sponge ahead of transplantation under the kidney capsule of NOD/SCID (CD45.1) mice. Graft tissues were dissected out after 4 weeks and frozen sections made for immunohistochemistry. Antibodies specific for CD11b and CD11c were used to detect hematopoietic cells, and antibodies to $\mathrm{H}-2 \mathrm{~K}^{\mathrm{k}}$ were used to detect $3 \mathrm{~B} 5$ stromal cells. (A) Lower magnification. Bar represents $250 \mu \mathrm{M}$. (B) Higher magnification. Bar represents $25 \mu \mathrm{M}$. 

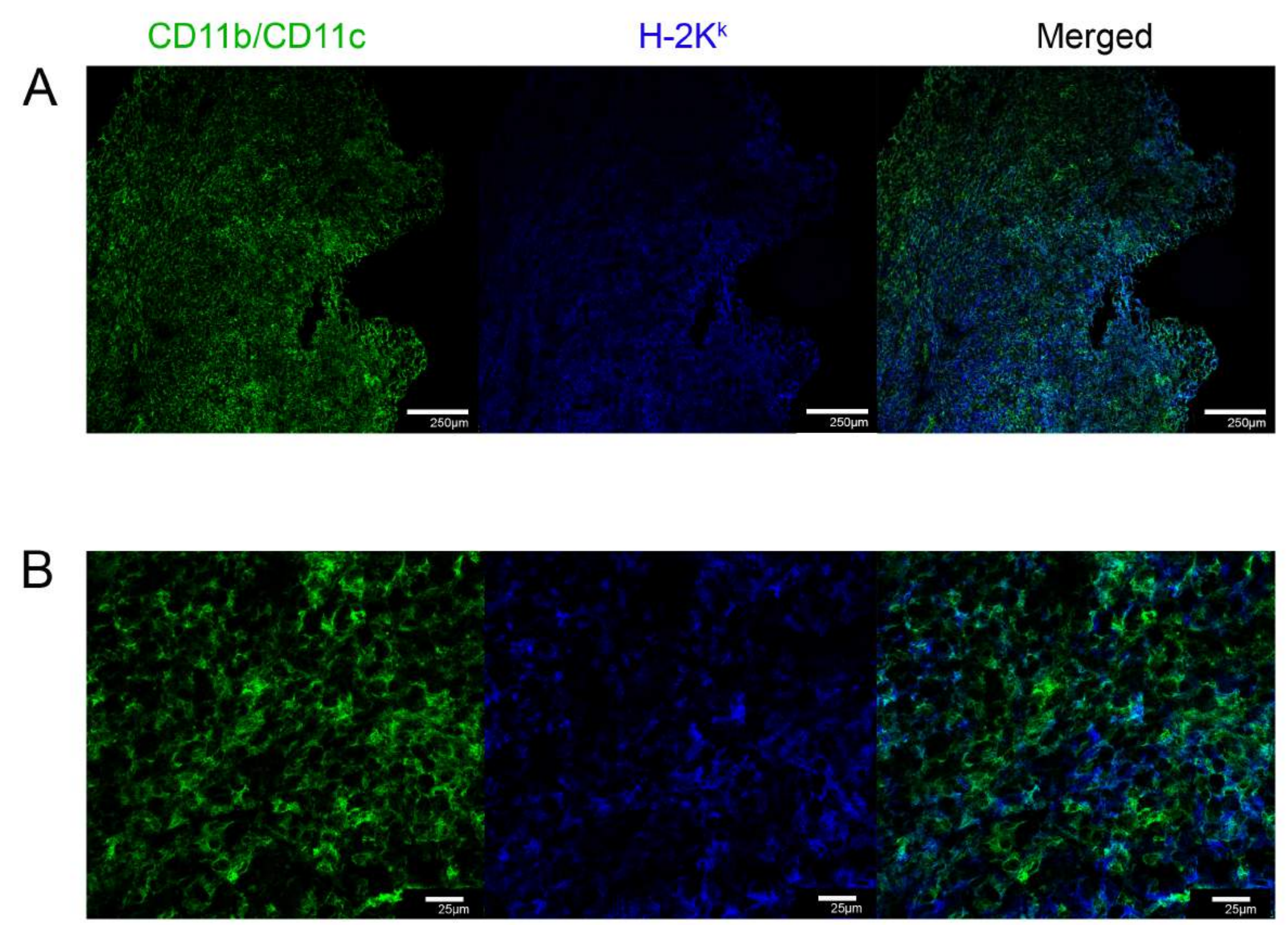
Figure 6.6 Identification of hematopoietic stem cells within 3B5 ectopic stromal grafts. Two separate grafts were prepared as described in Figure 6.1 were dissected from the kidney of NOD/SCID recipient mice at 4 weeks after transplantation and cells dissociated to distinguish hematopoietic cells of NOD/SCID host origin (CD45.1) from non-hematopoietic cells (CD45) (including 3B5 stromal cells). Hematopoietic progenitors were then identified as lineage-negative ( Lin $^{-}$) cells, with further staining for c-Kit, Sca-1, CD150 but not Flt3 to identify LT-HSC. 


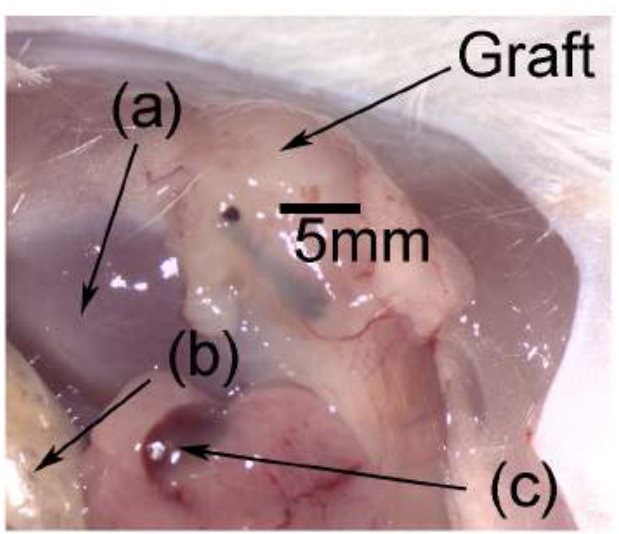

(a) Kidney

(b) Stomach

(c) Spleen

Dissociation of 3B5 graft cells

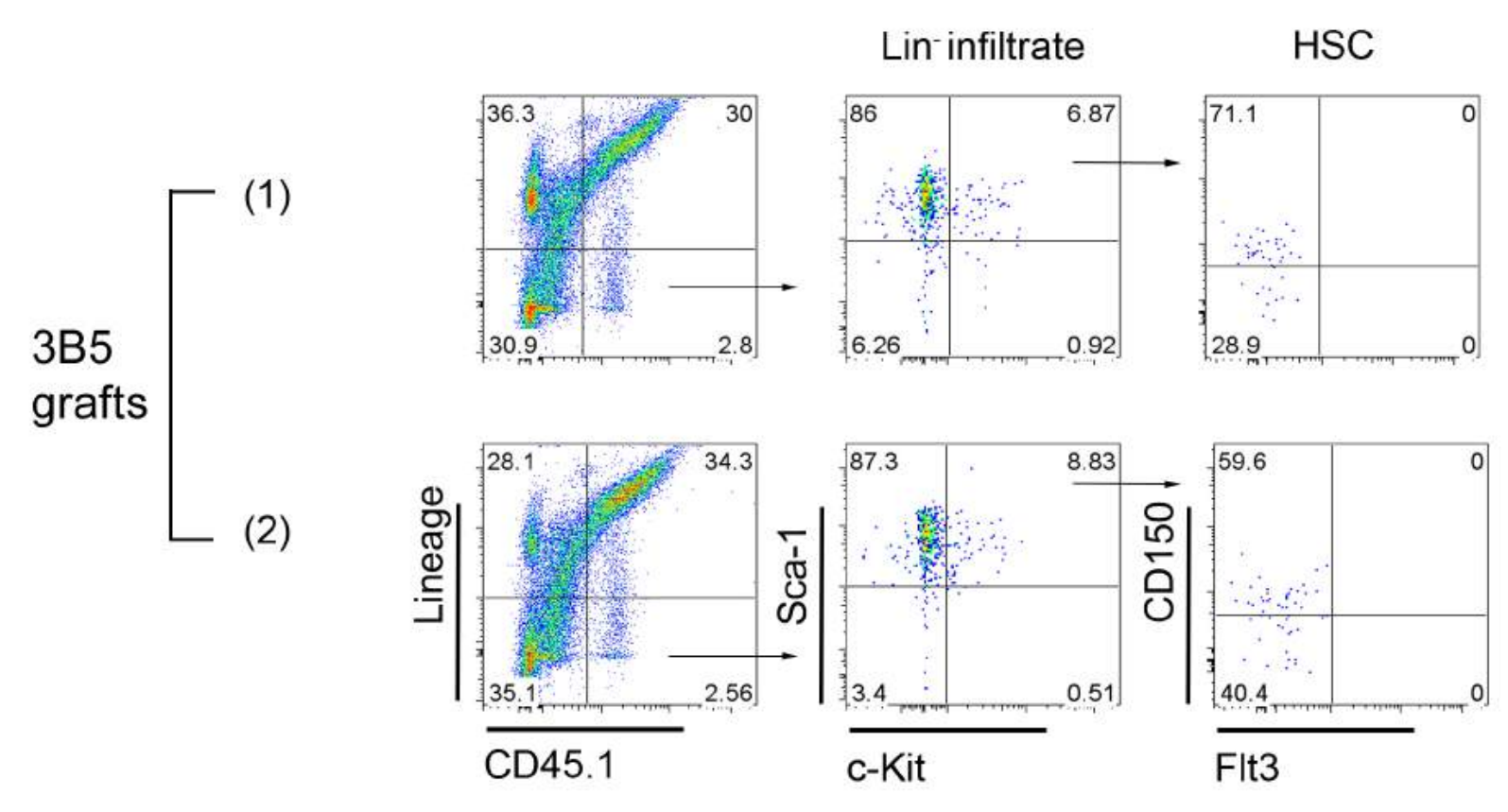


Figure 6.7 Localisation of HSC within 3 B5 stromal grafts. Trypsinised and dissociated 3B5 stromal cells were grown on a collagen sponge ahead of transplantation under the kidney capsule of 3 NOD/SCID (CD45.1) mice. Graft tissues were dissected out after 4 weeks and frozen sections made for immunohistochemistry. Antibodies to lineage markers, CD150, CD41 and CD48 were used to detect $\mathrm{HSC}$ as $\mathrm{Lin}^{-} \mathrm{CD} 150^{+} \mathrm{CD} 41^{-} / \mathrm{CD} 48^{-}$cells within 3B5 grafts. Bar represents $25 \mu \mathrm{M}$. 


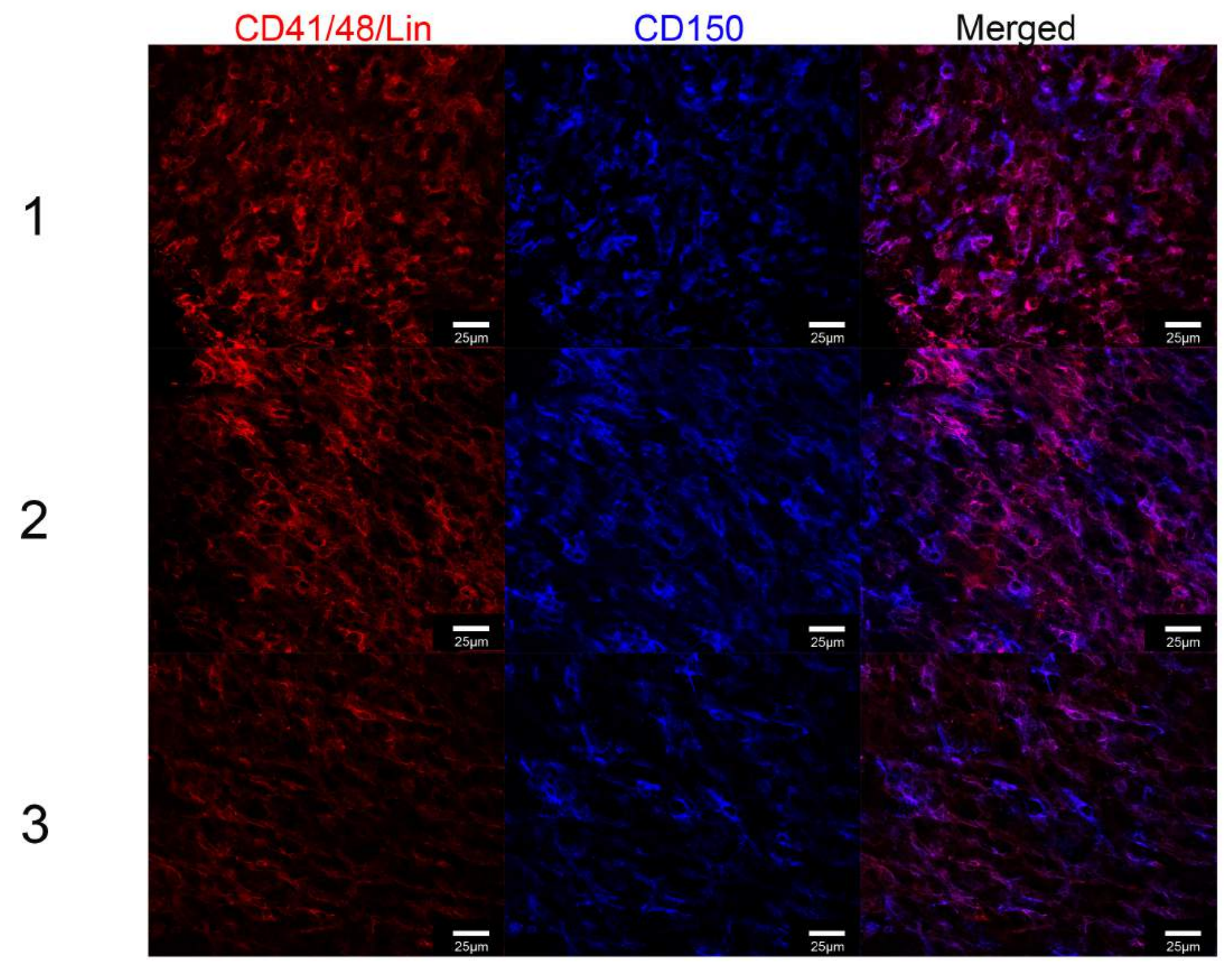


have differentiated from HSC which had become localised within 3B5 grafts. It does not, however rule out concurrent infiltration of mature cells. The Lin CD150 ${ }^{+} \mathrm{CD} 41^{-}$ phenotype also detects putative HSC with long-term reconstituting capacity.

Cells of the 10C9 splenic stromal line were also transplanted into the subcapsular space of the kidney in immunodeficient NOD/SCID mice, using a similar grafting procedure as used for 5G3 and 3B5 stroma. The success rate for 10C9 stromal cell grafting was $60 \%$ when $10^{6}$ cells were transplanted (Table 6.2). Three successive grafts obtained from three individual mice were analysed at 4 weeks after grafting. Flow cytometric analysis identified clear subsets of $\mathrm{CD} 11 \mathrm{~b}^{+} \mathrm{CD} 11 \mathrm{c}^{\mathrm{lo}} \mathrm{F} 4 / 80^{+}$cells which did not express CD3 or CD19, and which reflect L-DC in each of 3 grafts (Figure 6.8A and Figure 6.8B). In addition, another subset, which did not express the lineage markers CD11b, CD11c, F4/80, CD3 and CD19, was also detected. This subset could reflect hematopoietic stem/progenitor cells or indeed, 10C9 stromal cells. This result on a second cell line confirms the utility of splenic stroma in formation of ectopic spleen tissues.

\subsubsection{Sorted splenic stromal fractions did not engraft}

The defined splenic stromal subsets, P8, P9, P10 and P11 (Chapter 4), were chosen for transplantation on the basis of their phenotype and close resemblance with 5G3/3B5 stromal cells. To investigate whether these specific splenic stromal subsets could form ectopic grafts following transplantation into the subcapsular space of the kidney, cells were freshly sorted, mixed with Matrigel and introduced into the subcapsular space of the kidney capsule using a Wiretrol micropipette. Grafted tissue was isolated at 4 weeks and dissociated for flow cytometry.

Overall, grafting of freshly sorted, defined splenic cell stromal subsets was unsuccessful (Table 6.4). This was unrelated to host mouse strains, since three different hosts were tested. Low cell number was not the cause for graft failure, since a subset of CD45- cells reflecting the complete stromal fraction from C57BL/6J spleen (CD45.2) was sorted, mixed with Matrigel and transplanted in high cell number ( $7 \times 10^{6}$ cells). At 4 weeks, the CD45 stromal fraction did not form ectopic grafts despite high numbers of grafted cells (Table 6.4). Grafting success achieved with in vitro grown stromal cell lines begs the question of whether in vitro grown cells which are to some extent 
Figure 6.8 Identification of hematopoietic cells in 10C9 ectopic stromal grafts. Grafts prepared as described in Figure 6.1 were dissected from the kidney of NOD/SCID recipient mice 4 weeks after transplantation and cells dissociated for staining with antibodies specific for CD11b, CD11c, CD3, CD19 and F4/80. Live singlets were gated, and CD11b and CD11c myeloid cell staining used to divide subsets for analysis of expression of the lymphoid markers CD19 and CD3. Three individual grafts transplanted under the kidney capsule of a single mouse were analysed, and compared with spleen cells isolated from adult C57BL/6J and NOD/SCID mice. (A) Expression of lymphoid markers on subsets differing in expression of CD11b and CD11c. (B) Further analysis of two distinct subsets of cells in terms of myeloid and lymphoid markers. 


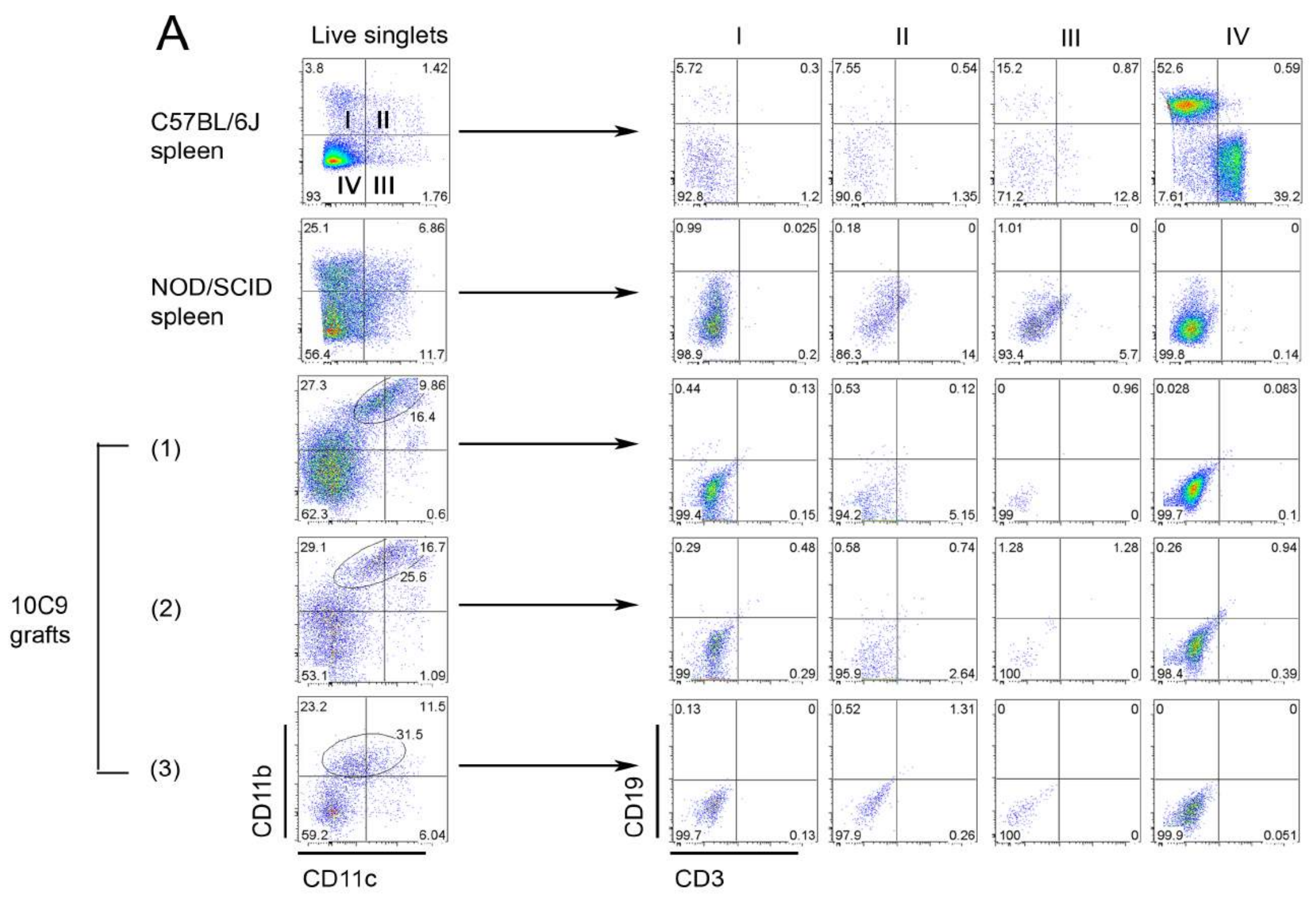



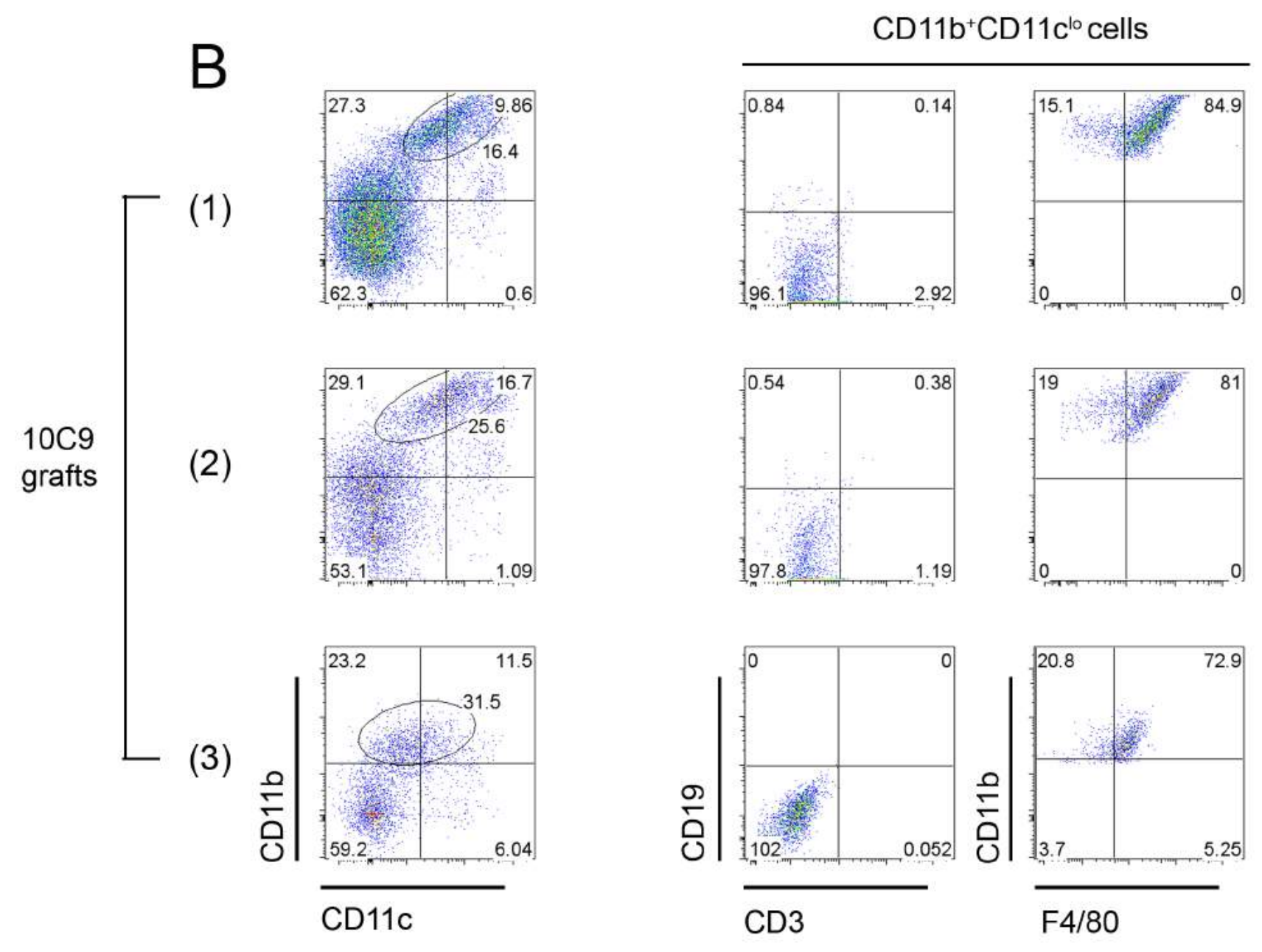
Table 6.4: Outcome of grafting experiments using splenic stromal subsets

\begin{tabular}{|c|c|c|c|}
\hline Grafted cell subset ${ }^{\#}$ & $\begin{array}{l}\text { No. of cells } \\
\text { grafted } \dagger\end{array}$ & Success rate $(\%){ }^{\#}$ & No. of hosts \\
\hline $\mathrm{CD}^{2} 5^{-}$ & $7 \times 10^{6} *$ & 0 & 2 \\
\hline $\mathrm{CD}_{140 \mathrm{a}^{+}}$ & $7 \times 10^{4} *$ & 0 & 2 \\
\hline $\mathrm{CD}_{140 \mathrm{a}^{-}}$ & $7 \times 10^{4} *$ & 0 & 1 \\
\hline \multirow{3}{*}{ Sca- $1^{\text {lo }}$ Thy $1.2^{-} \mathrm{CD} 105^{-} \mathrm{CD} 51^{+} \mathrm{CD} 140 \mathrm{a}^{\mathrm{lo}}(\mathrm{P} 8)$} & $8.74 \times 10^{2} *$ & 0 & $1 \%$ \\
\hline & $3.80 \times 10^{2} \wedge$ & 0 & 1 \\
\hline & $1.76 \times 10^{3} \S$ & 0 & 1 \\
\hline \multirow{3}{*}{ Sca- $1^{\text {lo }}$ Thy $1.2^{10} \mathrm{CD} 105^{+} \mathrm{CD} 51^{+} \mathrm{CD} 140 \mathrm{a}^{+}(\mathrm{P} 9)$} & $2.2 \times 10^{4} *$ & 0 & $1 \ddagger$ \\
\hline & $1.67 \times 10^{3} \wedge$ & 0 & 1 \\
\hline & $1 \times 10^{3} \S$ & 0 & 1 \\
\hline \multirow{3}{*}{ Sca- $1^{10}$ Thy $1.2^{-} \mathrm{CD} 105^{+} \mathrm{CD} 51^{10} \mathrm{CD} 140 \mathrm{a}^{\mathrm{lo}}(\mathrm{P} 10)$} & $4.6 \times 10^{4} *$ & 0 & $1 \dagger$ \\
\hline & $1 \times 10^{4} \wedge$ & 0 & 1 \\
\hline & $5.11 \times 10^{3} \S$ & 0 & 1 \\
\hline Sca- $^{\text {hi }}$ Thy $1.2^{-} \mathrm{CD} 105^{+} \mathrm{CD} 1^{\mathrm{lo}} \mathrm{CD} 140 \mathrm{a}^{-}(\mathrm{P} 11)$ & $7.4 \times 10^{4} *$ & 0 & $1 t$ \\
\hline
\end{tabular}

${ }^{\#}$ Stromal cell fractions were sorted from C57BL/6J mouse spleen (CD45.2, H-2K ${ }^{b}$ ) and grown in culture for 4 weeks before grafting under the kidney capsule of adult mice.

$\dagger$ Two separate grafts were placed on the same kidney. In most cases, cells were mixed with Matrigel ahead of transplantation. Grafts were analysed after 4 weeks.

* Host mice were C57BL/6J (CD45.2, H-2K $\left.{ }^{\mathrm{b}}\right)$.

$\S$ Host mice were B6.SJL (CD45.1, H-2K ${ }^{\mathrm{b}}$ ).

$\wedge^{\wedge}$ Host mice were C57BL6J Nzeg-enhanced GFP (CD45.2, H-2K $\left.{ }^{\mathrm{b}}\right)$.

$\$$ These mice were splenectomised ahead of grafting. 
transformed, are needed for successful grafting. To test this proposition further, stromal cells were sorted and grown in culture for 4 weeks before transplantation into the kidney subcapsular space. Examination of the grafted kidneys after 4 weeks showed that even cultured fresh cells gave no formation of grafts (Table 6.5). 
Table 6.5 Success of grafts involving splenic stromal subsets

\begin{tabular}{|c|c|c|c|c|}
\hline Sorted spleen subset* & $\begin{array}{l}\text { No. of cells } \\
\text { grafted } \S\end{array}$ & No. of hosts & $\begin{array}{l}\text { No. successful } \\
\text { grafts }\end{array}$ & Success rate $(\%)$ \\
\hline Thy $1.2^{+\#}$ & $5 \times 10^{5}-1 \times 10^{6}$ & 1 & 0 & 0 \\
\hline $\mathrm{CD}^{2} 9^{+}{\mathrm{gp} 38^{+} \mathrm{Sca}_{-1}^{+}}^{+}$ & & 1 & 0 & 0 \\
\hline $\mathrm{Sca}^{1 \mathrm{I}}{ }^{\mathrm{T}}$ Thy $1.2^{10} \mathrm{CD} 105^{+} \mathrm{CD}^{10} 1^{+} \mathrm{CD} 140 \mathrm{a}^{+}(\mathrm{P} 9) \dagger$ & & 2 & 0 & 0 \\
\hline
\end{tabular}

* Stromal cell subsets sorted from C57BL6/J mouse spleen (CD45.2, H-2K $\mathrm{K}^{\mathrm{b}}$ ) were grafted under the kidney capsule of adult C57BL6/J mouse (CD45.2, H-2K $\mathrm{K}^{\mathrm{b}}$.

${ }^{\#}$ Sorted CD45 cells were cultured for 4 weeks ahead of resorting. Isolated CD45 Thy $1.2^{+}$cells were grown for a further 2 weeks prior to grafting into the kidney subcapsular space of adult C57BL6/J mouse (CD45.2, H-2K $\mathrm{K}^{\mathrm{b}}$ ).

$\uparrow$ Cells were grown in culture for 4 weeks prior to grafting into the subcapsular space of kidney in adult C57BL/6J mouse

$\S$ Cells were grown overnight on a collagen sponge as a matrix for grafting, instead of mixing in Matrigel. 


\subsection{DISCUSSION}

Previous chapters demonstrated the role of splenic stroma in supporting restricted hematopoiesis in vitro. Here, we investigate the ability of cloned splenic stromal cell lines to form ectopic hematopoietic niches in vivo using a subcapsular kidney grafting technique to implant stromal cells. Earlier studies utilising this technique showed that enlargement of lymphoid follicles within neonatal spleen capsule grafts continued for up to 4 weeks post-transplant (Tan and Watanabe, 2014), while no grafts could be recovered at 8 weeks (Tan and O'Neill, 2010). Consistent with that study, we were able to recover tissue showing the presence of $\mathrm{T}$ and $\mathrm{B}$ cells at 4 weeks posttransplantation suggesting that grafted tissue could be maintained within the kidney subcapsular space for a period of at least 4 weeks. Four weeks post-transplantation was therefore used as a reference time point for graft examination and analysis of stromal grafts, although analyses at 1 and 3 weeks were also performed to assess grafting outcomes.

The overall success rate for grafting stromal cells into the subcapsular kidney region was low despite attempts to optimise grafting matrix, cell number, the need for splenectomy and time point for analysis. Uniformly, grafting of stromal cell lines was more successful than ex vivo isolated splenic stromal cell subsets. This is likely due to the transformed nature of cultured stromal cell lines, which may increase the proliferative potential of cells. The $5 \mathrm{G} 3$ stromal line was found to support in vivo production of unusual $\mathrm{CD} 11 \mathrm{~b}^{+} \mathrm{CD} 11 \mathrm{c}^{\text {hi }} \mathrm{CD}^{+} \mathrm{CD} 19^{+}$and $\mathrm{CD} 11 \mathrm{~b}^{+} \mathrm{CD} 11 \mathrm{c}^{\mathrm{lo}} \mathrm{CD} 19^{+}$cells. While the exact identity of these cells will require further investigation, $\mathrm{CD} 11 \mathrm{~b}^{+} \mathrm{CD} 11 \mathrm{c}^{\mathrm{lo}} \mathrm{CD} 19^{+}$and $\mathrm{CD} 11 \mathrm{~b}^{+} \mathrm{CD} 11 \mathrm{c}^{\mathrm{hi}} \mathrm{CD}^{+} \mathrm{CD} 19^{+}$cells reflect $\mathrm{B}-1$ lineage $\mathrm{B}$ cells (Ghosn et al., 2008) and atypical T cells (Lin et al., 2003), respectively. Interestingly, one study reported expression of myeloid markers CD11b, CD11c and F4/80 on $\mathrm{CD}^{+} \mathrm{T}$ cells following an acute viral infection (Lin et al., 2003). The expression of CD19 and CD3 by myeloid lineage cells can also occur with oncogenic transformation (Walter et al., 2010; Kita et al., 1992). This therefore raises another possibility that $5 \mathrm{G} 3$ stroma supports maintenance of cancer stem cells in vivo. This could result in production of leukemic cells with a mixed lineage phenotype commonly seen with acute myeloblastic leukemia (Walter et al., 2010; Kita et al., 1992). To this end however, it is noted that the superior capacity of 5G3 to support in vitro 
hematopoiesis was not reflected by its ability to engraft and support hematopoiesis in vivo.

Notably, the 3B5 and 10C9 stromal lines were found to grow as grafts which became infiltrated with hematopoietic cells in vivo with clear evidence of $\mathrm{CD} 11 \mathrm{~b}^{+} \mathrm{CD} 11 \mathrm{c}^{10} \mathrm{~F} 4 / 80^{+} \mathrm{L}-\mathrm{DC}-$ like cells within grafts. This finding was surprising since 3B5 stroma is a low or non-supporter of L-DC production in vitro, supporting instead the transient development of myeloid cells. Although lymphoid cells were not detected in 3B5-grafted tissue, cells resembling macrophages/monocytes, $\mathrm{cDC}, \mathrm{pDC}$ and myeloid cells were found to be present, suggesting that 3B5 stroma creates a niche which supports myelopoiesis leading to a range of mature myeloid cells. Indeed, it is possible that these cells developed from BM derived HSC, which had infiltrated the graft, were maintained within the graft, and then differentiated. It is also equally possible that HSC preferentially differentiate to give L-DC when influenced by microenvironment created by 3B5 stroma. Preferential differentiation of HSC into LDC could account for the high proportion of L-DC over other myeloid cells found within the graft. This is consistent with the previously published evidence that L-DC develop directly from HSC and MPP in stromal co-cultures in vitro (Petvises and O'Neill, 2014b).

Recently, this laboratory identified an in vivo equivalent L-DC as a subset of

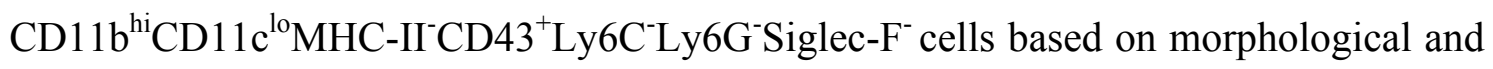
phenotypic analysis of myeloid subsets in spleen (Hey et al., 2015). Development of L$\mathrm{DC}$ was found to be distinct from that of $\mathrm{cDC}$ and monocytes, having a separate lineage origin (Hey et al., 2015). In addition, the distinct gene expression profile of L-DC distinguishes it from $\mathrm{CD}^{+} \mathrm{cDC}$ and $\mathrm{CD}^{-}$cDC (Hey and $\mathrm{O}^{\prime}$ Neill, 2016; Hey et al., 2015). On the basis of cell surface phenotype, L-DC-like cells obtained from the 3B5grafted tissue resemble L-DC described in vivo (Hey and O'Neill, 2016). It will however be important to investigate cells growing in stromal grafts more fully in terms of their relationship with L-DC found in spleen. One way to do this would be to analyse gene expression of L-DC-like cells derived from 3B5 grafts and to compare them with in vivo isolated L-DC. In addition, since 3B5 stroma is not an in vitro supporter of hematopoiesis, one needs to question whether it is able to support myelopoiesis in vitro. Ultimately, it will be important to determine the molecular signals which drive hematopoiesis in vivo. 
This chapter has presented a study which demonstrates in vivo hematopoietic support from stromal cell lines growing under the kidney capsule. While it has been possible to engraft splenic stromal cell lines, it has not been possible to form graft tissue from sorted ex vivo splenic stromal cells in the kidney subcapsular space. Specifically, 3B5 stromal cells represent a niche which maintains hematopoietic stem/progenitor cells. It would be of interest to know if these hematopoietic stem/progenitor cells could provide long-term reconstitution in irradiated mice by performing serial transplantation. The property of 3B5 in supporting hematopoiesis in vivo is different to its in vitro capacity, and is also restricted to myelopoiesis. This result opens the interesting possibility that splenic stromal niches have distinct hematopoietic potential which opens many questions in terms of the immune function and hematopoietic capacity of spleen. 
CHAPTER SEVEN

GENERAL DISCUSSION 


\subsection{CONCLUDING DISCUSSION}

Early investigations in this laboratory focused on understanding the splenic microenvironment for hematopoiesis. LTC established from 6-8 days old neonatal spleens were found to support the development of an immature dendritic-like cell named 'LTC-DC' (Ni and O'Neill, 1999; Ni and O'Neill, 1998). Subsequent studies cloned the STX3 parent stroma derived from one LTC to give stromal cell lines including 5G3, 3B5 and 10C9 under study here (Despars and O'Neill, 2006a). Cocultures involving 5G3 stroma overlaid with lineage-negative BM cells were able to support the production of immature dendritic-like cells similar to LTC-DC, and therefore named 'L-DC' (Periasamy and O'Neill, 2013; Periasamy et al., 2009). Interestingly, it was found that 5G3 and 10C9, but not 3B5 stroma were able to support this type of restricted in vitro hematopoiesis (Periasamy et al., 2009). The fact that splenic LTC and co-cultures could maintain DC production for an extended period reflects the presence of self-renewing progenitors. Indeed, other investigators in this laboratory have shown that L-DC develop directly from overlaid HSC and MPP in 5G3 stromal co-cultures, which also suggests that HSC are maintained within the in vitro stromal environment (Petvises and O'Neill, 2014b). While HSC or MPP in these cocultures have not been phenotypically delineated, long-term reconstitution studies in mice using cells from LTC have verify their presence (Tan and O'Neill, 2010; Tan and O'Neill, 2010).

HSC represent one of the most well studied adult stem cells. In fact, research into HSC biology and their use in allogeneic BM transplantation has been ongoing for the last fifty years. Despite a long history of research in this area, the regulation of selfrenewal of HSC and their differentiation, as well as quiescence and proliferation of HSC, remains incomplete. While research into HSC biology has been almost entirely conducted in the $\mathrm{BM}$, the spleen has recently gained attention in regenerative medicine as a potential substitute for $\mathrm{BM}$ as a hematopoietic organ. Our laboratory offers a valuable in vitro splenic LTC, and 5G3 stromal cell model, for the in vitro study of hematopoiesis in spleen. In addition, the differential hematopoietic support of the two stromal cell lines, 5G3 and 3B5, provides a unique channel for identifying factors which support hematopoiesis. 
In this thesis, the field has been advanced by characterising the splenic stromal population in an attempt to delineate in vivo $5 \mathrm{G} 3$ equivalent stromal cells which support hematopoiesis. In addition, localisation of HSC and its niches in spleen has been conducted using immunofluorescence imaging. Assessment of hematopoietic support in vivo has involved ectopic grafting of stromal subsets into the subcapsular space of kidney in mice. Finally, molecular interactions between stroma and non-adherent hematopoietic cells in co-cultures have been investigated using inhibitors which were added directly into established co-cultures.

In summary, Chapter 3 describes extensively the 5G3 splenic stromal co-culture system which was modelled on LTC. This system supports restricted in vitro hematopoiesis, leading to continuous production of a dendritic-like subset called L-DC, while maintaining progenitors for a long period of time. The lineage origin of 5G3 and 3B5 stroma based on their cell surface phenotype was assessed in Chapter 3. Both stroma express CD105, CD29, Sca-1, Thy1.2, CD51 and CD140a markers and do not express any hematopoietic or endothelial markers, consistent with a mesenchymal origin. 5G3 and 3B5 stroma express many markers which are also expressed by fibroblastic reticular cells, marginal reticular cells, red pulp fibroblasts and follicular dendritic cells, consistent with a common ancestry from a mesenchymal lineage. In Chapter 3, addition of specific signalling pathway inhibitors to in vitro stromal cocultures involving lineage-depleted BM over 5G3 stroma, was used to identify the important role of SCF but not CXCL12 in supporting in vitro hematopoiesis. In similar experiments the DAPT inhibitor of Notch signalling was used to identify a role for Notch signalling in the development of L-DC from MPP added into co-cultures over $5 \mathrm{G} 3$ stroma in vitro.

In Chapter 4, attempts were made to isolate a 5G3 equivalent stromal cell population in spleen. It was found that the stromal population in spleen is heterogeneous, and this contributed to variability in hematopoietic support capacity of isolated stromal fractions observed in initial co-culture assays. Several cell surface markers including Sca-1, gp38, Thy1.2, CD140a and CD105 were found to be important markers for stromal cells which could be established and grown in vitro. In addition, the cells which grew in these in vitro cultures consistently showed the phenotype of Sca$1^{+} \mathrm{gp} 38^{+}$Thy $1.2^{+} \mathrm{CD} 29^{+} \mathrm{CD} 51^{+}$cells. This phenotype also appeared to define stroma which support hematopoiesis. In vitro culturing of mesenchymal stromal cells in spleen 
appears to select the transformed 5G3-like cells which have enhanced in vitro growth and also show selective hematopoietic support capacity.

The stromal architecture of spleen was investigated in Chapter 5 with the aim of identifying stromal regions reflective of HSC niches. Adult and neonatal spleens were compared initially, and it was found that $\mathrm{T}$ and $\mathrm{B}$ cell zones in 6-day old neonatal spleen were not fully developed while adult murine spleen had well-developed $\mathrm{T}$ and $\mathrm{B}$ cell zones necessary for immune function. Neonatal spleen showed more F4/80 macrophages and a larger area of red pulp than did adult spleen. One explanation for this finding is that $\mathrm{F} 4 / 80^{+}$macrophages arise by hematopoiesis from HSC within fetal spleens which drive macrophage development by inhibiting lymphoid commitment (Bertrand et al., 2006). HSC were readily localised in the red pulp of both neonatal and pregnant adult spleens. The association of HSC with hematopoietic $\mathrm{F} 4 / 80^{+}$macrophages and Thy $1.2^{+}$stromal cells was characterised. In addition, gp $38^{+}$stromal cells were found to associate with HSC but only in neonatal spleen, which suggests that HSC niches in spleen might vary during different stages of development.

In Chapter 6, kidney subcapsular grafting was employed to study the hematopoietic support capacity of stromal cell subsets of interest identified in Chapter 4. While in vitro grown stromal cell lines proved successful in forming graft tissue within the subcapsular space of the kidney, no sorted subsets of splenic stromal cells were found to successfully form graft tissue. It was found that grafted 3B5 stroma supported myelopoiesis with production of cells including L-DC, macrophages, monocytes, DC and myeloid cells in vivo. This contrasts with in vitro data which shows that $3 \mathrm{~B} 5$ is a non-supporter of long-term hematopoiesis leading to L-DC production, although it does transiently produce myeloid cells. In contrast, 5G3, which is a supporter of in vitro hematopoiesis and L-DC production, did not support in vivo development of L-DC. Instead, it was found to support production of unusual $\mathrm{CD} 11 \mathrm{~b}^{+} \mathrm{CD} 11 \mathrm{c}^{10} \mathrm{CD} 19^{+}$and $\mathrm{CD} 11 \mathrm{~b}^{+} \mathrm{CD} 11 \mathrm{c}^{\mathrm{hi}} \mathrm{CD} 3^{+}$cells, which reflect B-1 cells (Ghosn et al., 2008) and atypical T cells (Lin et al., 2003), respectively. It is also possible however that these cells reflect oncogenic myeloid cells of acute myeloblastic leukemia (Walter et al., 2010; Kita et al., 1992). Indeed, the hematopoietic support capacity of the 5G3 and 3B5 cell lines may be enhanced in an in vivo environment, so that 3B5 now functions in terms of full support for L-DC and myeloid cell production not previously seen in vitro. In contrast, 5G3 
which is a very effective in vitro supporter may show enhanced signalling of HSC in vivo leading to oncogenesis. This model would need to be tested however. 


\subsection{AN IN VITRO MODEL FOR HEMATOPOIESIS}

The 5G3 stromal co-culture represents a valuable model for studying hematopoiesis and particularly L-DC production. One notable feature of this robust and highly reproducible stromal co-culture system lies on its technical simplicity such that the study of molecular factors, important for in vitro hematopoiesis, can be easily assessed using inhibitors which block receptor-ligand interactions in specific signalling pathways. Indeed, previous studies in this laboratory have successfully used inhibitors for Flt3L and M-CSFR in co-cultures to show that development of L-DC occurred independently of the factors which support development of cDC (Petvises and O'Neill, 2014b). Likewise, work here has also used the inhibitors Plerixafor and Imatinib to investigate the role of $\mathrm{CXCL} 12 / \mathrm{CXCR} 4$ and $\mathrm{SCF} / \mathrm{c}-\mathrm{Kit}$ interactions in in vitro hematopoiesis. Both interactions have been implicated in the maintenance of HSC in the BM (Ding and Morrison, 2013; Ding et al., 2012; Mendez-Ferrer et al., 2010; Omatsu et al., 2010; Sugiyama et al., 2006). In particular, it was recently shown that conditional deletion of $\mathrm{Cxcl1} 2$ from endothelial cells and perivascular stromal cells in BM caused a reduction in HSC frequency (Ding and Morrison, 2013). That same group has also demonstrated depletion of HSC in mice with conditional deletion of Scf from endothelial and LepR-expressing perivascular cells (Ding et al., 2012). While CXCL12/CXCR4 signalling did not appear to be important in our study, SCF/c-Kit interaction was found to be essential for L-DC development in co-cultures of HSC over $5 \mathrm{G} 3$ stroma. It is worthy to note that since most of the earlier studies involving conditional deletion of $\operatorname{Cxcl12}$ and $S c f$ were carried out in BM, there is a possibility that splenic hematopoiesis might be regulated slightly differently, although a recent study reported that induced splenic extramedullary hematopoiesis requires both SCF produced by both endothelial cells and $T c f 21^{+}$stromal cells, and CXCL12 produced by $T c f 21^{+}$ stromal cells (Inra et al., 2015). One explanation could be that the in vitro stromal environment reflects the native steady-state hematopoietic environment rather than stroma amplified due to physiological stress leading to increased numbers of HSC niches for support of extramedullary hematopoiesis. It is also important to consider that our study on CXCL12/CXCR4 signalling was performed with a more heterogeneous lineage-depleted cell population rather than purely isolated HSC.

One critical question relevant to the study of in vitro hematopoiesis, is whether the stromal co-culture system maintains a pool of self-renewing progenitors. It was 
shown in an earlier study that L-DC progenitors are enriched within the $\mathrm{Lin}^{-} \mathrm{c}-\mathrm{Kit}^{+}$ subset of spleen and maintained for at least 5 weeks in co-culture (Petvises and O'Neill, 2014b; Periasamy et al., 2013b; Tan et al., 2010). This is consistent with the data obtained in our present study, investigating the presence of $\mathrm{Lin}^{-} \mathrm{c}-\mathrm{Kit}^{+}$progenitors in stromal co-cultures that had been established with $\mathrm{CD}^{-} 5^{-}$and $\mathrm{CD} 140 \mathrm{a}^{+}$stroma for at least 5 weeks (Chapter 4). Previous investigations also confirmed that L-DC progenitors are distinct from progenitors of DC and macrophages, since L-DC develop directly from LT-HSC and MPP, but not from MDP or CDP (Petvises and O'Neill, 2014b). Consistent with those findings, are results obtained here involving HSC/MPP co-cultures treated with the $\gamma$-secretase Notch inhibitor, DAPT (Chapter 3). Indeed, production of L-DC was increased in cultures with added Notch inhibitor. This Notch inhibitor could be an important regulator of MPP maintenance. Several groups have reported similar findings on the role of Notch in the maintenance of HSC/MPP (Wang et al., 2015; Benveniste et al., 2014; Corselli et al., 2013; Varnum-Finney et al., 2011). Previously, Benveniste et al. (2014) showed that Notch signalling is required for in vitro maintenance of the CD90 ${ }^{\text {low }}$ HSC subset. Accelerated differentiation of CD90 ${ }^{\text {low }}$ HSC to CD45RA ${ }^{\text {int }}$ and CD45RA ${ }^{\text {hi }}$ cells was observed when Notch signalling was abrogated (Benveniste et al., 2014).

While in vitro hematopoietic studies using splenic stromal lines may not fully or truly reflect the hematopoietic process occurring in vivo in spleen, successful in vivo characterisation of L-DC and its progenitors would suggest that in vitro studies may be of great value. Recently, our laboratory identified the in vivo equivalent of L-DC as

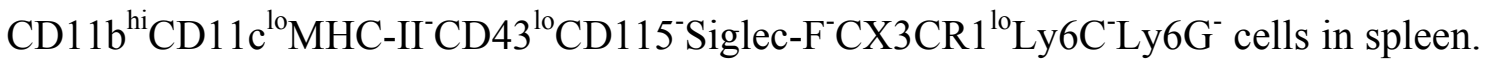
These cells do not activate $\mathrm{CD}^{+}{ }^{+} \mathrm{T}$ cells (Hey and O'Neill, 2016; Hey et al., 2015), but they do, however, activate $\mathrm{CD}^{+} \mathrm{T}$ cells by cross-presentation, reflecting similar functional capacity as in vitro produced L-DC (Hey and O'Neill, 2016). L-DC in vivo appear to be distinct from other conventional DC types and macrophages/monocytes based on gene expression profiling (Hey and O'Neill, 2016), suggesting a novel type of dendritic-like cell in spleen. Data from in vivo kidney subcapsular space grafting experiments have also revealed the presence of L-DC-like cells accumulating within grafted tissues (Chapter 6). Taken together, it is likely that the presence of L-DC within the context of a steady-state spleen is of biological relevance and not an artefact or product of in vitro culture procedures. 
This study also showed that 5G3 and 3B5 support the in vitro growth of different cell types within the kidney subcapsular space. In particular, while 5G3 stroma supports L-DC formation in vitro, this is not the case in vivo. Similar discrepancy is noted for 3B5 stroma which supported accumulation of multiple hematopoietic cell types including L-DC within grafts, despite its classification as a non-supporter of LDC in vitro. Such discrepancies highlight the complexity of the in vivo environment, where cells are subjected to numerous cues and signals for their development. While the in vitro model of a single cloned stromal cell type could recapitulate a specific signalling repertoire, it is unlikely to represent exactly the complex in vivo environment. This outcome emphasizes how it is important to couple each in vitro study with an in vivo one in terms of seeking physiological relevance. With regard to 5G3 and 3B5 kidney subcapsular grafting experiments, it will of interest to investigate the specific cues and signals which 5G3 and 3B5 stroma receive within the kidney subcapsular space that leads to discrepancies between in vivo and in vitro data. 


\subsection{SPLENIC STROMA SUPPORTS RESTRICTED HEMATOPOIESIS}

It is increasingly evident that the stromal cell population in spleen performs a diverse range of tasks in addition to having a structural role. Splenic stroma has been shown to support production of macrophages (Bertrand et al., 2006) and regulatory dendritic cells (Tang et al., 2006). Moreover, our laboratory has shown that splenic stroma can support production of dendritic-like cells, termed 'L-DC' over an extended period of time. Progress to date has led to the identification of several main stromal cell types in spleen. These include fibroblastic reticular cells, marginal reticular cells, follicular dendritic cells, red pulp fibroblasts and vascular endothelial cells (den Haan et al., 2012; Mueller and Germain, 2009). Each of these stromal subsets performs a specific set of tasks including lymphocyte migration, B cell homeostasis, chemokine production, attraction of macrophages and plasma cells and removal of aged red blood cells (Malhotra et al., 2013; Mueller and Germain, 2009). An important unanswered question has been which splenic stromal cell type has capacity to support hematopoiesis, particularly under steady-state conditions.

The study described here contributes to a better understanding of splenic stromal composition, as well as the potential of splenic stroma to support in vitro hematopoiesis. Since the 5G3 stromal cell line represents a valuable model for in vitro hematopoiesis, it has been important to characterise an in vivo equivalent subset of this cell line. However, splenic stroma characterisation is not without challenges. In fact, one of the biggest challenges is the lack of delineating markers. Previous research into lymph node stroma has provided some information (Chang and Turley, 2015; Malhotra et al., 2013; Malhotra et al., 2012). Here, we have used a step-wise reductionist approach to either deplete or enrich stromal cells expressing one or two cell surface markers. This experiment aimed to determine markers important for stromal growth and hematopoietic support capacity. A battery of cell surface markers including Sca-1, gp38, Thy1.2, CD140a and CD105 was found to be important for stromal cell establishment and in vitro growth. It is also worth noting that the proportion of cells expressing these markers is very low, reflecting stromal cells which are rare and infrequent.

One of the most important findings revealed by this study is the heterogeneity within the splenic stromal population which grows in vitro. It appears that heterogeneity can impact hematopoietic support capacity and this was shown for clonal cell lines 
derived from parental STX3 splenic stroma (Despars and O'Neill, 2006a). Heterogeneity in stromal composition could also be due to culture conditions since it is known that MSC exhibit altered cell surface expression profile when cultured extensively in vitro (Le Blanc et al., 2007). However, it can be disputed that the heterogeneity within the stromal population reflects diversity in terms of stromal cell types.

Since 5G3 is an in vitro hematopoietic supporter while 3B5 is a non-supporter, an analysis of differential gene/protein expression between these two cell lines could identify molecules which determine hematopoietic support capacity. Indeed, the two cell surface markers Thy1.2 and CD140a were found to be upregulated in 5G3 over 3B5. A recent report of the involvement of Thy1.2 in the self-renewal and differentiation of MSC begs the question of whether it has a similar functional role in 5G3 stroma (Maleki et al., 2014; Moraes et al., 2016). Upregulation of the CD140a cell surface protein, a tyrosine kinase receptor which binds platelet-derived growth factor (PDGF) to initiate signalling (Heldin and Westermark, 1999), suggests that this protein may be important for hematopoiesis. It has been reported that CD140a expression on mesenchymal cells is low in vivo, although expression increases drastically in culture or during inflammation (Andrae et al., 2008; Heldin and Westermark, 1999). While it is unclear if CD140a plays a functional role in hematopoiesis, it will be important to investigate it further since it is also recognised as an important marker of perivascular cells in BM and spleen (Inra et al., 2015). In order to better understand the role of Thy 1.2 and CD140a in hematopoiesis, knockout mice could be utilised.

In recognising the limitations of in vitro studies, we have analysed the function of stromal cells in vivo by grafting sorted splenic stromal cells and in vitro grown splenic cell lines into the mouse kidney subcapsular space in order to study their development and hematopoietic support capacity in vivo. The inability to graft freshly isolated stromal cells form spleen may suggest that mature stromal cells have no or low replication capacity and that grafting may depend on the isolation and transplantation of stromal progenitors to initiate ectopic niche formation. These may or may not be present in spleen, and may derive from another source such as BM or blood. The reason why stromal cell lines can be grafted could therefore be due to their induced replicative capacity due to in vitro transformation. The alternative explanation is that the kidney subcapsular space lacks specific signals required for these sorted splenic stromal cells to 
expand and form grafts. BM mesenchymal progenitors, have been shown to successfully induce ectopic niche formation under the kidney capsule in a recent report (Hu et al., 2016). To this end, it will be interesting to know if freshly sorted splenic stromal subsets can form grafts within the kidney subcapsular space in animals in which extramedullary hematopoiesis has been induced perhaps through bleeding or pregnancy. This will determine whether inflammation induced due to physiological stress is an important requirement for formation of ectopic niches by splenic stromal cells. 


\subsection{STEM CELL NICHES IN SPLEEN}

A stem cell niche by definition is a microenvironment which supports the selfrenewal, maintenance and differentiation of stem cells. For the last few decades, the concept of a stem cell niche was mainly hypothetical, without strong experimental evidence. This has, however, changed since technological advances have led to many approaches to experimentation. While most work has been dedicated to characterising HSC niches in BM, splenic niches which support extramedullary hematopoiesis remain largely uncharacterised despite the recognition of spleen as a common site for hematopoiesis. This thesis has improved current understanding of stromal niches in spleen by investigating the stromal subsets present in murine spleen and the localisation of HSC with respect to splenic architecture and stromal cell subsets distributed in spleen.

The thesis provides extensive evidence justifying the presence of a stromal HSC niche in spleen. For example, we have identified HSC in close association with Thy $1.2^{+}$ cells within the red pulp of the pregnant spleens. The gp $38^{+}$stromal subset is also associated with some HSC in neonatal spleen although not in adult or pregnant spleen. Our present data suggests potential for niches to change with age and hematopoietic requirements. Other cell types, like endothelial cells expressing CD31 and CD105, did not show any association with HSC. However, one limitation of this type of study is the inability to identify stromal cells which can act on HSC in a paracrine fashion without direct contact, perhaps by producing factors like CXCL12 and SCF (Ding and Morrison, 2013; Ding et al., 2012). Indeed, it was demonstrated recently that $T c f 21^{+}$cells and endothelial cells support splenic extramedullary hematopoiesis as niche elements through production of SCF and CXCL12 (Inra et al., 2015). It will be of interest to know if the splenic stromal lines and subsets identified here represent these cells.

Evidence presented here that stromal cell lines can form ectopic niches supporting HSC and leading to the development of L-DC and other myeloid cell types, adds physiological relevance to the in vitro studies reported previously. An important remaining consideration is whether in vitro grown and transformed stromal lines support the formation of cancer stem cells from HSC or MPP. Such a model would enhance the engraftment outcome of the transplanted cells, and in the case of the 5G3 stromal line, may lead to the formation of aberrant cell types reflective of leukemic stem cells as reported for acute myeloblastic leukemia (Walter et al., 2010; Kita et al., 1992). 
While the main role of spleen is immunity, its role in erythropoiesis and recycling of aged red blood cells have been well documented (Mebius and Kraal, 2005). Throughout ontogeny, spleen can also adopt the role of a hematopoietic organ under conditions of stress and inflammation (Johns and Christopher, 2012). During embryogenesis, the spleen and liver assume a major role in hematopoiesis (Wolber et al., 2002). In adults, spleen takes the place of BM as the primary hematopoietic organ during BM pathogenesis (Yamamoto et al., 2016). One would argue that this dynamic role for spleen relies on its ability to quickly expand its stromal cell populations. Indeed, rare stromal cells which support hematopoiesis may be laid down during fetal life as progenitors and remain dormant in spleen until required. Another hypothesis would be that rare MSC are maintained in spleen and can be quickly differentiated to give stromal cells at times of stress. Since most studies rely on models of hematopoiesis in spleen which involve induced extramedullary hematopoiesis (Inra et al., 2015; Miwa et al., 2013; Kiel et al., 2005), it is possible that hematopoietic supporting cell types implicated in these models differ from those naturally occurring in steady-state spleen. One possible investigation could involve cell-tracing experiments, looking at splenic MSC, or the in vivo $5 \mathrm{G} 3$ equivalent stromal cells as Sca$1^{+}$gp $38^{+}$Thy $1.2^{+} \mathrm{CD} 29^{+} \mathrm{CD} 51^{+} \mathrm{CD} 140 \mathrm{a}^{+/-} \mathrm{CD} 105^{+/-}$cells during steady-state conditions and after induced physiological stress leading to increased hematopoiesis in spleen. 


\subsection{CONCLUSION}

The spleen is now well recognised as an important organ for extramedullary hematopoiesis in the steady-state, and also under physiological stress including pregnancy, acute inflammation, excessive bleeding and drug treatment (Yamamoto et al., 2016; Inra et al., 2015; Miwa et al., 2013; Johns and Christopher, 2012; O'Neill et al., 2011; Kim, 2010; Kiel et al., 2005). In this thesis, we have advanced the concept of niches for hematopoiesis in spleen. Stromal cells with the phenotype of Sca$1^{+}$gp $38^{+}$Thy $1.2^{+} \mathrm{CD} 29^{+} \mathrm{CD} 51^{+}$appear to be important for in vitro hematopoiesis. Their phenotype reflects cells of mesenchymal lineage, consistent with our primary hypothesis that HSC niches involve at least perivascular reticular cells resembling the stromal line models of 5G3 and 3B5. Stromal cells expressing gp38 or Thy1.2 also appear to be associated with some HSC is spleen identified through section staining, although this association is restricted to neonatal spleen in the case of gp $38^{+}$stromal cells. Restricted hematopoiesis giving rise to L-DC and myeloid cells was replicated in vivo following grafting of splenic stromal cell lines including 5G3, 3B5 and 10C9. While L-DC production was clearly shown to occur within 3B5 and 10C9 grafts, 5G3 was difficult to engraft and then formed niches which appeared to support hematopoietic cells with a transformed phenotype.

The recognition of spleen as an important site for extramedullary hematopoiesis represents a significant advance for the area of regenerative medicine and transplantation. Clearly identified stromal progenitors and stromal cell subsets could be harvested for the purpose of reengineering niches in order to increase hematopoietic cell production either through expansion of HSC in vitro using co-cultures, or in vivo through formation of ectopic or artificial niches engrafted ahead of HSC transplantation. Patients undergoing myeloablative treatment, involution of lymphoid tissue with ageing, or HSC transplantation could stand to benefit from novel therapies based on knowledge of spleen and its role in hematopoiesis. 


\section{REFERENCES}


ANDERSON, A. O. \& SHAW, S. 1993. T cell adhesion to endothelium: the FRC conduit system and other anatomic and molecular features which facilitate the adhesion cascade in lymph node. Seminars in Immunology, 5, 271-282.

ANDRAE, J., GALLINI, R. \& BETSHOLTZ, C. 2008. Role of platelet-derived growth factors in physiology and medicine. Genes \& Development, 22, 1276-1312.

ASSELIN-PATUREL, C., BOONSTRA, A., DALOD, M., DURAND, I., YESSAAD, N., DEZUTTER-DAMBUYANT, C., VICARI, A., O'GARRA, A., BIRON, C., BRIERE, F. \& TRINCHIERI, G. 2001. Mouse type I IFN-producing cells are immature APCs with plasmacytoid morphology. Nature Immunology, 2, 11441150.

AUDET, J., MiLleR, C. L., ROSE-JOHN, S., PIRET, J. M. \& EAVES, C. J. 2001. Distinct role of gp130 activation in promoting self-renewal divisions by mitogenically stimulated murine hematopoietic stem cells. Proceedings of the National Academy of Sciences, USA, 98, 1757-1762.

AUSTYN, J. M. \& GORDON, S. 1981. F4/80, a monoclonal antibody directed specifically against the mouse macrophage. European Journal of Immunology, $11,805-815$.

BAJÉNOFF, M., GLAICHENHAUS, N. \& GERMAIN, R. N. 2008. Fibroblastic reticular cells guide $\mathrm{T}$ lymphocyte entry into and migration within the splenic $\mathrm{T}$ cell zone. Journal of Immunology, 181, 3947-3954.

BARON, M. H. 2003. Embryonic origins of mammalian hematopoiesis. Experimental Hematology, 31, 1160-1169.

BARTOLOVIC, K., BALABANOV, S., HARTMANN, U., KOMOR, M., BOEHMLER, A. M., BUHRING, H. J., MOHLE, R., HOELZER, D., KANZ, L., HOFMANN, W. K. \& BRUMMENDORF, T. H. 2004. Inhibitory effect of imatinib on normal progenitor cells in vitro. Blood, 103, 523-529.

BENVENISTE, P., SERRA, P., DERVOVIC, D., HERER, E., KNOWLES, G., MOHTASHAMI, M. \& ZUNIGA-PFLUCKER, J. C. 2014. Notch signals are required for in vitro but not in vivo maintenance of human hematopoietic stem cells and delay the appearance of multipotent progenitors. Blood, 123, 11671177.

BERTRAND, J. Y., DESANTI, G. E., LO-MAN, R., LECLERC, C., CUMANO, A. \& GOLUB, R. 2006. Fetal spleen stroma drives macrophage commitment. Development, 133, 3619-3628. 
BIANCO, P. 2011. Bone and the hematopoietic niche: a tale of two stem cells. Blood, 117, 5281-5288.

BONILlA, W. V., FROHLICH, A., SENN, K., KALLERT, S., FERNANDEZ, M., JOHNSON, S., KREUTZFELDT, M., HEGAZY, A. N., SCHRICK, C., FALlON, P. G., KLEMENZ, R., NAKAE, S., ADLER, H., MERKLER, D., LOHNING, M. \& PINSCHEWER, D. D. 2012. The alarmin interleukin-33 drives protective antiviral CD8(+) T cell responses. Science, 335, 984-989.

BOULAIS, P. E. \& FRENETTE, P. S. 2015. Making sense of hematopoietic stem cell niches. Blood, 125, 2621-2629.

BRASEL, K., MCKENNA, H. J., MORRISSEY, P. J., CHARRIER, K., MORRIS, A. E., LEE, C. C., WILLIAMS, D. E. \& LYMAN, S. D. 1996. Hematologic effects of flt3 ligand in vivo in mice. Blood, 88, 2004-2012.

BRATOSIN, D., MAZURIER, J., TISSIER, J. P., ESTAQUIER, J., HUART, J. J., AMEISEN, J. C., AMINOFF, D. \& MONTREUIL, J. 1998. Cellular and molecular mechanisms of senescent erythrocyte phagocytosis by macrophages. A review. Biochimie, 80, 173-195.

BRENDOLAN, A., ROSADO, M. M., CARSETTI, R., SELlERI, L. \& DEAR, T. N. 2007. Development and function of the mammalian spleen. Bioessays, 29, 166177.

BURN, S. F., BOOT, M. J., DE ANGELIS, C., DOOHAN, R., ARQUES, C. G., TORRES, M. \& HILL, R. E. 2008. The dynamics of spleen morphogenesis. Developmental Biology, 318, 303-311.

CALVI, L. M., ADAMS, G. B., WEIBRECHT, K. W., WEBER, J. M., OLSON, D. P., KNIGHT, M. C., MARTIN, R. P., SCHIPANI, E., DIVIETI, P., BRINGHURST, F. R., MILNER, L. A., KRONENBERG, H. M. \& SCADDEN, D. T. 2003. Osteoblastic cells regulate the haematopoietic stem cell niche. Nature, 425, 841846.

CESTA, M. F. 2006. normal structure, function, and histology of the spleen. Toxicologic Pathology, 34, 455-465.

CHANG, J. E. \& TURLEY, S. J. 2015. Stromal infrastructure of the lymph node and coordination of immunity. Trends in Immunology, 36, 30-39.

CHEONG, C., MATOS, I., CHOI, J.-H., DANDAMUdi, D. B., SHRESTHA, E., LONGHI, M. P., JEFFREY, K. L., ANThONY, R. M., KLUGER, C., NCHINDA, G., KOH, H., RODRIGUEZ, A., IDOYAGA, J., PACK, M., VELINZON, K., PARK, C. G. \& STEINMAN, R. M. 2010. Microbial 
stimulation fully differentiates monocytes to DC-SIGN/CD209+ dendritic cells for Immune T cell areas. Cell, 143, 416-429.

CHOW, A., LUCAS, D., HIDALGO, A., MENDEZ-FERRER, S., HASHIMOTO, D., SCHEIERMANN, C., BATTISTA, M., LEBOEUF, M., PROPHETE, C., VAN ROOIJEN, N., TANAKA, M., MERAD, M. \& FRENETTE, P. S. 2011. Bone marrow CD169+ macrophages promote the retention of hematopoietic stem and progenitor cells in the mesenchymal stem cell niche. The Journal of Experimental Medicine, 208, 261-271.

CHRISTENSEN, J. L. \& WEISSMAN, I. L. 2001. Flk-2 is a marker in hematopoietic stem cell differentiation: A simple method to isolate long-term stem cells. Proceedings of the National Academy of Sciences, 98, 14541-14546.

CHRISTENSEN, J. L., WRIGHT, D. E., WAGERS, A. J. \& WEISSMAN, I. L. 2004. Circulation and chemotaxis of fetal hematopoietic stem cells. PLOS Biology, 2, E75.

ClEVERS, H., ALARCON, B., WILEMAN, T. \& TERHORST, C. 1988. The T cell receptor/CD3 complex: a dynamic protein ensemble. Annual Review of Immunology, 6, 629-662.

CORSElli, M., CHIN, C. J., PAREKH, C., SAHAGHIAN, A., WANG, W., GE, S., EVSEENKO, D., WANG, X., MONTELATICI, E., LAZZARI, L., CROOKS, G. M. \& PEAULT, B. 2013. Perivascular support of human hematopoietic stem/progenitor cells. Blood, 121, 2891-2901.

CUPEDO, T., JANSEN, W., KRAAL, G. \& MEBIUS, R. E. 2004. Induction of secondary and tertiary lymphoid structures in the skin. Immunity, 21, 655-667.

DE TOGNI, P., GOELlnER, J., RUDDle, N. H., STREETER, P. R., FICK, A., MARIATHASAN, S., SMITH, S. C., CARLSON, R., SHORNICK, L. P., STRAUSS-SCHOENBERGER, J. \& ET AL. 1994. Abnormal development of peripheral lymphoid organs in mice deficient in lymphotoxin. Science, 264, 703707.

DEJARDIN, E., DROIN, N. M., DELHASE, M., HAAS, E., CAO, Y., MAKRIS, C., LI, Z. W., KARIN, M., WARE, C. F. \& GREEN, D. R. 2002. The lymphotoxinbeta receptor induces different patterns of gene expression via two NF-kappaB pathways. Immunity, 17, 525-535.

DEN HAAN, J. M., MEBIUS, R. E. \& KRAAL, G. 2012. Stromal cells of the mouse spleen. Frontiers in Immunology, 3, 201. 
DESPARS, G. \& O'NEILL, H. C. 2006a. Heterogeneity amongst splenic stromal cell lines which support dendritic cell haematopoiesis In Vitro Cellular \& Developmental Biology - Animal, 42, 208-215.

DESPARS, G. \& O'NEILL, H. C. 2006b. Splenic endothelial cell lines support development of dendritic cells from bone marrow. Stem Cells, 24, 1496-1504.

DING, L. \& MORRISON, S. J. 2013. Haematopoietic stem cells and early lymphoid progenitors occupy distinct bone marrow niches. Nature, 495, 231-235.

DING, L., SAUNDERS, T. L., ENIKOLOPOV, G. \& MORRISON, S. J. 2012. Endothelial and perivascular cells maintain haematopoietic stem cells. Nature, 481, 457-462.

DOMINICI, M., LE BLANC, K., MUELLER, I., SLAPER-CORTENBACH, I., MARINI, F., KRAUSE, D., DEANS, R., KEATING, A., PROCKOP, D. \& HORWITZ, E. 2006. Minimal criteria for defining multipotent mesenchymal stromal cells. The International Society for Cellular Therapy position statement. Cytotherapy, 8, 315-317.

DOR, F. J., RAMIREZ, M. L., PARMAR, K., AltMAN, E. L., HUANG, C. A., DOWN, J. D. \& COOPER, D. K. 2006. Primitive hematopoietic cell populations reside in the spleen: Studies in the pig, baboon, and human. Experimental Hematology, 34, 1573-1582.

DOUGALL, W. C., GLACCUM, M., CHARRIER, K., ROHRBACH, K., BRASEL, K., DE SMEDT, T., DARO, E., SMITH, J., TOMETSKO, M. E., MALISZEWSKI, C. R., ARMSTRONG, A., SHEN, V., BAIN, S., COSMAN, D., ANDERSON, D., MORRISSEY, P. J., PESCHON, J. J. \& SCHUH, J. 1999. RANK is essential for osteoclast and lymph node development. Genes \& Development, 13, 2412-2424.

DOUlatov, S., NOTTA, F., LAURENTI, E. \& DICK, JOHN E. 2012. Hematopoiesis: A human perspective. Cell Stem Cell, 10, 120-136.

DRENCKHAHN, D. \& WAGNER, J. 1986. Stress fibers in the splenic sinus endothelium in situ: molecular structure, relationship to the extracellular matrix, and contractility. The Journal of Cell Biology, 102, 1738-1747.

DUFF, S. E., LI, C., GARLAND, J. M. \& KUMAR, S. 2003. CD105 is important for angiogenesis: evidence and potential applications. FASEB Journal, 17, 984-992.

DUNCAN, A. W., RATTIS, F. M., DIMASCIO, L. N., CONGDON, K. L., PAZIANOS, G., ZHAO, C., YOON, K., COOK, J. M., WILlERT, K., 
GAIANO, N. \& REYA, T. 2005. Integration of Notch and Wnt signaling in hematopoietic stem cell maintenance. Nature Immunology, 6, 314-322.

DUTTA, P., HOYER, F. F., GRIGORYEVA, L. S., SAGER, H. B., LEUSCHNER, F., COURTIES, G., BORODOVSKY, A., NOVOBRANTSEVA, T., RUDA, V. M., FITZGERALD, K., IWAMOTO, Y., WOJTKIEWICZ, G., SUN, Y., DA SILVA, N., LIBBY, P., ANDERSON, D. G., SWIRSKI, F. K., WEISSLEDER, R. \& NAHRENDORF, M. 2015. Macrophages retain hematopoietic stem cells in the spleen via VCAM-1. The Journal of Experimental Medicine, 212, 497512.

DZIERZAK, E. \& SPECK, N. A. 2008. Of lineage and legacy: the development of mammalian hematopoietic stem cells. Nature Immunology, 9, 129-136.

ELIASSON, P. \& JONSSON, J. I. 2010. The hematopoietic stem cell niche: low in oxygen but a nice place to be. Journal of Cellular Physiology, 222, 17-22.

ELlyARD, J. I., AVERY, D. T., MACKAY, C. R. \& TANGYE, S. G. 2005. Contribution of stromal cells to the migration, function and retention of plasma cells in human spleen: potential roles of CXCL12, IL-6 and CD54. European Journal of Immunology, 35, 699-708.

EMA, H. \& NAKAUCHI, H. 2000. Expansion of hematopoietic stem cells in the developing liver of a mouse embryo. Blood, 95, 2284-2288.

FARR, A. G., BERRY, M. L., KIM, A., NELSON, A. J., WELCH, M. P. \& ARUFFO, A. 1992. Characterization and cloning of a novel glycoprotein expressed by stromal cells in T-dependent areas of peripheral lymphoid tissues. Journal of Experimental Medicine, 176, 1477-1482.

FLEMING, T. J., FLEMING, M. L. \& MALEK, T. R. 1993. Selective expression of Ly-6G on myeloid lineage cells in mouse bone marrow. RB6-8C5 mAb to granulocyte-differentiation antigen (Gr-1) detects members of the Ly-6 family. The Journal of Immunology 151, 2399-2408.

FORSTER, R., SCHUBEL, A., BREITFELD, D., KREMMER, E., RENNERMULLER, I., WOLF, E. \& LIPP, M. 1999. CCR7 coordinates the primary immune response by establishing functional microenvironments in secondary lymphoid organs. Cell, 99, 23-33.

FRENETTE, P. S., SUBbARAO, S., MAZO, I. B., VON ANDRIAN, U. H. \& WAGNER, D. D. 1998. Endothelial selectins and vascular cell adhesion molecule-1 promote hematopoietic progenitor homing to bone marrow. Proceedings of the National Academy of Sciences, USA, 95, 14423-14428. 
FUJiSAKI, J., WU, J., CARLSON, A. L., SilberSTEIN, L., PUTHETI, P., LAROCCA, R., GAO, W., SAITO, T. I., LO CELSO, C., TSUYUZAKI, H., SATO, T., COTE, D., SYKES, M., STROM, T. B., SCADDEN, D. T. \& LIN, C. P. 2011. In vivo imaging of Treg cells providing immune privilege to the haematopoietic stem-cell niche. Nature, 474, 216-219.

GARG, S., MADKAIKAR, M. \& GHOSH, K. 2013. Investigating cell surface markers on normal hematopoietic stem cells in three different niche conditions. International Journal of Stem Cells, 6, 129-133.

GEISSMANN, F., MANZ, M. G., JUNG, S., SIEWEKE, M. H., MERAD, M. \& LEY, K. 2010. Development of Monocytes, Macrophages, and Dendritic Cells. Science, 327, 656-661.

GERBERICK, G. F., CRUSE, L. W., RYAN, C. A., HULETTE, B. C., CHANEY, J. G., SKINNER, R. A., DEARMAN, R. J. \& KIMBER, I. 2002. Use of a B cell marker (B220) to discriminate between allergens and irritants in the local lymph node assay. Toxicological Sciences, 68, 420-428.

GHOSN, E. E. B., YANG, Y., TUNG, J., HERZENBERG, L. A. \& HERZENBERG, L. A. 2008. CD11b expression distinguishes sequential stages of peritoneal B-1 development. Proceedings of the National Academy of Sciences, USA, 105, 5195-5200.

GODIN, I., GARCIA-PORRERO, J. A., DIETERLEN-LIÈVRE, F. \& CUMANO, A. 1999. Stem cell emergence and hemopoietic activity are incompatible in mouse intraembryonic sites. Journal of Experimental Medicine, 190, 43-52.

GOLUB, R. \& CUMANO, A. 2013. Embryonic hematopoiesis. Blood Cells, Molecules, and Diseases, 51, 226-231.

GRETZ, J. E., ANDERSON, A. O. \& SHAW, S. 1997. Cords, channels, corridors and conduits: critical architectural elements facilitating cell interactions in the lymph node cortex. Immunological Reviews, 156, 11-24.

HAAR, J. L. \& ACKERMAN, G. A. 1971. A phase and electron microscopic study of vasculogenesis and erythropoiesis in the yolk sac of the mouse. The Anatomical Record, 170, 199-223.

HARDING, C. V. \& UNANUE, E. R. 1990. Quantitation of antigen-presenting cell MHC class II/peptide complexes necessary for T-cell stimulation. Nature, 346, 574-6.

HE, S., NAKADA, D. \& MORRISON, S. J. 2009. Mechanisms of stem cell selfrenewal. Annual Review of Cell and Developmental Biology, 25, 377-406. 
HECKSHER-SORENSEN, J., WATSON, R. P., LETTICE, L. A., SERUP, P., ELEY, L., DE ANGElis, C., AHLGREN, U. \& HILL, R. E. 2004. The splanchnic mesodermal plate directs spleen and pancreatic laterality, and is regulated by Bapx1/Nkx3.2. Development, 131, 4665-75.

HELDIN, C. H. \& WESTERMARK, B. 1999. Mechanism of action and in vivo role of platelet-derived growth factor. Physiological Reviews, 79, 1283-316.

HEY, Y. Y. \& O'NEILL, H. C. 2016. Antigen presenting properties of a myeloid dendritic-like cell in murine spleen. PLOS ONE, 11, e0162358.

HEY, Y. Y., TAN, J. K. \& O'NEILL, H. C. 2015. Redefining myeloid cell subsets in murine spleen. Frontiers in Immunology, 6, 652.

HINTON, R., PETVISES, S. \& O'NEILL, H. 2011. Myelopoiesis related to perinatal spleen. Immunology \& Cell Biology, 89, 689-695.

HIRSCHI, K. K. 2012. Hemogenic endothelium during development and beyond. Blood, 119, 4823-4827.

HONDA, K., NAKANO, H., YOSHIDA, H., NISHIKAWA, S., RENNERT, P., IKUTA, K., TAMECHIKA, M., YAMAGUCHI, K., FUKUMOTO, T., CHIBA, T. \& NISHIKAWA, S. I. 2001. Molecular basis for hematopoietic/mesenchymal interaction during initiation of Peyer's patch organogenesis. Journal of Experimental Medicine, 193, 621-630.

HOOPER, A. T., BUTLER, J. M., NOLAN, D. J., KRANZ, A., IIDA, K., KOBAYASHI, M., KOPP, H. G., SHIDO, K., PETIT, I., YANGER, K., JAMES, D., WITTE, L., ZHU, Z., WU, Y., PYTOWSKI, B., ROSENWAKS, Z., MITTAL, V., SATO, T. N. \& RAFII, S. 2009. Engraftment and reconstitution of hematopoiesis is dependent on VEGFR2-mediated regeneration of sinusoidal endothelial cells. Cell Stem Cell, 4, 263-274.

HU, X., GARCIA, M., WENG, L., JUNG, X., MURAKAMI, J. L., KUMAR, B., WARDEN, C. D., TODOROV, I. \& CHEN, C. C. 2016. Identification of a common mesenchymal stromal progenitor for the adult haematopoietic niche. Nature Communications, 7, 13095.

HUBER, T. L., KOUSKOFF, V., JOERG FEHLING, H., PALIS, J. \& KELLER, G. 2004. Haemangioblast commitment is initiated in the primitive streak of the mouse embryo. Nature, 432, 625-630.

HuGHeS, C. S., POSTOVIT, L. M. \& LAJOIE, G. A. 2010. Matrigel: a complex protein mixture required for optimal growth of cell culture. Proteomics, 10, 1886-1890. 
HYNES, R. O. 1987. Integrins: A family of cell surface receptors. Cell, 48, 549-554.

IKUTA, K., KINA, T., MACNEIL, I., UCHIDA, N., PEAULT, B., CHIEN, Y. H. \& WEISSMAN, I. L. 1990. A developmental switch in thymic lymphocyte maturation potential occurs at the level of hematopoietic stem cells. Cell, 62, 863-874.

INRA, C. N., ZHOU, B. O., ACAR, M., MURPHY, M. M., RICHARDSON, J., ZHAO, Z. \& MORRISON, S. J. 2015. A perisinusoidal niche for extramedullary haematopoiesis in the spleen. Nature, 527, 466-471.

JOHNS, J. L. \& CHRISTOPHER, M. M. 2012. Extramedullary hematopoiesis: a new look at the underlying stem cell niche, theories of development, and occurrence in animals. Veterinary Pathology Online, 49, 508-523.

KATAKAI, T., SUTO, H., SUGAI, M., GONDA, H., TOGAWA, A., SUEMATSU, S., EBISUNO, Y., KATAGIRI, K., KINASHI, T. \& SHIMIZU, A. 2008. Organizer-like reticular stromal cell layer common to adult secondary lymphoid organs. Journal of Immunology, 181, 6189-6200.

KIEL, M. J. \& MORRISON, S. J. 2008. Uncertainty in the niches that maintain haematopoietic stem cells. Nature Reviews Immunology, 8, 290-301.

KIEL, M. J., RADICE, G. L. \& MORRISON, S. J. 2007. Lack of evidence that hematopoietic stem cells depend on $\mathrm{N}$-cadherin-mediated adhesion to osteoblasts for their maintenance. Cell Stem Cell, 1, 204-217.

KIEL, M. J., YILMAZ, M. H., IWASHITA, T., YILMAZ, O. H., TERHORST, C. \& MORRISON, S. J. 2005. SLAM family receptors distinguish hematopoietic stem and progenitor cells and reveal endothelial niches for stem cells. Cell, 121, 1109-1121.

KIM, C. H. 2010. Homeostatic and pathogenic extramedullary hematopoiesis. Journal of Blood Medicine, 1, 13-19.

KITA, K., NAKASE, K., MIWA, H., MASUYA, M., NISHII, K., MORITA, N., TAKAKURA, N., OTSUJI, A., SHIRAKAWA, S., UEDA, T. \& ET AL. 1992. Phenotypical characteristics of acute myelocytic leukemia associated with the $\mathrm{t}(8 ; 21)(\mathrm{q} 22 ; \mathrm{q} 22)$ chromosomal abnormality: frequent expression of immature Bcell antigen CD19 together with stem cell antigen CD34. Blood, 80, 470-477.

KleinMAN, H. K., MCGARVEY, M. L., LiOtTA, L. A., ROBEY, P. G., TRYGGVASON, K. \& MARTIN, G. R. 1982. Isolation and characterization of type IV procollagen, laminin, and heparan sulfate proteoglycan from the EHS sarcoma. Biochemistry, 21, 6188-6193. 
KNUTSON, M. \& WESSLING-RESNICK, M. 2003. Iron metabolism in the reticuloendothelial system. Critical Reviews in Biochemistry and Molecular Biology, 38, 61-88.

KUNISAKI, Y., BRUNS, I., SCHEIERMANN, C., AHMED, J., PINHO, S., ZHANG, D., MIZOGUCHI, T., WEI, Q., LUCAS, D., ITO, K., MAR, J. C., BERGMAN, A. \& FRENETTE, P. S. 2013. Arteriolar niches maintain haematopoietic stem cell quiescence. Nature, 502, 637-643.

KUPER, C. F., VAN BILSEN, J., CNOSSEN, H., HOUBEN, G., GARTHOFF, J. \& WOLTERBEEK, A. 2016. Development of immune organs and functioning in humans and test animals: Implications for immune intervention studies. Reproductive Toxicology, 64, 180-190.

LE BLANC, K., SAMUELSSON, H., LONNIES, L., SUNDIN, M. \& RINGDEN, O. 2007. Generation of immunosuppressive mesenchymal stem cells in allogeneic human serum. Transplantation, 84, 1055-1059.

LEARY, A. G., ZENG, H. Q., CLARK, S. C. \& OGAWA, M. 1992. Growth factor requirements for survival in G0 and entry into the cell cycle of primitive human hemopoietic progenitors. Proceedings of the National Academy of Sciences, USA, 89, 4013-4017.

LI, Z., LAN, Y., HE, W., CHEN, D., WANG, J., ZHOU, F., WANG, Y., SUN, H., CHEN, X., XU, C., LI, S., PANG, Y., ZHANG, G., YANG, L., ZHU, L., FAN, M., SHANG, A., JU, Z., LUO, L., DING, Y., GUO, W., YUAN, W., YANG, X. \& LIU, B. 2012. Mouse embryonic head as a site for hematopoietic stem cell development. Cell Stem Cell, 11, 663-675.

LILLY, A. J., JOHNSON, W. E. \& BUNCE, C. M. 2011. The haematopoietic stem cell niche: new insights into the mechanisms regulating haematopoietic stem cell behaviour. Stem Cells International, 2011.

LIN, Y., ROBERTS, T. J., SRIRAM, V., CHO, S. \& BRUTKIEWICZ, R. R. 2003. Myeloid marker expression on antiviral CD8+ T cells following an acute virus infection. European Journal of Immunology, 33, 2736-2743.

LINDNER, U., KRAMER, J., ROHWEDEL, J. \& SCHLENKE, P. 2010. Mesenchymal stem or stromal cells: toward a better understanding of their biology? Transfusion Medicine and Hemotherapy, 37, 75-83.

LIU, K. \& NUSSENZWEIG, M. C. 2010. Origin and development of dendritic cells. Immunological Reviews, 234, 45-54. 
LIU, K., VICTORA, G. D., SCHWICKERT, T. A., GUERMONPREZ, P., MEREDITH, M. M., YAO, K., CHU, F. F., RANDOLPH, G. J., RUDENSKY, A. Y. \& NUSSENZWEIG, M. 2009. In vivo analysis of dendritic cell development and homeostasis. Science, 324, 392-397.

LO CELSO, C., Fleming, H. E., WU, J. W., ZHAO, C. X., MiAKE-LYE, S., FUJISAKI, J., COTE, D., ROWE, D. W., LIN, C. P. \& SCADDEN, D. T. 2009. Live-animal tracking of individual haematopoietic stem/progenitor cells in their niche. Nature, 457, 92-96.

LOKMIC, Z., LÄMMERMANN, T., SIXT, M., CARDELL, S., HALLMANN, R. \& SOROKIN, L. 2008. The extracellular matrix of the spleen as a potential organizer of immune cell compartments. Seminars in Immunology, 20, 4-13.

LUTHER, S. A., TANG, H. L., HYMAN, P. L., FARR, A. G. \& CYSTER, J. G. 2000. Coexpression of the chemokines ELC and SLC by T zone stromal cells and deletion of the ELC gene in the plt/plt mouse. Proceedings of the National Academy of Sciences, USA, 97, 12694-12699.

MALEKI, M., GHANBARVAND, F., REZA BEHVARZ, M., EJTEMAEI, M. \& GHADIRKHOMI, E. 2014. Comparison of mesenchymal stem cell markers in multiple human adult stem cells. International Journal of Stem Cells, 7, 118-126.

MALHOTRA, D., FLETCHER, A. L., ASTARITA, J., LUKACS-KORNEK, V., TAYAliA, P., GONZALEZ, S. F., ELPEK, K. G., CHANG, S. K., KNOBliCH, K., HEMler, M. E., BRENNER, M. B., CARROLL, M. C., MOONEY, D. J. \& TURLEY, S. J. 2012. Transcriptional profiling of stroma from inflamed and resting lymph nodes defines immunological hallmarks. Nature Immunology, 13, 499-510.

MALHOTRA, D., FLETCHER, A. L. \& TURLEY, S. J. 2013. Stromal and hematopoietic cells in secondary lymphoid organs: partners in immunity. Immunological Reviews, 251, 160-176.

MASSBERG, S., SCHAERLI, P., KNEZEVIC-MARAMICA, I., KÖLLNBERGER, M., TUBO, N., MOSEMAN, E. A., HUFF, I. V., JUNT, T., WAGERS, A. J., MAZO, I. B. \& VON ANDRIAN, U. H. 2007. Immunosurveillance by hematopoietic progenitor cells trafficking through blood, lymph, and peripheral tissues. Cell, 131, 994-1008.

MAZO, I. B., GUTIERREZ-RAMOS, J.-C., FRENETTE, P. S., HYNES, R. O., WAGNER, D. D. \& VON ANDRIAN, U. H. 1998. Hematopoietic progenitor cell rolling in bone marrow microvessels: parallel contributions by endothelial 
selectins and vascular cell adhesion molecule 1. Journal of Experimental Medicine, 188, 465-474.

MCARDEL, S. L., TERHORST, C. \& SHARPE, A. H. 2016. Roles of CD48 in regulating immunity and tolerance. Clinical Immunology 164, 10-20.

MCNIECE, I. K. \& BRIDDELL, R. A. 1995. Stem cell factor. Journal of Leukocyte Biology, 58, 14-22.

MEBIUS, R. E. \& KRAAL, G. 2005. Structure and function of the spleen. Nature Reviews Immunology, 5, 606-616.

MEBIUS, R. E., RENNERT, P. \& WEISSMAN, I. L. 1997. Developing lymph nodes collect CD4+CD3- LT beta+ cells that can differentiate to APC, NK cells, and follicular cells but not T or B cells. Immunity, 7, 493-504.

MEDVINSKY, A. \& DZIERZAK, E. 1996. Definitive hematopoiesis is autonomously initiated by the AGM region. Cell, 86, 897-906.

MENDEZ-FERRER, S., MICHURINA, T. V., FERRARO, F., MAZLOOM, A. R., MACARTHUR, B. D., LIRA, S. A., SCADDEN, D. T., MA'AYAN, A., ENIKOLOPOV, G. N. \& FRENETTE, P. S. 2010. Mesenchymal and haematopoietic stem cells form a unique bone marrow niche. Nature, 466, 829834.

MERAD, M., SATHE, P., HELFT, J., MILlER, J. \& MORTHA, A. 2013. The dendritic cell lineage: ontogeny and function of dendritic cells and their subsets in the steady state and the inflamed setting. Annual Review of Immunology, 31, 563-604.

MILOUD, T., HAMMERLING, G. J. \& GARBI, N. 2010. Review of murine dendritic cells: types, location, and development. Methods in Molecular Biology, 595, 2142.

MIWA, Y., HAYASHI, T., SUZUKI, S., ABE, S., ONISHI, I., KIRIMURA, S., KITAGAWA, M. \& KURATA, M. 2013. Up-regulated expression of CXCL12 in human spleens with extramedullary haematopoiesis. Pathology, 45, 408-416.

MORA, J. R., BONO, M. R., MANJUNATH, N., WENINGER, W., CAVANAGH, L. L., ROSEMBLATT, M. \& VON ANDRIAN, U. H. 2003. Selective imprinting of gut-homing T cells by Peyer's patch dendritic cells. Nature, 424, 88-93.

MORAES, D. A., SIBOV, T. T., PAVON, L. F., ALVIM, P. Q., BONADIO, R. S., DA SILVA, J. R., PIC-TAYLOR, A., TOLEDO, O. A., MARTI, L. C., AZEVEDO, R. B. \& OLIVEIRA, D. M. 2016. A reduction in CD90 (THY-1) expression 
results in increased differentiation of mesenchymal stromal cells. Stem Cell Research \& Therapy, 7, 97.

MORITA, Y., ISEKI, A., OKAMURA, S., SUZUKI, S., NAKAUCHI, H. \& EMA, H. 2011. Functional characterization of hematopoietic stem cells in the spleen. Experimental Hematology, 39, 351-359.

MORRISON, S. J. \& SPRADLING, A. C. 2008. Stem cells and niches: mechanisms that promote stem cell maintenance throughout life. Cell, 132, 598-611.

MORRISON, S. J., WRIGHT, D. E. \& WEISSMAN, I. L. 1997. Cyclophosphamide/granulocyte colony-stimulating factor induces hematopoietic stem cells to proliferate prior to mobilization. Proceedings of the National Academy of Sciences, USA, 94, 1908-1913.

MUELLER, S. N. \& GERMAIN, R. N. 2009. Stromal cell contributions to the homeostasis and functionality of the immune system. Nature Reviews Immunology, 9, 618-629.

MÜller, A. M., MEDVINSKY, A., STROUBOUliS, J., GROSVELD, F. \& DZIERZAKT, E. 1994. Development of hematopoietic stem cell activity in the mouse embryo. Immunity, 1, 291-301.

MUller-SIEBURG, C., SIEBURG, H. B., BERNITZ, J. M. \& CATTAROSSI, G. 2012. Stem cell heterogeneity: implications for aging and regenerative medicine. Blood, 119, 3900-3907.

NAGAI, Y., GARRETT, K. P., OHTA, S., BAHRUN, U., KOURO, T., AKIRA, S., TAKATSU, K. \& KINCADE, P. W. 2006. Toll-like receptors on hematopoietic progenitor cells stimulate innate immune system replenishment. Immunity, 24, 801-12.

NAGASAWA, T., OMATSU, Y. \& SUGIYAMA, T. 2011. Control of hematopoietic stem cells by the bone marrow stromal niche: the role of reticular cells. Trends in Immunology, 32, 315-320.

NAIK, S. H., SATHE, P., PARK, H. Y., METCALF, D., PROIETTO, A. I., DAKIC, A., CAROTTA, S., O'KEEFFE, M., BAHLO, M., PAPENFUSS, A., KWAK, J. Y., WU, L. \& SHORTMAN, K. 2007. Development of plasmacytoid and conventional dendritic cell subtypes from single precursor cells derived in vitro and in vivo. Nature Immunology, 8, 1217-1226.

NAKADA, D., OGURO, H., LEVI, B. P., RYAN, N., KITANO, A., SAITOH, Y., TAKEICHI, M., WENDT, G. R. \& MORRISON, S. J. 2014. Oestrogen 
increases haematopoietic stem-cell self-renewal in females and during pregnancy. Nature, 505, 555-558.

NEIPP, M., ZORINA, T., DOMENICK, M. A., EXNER, B. G. \& ILDSTAD, S. T. 1998. Effect of FLT3 ligand and granulocyte colony-stimulating factor on expansion and mobilization of facilitating cells and hematopoietic stem cells in mice: kinetics and repopulating potential. Blood, 92, 3177-3188.

NEWMAN, P. J. 1997. The biology of PECAM-1. The Journal of Clinical Investigation, 99, 3-8.

NI, K. \& O'NEILL, H. 1999. Spleen stromal cells support haemopoiesis and in vitro growth of dendritic cells from bone marrow. British Journal of Haematology, 105, 58-67.

NI, K. \& O'NEILL, H. C. 1997. Long-term stromal cultures produce dendritic-like cells. British Journal of Haematology, 97, 710-725.

NI, K. \& O'NEILL, H. C. 1998. Hemopoiesis in long-term stroma-dependent cultures from lymphoid tissue: production of cells with myeloid/dendritic characteristics. In Vitro Cellular \& Developmental Biology - Animal, 34, 298-307.

NILSSON, S. K., JOHNSTON, H. M., WHITTY, G. A., WILLIAMS, B., WEBB, R. J., DENHARDT, D. T., BERTONCELLO, I., BENDALL, L. J., SIMMONS, P. J. \& HAYLOCK, D. N. 2005. Osteopontin, a key component of the hematopoietic stem cell niche and regulator of primitive hematopoietic progenitor cells. Blood, 106, 1232-1239.

NOLTE, M. A., BELIEN, J. A., SCHADEE-EESTERMANS, I., JANSEN, W., UNGER, W. W., VAN ROOIJEN, N., KRAAL, G. \& MEBIUS, R. E. 2003. A conduit system distributes chemokines and small blood-borne molecules through the splenic white pulp. Journal of Experimental Medicine, 198, 505-512.

O'NEILL, H. C., GRIFFITHS, K. L., PERIASAMY, P., HINTON, R. A., HEY, Y. Y. \& TAN, J. K. H. 2011. Spleen as a site for hematopoiesis of a distinct antigen presenting cell type. Stem Cells International, 2011.

OGAWA, M., MATSUZAKI, Y., NISHIKAWA, S., HAYASHI, S., KUNISADA, T., SUDO, T., KINA, T. \& NAKAUCHI, H. 1991. Expression and function of c-kit in hemopoietic progenitor cells. Journal of Experimental Medicine, 174, 63-71.

OGURO, H., DING, L. \& MORRISON, S. J. 2013. SLAM family markers resolve functionally distinct subpopulations of hematopoietic stem cells and multipotent progenitors. Cell stem cell, 13, 102-116. 
OH, I.-H. \& KWON, K.-R. 2010. Concise Review: Multiple Niches for Hematopoietic Stem Cell Regulations. STEM CELLS, 28, 1243-1249.

OMATSU, Y., SUGIYAMA, T., KOHARA, H., KONDOH, G., FUJI, N., KOHNO, K. \& NAGASAWA, T. 2010. The Essential Functions of Adipo-osteogenic Progenitors as the Hematopoietic Stem and Progenitor Cell Niche. Immunity, 33, 387-399.

ORKIN, R. W., GEHRON, P., MCGOODWIN, E. B., MARTIN, G. R., VALENTINE, T. \& SWARM, R. 1977. A murine tumor producing a matrix of basement membrane. Journal of Experimental Medicine, 145, 204-220.

PAJCINI, K. V., SPECK, N. A. \& PEAR, W. S. 2011. Notch signaling in mammalian hematopoietic stem cells. Leukemia, 25, 1525-1532.

PALIS, J., ROBERTSON, S., KENNEDY, M., WALL, C. \& KELLER, G. 1999. Development of erythroid and myeloid progenitors in the yolk sac and embryo proper of the mouse. Development, 126, 5073-5084.

PERIASAMY, P. \& O'NEILL, H. C. 2013. Stroma-dependent development of two dendritic-like cell types with distinct antigen presenting capability. Experimental Hematology, 41, 281-292.

PERIASAMY, P., PETVISES, S. \& O'NEILL, H. C. 2013a. Development of two distinct dendritic-like APCs in the context of splenic stroma. Frontiers of Immunology, 4, 73.

PERIASAMY, P., TAN, J. K. \& O'NEILL, H. C. 2013b. Novel splenic antigenpresenting cells derive from a Lin(-) c-kit(lo) progenitor. Journal of Leukocyte Biology, 93, 63-69.

PERIASAMY, P., TAN, J. K. H., GRIFFITHS, K. L. \& O' NEILL, H. C. 2009. Splenic stromal niches support hematopoiesis of dendritic-like cells from precursors in bone marrow and spleen. Experimental Hematology, 37, 1060-1071.

PETVISES, S. \& O'NEILL, H. C. 2014a. Characterisation of dendritic cells arising from progenitors endogenous to murine spleen. Plos One, 9, e88311.

PETVISES, S. \& O'NEILL, H. C. 2014b. Distinct progenitor origin distinguishes a lineage of dendritic-like cells in spleen. Frontiers in Immunology, 4, 501.

PETViSES, S., TALAULIKAR, D. \& O'NEILL, H. C. 2016. Delineation of a novel dendritic-like subset in human spleen. Cellular \& Molecular Immunology, 13, 443-450. 
PEVSNER-FISCHER, M., LEVIN, S. \& ZIPORI, D. 2011. The origins of mesenchymal stromal cell heterogeneity. Stem Cell Reviews and Reports, 7, 560-568.

PIETRAS, E. M., REYNAUD, D., KANG, Y.-A., CARLIN, D., CALERO-NIETO, F. J., LEAVITT, A. D., STUART, J. M., GÖTTGENS, B. \& PASSEGUÉ, E. 2015. Functionally distinct subsets of lineage-biased multipotent progenitors control blood production in normal and regenerative conditions. Cell Stem Cell, 17, 3546.

PULENDRAN, B., LINGAPPA, J., KENNEDY, M. K., SMITH, J., TEEPE, M., RUDENSKY, A., MALISZEWSKI, C. R. \& MARASKOVSKY, E. 1997. Developmental pathways of dendritic cells in vivo: distinct function, phenotype, and localization of dendritic cell subsets in FLT3 ligand-treated mice. Journal of Immunology, 159, 2222-2231.

QIAN, H., BUZA-VIDAS, N., HYLAND, C. D., JENSEN, C. T., ANTONCHUK, J., MANSSON, R., THOREN, L. A., EKBLOM, M., ALEXANDER, W. S. \& JACOBSEN, S. E. 2007. Critical role of thrombopoietin in maintaining adult quiescent hematopoietic stem cells. Cell Stem Cell, 1, 671-684.

QUESENBERRY, P. J. \& BECKER, P. S. 1998. Stem cell homing: Rolling, crawling, and nesting. Proceedings of the National Academy of Sciences, USA, 95, 1515515157.

RAAIJMAKERS, M. H., MUKHERJEE, S., GUO, S., ZHANG, S., KOBAYASHI, T., SCHOONMAKER, J. A., EBERT, B. L., AL-SHAHROUR, F., HASSERJIAN, R. P., SCADDEN, E. O., AUNG, Z., MATZA, M., MERKENSCHLAGER, M., LIN, C., ROMMENS, J. M. \& SCADDEN, D. T. 2010. Bone progenitor dysfunction induces myelodysplasia and secondary leukaemia. Nature, 464, $852-857$.

RANDALL, T. D., CARRAGHER, D. M. \& RANGEL-MORENO, J. 2008. Development of secondary lymphoid organs. Annual Review of Immunology, 26, 627-650.

ROBinson, S., MOSley, R. L., PARAJuli, P., PISAREV, V., SUblet, J., ULRICH, A. \& TALMADGE, J. 2000. Comparison of the hematopoietic activity of flt-3 ligand and granulocyte-macrophage colony-stimulating factor acting alone or in combination. Journal of Hematotherapy \& Stem Cell Research 9, 711-20. 
ROOZENDAAL, R. \& MEBIUS, R. E. 2011. Stromal cell-immune cell interactions. Annual Review of Immunology, 29, 23-43.

RUGH, R. \& GRUPP, E. 1960. Splenic radioprotective agent: particulate or diffusible? Radiation Research, 13, 657-660.

SCHOFIELD, R. 1978. The relationship between the spleen colony-forming cell and the haemopoietic stem cell. Blood Cells, 4, 7-25.

SEITA, J. \& WEISSMAN, I. L. 2010. Hematopoietic stem cell: self-renewal versus differentiation. Wiley Interdisciplinary Reviews: Systems Biology and Medicine, 2, 640-653.

SHATRY, A. M. \& LEVY, R. B. 2004. Engraftment of splenic tissue as a method to investigate repopulation by hematopoietic cells from host and donor marrow. Stem Cells and Development 13, 390-399.

SHIN, J. Y., HU, W., NARAMURA, M. \& PARK, C. Y. 2014. High c-Kit expression identifies hematopoietic stem cells with impaired self-renewal and megakaryocytic bias. Journal of Experimental Medicine, 211, 217-231.

SHORTMAN, K. \& NAIK, S. H. 2007. Steady-state and inflammatory dendritic-cell development. Nature Reviews Immunology, 7, 19-30.

SIPKINS, D. A., WEI, X., WU, J. W., RUNNELS, J. M., COTE, D., MEANS, T. K., LUSTER, A. D., SCADDEN, D. T. \& LIN, C. P. 2005. In vivo imaging of specialized bone marrow endothelial microdomains for tumour engraftment. Nature, 435, 969-973.

SITNICKA, E., RUSCETTI, F. W., PRIESTley, G. V., WOLF, N. S. \& BARTELMEZ, S. H. 1996. Transforming growth factor beta 1 directly and reversibly inhibits the initial cell divisions of long-term repopulating hematopoietic stem cells. Blood, 88, 82-88.

SMITH, C. 2005. Trouble in the hood: culturing difficult cell types. Nature Methods 2, 385-391.

SPANGRUDE, G. J., HEIMFELD, S. \& WEISSMAN, I. L. 1988. Purification and characterization of mouse hematopoietic stem cells. Science, 241, 58-62.

SPRINGER, T., GALFRÉ, G., SECHER, D. S. \& MILSTEIN, C. 1979. Mac-1: a macrophage differentiation antigen identified by monoclonal antibody. European Journal of Immunology, 9, 301-306.

STEINIGER, B., ULFIG, N., RISSE, M. \& BARTH, P. J. 2007. Fetal and early postnatal development of the human spleen: from primordial arterial B cell lobules to a non-segmented organ. Histochemistry and Cell Biology 128, 205-215. 
SUGIYAMA, T., KOHARA, H., NODA, M. \& NAGASAWA, T. 2006. Maintenance of the hematopoietic stem cell pool by CXCL12-CXCR4 chemokine signaling in bone marrow stromal cell niches. Immunity, 25, 977-988.

SUN, Z., UNUTMAZ, D., ZOU, Y. R., SUNSHINE, M. J., PIERANI, A., BRENNERMORTON, S., MEBIUS, R. E. \& LITTMAN, D. R. 2000. Requirement for RORgamma in thymocyte survival and lymphoid organ development. Science, 288, 2369-2373.

TAN, J. K. \& O'NEILL, H. C. 2010. Investigation of murine spleen as a niche for hematopoiesis. Transplantation, 89, 140-145.

TAN, J. K. \& O'NEILL, H. C. 2012. Myelopoiesis in spleen-producing distinct dendritic-like cells. Journal of Cellular and Molecular Medicine, 16, 1924-1933.

TAN, J. K., PERIASAMY, P. \& O'NEILL, H. C. 2010. Delineation of precursors in murine spleen that develop in contact with splenic endothelium to give novel dendritic-like cells. Blood, 115, 3678-3685.

TAN, J. K., QUAH, B. J., GRIFFITHS, K. L., PERIASAMY, P., HEY, Y. Y. \& O'NEILL, H. C. 2011. Identification of a novel antigen cross-presenting cell type in spleen. Journal of Cellular and Molecular Medicine, 15, 1189-1199.

TAN, J. K. \& WATANABE, T. 2010. Artificial engineering of secondary lymphoid organs. Advances in Immunology, 105, 131-57.

TAN, J. K. \& WATANABE, T. 2014. Murine spleen tissue regeneration from neonatal spleen capsule requires lymphotoxin priming of stromal cells. Journal of Immunology, 193, 1194-1203.

TAN, J. K. H. \& O’NEILL, H. C. 2010. Haematopoietic stem cells in spleen have distinct differentiative potential for antigen presenting cells. Journal of Cellular and Molecular Medicine, 14, 2144-2150.

TANG, H., GUO, Z., ZHANG, M., WANG, J., CHEN, G. \& CAO, X. 2006. Endothelial stroma programs hematopoietic stem cells to differentiate into regulatory dendritic cells through IL-10. Blood, 108, 1189-1197.

TRUMPP, A., ESSERS, M. \& WILSON, A. 2010. Awakening dormant haematopoietic stem cells. Nature Reviews Immunology, 10, 201-209.

UENO, H. \& WEISSMAN, I. L. 2006. Clonal analysis of mouse development reveals a polyclonal origin for yolk sac blood islands. Developmental Cell, 11, 519-533.

UGARTE, F. \& FORSBERG, E. C. 2013. Haematopoietic stem cell niches: new insights inspire new questions. EMBO Journal, 32, 2535-2547. 
VARNUM-FINNEY, B., HALASZ, L. M., SUN, M., GRIDLEY, T., RADTKE, F. \& BERNSTEIN, I. D. 2011. Notch2 governs the rate of generation of mouse longand short-term repopulating stem cells. Journal of Clinical Investigation, 121, 1207-1216.

VISNJIC, D., KALAJZIC, Z., ROWE, D. W., KATAVIC, V., LORENZO, J. \& AGUILA, H. L. 2004. Hematopoiesis is severely altered in mice with an induced osteoblast deficiency. Blood, 103, 3258-3264.

VREMEC, D., POOLEY, J., HOCHREIN, H., WU, L. \& SHORTMAN, K. 2000. CD4 and CD8 expression by dendritic cell subtypes in mouse thymus and spleen. The Journal of Immunology, 164, 2978-2986.

WALTER, K., COCKERILl, P. N., BARLOW, R., CLARKE, D., HOOGENKAMP, M., FOLlOWS, G. A., RICHARDS, S. J., CULLEN, M. J., BONIFER, C. \& TAGOH, H. 2010. Aberrant expression of CD19 in AML with t $(8 ; 21)$ involves a poised chromatin structure and PAX5. Oncogene, 29, 2927-2937.

WANG, W., YU, S., ZIMMERMAN, G., WANG, Y., MYERS, J., YU, V. W., HUANG, D., HUANG, X., SHIM, J., HUANG, Y., XIN, W., QIAO, P., YAN, M., XIN, W., SCADDEN, D. T., STANLEY, P., LOWE, J. B., HUANG, A. Y., SIEBEL, C. W. \& ZHOU, L. 2015. Notch receptor-ligand engagement maintains hematopoietic stem cell quiescence and niche retention. Stem Cells, 33, 2280-2293.

WETZIG, A., ALAIYA, A., AL-ALWAN, M., PRADEZ, C. B., PULICAT, M. S., ALMAZROU, A., SHINWARI, Z., SLEIMAN, G. M., GHEBEH, H., ALHUMAIDAN, H., GAAFAR, A., KANAAN, I. \& ADRA, C. 2013. Differential marker expression by cultures rich in mesenchymal stem cells. BMC Cell Biology, 14, 54.

WILLIAMS, A. F. \& BARCLAY, A. N. 1988. The immunoglobulin superfamilydomains for cell surface recognition. Annual Review of Immunology, 6, 381-405. WILSON, A., LAURENTI, E., OSER, G., VAN DER WATH, R. C., BLANCO-BOSE, W., JAWORSKI, M., OFFNER, S., DUNANT, C. F., ESHKIND, L., BOCKAMP, E., LIÓ, P., MACDONALD, H. R. \& TRUMPP, A. 2008. Hematopoietic stem cells reversibly switch from dormancy to self-renewal during homeostasis and repair. Cell, 135, 1118-1129.

WILSON, H. L., NI, K. \& O'NEILL, H. C. 2000. Identification of progenitor cells in long-term spleen stromal cultures that produce immature dendritic cells. Proceedings of the National Academy of Sciences, USA, 97, 4784-4789. 
WINKLER, I. G., BARBIER, V., NOWLAN, B., JACOBSEN, R. N., FORRISTAL, C. E., PATTON, J. T., MAGNANI, J. L. \& LEVESQUE, J. P. 2012. Vascular niche E-selectin regulates hematopoietic stem cell dormancy, self renewal and chemoresistance. Nature Medicine, 18, 1651-1657.

WOLBER, F. M., LEONARD, E., MICHAEL, S., ORSCHELL-TRAYCOFF, C. M., YODER, M. C. \& SROUR, E. F. 2002. Roles of spleen and liver in development of the murine hematopoietic system. Experimental Hematology, 30, 1010-1019.

WRIGHT, D. E., CHESHIER, S. H., WAGERS, A. J., RANDALL, T. D., CHRISTENSEN, J. L. \& WEISSMAN, I. L. 2001. Cyclophosphamide/granulocyte colony-stimulating factor causes selective mobilization of bone marrow hematopoietic stem cells into the blood after $\mathrm{M}$ phase of the cell cycle. Blood, 97, 2278-2285.

WU, L. \& LIU, Y. J. 2007. Development of dendritic-cell lineages. Immunity, 26, 741750.

YAMAMOTO, K., MIWA, Y., ABE-SUZUKI, S., ABE, S., KIRIMURA, S., ONISHI, I., KITAGAWA, M. \& KURATA, M. 2016. Extramedullary hematopoiesis: Elucidating the function of the hematopoietic stem cell niche (Review). Molecular Medicine Reports, 13, 587-591.

YANG, L., BRYDER, D., ADOLFSSON, J., NYGREN, J., MÅNSSON, R., SIGVARDSSON, M. \& JACOBSEN, S. E. W. 2005. Identification of LinSca1+kit+CD34+Flt3 - short-term hematopoietic stem cells capable of rapidly reconstituting and rescuing myeloablated transplant recipients. Blood, 105, 2717-2723.

YAO, L., YOKOTA, T., XIA, L., KINCADE, P. W. \& MCEVER, R. P. 2005. Bone marrow dysfunction in mice lacking the cytokine receptor gp130 in endothelial cells. Blood, 106, 4093-4101.

YOKOTA, Y., MANSOURI, A., MORI, S., SUGAWARA, S., ADACHI, S., NISHIKAWA, S.-I. \& GRUSS, P. 1999. Development of peripheral lymphoid organs and natural killer cells depends on the helix-loop-helix inhibitor Id2. Nature, 397, 702-706.

YU, H., GIBSON, J. A., PINKUS, G. S. \& HORNICK, J. L. 2007. Podoplanin (D2-40) is a novel marker for follicular dendritic cell tumors. American Journal of Clinical Pathology, 128, 776-782. 
ZHANG, N., GUO, J. \& HE, Y. W. 2003. Lymphocyte accumulation in the spleen of retinoic acid receptor-related orphan receptor gamma-deficient mice. The Journal of Immunology, 171, 1667-1675.

ZHOU, B. O., YUE, R., MURPHY, M. M., PEYER, J. G. \& MORRISON, S. J. 2014. Leptin-receptor-expressing mesenchymal stromal cells represent the main source of bone formed by adult bone marrow. Cell Stem Cell, 15, 154-168. 


\section{PUBLICATIONS}


HONG KIAT LIM AND HELEN O’NEILL (2014). Delineation of niches which support hematopoiesis, Adult Stem Cell Niches, Dr Sabine Wislet-Gendebien (Ed.), ISBN: 978-953-51-1718-6, InTech, DOI: 10.5772/58715. Available from: http://www.intechopen.com/books/adult-stem-cell-niches/delineation-of-nicheswhich-support-hematopoiesis

LIM, H. K., TAN, J. K. \& O’NEILL, H. C. 2017. Characterisation of splenic stroma which supports hematopoiesis. In preparation.

LIM, H. K. \& O’NEILL, H. C. 2017. Characterisation of hematopoietic stem cell niches in spleen. In preparation.

LIM et al. 2017. Differentiation of HSC in vitro is supported by splenic stromal factor $s c f$ and is regulated by Notch. In preparation.

LIM et al. 2017. Ectopic HSC niches can be formed through grafting splenic stroma. In preparation. 